\title{
Arrays of Bottles of Plutonium Nitrate Solution
}

\author{
Margaret A. Marshall \\ John D. Bess \\ J. Blair Briggs \\ Bruce Michael Durst \\ Raymond L. Reed \\ Ian M. Stuart
}

September 2012

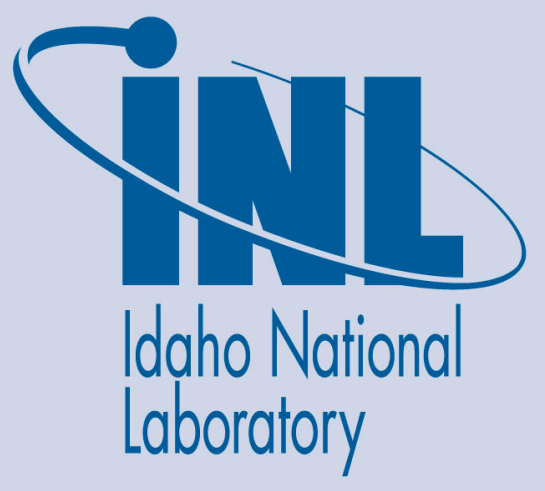

The INL is a U.S. Department of Energy National Laboratory operated by Battelle Energy Alliance 
INL/EXT-11-21157

NEA/NSC/DOC/(95)03/I

PU-SOL-THERM-037

\title{
Arrays of Bottles of Plutonium Nitrate Solution
}

\author{
Margaret A. Marshall ${ }^{1}$ \\ John D. Bess \\ J. Blair Briggs \\ Bruce Michael Durst ${ }^{2}$ \\ Raymond L. Reed ${ }^{3}$ \\ Ian M. Stuart ${ }^{3}$ \\ ${ }^{1}$ Idaho National Laboratory/University of Idaho \\ ${ }^{2}$ Columbia Basin College \\ ${ }^{3}$ URS Safety Management Solutions LLC
}

September 2012

\section{Idaho National Laboratory \\ Idaho Falls, Idaho 83415}

http://www.inl.gov

Prepared for the

U.S. Department of Energy

Office of National Nuclear Security Administration

Under DOE Idaho Operations Office

Contract DE-AC07-05ID14517 


\title{
ARRAYS OF BOTTLES OF PLUTONIUM NITRATE SOLUTION
}

\author{
Evaluator \\ Margaret A. Marshall \\ Idaho National Laboratory/University of Idaho
}

Internal Reviewers

John D. Bess

J. Blair Briggs

Idaho National Laboratory

Independent Reviewer

Bruce Michael Durst

Columbia Basin College

Raymond L. Reed

Ian M. Stuart

URS Safety Management Solutions LLC 
NEA/NSC/DOC/(95)03/I

Volume I

PU-SOL-THERM-037

\section{ACKNOWLEDGEMENTS}

The author would like to recognize and thank B. Michael Durst for providing insight and clarification on the experiment.

Revision: 0

Date: September 30, 2012

Page 2 of 142 


\section{ARRAYS OF BOTTLES OF PLUTONIUM NITRATE SOLUTION}

IDENTIFICATION NUMBER: PU-SOL-THERM-037

KEY WORDS: $\quad$ unacceptable, approach-to-critical, arrays, bottles, Plexiglas, plutonium nitrate, polyethylene, solution, split table

\subsection{DETAILED DESCRIPTION}

\subsection{Overview of Experiment}

In October and November of 1981 thirteen subcritical approach experiments were performed on a remote split table machine (RSTM) in the Critical Mass Laboratory (CML) of Pacific Northwest Laboratory (PNL) on the Hanford Reservation. The experiments were conducted using uniform planar arrays of polyethylene bottles filled with plutonium $(\mathrm{Pu})$ nitrate solution. Arrays of up to sixteen bottles were used to measure the critical number of bottles and critical array spacing with a tight fitting Plexiglas ${ }^{\circledR}$ reflector on all sides of the arrays except the top. Some experiments used Plexiglas shells fitted around each bottle to determine the effect of interstitial moderation on criticality. Each bottle contained approximately $2.4 \mathrm{~L}$ of $\mathrm{Pu}\left(\mathrm{NO}_{3}\right)_{4}$ solution with a Pu content of $105 \mathrm{~g} \mathrm{Pu} / \mathrm{L}$ and a free acid molarity $\mathrm{H}^{+}$of 5.1. The plutonium was of low ${ }^{240} \mathrm{Pu}(2.9$ wt. $\%)$ content.

These experiments were sponsored by Rockwell Hanford Operations to fill a lack of experimental data on the criticality of arrays of bottles of Pu solution such as might be found in storage and handling at the Purex Facility at Hanford. The results of these experiments were used "to provide benchmark data to validate calculational codes used in criticality safety assessments of [the] plant configurations" (see Reference 1).

Data for this evaluation were collected from the published report (Reference 1), the approach-to-critical logbook, ${ }^{\text {a }}$ the experimenter's logbook, and communication with the primary experimenter, B. Michael Durst. Of the thirteen experiments performed, ten were evaluated. One of the experiments was not evaluated because the final setup was not large enough to yield an accurate critical value and was not even reported in Reference 1 by the experimenter, one was not evaluated because it was a repeat of another experiment and the third was not evaluated because it reported the critical number of bottles as being greater than 25 . The evaluated experiments were determined to be unacceptable as benchmark experiments because of inconsistencies in solution chemistry (see Sections 2.0 and 2.4).

A similar experiment using uranyl nitrate was evaluated as a benchmark experiment in U233-SOLTHERM-014.

\footnotetext{
${ }^{\text {a }}$ Critical Experiment Data Log Book from Hanford Plutonium Critical Mass Laboratory, "Exp. RSTM - (L-3) 1-13: 10/26/81 to 11/10/81 (Pu Solution in L-3 Bottles)," Los Alamos National Laboratory Archives, Box 9 [29-6].

Revision: 0

Date: September 30, 2012
} 
NEA/NSC/DOC/(95)03/l

Volume I

PU-SOL-THERM-037

\subsection{Description of Experimental Configuration}

The approach-to-critical experiments were performed using sixteen polyethylene bottles called L-3 bottles. These bottles were arranged into arrays on a split table machine in the CML at PNL. The bottles were reflected on all four sides and the bottom with Plexiglas reflectors; the top was unreflected. Some experiments had Plexiglas shells around each bottle to determine the effect of moderation on the system.

\subsubsection{L-3 Bottles}

The L-3 bottles were three-liter polyethylene bottles (see Figure 1). Bottle inner diameters were measured using bottle destruction methods. ${ }^{a}$ Calipers with an accuracy of 0.001 in. were used but bottle variation and measurement inaccuracies could have led to an additional random uncertainty of about 1/32 in.

The bottles were filled with $\mathrm{Pu}\left(\mathrm{NO}_{3}\right)_{4}$ solution. "Prior to bottle filling, the solution was thoroughly mixed to ensure the same concentration of plutonium in each bottle" and during filling "the solution height was limited to levels below the curved neck of the L-3 bottle." Bottles were filled from the mix room storage tanks "by snaking a Tygon ${ }^{\circledR}$ tubing from the storage tanks through the dispensing header... [The delivery system] was a very precise pump that delivered amounts very accurately". ${ }^{\mathrm{c}}$ The solution had a "filling accuracy on volume of less than $1 / 2 \%$ per bottle."

Table 1 lists the diameter, solution volume, and solution height for each of the bottles as reported in Reference 1. Solution heights in Table 1 were not measured but calculated using the solution volume and the bottle inner diameter. Footnotes added by the evaluator are shown in brackets.

\footnotetext{
${ }^{\text {a }}$ Personal email communication with B.M. Durst, November 30, 2010 and December 1, 2010.

${ }^{\mathrm{b}}$ Personal phone communication with B.M. Durst, March 9, 2011.

c Personal email communication with B.M. Durst, December 16, 2010.

Revision: 0

Date: September 30, 2012
} 
NEA/NSC/DOC/(95)03/l

Volume I

PU-SOL-THERM-037

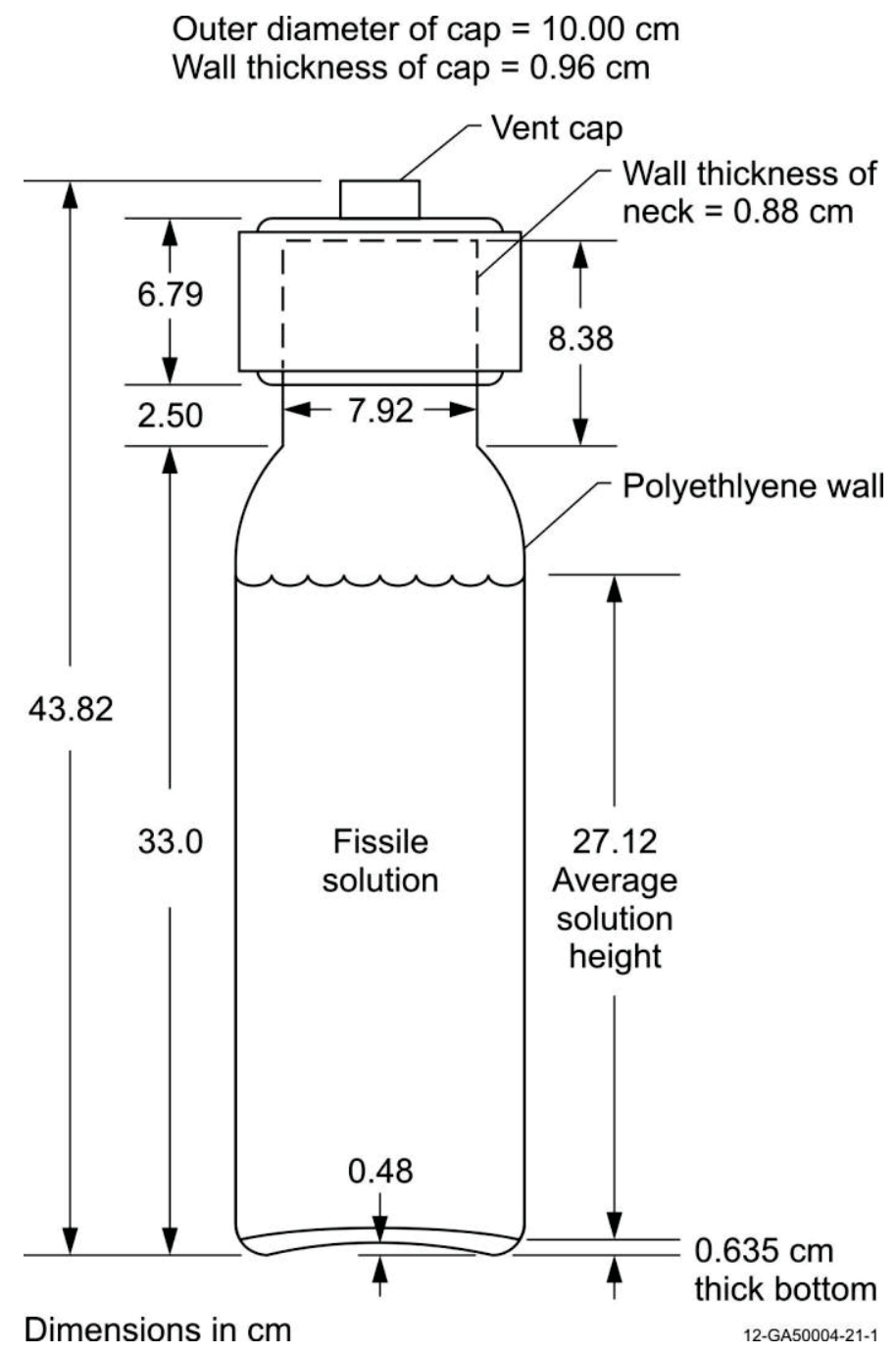

Figure 1. L-3 Bottles (redrawn from Figure 1 of Reference 1).

Revision: 0

Date: September 30, 2012

Page 5 of 142 
NEA/NSC/DOC/(95)03/l

Volume I

PU-SOL-THERM-037

Table 1. Description of L-3 Bottles (Reference 1).

\begin{tabular}{|c|c|c|c|c|}
\hline $\begin{array}{c}\text { Bottle } \\
\text { Number }\end{array}$ & $\begin{array}{c}\text { Outside } \\
\text { Diameter } \\
(\mathrm{cm})\end{array}$ & $\begin{array}{c}\text { Inside } \\
\text { Diameter } \\
(\mathrm{cm})\end{array}$ & $\begin{array}{c}\text { Volume of } \\
\text { Solution } \\
(\mathrm{L})\end{array}$ & $\begin{array}{c}\text { Solution Height in } \\
\text { Bottle }^{(\mathrm{b})}(\mathrm{cm})\end{array}$ \\
\hline 1 & 11.740 & 10.533 & 2.399 & 27.538 \\
\hline 2 & & 10.571 & 2.399 & 27.333 \\
\hline 3 & & 10.604 & 2.436 & 27.580 \\
\hline 4 & & 10.535 & 2.410 & 27.644 \\
\hline 6 & & 10.645 & 2.414 & 27.123 \\
\hline 7 & & 10.605 & 2.417 & 27.361 \\
\hline 8 & & 10.640 & 2.411 & 27.116 \\
\hline 10 & & 10.681 & 2.395 & $27.725^{(\mathrm{c})}$ \\
\hline 11 & & 10.681 & 2.423 & $26.041^{(\mathrm{d})}$ \\
\hline 12 & 11.826 & 10.678 & 2.402 & 26.825 \\
\hline 13 & 11.766 & 10.643 & 2.398 & 26.954 \\
\hline 14 & & 10.681 & 2.403 & 26.824 \\
\hline 15 & & 10.681 & 2.401 & 26.801 \\
\hline 16 & & 10.678 & 2.403 & 26.831 \\
\hline 17 & & 10.602 & 2.401 & 27.195 \\
\hline 18 & & 10.640 & 2.400 & 26.993 \\
\hline Average & 11.777 & 10.631 & 2.407 & 27.118 \\
& \pm 0.044 & \pm 0.051 & \pm 0.011 & \pm 0.298 \\
\hline
\end{tabular}

(a) [Calculated] based on specific gravity of solution and net weight of solution per bottle. Also, volumes were checked against a known [or measured] volume

(b) Calculated [by experimenters] depending on volume per bottle and inside bottle diameter

(c) [When reproducing the calculation of this value it appears that this value was incorrectly reported in Reference 1 and should actually be 26.730.]

(d) [When reproducing the calculation of this value it appears that this value was incorrectly reported in Reference 1 and should actually be 27.042.]

Only three outside diameter measurements were recorded in Reference 1. It is unclear why only three outer diameter measurements were taken.

The experimenter's logbook also reported the solution volumes and masses as reproduced in Table 2. These volumes were measured at a temperature of $28.5^{\circ} \mathrm{C}$. The bottles were filled with "a filling accuracy on volume of less than $1 / 2 \%$ per bottle" (see Reference 1 ). The masses were measured on a "Mettler Balance, spring scale". a An uncertainty for mass measurements was given in the experimenter's logbook but the value is unreadable. It is, however, obvious that the uncertainty in mass measurements is between 0.1 and 1.0 gram.

${ }^{\text {a }}$ Personal email communication with B.M. Durst, March 9, 2011.

Revision: 0

Date: September 30, 2012 
NEA/NSC/DOC/(95)03/I

Volume I

PU-SOL-THERM-037

Table 2. Solution Content in L-3 Bottles. ${ }^{(a)}$

\begin{tabular}{|c|c|c|c|c|}
\hline Bottle Number & $\begin{array}{c}\text { Volume } \\
(\mathrm{L})\end{array}$ & $\begin{array}{c}\text { Empty Bot. } \\
\text { Mass } \\
\text { (gasket }+ \text { cap) } \\
(\mathrm{g})\end{array}$ & $\begin{array}{c}\text { Full Bottle Mass } \\
\text { (gasket + cap }+ \\
\text { solution) } \\
(\mathrm{g})\end{array}$ & $\begin{array}{c}\text { Net Mass (solution) } \\
(\mathrm{g})\end{array}$ \\
\hline 1 & 2.3995 & 1008.9 & 4418.6 & 3409.7 \\
\hline 2 & 2.3989 & 1010.8 & 4419.7 & 3408.9 \\
\hline 3 & 2.4357 & 1007.7 & 4468.8 & 3461.1 \\
\hline 4 & 2.4097 & 1019.2 & 4443.4 & 3424.2 \\
\hline 6 & 2.4139 & 1001.6 & 4431.8 & 3430.2 \\
\hline 7 & 2.4168 & 1001.6 & 4435.9 & 3434.3 \\
\hline 8 & 2.4110 & 970.4 & 4396.5 & 3426.1 \\
\hline 10 & 2.3946 & 972.2 & 4375.0 & 3402.8 \\
\hline 11 & 2.4229 & 972.0 & 4415.0 & 3443.0 \\
\hline 12 & 2.4022 & 960.1 & 4373.7 & 3413.6 \\
\hline 13 & 2.3980 & 977.6 & 4385.2 & 3407.6 \\
\hline 14 & 2.4035 & 970.3 & 4385.7 & 3415.4 \\
\hline 15 & 2.4014 & 978.9 & 4391.3 & 3412.4 \\
\hline 16 & 2.4027 & 971.3 & 4385.5 & 3414.2 \\
\hline 17 & 2.4008 & 988.5 & 4400.1 & 3411.6 \\
\hline 18 & 2.4001 & 980.8 & 4391.3 & 3410.5 \\
\hline Average \pm & $2.407 \pm$ & $987.0 \pm 18.4$ & $4407.3 \pm 27.2$ (b) & $3420.4 \pm 15.4$ (b) \\
\hline Standard & 0.0108 & & & \\
\hline Deviation & & & & \\
\hline
\end{tabular}

(a) Information from experimenter's logbook unless noted otherwise.

(b) Values computed by evaluator.

\subsubsection{Array Setup}

\subsubsection{Aluminum Framework}

An aluminum framework was used to accurately position the L-3 bottles. The framework consisted of dovetail slider rails, side slider plates, and bottle slider plates. Bottles sat on the bottle slider plates and were held in with four aluminum pins or support rods (hereafter referred to as support rods) which were 4-in. tall. ${ }^{\text {a }}$ The bottle slider plates were placed on side slider plates and movement was controlled using a dovetailed slider rail. Side slider plates were mounted on dovetail slider rails on top of the bottom Plexiglas reflector. The dimensions for the bottle and side slider plates can be found in Figure 2 .

\footnotetext{
${ }^{a}$ Pin height from experimenter's logbook.

Revision: 0

Date: September 30, 2012
} 
NEA/NSC/DOC/(95)03/l

Volume I

PU-SOL-THERM-037

\subsubsection{Plexiglas Reflectors}

The array and framework were on top of a 14.92-cm-thick Plexiglas reflector which was placed on top of the aluminum honeycomb structure on the split table machine. Plexiglas reflectors were arranged so that they fit tightly around the array. "[The reflector blocks] were composites of one inch thick blocks in general. The larger segments that never changed were (or may have been) glued together. The flatness of the block surfaces were such that there was less than the thickness of a sheet of paper between any two blocks." Due to variations in the reflector and/or bottle surface it is possible that a gap between the bottles and the reflector existed but "the [gap couldn't have been] more than one-tenth of an inch". Reflector blocks on the sides of the bottles were 30.48-cm tall and 15.24-cm thick. The bottles were arranged on the bottom reflector such that the reflector farther from the experimenter during set up (see Figures 4 and 5) was flush with the bottom reflector. The reflector on the opposite side was allowed to overhang the bottom reflector when necessary. ${ }^{\mathrm{c}}$ The bottom reflector was $14.92-\mathrm{cm}$ thick but the length and width of the reflector is unclear. The sizes of the reflectors were measured using a ruler with an accuracy of $1 / 32$ in. $^{\text {d }}$

\subsubsection{Bottle Placement}

The bottles and reflectors were placed and adjusted by hand while the split table was fully open and then the split table was closed remotely. When spacings between bottles were needed small aluminum spacers were placed between the bottles to obtain the desired spacing. "The spacers were milled by special milling equipment to precise dimensions." "The experimenter's logbook gives the thicknesses of these spacers as $0.253,0.507,0.752$, and 1.006 in. The other length and height of the spacers were not given but they were small enough that they had little effect on the system reactivity. These measurements were done with a micrometer with an accuracy of $0.001 \mathrm{in}$. Bottles were placed on both halves of the split table such that bottle spacing was fully replicated through the array upon table closure. Figure 2 is an isometric view of the array setup.

The 60.96-cm-dimension for the inside of the reflector to the inside of the reflector in Figure 2 was not a constant dimension through the experiments but actually varied as the reflectors were pushed flush against the outsides of the bottles.

\footnotetext{
${ }^{\text {a }}$ Personal email communication with B.M. Durst, March 9, 2011.

${ }^{\mathrm{b}}$ Personal phone and email communication with B.M. Durst, January 24 and 25, 2011.

${ }^{\mathrm{c}}$ Personal phone communication with B.M. Durst, March 9, 2011.

${ }^{\mathrm{d}}$ Personal phone communication with B.M. Durst, January 24, 2011.

${ }^{\text {e }}$ Personal phone communication with B.M. Durst, March 9, 2011.

Revision: 0

Date: September 30, 2012
} 


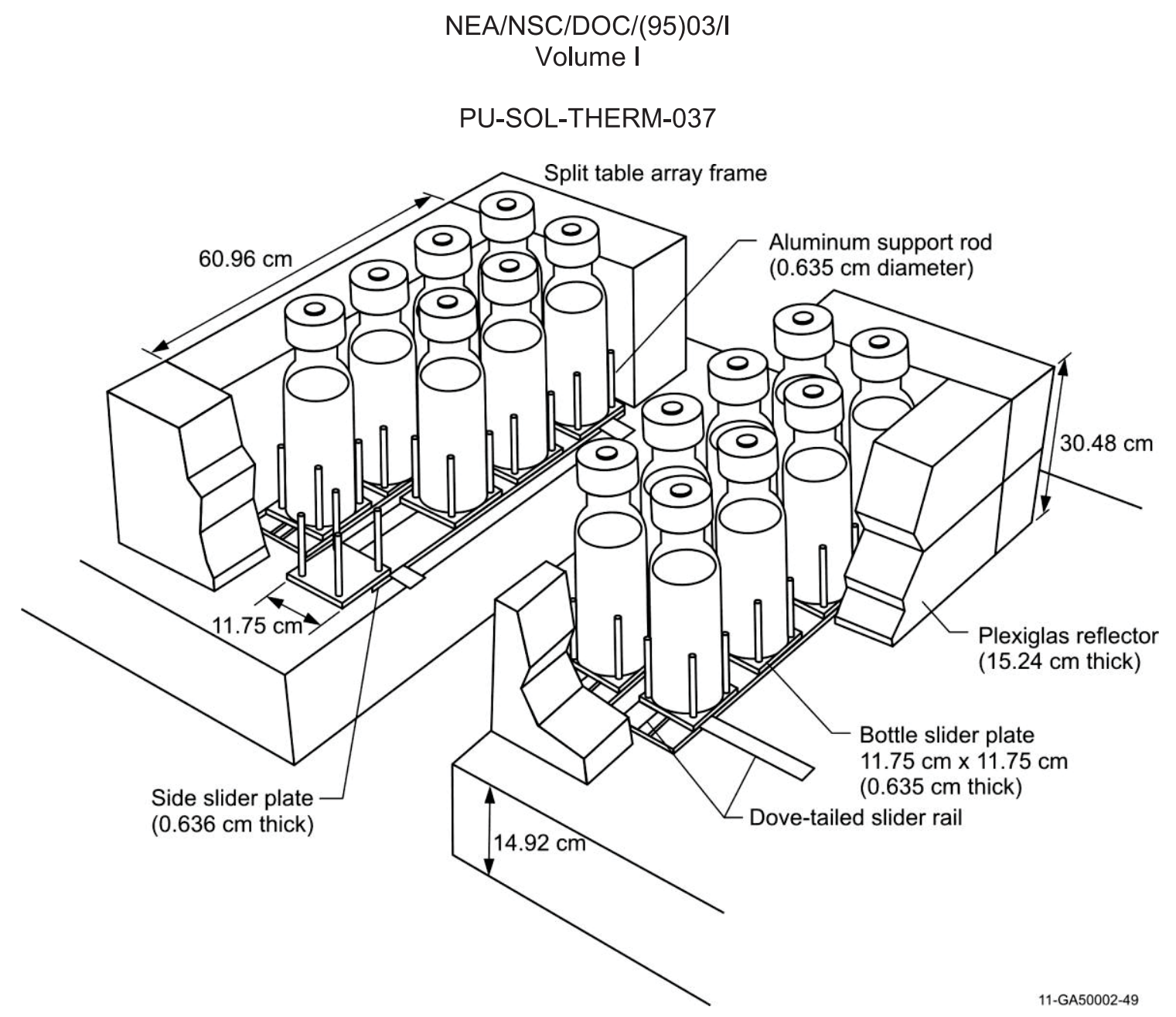

Figure 2. Isometric View of Array Setup (redrawn from Figure 2 of Reference 1).

\subsubsection{Plexiglas Shells}

Plexiglas shells were added around the bottles to "determine the effect of adding a moderating material in the space between bottles." These shells were made from three different sizes of Plexiglas tubing ordered from Port Plastics. Four tubes, $6 \mathrm{ft}$. in length, were ordered for each size of shell. Grooves had to be put into the Plexiglas shells to allow for the aluminum support rods. These shells were used in experiments RSTM-L-3-08, 09, 10, 11, and 12 and are described in Figure 3, Table 3, and Table 4.

Revision: 0

Date: September 30, 2012 
NEA/NSC/DOC/(95)03/l

Volume I

PU-SOL-THERM-037
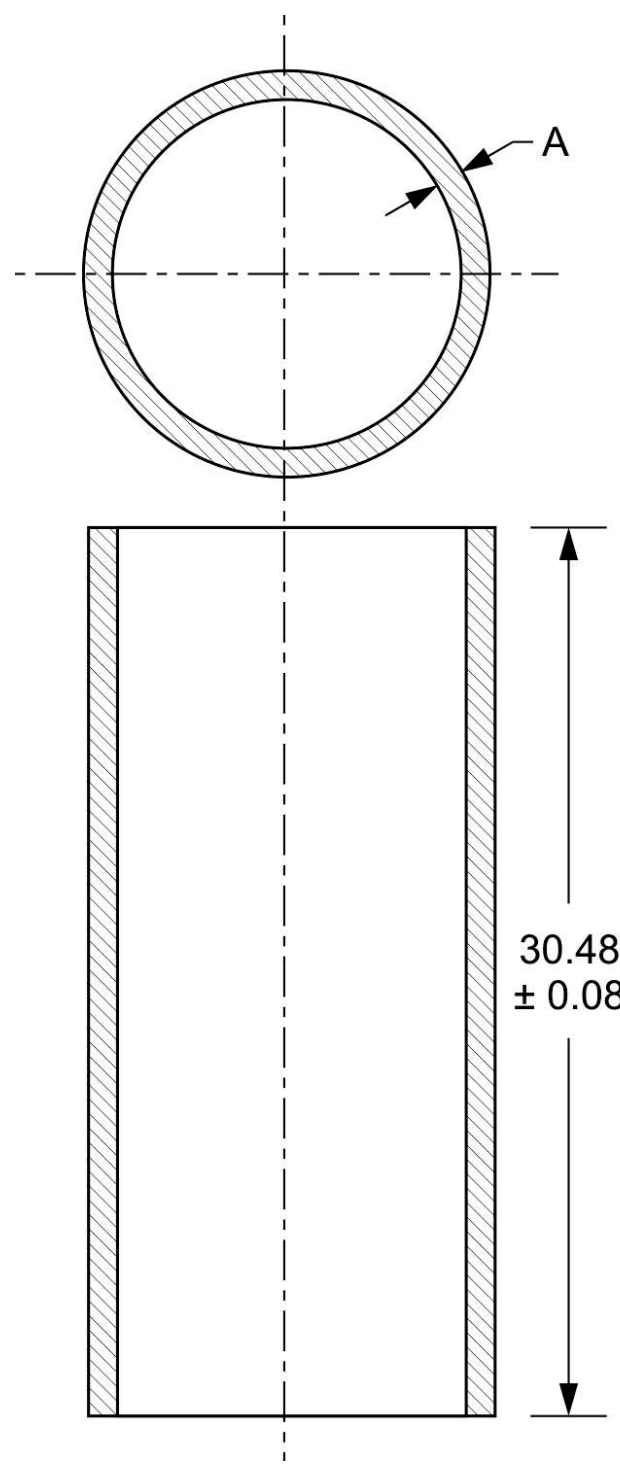

Shell outside diameter Shell thickness, A

$15.25 \pm 0.03$

$13.94 \pm 0.04$

$12.72 \pm 0.07$

Composition of shell

$\mathrm{H}$

C

$\mathrm{O}$

Density of $1.185 \mathrm{~g} / \mathrm{cm}^{3}$
$1.62 \pm 0.03$

$0.99 \pm 0.01$

$0.33 \pm 0.01$

wt. $\%$

8.0

60.0

32.0

Figure 3. Diagram of Plexiglas Shells (redrawn from Figure 4 of Reference 1)

A table of measurements for the shell thickness and outer diameter was provided in the experimenter's logbook. This table provides twelve measurements for thickness and twelve measurements for outer diameter. These measurements were taken using calipers with an accuracy of 0.001 in. ${ }^{\text {a }}$ These values, along with the average and deviation of these measurements, are shown in Table 3 . The average outer diameter value for the shell with a $0.33 \mathrm{~cm}$ or $0.129 \mathrm{in}$. thickness was incorrectly calculated and reported by the experimenter in the experimenter's logbook and Figure 3 above. There is also a discrepancy between the shell thicknesses for the $15.25 \mathrm{~cm}$ or 6.003 in. shell in Table 3 and Figure 3. See Section 2.2.4 for a discussion of these discrepancies.

${ }^{a}$ Personal phone communication with B.M. Durst, March 9, 2011.

Revision: 0

Date: September 30, 2012 


\section{NEA/NSC/DOC/(95)03//}

Volume I

\section{PU-SOL-THERM-037}

Table 3. Experimenter's Shell Dimensions. ${ }^{\text {(a) }}$

\begin{tabular}{|c|cccc|c|c|}
\hline $\begin{array}{c}\text { Shell OD } \\
\text { (in.) }\end{array}$ & 5.000 & 5.005 & 5.000 & 5.008 & & \\
& 5.017 & 5.002 & 5.007 & 5.005 & Average: $^{(b)}$ & $\begin{array}{c}5.010 \\
\pm 0.029\end{array}$ \\
\hline Shell & 0.129 & 0.138 & 0.122 & 0.132 & & \\
$\begin{array}{c}\text { Thickness } \\
\text { (in.) }\end{array}$ & 0.125 & 0.138 & 0.128 & 0.131 & Average: & 0.129 \\
& 0.127 & 0.127 & 0.135 & 0.121 & & \pm 0.006 \\
\hline Shell OD & 5.476 & 5.507 & 5.474 & 5.497 & & \\
(in.) & 5.480 & 5.508 & 5.476 & 5.500 & Average: & 5.489 \\
& 5.476 & 5.502 & 5.478 & 5.499 & & \pm 0.014 \\
\hline Shell & 0.381 & 0.396 & 0.393 & 0.388 & & \\
Thickness & 0.392 & 0.382 & 0.396 & 0.385 & Average: & 0.388 \\
(in.) & 0.386 & 0.388 & 0.385 & 0.392 & & \pm 0.005 \\
\hline Shell OD & 5.995 & 6.005 & 5.990 & 6.003 & & \\
(in.) & 5.988 & 6.005 & 6.015 & 6.019 & Average: & 6.003 \\
& 5.985 & 6.012 & 5.991 & 6.017 & & \pm 0.012 \\
& & & & 6.012 & & \\
\hline Shell & 0.250 & 0.227 & 0.250 & 0.234 & & \\
Thickness & 0.253 & 0.272 & 0.254 & 0.271 & Average: & 0.251 \\
(in.) & 0.248 & 0.255 & 0.257 & 0.250 & & \pm 0.013 \\
& & & & 0.241 & & \\
\hline
\end{tabular}

(a) Information provided in experimenter's logbook.

(b) This average value was reported by the experimenter and is not the correct average value of the 12 measured values. See Section 2.2.4.

An order form to Port Plastics was placed in the experimenter's logbook for Plexiglas tubing which was cut down to be used as the shells in these experiments. The order form includes tubing thicknesses, inner and outer diameters, and manufacturing tolerances. This information is summarized in Table 4.

Table 4. Manufacturer's Shell Dimensions. ${ }^{\text {(a) }}$

\begin{tabular}{|rrr|rrr|rrr|}
\hline \multicolumn{2}{|c|}{ Thickness (in) } & \multicolumn{3}{|c|}{ OD (in) } & \multicolumn{3}{|c|}{ ID (in) } \\
\hline $1 / 8$ & \pm & 0.018 & 5.0 & \pm & 0.030 & 4.75 & \pm & 0.030 \\
\hline $3 / 8$ & \pm & 0.035 & 5.5 & \pm & 0.030 & 4.75 & \pm & 0.030 \\
\hline $1 / 4$ & \pm & 0.025 & 6.0 & \pm & 0.030 & 5.5 & \pm & 0.030 \\
\hline
\end{tabular}

(a) Information provided in experimenter's logbook and compiled into table form by evaluator.

Revision: 0

Date: September 30, 2012 


\section{NEA/NSC/DOC/(95)03/l \\ Volume I}

\section{PU-SOL-THERM-037}

Figures 4 and 5 are photos, provided by the experimenter, of the setting up of the experiment and the experimental configurations.

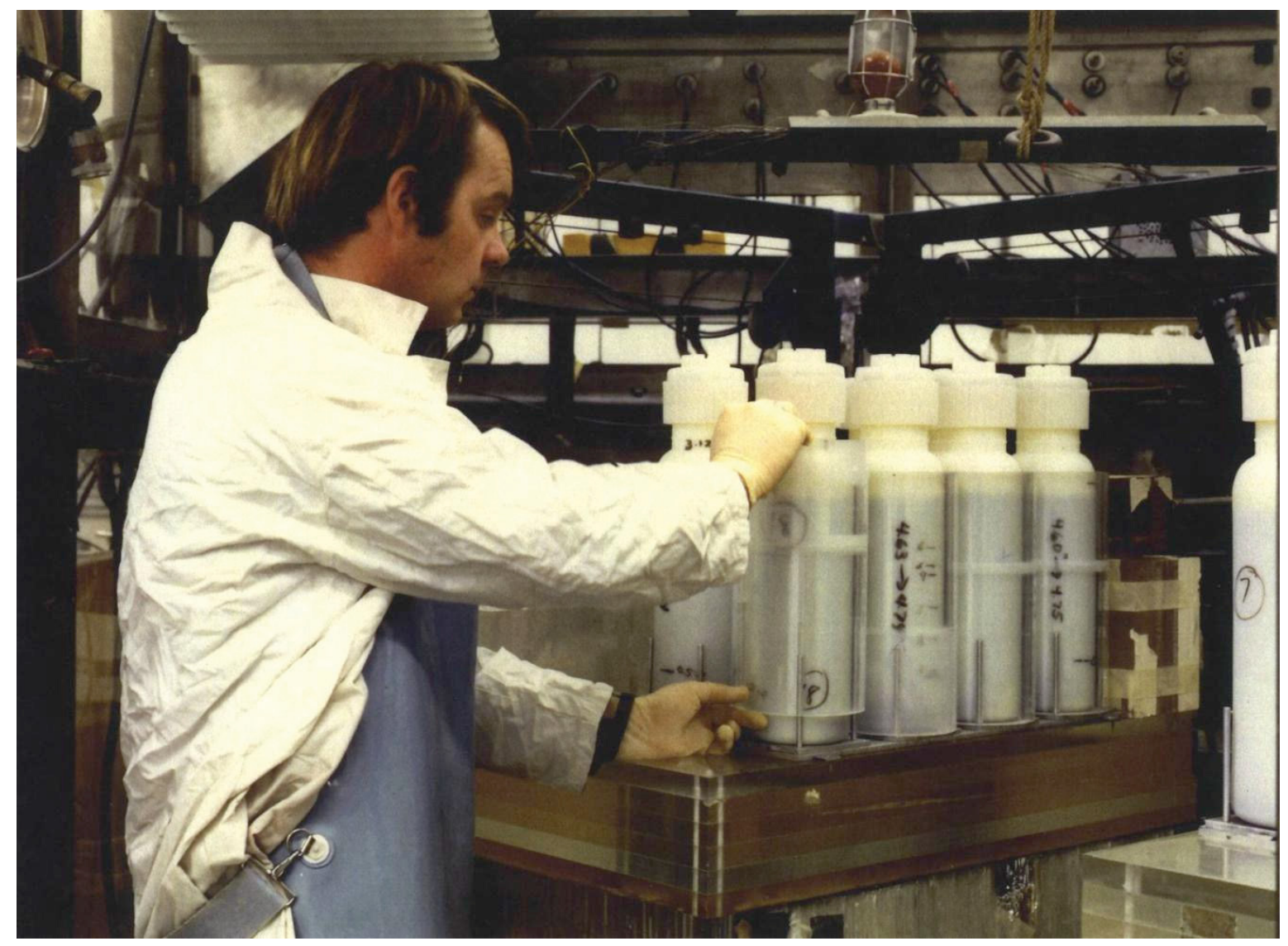

Figure 4. B. Michael Durst Performing Experimental Setup. 
NEA/NSC/DOC/(95)03/I

Volume I

PU-SOL-THERM-037

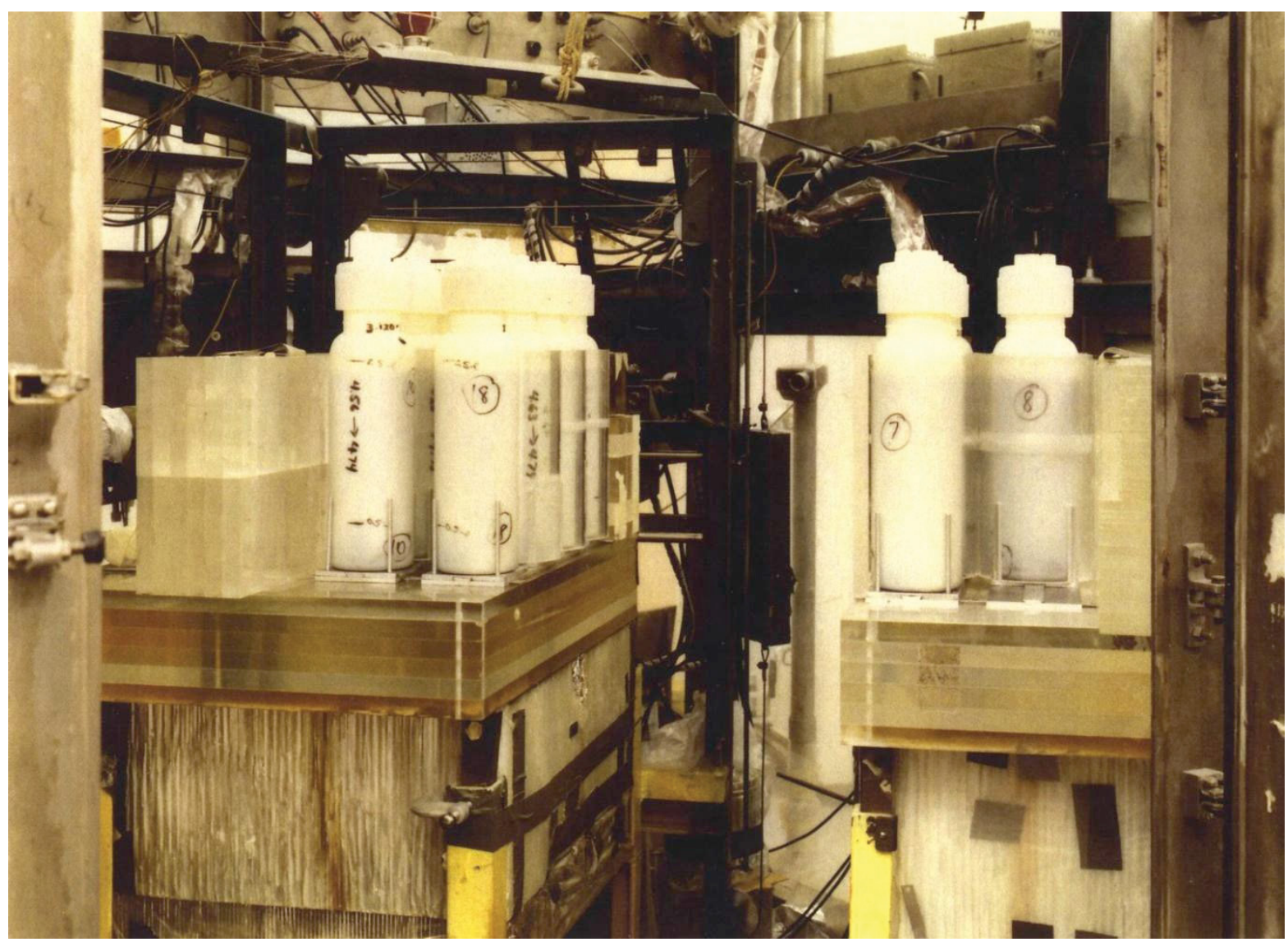

Figure 5. Experimental Setup.

\subsubsection{Surroundings}

Little information about the split table machine and the area in which it was housed was given in Reference 1 or the logbooks. Information about the split table machine and the area in which it was housed was obtained from the Hazards Summary Report for the Hanford Plutonium Critical Mass Laboratory, ${ }^{a}$ and the Remote Split-Table Machine supplement to that report. ${ }^{b}$ U233-SOL-THERM-014 was also conducted in the CML and was also referenced for details regarding the surroundings.

The array setup was on a split table machine. The Plexiglas reflectors sat on top of an aluminum honeycomb structure that was 12 -in. thick, 30-in. wide, and 42-in. long when closed. The stationary portion of the table was 24 -in. long and the moveable portion was 18 -in. long. The top of the table sat 32-in. above the floor and there was an aluminum facing material covering the honeycomb core. The table was attached to a framework of steel beams which also supported the safety and control rod drives as well

\footnotetext{
${ }^{a}$ W.A. Reardon, E.D. Clayton, C.L. Brown, R.H. Masterson, T.J. Powell, C.R. Richey, R.B. Smith, and J.W. Healy, "Hazards Summary Report For The Hanford Plutonium Critical Mass Laboratory," HW-66266, August, 1960.

${ }^{b}$ C.R. Richey, E.D. Clayton, R.H. Odegaarden, J.D. White, and W.A. Reardon, "Hazards Summary Report For The Hanford Plutonium Critical Mass Laboratory, Supplement No. 1, The Remote Split-Table Machine," HW-6266 SUP1 REV, October 1963.
}

Revision: 0

Date: September 30, 2012 


\section{NEA/NSC/DOC/(95)03/I \\ Volume I}

\section{PU-SOL-THERM-037}

as the driver for the moveable portion of the table. Figure 6 is a drawing of the split table machine being used for another experiment. It is clear from Figures 4 and 5 that the poison control rod assemblies were not in place for this experimental series.

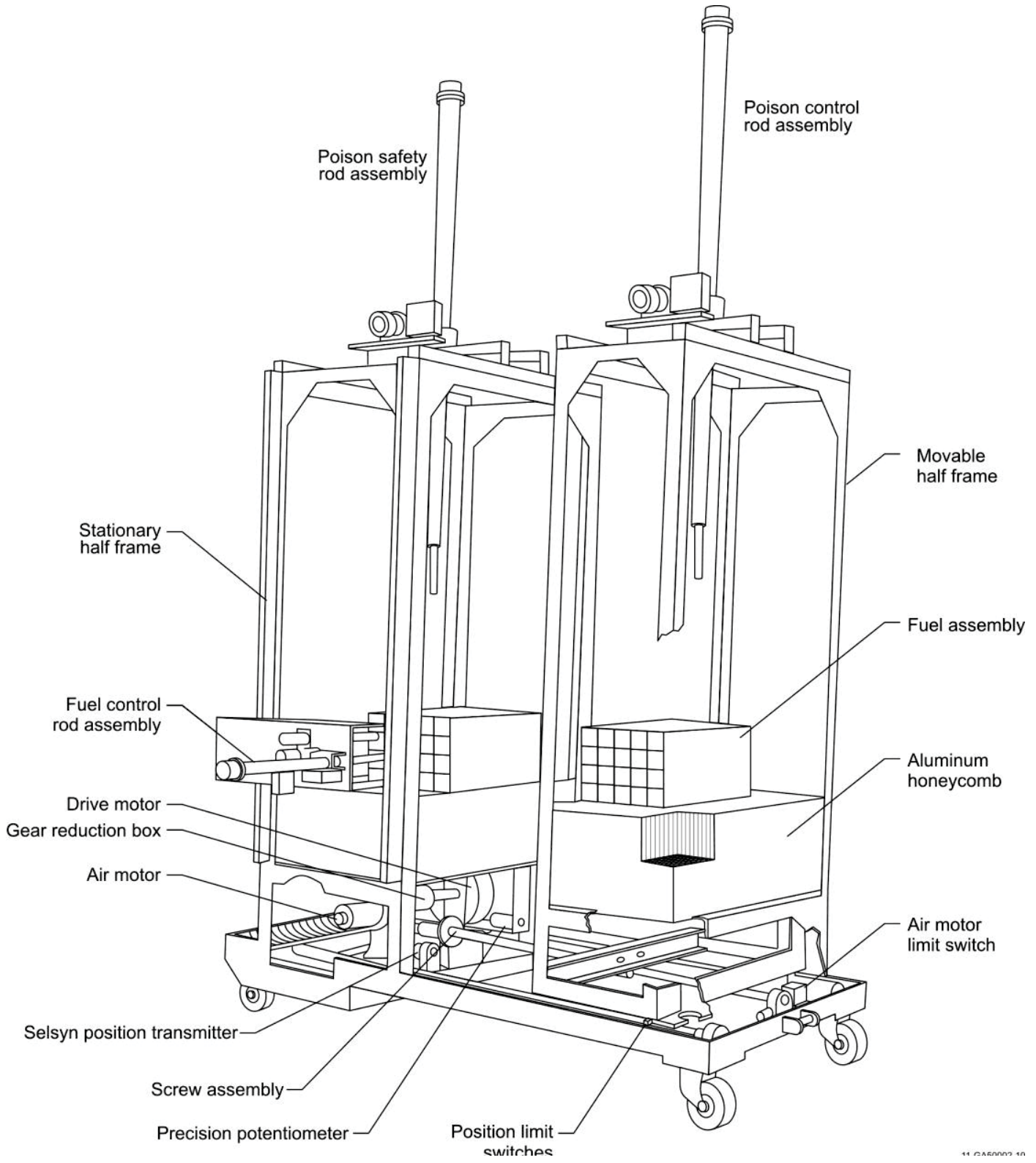

Figure 6. Split Table Machine (redrawn from Hazard Summary Report ${ }^{\mathrm{a}}$ ).

${ }^{a}$ C. R. Richey, E. D. Clayton, R. H. Odegaarden, J. D. White, and W. A. Reardon, "Hazards Summary Report For The Hanford Plutonium Critical Mass Laboratory, Supplement No. 1, The Remote Split-Table Machine," HW-6266 SUP1 REV, October 1963.

Revision: 0

Date: September 30, 2012 
The split table machine was housed within one of two large walk-in experimental hoods in the reactor room of the CML. Both hoods were 8-ft. square and 15-ft. tall. The framework and floor were constructed of welded stainless steel. Plexiglas sheets were attached to the framework of the walk-in hoods to provide confinement of potential contamination to the reactor room and contained optional glove ports for use when remote access from outside the hood was necessary. The hoods had two primary access points: a large door for equipment access, and a circular opening for removing contaminated equipment or for personnel entry.

The reactor room was $35 \times 35 \mathrm{ft}$. with steel bar reinforced concrete walls, 5 -ft. thick on three sides and 3-ft. thick on the fourth side. The floor and ceiling were 2 -ft. thick. The ceiling height sloped from $20-21 \mathrm{ft}$. "Conventional design and construction practices were used." All six interior surfaces of the room were coated with a fiber glass reinforced resin, Amercoat No. 74; this coating aided in cleanup and creating a gas tight seal of the room. Four solution storage slab tanks were against the north wall of the reactor room adjacent to the mixing room. These tanks were selected to be a thickness for solution storage that was critically safe. Two of the tanks had a 22.5 -liter capacity, the other two had a 45 -liter capacity and all tanks were made of " 12 vertical 4 -in.-OD pipe sections spaced on 2 -ft. centers and rigidly fastened to the wall." There were two entrances to the reactor room. The first was a labyrinth passage with a gasketed, lockable steel door at the reactor room entrance end and a regular large equipment access door at the south end of the room that was used primarily for loading large pieces of experimental equipment into the reactor room. The $9 \times 9-1 / 2-\mathrm{ft}$. access door on the south wall was constructed of $2-1 / 2 \mathrm{ft}$--thick concrete sandwiched between steel plates. This door was sealed by two inflatable gaskets between the door and the door frame.

\subsubsection{Experimental Procedure and Results}

The experiment was carried out on the RSTM in Critical Assembly Hood No. 2. In order to create the array, bottles were hand-loaded in the aluminum framework one at a time on alternating sides of the opened RSTM so that bottles would form a uniform array when the split table was fully closed. In instances where experiments were conducted with bottles touching, the bottles on both the moveable and fixed halves of the split table would complete the tight packed array upon closure. In other experiments spacers were used to establish well-defined distances between the bottles; these gaps were fully replicated upon table closure. After the addition of each bottle, the table was closed and count rate measurements were made with units of counts per 90 seconds. For the tight packed experiment arrays, bottles were added until the "inverse multiplication curves [indicated] that the addition of one more bottle in contact with the existing array would yield an array which [was] no longer subcritical."b The minimum number of bottles required to achieve critical was determined by extrapolation to critical. In order to bracket the critical value, two methods of extrapolation were carried out and then averaged. The first method used the number of bottles versus the number of bottles divided by the count rate (bott. vs. bott./CR). The second method used the number of bottles versus the inverse of the count rate (bott. vs. ${ }^{1} / C R$ ). An example of an extrapolation can be found in Appendix B.

\footnotetext{
${ }^{a}$ W.A. Reardon, E.D. Clayton, C.L. Brown, R.H. Masterson, T.J. Powell, C.R. Richey, R.B. Smith, and J.W. Healy, "Hazards Summary Report For The Hanford Plutonium Critical Mass Laboratory," HW-66266, August, 1960, pg 17.

${ }^{b}$ B.M. Durst, "Request for Authorization to Perform Subcritical Experiments With Arrays of L-3 Bottles Containing Plutonium Nitrate Solution," Serial No. EA-CML 80-2, November 1980.

Revision: 0
}

Date: September 30, 2012 


\section{NEA/NSC/DOC/(95)03/l}

Volume I

\section{PU-SOL-THERM-037}

Once the minimum number of bottles in a tightly packed array required for criticality was determined the bottles were spaced out to reduce reactivity. Bottles were then added one at a time until the desired array configuration was achieved with a constant spacing between bottles. The bottle spacing was then reduced uniformly in one direction with the table open and then the count rates were measured with the table closed. Bottle spacing was measured using small aluminum spacers between the bottles (see Section 1.2.2). The "extrapolation of [the] inverse multiplication curves [were then] used to determine the critical spacing." The extrapolation to critical spacing also utilized two methods of extrapolation in order to bracket the critical value and then the averaging of the two methods. The first method used the bottle separation versus the bottle separation divided by the count rate (sep. vs. ${ }^{\mathrm{sep}} / \mathrm{CR}$ ). The second method used the bottle separation versus the inverse count rate (sep. vs. $1 / C R$ ). An example of an extrapolation to critical spacing can be found in Appendix B.

A similar approach to finding the critical number of bottles and bottle spacing was taken when Plexiglas shells were used as interstitial moderator.

It is believed that "a better estimate of criticality . . during the initial portion of the experiment," is provided by the first method of extrapolating to critical (bott. vs. bott./CR and sep. vs. ${ }^{\mathrm{sep}} / \mathrm{CR}$ ) although both methods should give the same result as criticality is approached. This belief was based on findings by Lloyd et al. in "Criticality of Arrays of ${ }^{233} \mathrm{U}$ Solution". a

Count rates were measured using three detectors. The counts recorded from each of the three detectors were used to generate curves which were extrapolated. The three predicted critical approach values resulting from the curves generated by each detector's count rates were then averaged (see Appendix B). For all experiments plots of the approach-to-critical data were generated by hand during the experiment to predict critical values. Once the experiments were completed a computer was used to perform the leastsquares-regression to obtain the reported critical configuration data. ${ }^{\mathrm{b}}$

Table 5 is a summary of all critical experimental array results that were reported by the experimenter in Reference 1. Values found by extrapolation have been highlighted in Table 5 by the evaluator; it is not clear in Reference 1 which spacings were measured versus which spacings were extrapolation-to-critical values. All footnotes are from Reference 1 with comments from the evaluator shown in brackets.

Experiment RSTM-L3-01 was not reported in Reference 1 because the final setup was not large enough to yield an accurate critical value. ${ }^{c}$

\footnotetext{
${ }^{a}$ R.C. Lloyd, E.D. Clayton, and J.H Chalmers, “Criticality of Arrays of ${ }^{233}$ U Solution,” Nuclear Applications, Vol. 4, p. 136-141, (1968)

${ }^{\mathrm{b}}$ Personal phone communication with B.M. Durst, March 9, 2011.

${ }^{\mathrm{c}}$ Personal phone communication with B.M. Durst, January 24, 2011.

Revision: 0
}

Date: September 30, 2012

Page 16 of 142 
NEA/NSC/DOC/(95)03/l

Volume I

PU-SOL-THERM-037

Table 5. Experimental Results (see Reference 1).

\begin{tabular}{|c|c|c|c|c|c|c|c|c|c|c|c|c|c|}
\hline \multicolumn{2}{|c|}{$\begin{array}{c}\text { Experiment } \\
\text { Number } \\
\end{array}$} & \multicolumn{3}{|c|}{$\begin{array}{c}\text { Critical Number } \\
\text { of Bottles }{ }^{(\mathrm{a})}\end{array}$} & \multicolumn{3}{|c|}{$\begin{array}{c}\begin{array}{c}\text { X Spacing } \\
(\mathrm{b}) \\
(\mathrm{cm})\end{array} \\
\end{array}$} & \multicolumn{3}{|c|}{$\begin{array}{l}\text { Y Spacing }{ }^{(\mathrm{c})} \\
(\mathrm{cm})\end{array}$} & \multicolumn{3}{|c|}{ Shell Thickness $(\mathrm{cm})$} \\
\hline RSTM-L3- & 02 & 10.89 & \pm & 0.10 & 0.0 & & & 0.0 & & & 0.0 & & \\
\hline & 03 & 12 & & & 0.0 & & & 0.49 & \pm & 0.03 & 0.0 & & \\
\hline & 04 & 12 & & & 0.33 & \pm & 0.01 & 0.36 & \pm & 0.03 & 0.0 & & \\
\hline & 05 & 12 & & & 0.59 & \pm & 0.01 & 0.0 & & & 0.0 & & \\
\hline & 06 & 16 & & & 0.0 & & & 1.92 & \pm & 0.04 & 0.0 & & \\
\hline & 07 & 16 & & & 1.26 & \pm & 0.01 & 0.66 & \pm & 0.05 & 0.0 & & \\
\hline & $08^{(\mathrm{d})}$ & $>25$ & & & 3.47 & \pm & 0.05 & 3.47 & \pm & 0.05 & 1.62 & \pm & 0.03 \\
\hline & $09^{(\mathrm{d})}$ & 16.89 & \pm & 0.16 & 2.16 & \pm & 0.06 & 2.16 & \pm & 0.06 & 0.99 & \pm & 0.01 \\
\hline & $10^{(\mathrm{d})}$ & 13.1 & \pm & $0.3^{(\mathrm{e})}$ & 0.95 & \pm & 0.09 & 0.95 & \pm & 0.09 & 0.33 & \pm & 0.01 \\
\hline & $11^{(\mathrm{d})}$ & 13.1 & \pm & $0.3^{(t)}$ & 0.95 & \pm & 0.09 & 0.95 & \pm & 0.09 & 0.33 & \pm & 0.01 \\
\hline & 12 & 16 & & & 0.95 & \pm & 0.09 & 2.19 & \pm & 0.10 & 0.33 & \pm & 0.01 \\
\hline & 13 & 16 & & & 0.68 & \pm & 0.02 & 1.20 & \pm & 0.02 & 0.0 & & \\
\hline
\end{tabular}

(a) The aluminum positioning pins [rods] or grooves cut in plastics shells had no appreciable effect on the extrapolated values shown (see footnote f).

(b) Measured from bottle surface to bottle surface.

(c) Measured from bottle surface to bottle surface.

(d) In these experiments, the outer Plexiglas shells were touching in the $\mathrm{X}$ and $\mathrm{Y}$ directions. The $\mathrm{X}$ and $\mathrm{Y}$ spacings shown are measured from bottle surface to bottle surface. Any difference in spacing is due to void around each bottle. [This footnote also applies to experiment 12 although Reference 1 did not have this footnote for experiment 12.]

(e) Average of two experiments, one where the $13^{\text {th }}$ bottle is placed in the center of the array and one where the $13^{\text {th }}$ bottle is on the array edge.

(f) Repeat of Experiment 10 with twice as many grooves in shells to establish the worth of the reflector displaced by support pegs [rods].

A summary table at the end of the experimenter's logbook also contains the extrapolated experimental results. This table, summarized in Table 6 below, includes the results from the two extrapolation methods and the average of the two methods to more precision than was given in Reference 1.

Revision: 0

Date: September 30, 2012 


\section{NEA/NSC/DOC/(95)03/I}

Volume I

\section{PU-SOL-THERM-037}

Table 6. Experimental Results as Summarized in Experimenter's Logbook.

\begin{tabular}{|c|l|c|c|c|}
\hline RSTM-L3- & \multicolumn{1}{|c|}{$\begin{array}{c}\text { Bottle or } \\
\text { Sep/CR }\end{array}$} & \multicolumn{2}{|c|}{ No Fit } \\
\hline 1 & bottles & \multicolumn{3}{|c|}{ Average } \\
\hline 2 & bottles & 10.981 & 10.804 & 10.893 \\
\hline 3 & separation (in.) & 0.21738 & 0.16992 & 0.19365 \\
\hline 4 & separation (in.) & 0.19213 & 0.09236 & 0.14225 \\
\hline 5 & separation (in.) & 0.23845 & 0.22207 & 0.23026 \\
\hline 6 & separation (in.) & 0.77269 & 0.74120 & 0.75695 \\
\hline 7 & separation (in.) & 0.37139 & 0.18674 & 0.27907 \\
\hline 8 & bottles & 17.046 & 16.736 & 16.891 \\
\hline 9 & bottles & 13.566 & 13.501 & 13.534 \\
\hline 10 & bottles & 13.292 & 13.264 & 13.278 \\
\hline $10 \mathrm{a}^{(\text {a) }}$ & bottles & 13.573 & 13.506 & 13.540 \\
\hline 11 & bottles & 0.49471 & 0.48200 & 0.48836 \\
\hline $12^{(\text {b) }}$ & separation (in.) & 0.48122 & 0.46670 & 0.47396 \\
\hline 13 & separation (in.) & \multicolumn{3}{|}{} \\
\hline
\end{tabular}

(a) Face of RSTM did not close in this experiment.

(b) It is important to note that this separation is from shell-to-shell surface, not from bottle-to-bottle surface as it is in Table 5.

Some additional information for array spacings can be found in the approach-to-critical logbook referring to the array spacing with more detail than can be found in Reference 1. A compilation of this information from the logbook is provided in Table 7.

Revision: 0

Date: September 30, 2012 
NEA/NSC/DOC/(95)03/l

Volume I

PU-SOL-THERM-037

Table 7. Array Spacing. ${ }^{(a)}$

\begin{tabular}{|c|c|c|}
\hline RSTM-L3- & $\begin{array}{c}\text { X Spacing } \\
\text { (in.) }\end{array}$ & $\begin{array}{c}\text { Y Spacing } \\
\text { (in.) }\end{array}$ \\
\hline 1 & Touching & Touching \\
\hline 2 & Touching & Touching \\
\hline 3 & Touching & Extrapolated \\
\hline 4 & 0.130 & Extrapolated \\
\hline $5^{(\mathrm{b})}$ & Touching & Extrapolated \\
\hline 6 & Touching & Extrapolated \\
\hline 7 & 0.495 & Extrapolated \\
\hline $8^{(\mathrm{c})}$ & Touching & Touching \\
\hline $9^{(\mathrm{c})}$ & Touching & Touching \\
\hline $10^{(\mathrm{c})}$ & Touching & Touching \\
\hline $11^{(\mathrm{c})}$ & Touching & Touching \\
\hline $12^{(\mathrm{c})}$ & Touching & Extrapolated \\
\hline 13 & 0.27 & Extrapolated \\
\hline
\end{tabular}

(a) Data compiled from the approach-to-critical logbook by the evaluator.

(b) It appears that the $\mathrm{X}$ and $\mathrm{Y}$ axis were switched by the experimenter thus giving a $0.0 \mathrm{Y}$ spacing and extrapolated X spacing when values were reported in Reference 1 (see Table 5).

(c) Shell to shell surface spacing.

For RSTM-L3-5, 4 bottles were touching in the $\mathrm{x}$ direction and 3 bottles with variable spacing were in the y direction according to the approach-to-critical logbook. When RSTM-L3-5 was reported in Reference 1, the axes appear to have been switched so that 3 bottles were spaced out in the $\mathrm{x}$ direction and 4 bottles were touching in the $\mathrm{y}$ direction, see Figure 9 and $\mathrm{X}$ and $\mathrm{Y}$ spacing in Table 5. It is believed that the experimenter switched the axis when reporting this experiment to have a $3 \times 4$ array rather than a $4 \times 3$ array to be consistent with RSTM-L3-3 and 4.

The X spacing for experiments RSTM-L3-4, 7, and 13 would have been held constant through the approach to critical using aluminum spacers; however, these spacings do not agree exactly with the dimensions of any of the aluminum spacers given in the experimenter's logbook. It is certain that aluminum spacers would have been used to define the $\mathrm{X}$ spacing in these experiments but the experimenter could not recall if the discrepancy in the spacings from the spacer dimensions was due to rounding or if the bottle-to-bottle spacings were measured with calipers to obtaining the spacings in Table 7. The uncertainty in the extrapolated spacings was $0.001 \mathrm{in}$. based on the uncertainty in the spacers used in the approach to critical. Because it is uncertain how the X spacing for RSTM-L3-4, 7, and 13 were obtained, the experimenter recommended the uncertainty in these values should be increased from $0.001-$ 0.005 in. $^{\mathrm{a}}$

\footnotetext{
${ }^{\text {a }}$ Personal phone communication with B.M. Durst, March 9, 2011.
}

Revision: 0

Date: September 30, 2012 


\section{NEA/NSC/DOC/(95)03/I \\ Volume I}

PU-SOL-THERM-037

Figures 7-13 show the extrapolation results for experiments that were investigating critical array spacing. These figures also show bottle arrangement for the experiments.

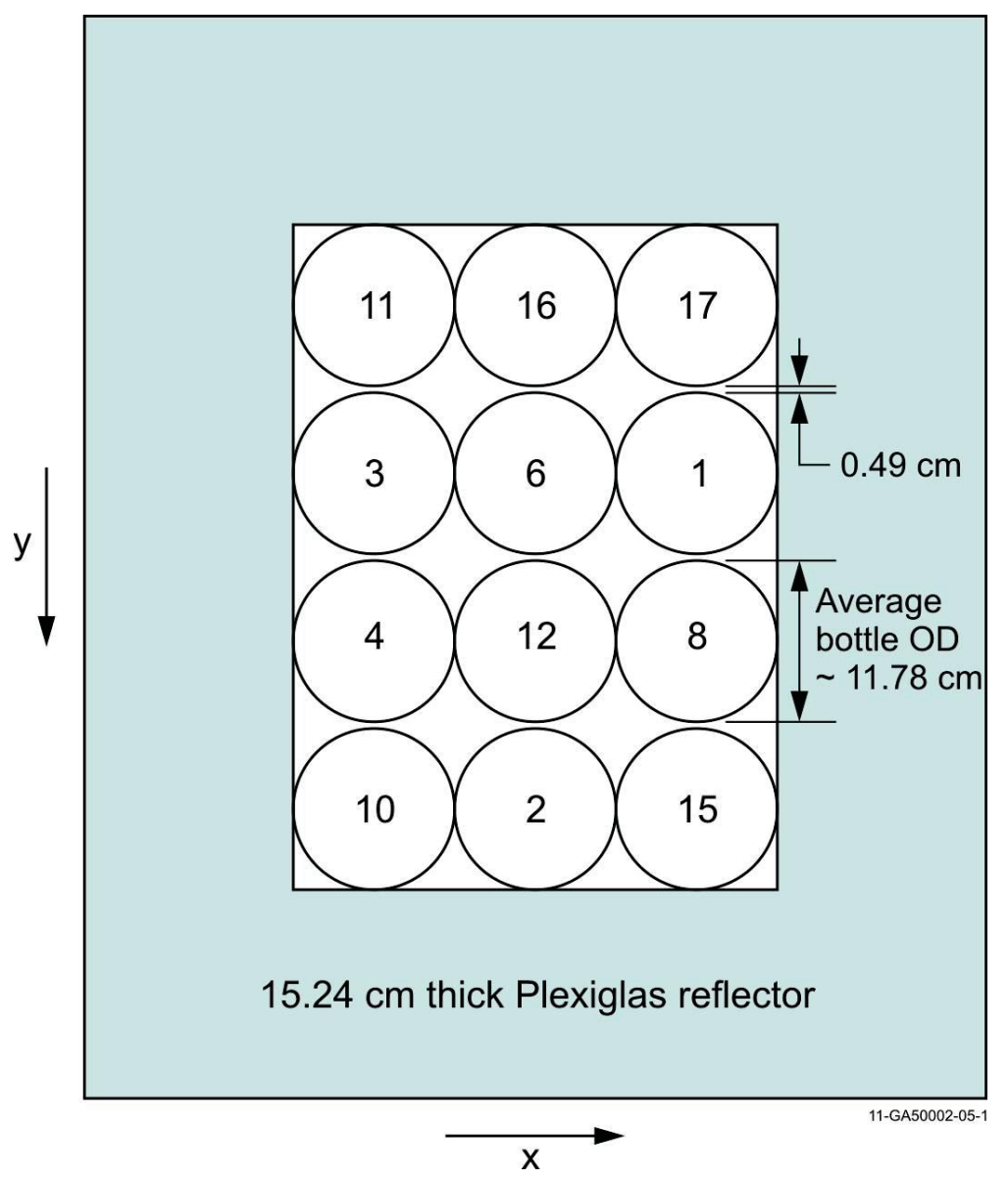

Figure 7. Experiment RSTM-L3-03 (redrawn from Figure 5 of Reference 1). 
NEA/NSC/DOC/(95)03/l

Volume I

PU-SOL-THERM-037

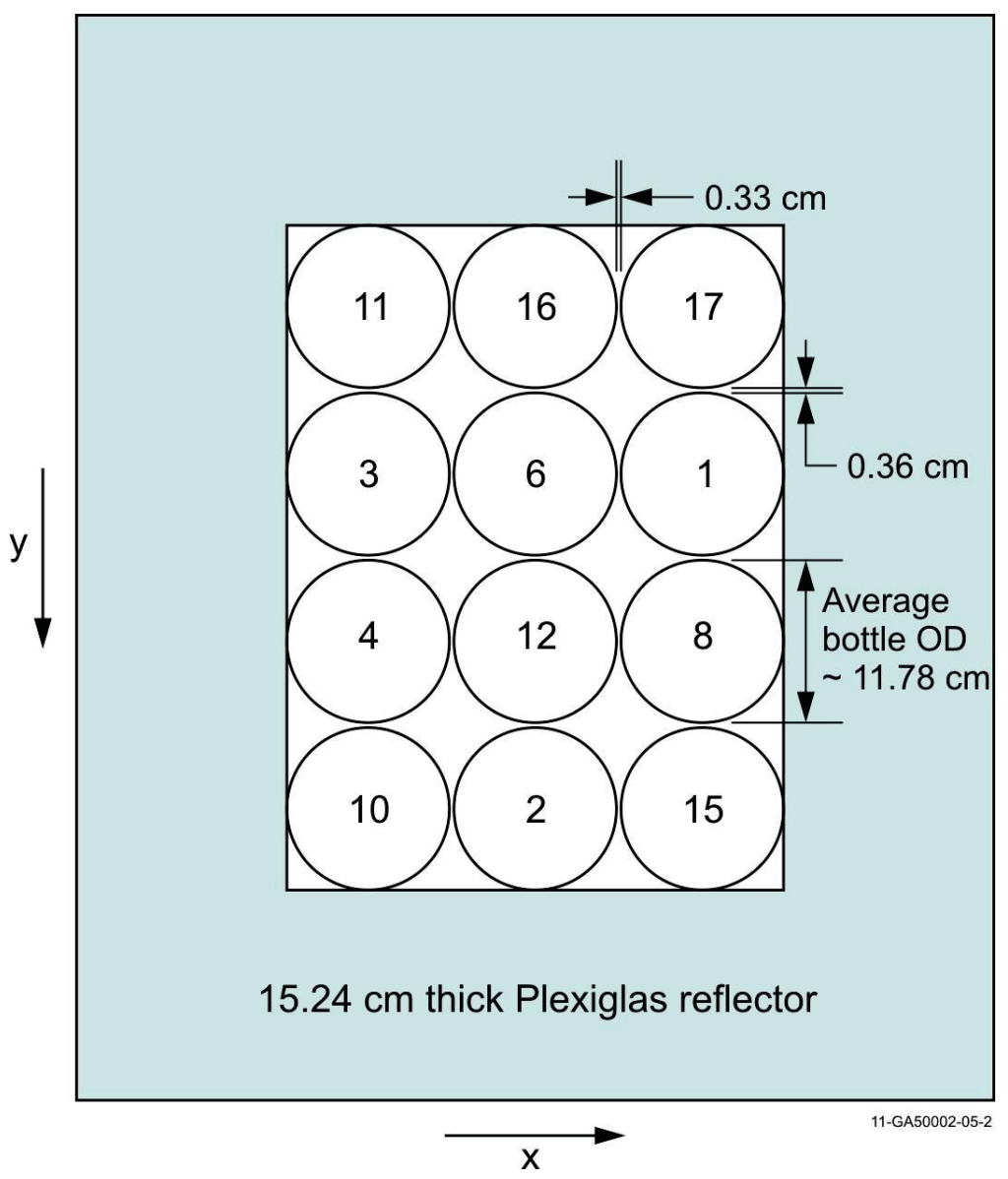

Figure 8. Experiment RSTM-L3-04 (redrawn from Figure 6 of Reference 1). 
NEA/NSC/DOC/(95)03/I

Volume I

PU-SOL-THERM-037

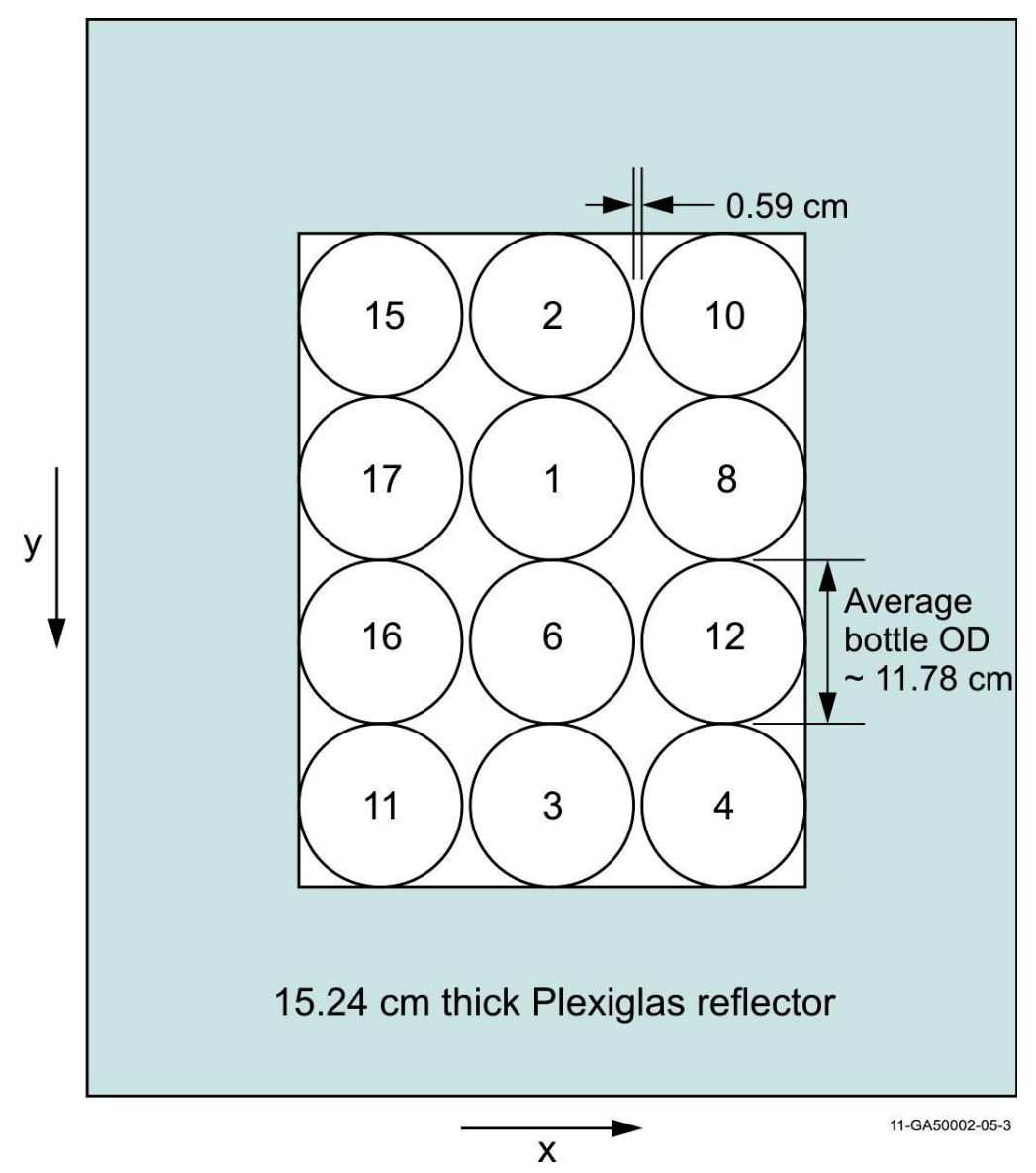

Figure 9. Experiment RSTM-L3-05 (redrawn from Figure 7 of Reference 1). 
NEA/NSC/DOC/(95)03/l

Volume I

PU-SOL-THERM-037

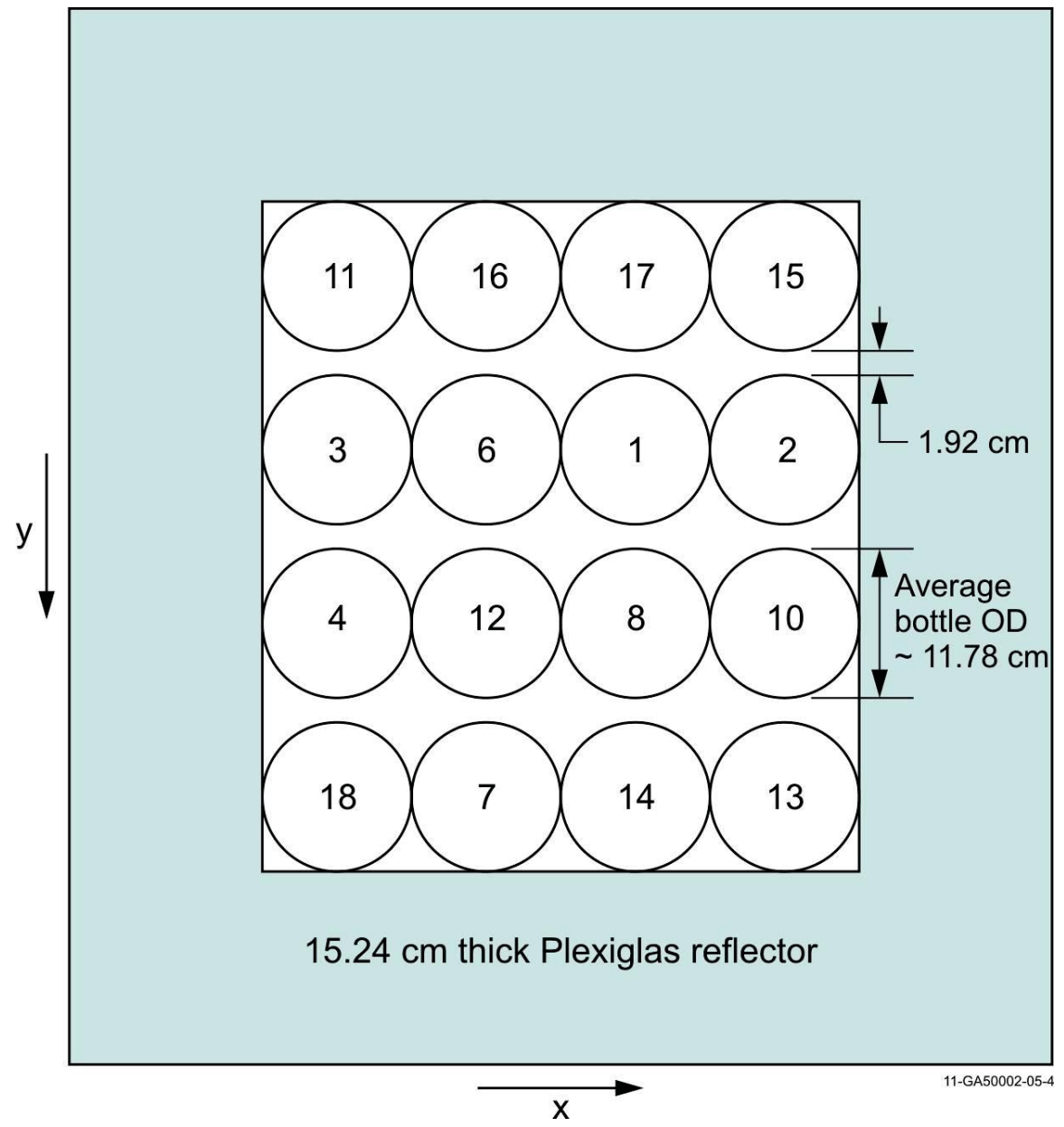

Figure 10. Experiment RSTM-L3-06 (redrawn from Figure 8 of Reference 1) 
NEA/NSC/DOC/(95)03/I

Volume I

PU-SOL-THERM-037

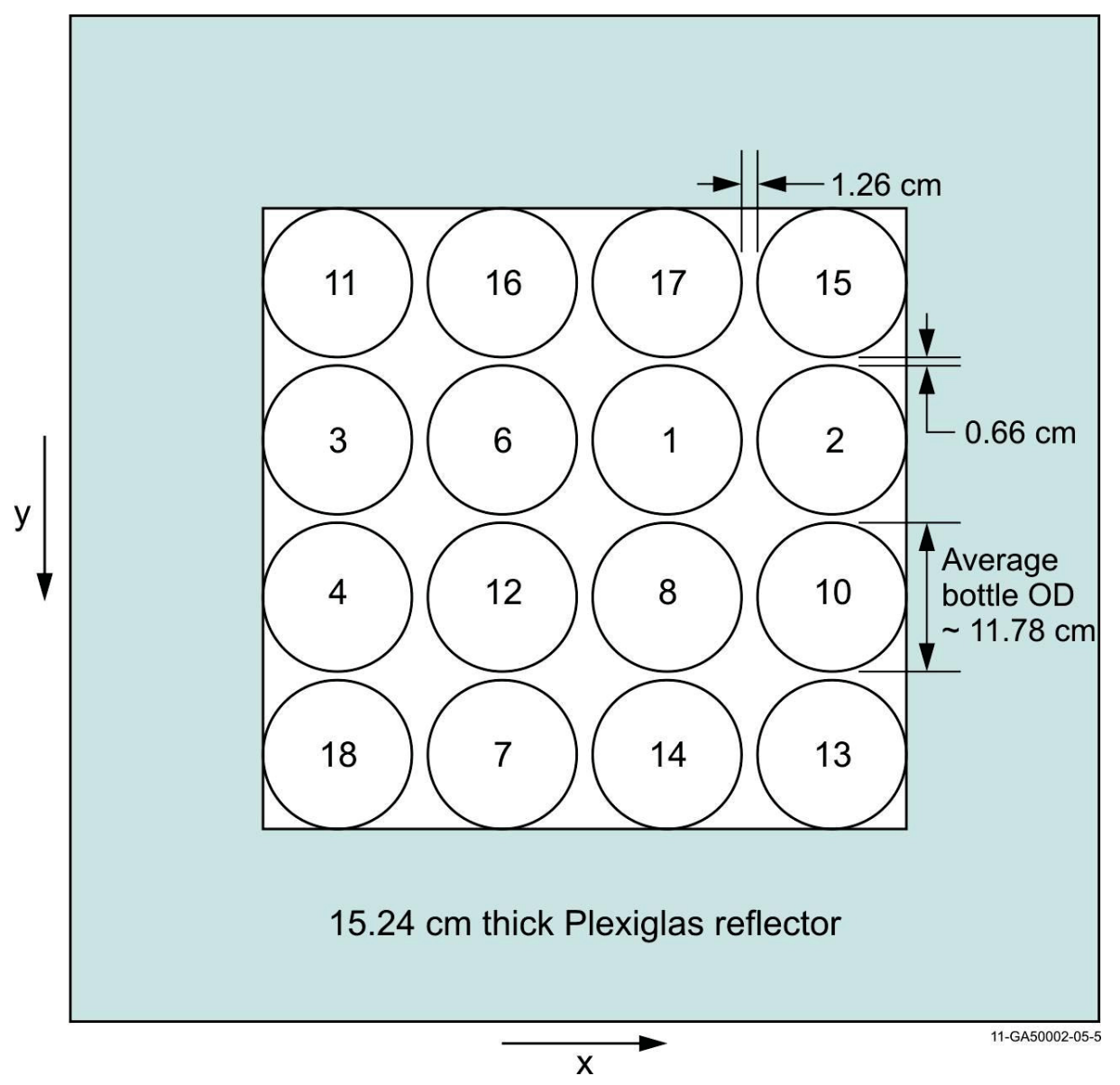

Figure 11. Experiment RSTM-L3-07 (redrawn from Figure 9 of Reference 1). 


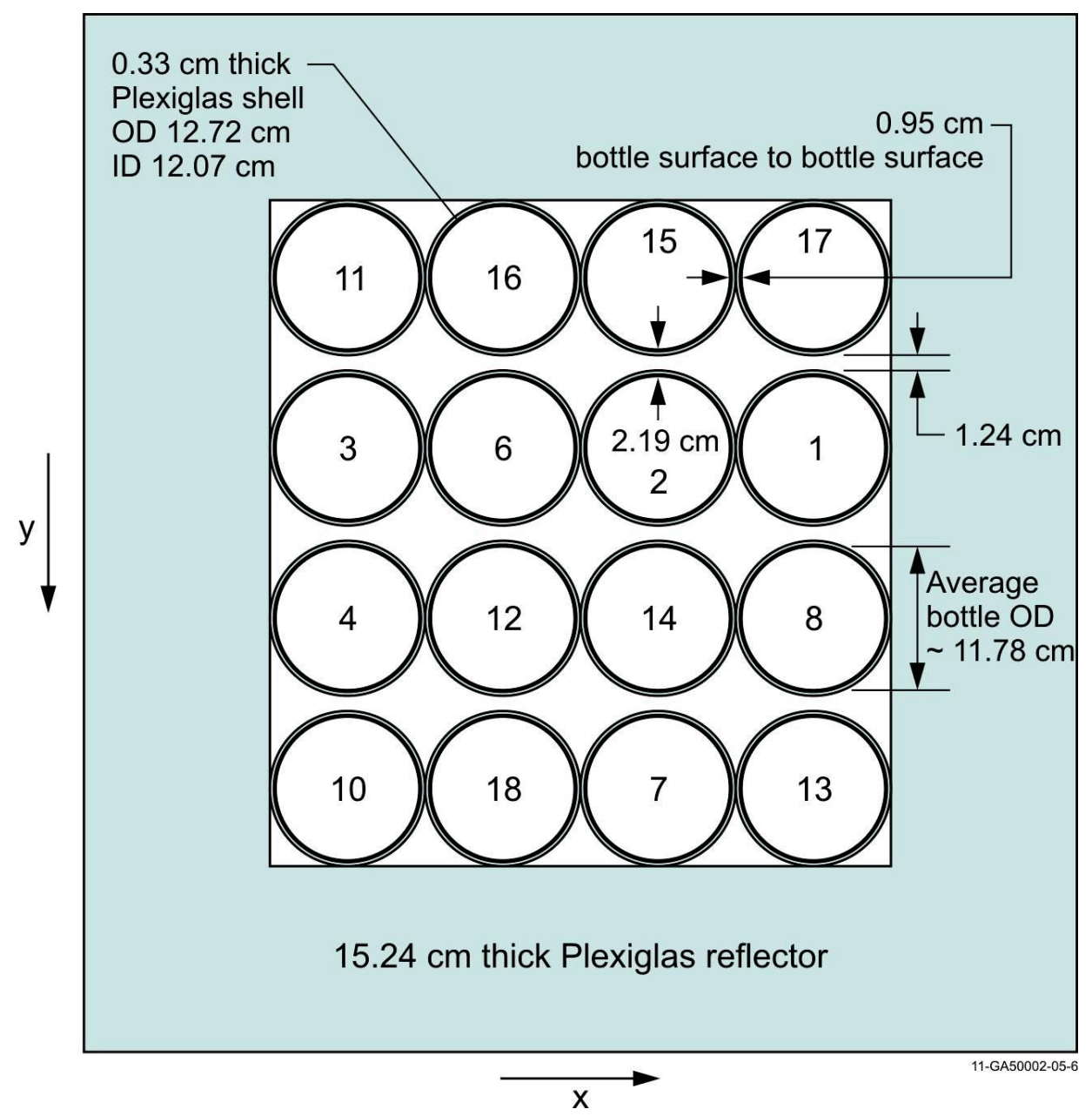

Figure 12. Experiment RSTM-L3-012 (redrawn from Figure 10 of Reference 1).

The bottle surface to bottle surface measurement in Figure 12 is between the bottle exterior surfaces.

The shell inner diameter, outer diameter, and thickness shown in Figure 12 do not agree with each other. This discrepancy is believed to be due to rounding when converting from inches, which measurements were originally taken in, to centimeters. 


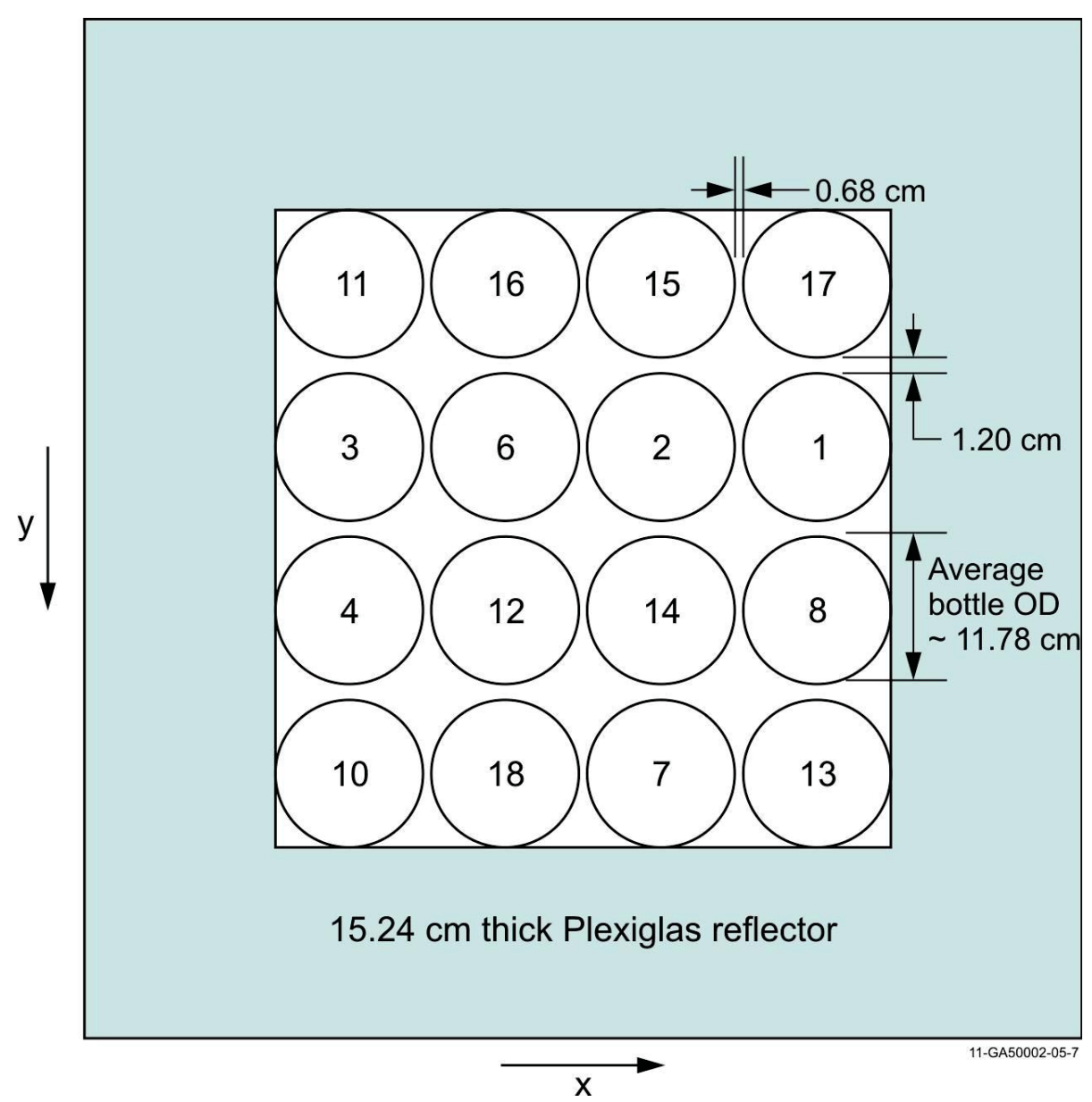

Figure 13. Experiment RSTM-L3-013 (redrawn from Figure 11 of Reference 1).

\section{$1.3 \quad$ Description of Material Data}

\subsubsection{Plutonium Nitrate Solution}

Reference 1 gives a description of the plutonium nitrate solution which can be found in Table 8 . Prior to filling the bottles with fissile solution, the solution was thoroughly mixed to ensure the solution composition was the same in all the bottles. There is not believed to have been any settling or change in solution over the span of the experimental series. ${ }^{\text {a }}$ Each bottle was filled such that the solution height was always below the curved neck of the bottle and the "filling accuracy on volume [was] less than $1 / 2 \%$ per bottle."

${ }^{a}$ Personal email communication with B.M. Durst, March 9, 2011.

Revision: 0

Date: September 30, 2012 


\section{NEA/NSC/DOC/(95)03/l \\ Volume I}

\section{PU-SOL-THERM-037}

Table 8. Plutonium Nitrate Solution (Reference 1).

\begin{tabular}{|c|c|}
\hline Component & Concentration $(\mathrm{g} / \mathrm{L})^{(\mathrm{a})}$ \\
\hline Plutonium & 105 \\
\hline Uranium & 3.1 \\
\hline Nitrate $\left(\right.$ Total) ${ }^{(b)}$ & 505 \\
\hline Iron & 3.2 \\
\hline Chromium & 0.8 \\
\hline Nickel & 0.6 \\
\hline Aluminum & 8.0 \\
\hline Manganese & 0.7 \\
\hline Cadmium & 0.0005 \\
\hline Boron & 0.005 \\
\hline Water & 788.3 (obtained by difference) \\
\hline Am-241 (4/6/83) & 0.18 \\
\hline Acid Molarity $(\mathrm{H}+)$ & 5.1 \\
\hline Specific Gravity ${ }^{(c)}$ & $1.420(\mathrm{~g} / \mathrm{cc})$ \\
\hline
\end{tabular}

(a) The temperature of the solution during composition analysis is not known.

(b) According to the experimenter the nitrate content was difficult to measure and could have varied by as much as $10 \%$. (Personal phone communication, December 8 and 14, 2011).

(c) Because of the units given in Reference 1 it is assumed the term specific gravity is used interchangeably with density.

The isotopic distribution of the plutonium, shown in Table 9, was also given in Reference 1.

Table 9. Plutonium Isotopic Distribution (Reference 1).

\begin{tabular}{|c|c|}
\hline Isotope & Wt.\% \\
\hline $\mathrm{Pu}-238$ & 0.011 \\
\hline $\mathrm{Pu}-239$ & 96.942 \\
\hline $\mathrm{Pu}-240$ & 2.882 \\
\hline $\mathrm{Pu}-241$ & 0.119 \\
\hline $\mathrm{Pu}-242$ & 0.046 \\
\hline
\end{tabular}

Revision: 0

Date: September 30, 2012 


\section{NEA/NSC/DOC/(95)03/I}

Volume I

\section{PU-SOL-THERM-037}

Reference 1 did not report any uncertainty in the solution composition or plutonium isotopic distribution. The experimenter has suggested that one half the least significant digit would be an appropriate uncertainty for the solution composition and plutonium isotopic distribution. ${ }^{\mathrm{a}}$

A spectro-chemical analysis report was given in the experimenter's logbook. The report states that the plutonium material was chemically converted to a mixed oxide, the analysis thus being semi-quantitative in nature only. It was completed on January 11, 1982. Table 10 shows the results of this analysis. The 2 , 3 , and 4 refer to three separate analyses of the same sample. ${ }^{b}$

Table 10. Spectrochemical Analysis Report.

\begin{tabular}{|c|r|r|r|}
\hline & 2 & 3 & 4 \\
\hline $\mathrm{Al}(\mathrm{ppm})$ & 40000 & 60000 & 700 \\
\hline $\mathrm{B}(\mathrm{ppm})$ & 50 & 40 & 20 \\
\hline $\mathrm{Ca}(\mathrm{ppm})$ & 400 & 500 & 600 \\
\hline $\mathrm{Co}(\mathrm{ppm})$ & 30 & 30 & 20 \\
\hline $\mathrm{Fe}(\mathrm{ppm})$ & 700 & 14000 & 1000 \\
\hline $\mathrm{Ni}(\mathrm{ppm})$ & 2000 & 4000 & 300 \\
\hline $\mathrm{Ti}(\mathrm{ppm})$ & 500 & 600 & 300 \\
\hline $\mathrm{V}(\mathrm{ppm})$ & 2000 & 2000 & 2000 \\
\hline
\end{tabular}

\subsubsection{Polyethylene}

The L-3 bottles were composed of polyethylene. Reference 1 gives the density of the polyethylene as $0.98 \pm 0.04 \mathrm{~g} / \mathrm{cm}^{3}$. The average mass of the empty bottles was $987.0 \pm 18.4 \mathrm{~g}$. The composition was given as $85.63 \mathrm{wt} . \%$ carbon and $14.37 \mathrm{wt} \% \%$ hydrogen. These weight percents correspond to the weight percent based on the polyethylene monomer - $\mathrm{CH}_{2}$. The experimenter's logbook contains the results of an elemental analysis on the L-3 bottles. Two techniques were used to test the bottles. For carbon and hydrogen content a $\mathrm{CHO}$ analyzer ${ }^{\mathrm{c}}$ was used. The rest of the elements were analyzed using EDXRF (energy dispersive x-ray fluorescence) techniques with Am-241, Zr, Ag, and Gd sources. The tested "bottle was divided into three sections -top, middle, and bottom - of which aliquots were taken for the two analyses." Table 11 contains the results from these tests.

\footnotetext{
${ }^{\text {a }}$ Personal phone communication with B.M. Durst, September 21, 2010.

${ }^{\mathrm{b}}$ Personal email communication with B.M. Durst, February 1, 2011.

${ }^{\mathrm{c}} \mathrm{CHO}$ analyzer is believed to stand for carbon, hydrogen, oxygen analyzer.
}

Revision: 0

Date: September 30, 2012 
NEA/NSC/DOC/(95)03/I

Volume I

PU-SOL-THERM-037

Table 11. Polyethylene Composition. ${ }^{\text {(a) }}$

\begin{tabular}{|c|c|c|c|c|c|c|c|c|c|c|}
\hline Element & Units & \multicolumn{3}{|c|}{ Top } & \multicolumn{3}{|c|}{ Middle } & \multicolumn{3}{|c|}{ Bottom } \\
\hline $\mathrm{H}$ & $\%$ & 16.1 & \pm & 0.8 & 15.3 & \pm & 0.8 & & & (b) \\
\hline $\mathrm{C}$ & $\%$ & 87.8 & \pm & 2.6 & 88.0 & \pm & 2.6 & & & (b) \\
\hline $\mathrm{Al}$ & $\%$ & $<1$ & & & $<1.2$ & & & $<1.3$ & & \\
\hline $\mathrm{Si}$ & $\%$ & $<0.3$ & & & $<0.4$ & & & $<0.4$ & & \\
\hline $\mathrm{P}$ & $\%$ & $<0.1$ & & & $<0.1$ & & & $<0.2$ & & \\
\hline $\mathrm{S}$ & ppm & $<500$ & & & $<560$ & & & $<620$ & & \\
\hline $\mathrm{Cl}$ & $\mathrm{ppm}$ & $<230$ & & & $<240$ & & & $<270$ & & \\
\hline $\mathrm{K}$ & ppm & $<40$ & & & $<40$ & & & $<50$ & & \\
\hline $\mathrm{Ca}$ & ppm & 220 & \pm & 20 & 230 & \pm & 20 & 260 & \pm & 20 \\
\hline $\mathrm{Ti}$ & ppm & 39 & \pm & 4 & 40 & \pm & 4 & 43 & \pm & 5 \\
\hline $\mathrm{V}$ & ppm & $<3$ & & & $<3$ & & & $<4$ & & \\
\hline $\mathrm{Cr}$ & ppm & 2.3 & \pm & 0.8 & $<2$ & & & $<2$ & & \\
\hline $\mathrm{Mn}$ & ppm & $<1$ & & & $<1$ & & & $<1$ & & \\
\hline $\mathrm{Fe}$ & ppm & 3.1 & \pm & 0.5 & 4 & \pm & 0.5 & 4 & \pm & 0.5 \\
\hline Co & ppm & $<0.5$ & & & $<0.5$ & & & $<0.5$ & & \\
\hline $\mathrm{Ni}$ & ppm & $<0.4$ & & & $<0.4$ & & & $<0.4$ & & \\
\hline $\mathrm{Cu}$ & ppm & 2.3 & \pm & 0.3 & 2.3 & \pm & 0.3 & 2.3 & \pm & 0.3 \\
\hline $\mathrm{Zn}$ & $\mathrm{ppm}$ & 0.49 & \pm & 0.15 & 0.49 & \pm & 0.13 & 0.65 & \pm & 0.1 \\
\hline $\mathrm{Ga}$ & ppm & $<0.3$ & & & $<0.2$ & & & $<0.2$ & & \\
\hline As & ppm & $<0.3$ & & & $<0.2$ & & & $<0.2$ & & \\
\hline $\mathrm{Se}$ & ppm & $<0.3$ & & & $<0.2$ & & & $<0.2$ & & \\
\hline $\mathrm{Br}$ & $\mathrm{ppm}$ & $<0.3$ & & & $<0.2$ & & & $<0.2$ & & \\
\hline $\mathrm{Rb}$ & $\mathrm{ppm}$ & $<0.4$ & & & $<0.4$ & & & $<0.3$ & & \\
\hline $\mathrm{Sr}$ & ppm & $<0.7$ & & & $<0.6$ & & & $<0.5$ & & \\
\hline $\mathrm{Y}$ & $\mathrm{ppm}$ & $<0.8$ & & & $<0.6$ & & & $<0.6$ & & \\
\hline $\mathrm{Zr}$ & ppm & $<0.9$ & & & $<0.7$ & & & $<0.6$ & & \\
\hline $\mathrm{Nb}$ & $\mathrm{ppm}$ & $<1$ & & & $<0.7$ & & & $<0.6$ & & \\
\hline Mo & ppm & $<1$ & & & $<0.8$ & & & $<0.7$ & & \\
\hline $\mathrm{Ag}$ & ppm & $<4$ & & & $<3$ & & & $<2$ & & \\
\hline $\mathrm{Cd}$ & ppm & $<3$ & & & $<3$ & & & $<3$ & & \\
\hline In & ppm & $<4$ & & & $<4$ & & & $<4$ & & \\
\hline $\mathrm{Sn}$ & ppm & $<6$ & & & $<4$ & & & $<3$ & & \\
\hline $\mathrm{Sb}$ & ppm & $<7$ & & & $<4$ & & & $<4$ & & \\
\hline $\mathrm{Te}$ & ppm & $<5$ & & & $<3$ & & & $<3$ & & \\
\hline I & $\mathrm{ppm}$ & $<5$ & & & $<3$ & & & $<3$ & & \\
\hline Cs & $\mathrm{ppm}$ & $<6$ & & & $<3$ & & & $<3$ & & \\
\hline
\end{tabular}

Revision: 0

Date: September 30, 2012 
NEA/NSC/DOC/(95)03/l

Volume I

PU-SOL-THERM-037

\begin{tabular}{|c|c|c|c|c|c|c|c|c|c|}
\hline Element & Units & \multicolumn{3}{|c|}{ Top } & \multicolumn{2}{|c|}{ Middle } & \multicolumn{3}{|c|}{ Bottom } \\
\hline $\mathrm{Ba}$ & ppm & 11 & \pm & 3 & $<4$ & & 3.4 & \pm & 1.6 \\
\hline $\mathrm{La}$ & ppm & $<7$ & & & $<4$ & & $<4$ & & \\
\hline $\mathrm{Ce}$ & ppm & $<8$ & & & $<5$ & & $<4$ & & \\
\hline Po & ppm & $<11$ & & & $<7$ & & $<6$ & & \\
\hline $\mathrm{Nd}$ & ppm & 23 & \pm & 7 & $<10$ & & $<9$ & & \\
\hline $\mathrm{Sm}$ & ppm & $<25$ & & & $<16$ & & $<15$ & & \\
\hline $\mathrm{Eu}$ & ppm & 75 & \pm & 20 & 48 & $\pm \quad 12$ & 44 & \pm & 10 \\
\hline $\mathrm{Gd}$ & ppm & $<43$ & & & $<30$ & & $<30$ & & \\
\hline $\mathrm{Hg}$ & ppm & $<0.8$ & & & $<0.7$ & & $<0.6$ & & \\
\hline $\mathrm{Pb}$ & ppm & $<1$ & & & $<0.9$ & & $<0.7$ & & \\
\hline $\mathrm{U}$ & ppm & $<1.5$ & & & $<1$ & & $<1$ & & \\
\hline
\end{tabular}

(a) Data from experimenter's logbook. Although not stated it is assumed that all percentage values are weight percents.

(b) No values for hydrogen or carbon content were given for the bottom portion of the bottle. It is not known why these values were not given.

\subsubsection{Plexiglas}

Plexiglas was used for the reflector material and the shells around the bottles when the effect of interstitial moderation was tested. Information given in Reference 1 regarding the Plexiglas composition is summarized in Table 12.

Table 12. Plexiglas Composition

(Reference 1).

\begin{tabular}{|c|c|}
\hline Element & wt. $\%$ \\
\hline $\mathrm{H}$ & 8 \\
\hline $\mathrm{C}$ & 60 \\
\hline $\mathrm{O}$ & 32 \\
\hline \hline Density $(\mathrm{g} / \mathrm{cc})$ & 1.185 \\
\hline
\end{tabular}

No further information regarding impurity content of the Plexiglas was provided in Reference 1 or in the logbooks.

Revision: 0

Date: September 30, 2012 


\subsubsection{Aluminum}

The dovetail slider rails, side slider plates, bottle slider plates, and spacers were composed of aluminum

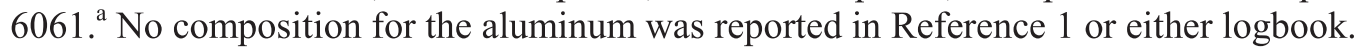

\subsubsection{Structural Material}

Reference 1 and the logbooks gave no information regarding the material used for the split-table machine, the hood, or the surrounding room. The Hazard Summary Report and its supplement referenced in Section 1.2.3 only provide minimal information. They state that the split-table was constructed of a steel beam framework, the hood had a welded stainless steel framework and plastic or glass transparent panels, and the room is built of "ordinary concrete containing reinforcing steel bars". The experimenter remembered the table and hood framework as being SS304L. ${ }^{b}$ A Nuclear Science and Engineering report on another experiment performed in the CML states that the aluminum honeycomb structure had a density of $0.037 \mathrm{~g} / \mathrm{cm}^{3}$.

\section{$1.4 \quad$ Temperature Data}

The temperature of the experiment was not reported in Reference 1 or recorded in the logbooks, but according to the experimenter, the experiment was performed at room temperature with $20-24^{\circ} \mathrm{C}$ being a typical range and $22^{\circ} \mathrm{C}$ being a good average. ${ }^{\mathrm{d}}$

\subsection{Supplemental Experimental Measurements}

No supplemental experimental measurements were reported.

\footnotetext{
${ }^{\text {a }}$ Experimenter's logbook.

${ }^{\mathrm{b}}$ Personal phone communication with B.M. Durst, September 21, 2010.

${ }^{c}$ C.R. Richey, J.D. White, E.D. Clayton, and R.C. Lloyd, "Criticality of Homogeneous Plutonium Oxide-Plastics Compacts at $\mathrm{H}: \mathrm{Pu}=15$," Nuclear Science and Engineering, 23, 150-158, 1965. Information taken from page 151.

${ }^{d}$ Personal email communication with B.M. Durst, November 30, 2010 and December 16, 2010.

Revision: 0

Date: September 30, 2012
} 
NEA/NSC/DOC/(95)03/l

Volume I

PU-SOL-THERM-037

\subsection{EVALUATION OF EXPERIMENTAL DATA}

Twelve configurations were reported in Reference 1, the thirteenth configuration (RSTM-L3-01) was not reported in Reference 1 because the final set up was not large enough to yield an accurate critical value. Four of the configurations (RSTM-L3-02, -09, -10, and -11) were rejected because the critical configuration required a fraction of a bottle and would be impossible to model explicitly. Because of the large uncertainty associated with the modeling of a fraction of a bottle these configurations were not further evaluated. One of the configurations (RSTM-L3-08) required greater than 25 bottles to achieve criticality. This configuration was rejected and not evaluated further because of the ambiguity of the number of bottles and only 16 bottles were described in Reference 1 and the logbooks.

Seven configurations were modeled using Monte Carlo N-Particle version 5.1.51 (MCNP5) ${ }^{\mathrm{a}}$ and ENDF/B-VII. $0^{\mathrm{b}}$ neutron cross section libraries. A detailed model was created for each of these configurations using exact bottle, solution, material, and array dimensions, except for bottle mass, and then a simplified model was derived from the detailed model using methods described in Appendix C.1 of this report. The simple model was used to evaluate the uncertainty in all measured parameters of each configuration. Due to the large experimental uncertainty, these experiments are judged to be unacceptable as benchmark experiments. The largest contribution to the total experimental uncertainty was due to uncertainty in the solution composition.

For measurements with systematic and random components for the uncertainty, the following equation was used to calculate the total uncertainty, $\sigma_{\text {tot }}$.

$$
\sigma_{\text {tot }}=\sqrt{\sigma_{\text {sys. }}^{2}+\frac{\sigma_{\text {rand. }}^{2}}{N}} \quad \text { Equation 1 }
$$

Where $\sigma_{\text {sys. }}$ is the systematic uncertainty, $\sigma_{\text {rand }}$ is the random uncertainty, and $N$ is the number of measurements or the number of bottles.

The effect of the uncertainty in a given parameter was determined by perturbing that parameter in the model above and below the value specified for the simple model and then calculating the resulting $\Delta \mathrm{k}_{\text {eff }}$. The statistical uncertainty, $\sigma_{\mathrm{MCNP}}$, was found by taking the square root of the sum of the square of the MCNP statistical uncertainty for the base case and the upper or lower perturbed case. For some uncertainty analyses the perturbation of the parameter was increased, sometimes much greater than the $1 \sigma$ uncertainty, to yield $\Delta \mathrm{k}_{\text {eff }}$ values greater than the statistical uncertainty $(0.00005)$ in the MCNP calculation. The ratio of the perturbation to the $1 \sigma$ uncertainty for the parameter was a factor in the "scaling factor" used to convert the calculated $\Delta \mathrm{k}_{\text {eff }}$ to a $1 \sigma$ uncertainty in $\mathrm{k}_{\text {eff. }}$ These scaling factors, where used, are reflected in the tables throughout Section 2. For some analyses a scaling factor that was not a whole number was used. This occurs because the perturbations of the model were performed before exact $1 \sigma$ uncertainties had been determined. An uncertainty was considered to have negligible effect (NEG) when the magnitude of the $1 \sigma \Delta \mathrm{k}_{\text {eff }}$ was less than 0.00010 .

\footnotetext{
${ }^{a}$ F.B. Brown, R.F. Barrett, T.E. Booth, J.S. Bull, L.J. Cox, R.A. Forster, T.J. Goorley, R.D. Mosteller, S.E. Post, R.E. Prael, E.C. Selcow, A. Sood, and J. Sweezy, "MCNP Version 5," LA-UR-02-3935, Los Alamos National Laboratory (2002).

${ }^{\mathrm{b}}$ M.B. Chadwick, et al., "ENDF/B-VII.0: Next Generation Evaluated Nuclear Data Library for Nuclear Science and Technology," Nucl. Data Sheets, 107: 2931-3060 (2006).

Revision: 0
}

Date: September 30, 2012

Page 32 of 142 
NEA/NSC/DOC/(95)03/I

Volume I

PU-SOL-THERM-037

\subsection{Critical Array Spacing Uncertainties}

The critical array spacing between bottles was found by extrapolation to critical. An example of the extrapolation to critical as reproduced by the evaluator can be found in Appendix B. Spacing values from Tables 6 and 7 agree fairly well with the values in Table 5 for all experiments except RSTM-L3-07. The discrepancies between the extrapolated-to-critical Y spacing for RSTM-L3-07 is unclear but values for array spacing from Tables 6 and 7 were used in the models for all experiments. These values were used over those in Table 5 based on input from the experimenter. Bottle spacing was achieved with small aluminum spacers which were measured with a micrometer with an accuracy of $0.00254 \mathrm{~cm}$. ${ }^{\text {a }}$ To evaluate the uncertainty in the critical array spacing the $\mathrm{X}$ and $\mathrm{Y}$ spacings were evaluated separately. Three types of spacing uncertainties were used; one for bottles that were touching, one for bottles that were separated by a spacer and one for spacings found by extrapolation. The uncertainty for each was found in the following ways.

- For bottles that were touching, it is possible that gaps between bottles were present due to random imperfections in the bottle surfaces. To account for the possibility of these gaps between bottles and between the bottles and the reflector, the maximum gap possible between the reflectors and the bottles of $0.01 \mathrm{in}$. or $0.0254 \mathrm{~cm}$ was used as a one-sided-bounding uncertainty with a right-triangular distribution. This uncertainty was assumed to have no systematic component due to the fact that variations and imperfections in the bottle surfaces would have been completely random. A factor of $\sqrt{N}$ was also included in the scaling factor for bottles that were touching to account for the fact that $N$ bottle-to-bottle spacings were perturbed simultaneously for this random uncertainty ( $N$ was 9 for $3 \times 4$ arrays and 12 for $4 \times 4$ arrays).

$$
\sigma_{\text {tot }}=\sqrt{0.0254 / 2 \sqrt{3} \sqrt{N}}
$$

- For spacings that were held constant through the experiment using aluminum spacers the uncertainty was found by adding in quadrature the uncertainty due to bottle surface variations, which is no longer one-sided, and the uncertainty of the spacers which was $0.00254 \mathrm{~cm}$.

$$
\sigma_{\text {tot }}=\sqrt{(0.0254 / \sqrt{3} \sqrt{N})^{2}+0.00254^{2}}
$$

- For spacings that were determined by an extrapolation-to-critical the uncertainty was found in the same way except an additional uncertainty in the extrapolation $\left(\sigma_{\text {ext. }}\right)$ was included. One half the difference between the results from the two extrapolation methods (see Table 6) was used as the $1 \sigma$ extrapolation uncertainty and is believed to be an overestimate. These extrapolation method differences are believed to be more indicative of the true extrapolation uncertainty than the spacing uncertainties listed in Table 5.

$$
\sigma_{\text {tot }}=\sqrt{(0.0254 / \sqrt{3} \sqrt{N})^{2}+0.00254^{2}+\sigma_{\text {ext }}^{2}}
$$

\footnotetext{
${ }^{a}$ Personal phone and email communication with B.M. Durst, January 24, 2011 and February 28, 2011.
}

Revision: 0

Date: September 30, 2012 


\section{NEA/NSC/DOC/(95)03/I}

Volume I

\section{PU-SOL-THERM-037}

Spacings were perturbed by $1 \sigma$. Tables 13 and 14 summarize the effect of uncertainty in array spacing in the $\mathrm{X}$ and $\mathrm{Y}$ directions.

It should be noted that the same methodology was followed for RSTM-L3-12 but using shell-to-shell spacings.

Table 13. $\Delta \mathrm{k}_{\text {eff }}$ for Uncertainty in Array Spacing in X-Direction.

\begin{tabular}{|c|c|c|c|c|c|c|}
\hline RSTM-L3- & $\begin{array}{c}\text { Method of } \\
\text { Obtaining Spacing }\end{array}$ & $\begin{array}{c}\text { X-Direction } \\
\text { Spacing }(\mathrm{cm}) \\
\end{array}$ & $\begin{array}{c}\Delta \text { Spacing } \\
(1 \sigma, \mathrm{cm}) \\
\end{array}$ & $\Delta \mathrm{k}_{1 \sigma}$ & \pm & $\sigma_{\mathrm{MCNP}, 1 \sigma}$ \\
\hline \multirow{2}{*}{3} & \multirow{2}{*}{ touching } & \multirow{2}{*}{0} & & & & \\
\hline & & & +0.0049 & -0.00016 & \pm & 0.00006 \\
\hline \multirow{2}{*}{4} & \multirow{2}{*}{ spacers } & \multirow{2}{*}{0.33020} & -0.0055 & 0.00014 & \pm & 0.00007 \\
\hline & & & +0.0055 & -0.00014 & \pm & 0.00006 \\
\hline \multirow{2}{*}{$5^{(\mathrm{b})}$} & \multirow{2}{*}{ extrapolated } & \multirow{2}{*}{0.58486} & -0.0211 & 0.00066 & \pm & 0.00006 \\
\hline & & & +0.0211 & -0.00060 & \pm & 0.00006 \\
\hline \multirow{2}{*}{6} & \multirow{2}{*}{ touching } & \multirow{2}{*}{0} & & & & \\
\hline & & & +0.0042 & -0.00025 & \pm & 0.00006 \\
\hline \multirow{2}{*}{7} & \multirow{2}{*}{ spacers } & \multirow{2}{*}{1.25730} & -0.0049 & 0.00015 & \pm & 0.00006 \\
\hline & & & +0.0049 & -0.00018 & \pm & 0.00006 \\
\hline \multirow{2}{*}{$12^{(\mathrm{a})}$} & \multirow{2}{*}{ touching } & \multirow{2}{*}{0} & & & & \\
\hline & & & +0.0042 & -0.00031 & \pm & 0.00006 \\
\hline \multirow{2}{*}{13} & \multirow{2}{*}{ spacers } & \multirow{2}{*}{0.68580} & -0.0049 & 0.00014 & \pm & 0.00006 \\
\hline & & & +0.0049 & -0.00015 & \pm & 0.00007 \\
\hline
\end{tabular}

(a) Spacings for RSTM-L3-12 are shell-to-shell-outer surface spacings rather than bottle-tobottle surface spacings.

(b) X and Y axis were switched for RSTM-L3-5 as discussed in Section 1.2.4. 
NEA/NSC/DOC/(95)03/I

Volume I

PU-SOL-THERM-037

Table 14. $\Delta \mathrm{k}_{\mathrm{eff}}$ for Uncertainty in Array Spacing in $\mathrm{Y}$-Direction.

\begin{tabular}{|c|c|c|c|c|c|c|}
\hline RSTM-L3- & & $\begin{array}{c}\text { Y-Direction } \\
\text { Spacing }(\mathrm{cm})\end{array}$ & $\begin{array}{c}\Delta \text { Spacing } \\
(\mathrm{cm})\end{array}$ & $\Delta \mathrm{k}_{1 \sigma}$ & \pm & $\sigma_{\mathrm{MCNP}, 1 \sigma}$ \\
\hline \multirow{2}{*}{3} & \multirow{2}{*}{ extrapolated } & \multirow{2}{*}{0.49187} & -0.0605 & 0.00216 & \pm & 0.00007 \\
\hline & & & +0.0605 & -0.00220 & \pm & 0.00008 \\
\hline \multirow{2}{*}{4} & \multirow{2}{*}{ extrapolated } & \multirow{2}{*}{0.36132} & -0.1268 & 0.00456 & \pm & 0.00007 \\
\hline & & & +0.1268 & -0.00448 & \pm & 0.00006 \\
\hline \multirow{2}{*}{$5^{(\mathrm{b})}$} & \multirow{2}{*}{ touching } & \multirow{2}{*}{0} & & & & \\
\hline & & & +0.0024 & \multicolumn{3}{|c|}{$\overline{\mathrm{NEG}}$} \\
\hline \multirow{2}{*}{6} & \multirow{2}{*}{ extrapolated } & \multirow{2}{*}{1.92265} & -0.0403 & 0.00115 & \pm & 0.00007 \\
\hline & & & +0.0403 & -0.00129 & \pm & 0.00007 \\
\hline \multirow{2}{*}{7} & \multirow{2}{*}{ extrapolated } & \multirow{2}{*}{0.70884} & -0.2346 & 0.00545 & \pm & 0.00006 \\
\hline & & & +0.2346 & -0.00771 & \pm & 0.00007 \\
\hline \multirow{2}{*}{$12^{(\mathrm{a})}$} & \multirow{2}{*}{ extrapolated } & \multirow{2}{*}{1.24043} & -0.0169 & 0.00037 & \pm & 0.00006 \\
\hline & & & +0.0169 & -0.00050 & \pm & 0.00006 \\
\hline \multirow{2}{*}{13} & \multirow{2}{*}{ extrapolated } & \multirow{2}{*}{1.20386} & -0.0191 & -0.00057 & \pm & 0.00006 \\
\hline & & & +0.0191 & 0.00057 & \pm & 0.00006 \\
\hline
\end{tabular}

(a) Spacings for RSTM-L3-12 are shell-to-shell-outer surface spacings rather than bottle-to-bottle surface spacings.

(b) X and Y axis were switched for RSTM-L3-5 as discussed in Section 1.2.4.

For RSTM-L3-5 the axes were switched from how they appear in Tables 6 and 7 to how they appear in Table 5 and Figure 9. This changing of axis was done by the experimenter when reporting results in Reference 1 and is believed to have no effect due to the Plexiglas reflector being tight on all sides of the array.

An additional analysis was completed to determine the effect of random movements of the bottles within the array structure. When the positions of the bottles were randomly varied with a URAN analysis in MCNP5 it was found that the effect on $\mathrm{k}_{\mathrm{eff}}$ was negligible. The bottle position was varied by the uncertainty in the array spacing except for bottles that were touching; the array position for touching bottles was not varied.

\subsection{Geometry Uncertainties}

\subsubsection{Bottle Dimensions}

Figure 14 is a schematic of the simple model of the L-3 bottles. The curves at the bottom and top of the bottle were homogenized. To homogenize the bottom of the bottle, the volume of the bottle below the solution height was estimated and then homogenized into a plug shape. Exact dimensions of the curve at the top of the bottle and the lid were not provided so the exact volume of polyethylene bottle above the solution could not be precisely determined. For the benchmark model this curve was not modeled. In order to conserve mass, the volume and mass of the bottle below the solution height was first calculated. The mass of bottle above $28.995 \mathrm{~cm}$ was then found and homogenized over the volume above that height in the simple model bottle. Figure 14 is a diagram of the simple model of the L-3 bottle including all dimensions critical to the homogenization of mass above the solution height.

Revision: 0

Date: September 30, 2012

Page 35 of 142 
NEA/NSC/DOC/(95)03/l

Volume I

PU-SOL-THERM-037

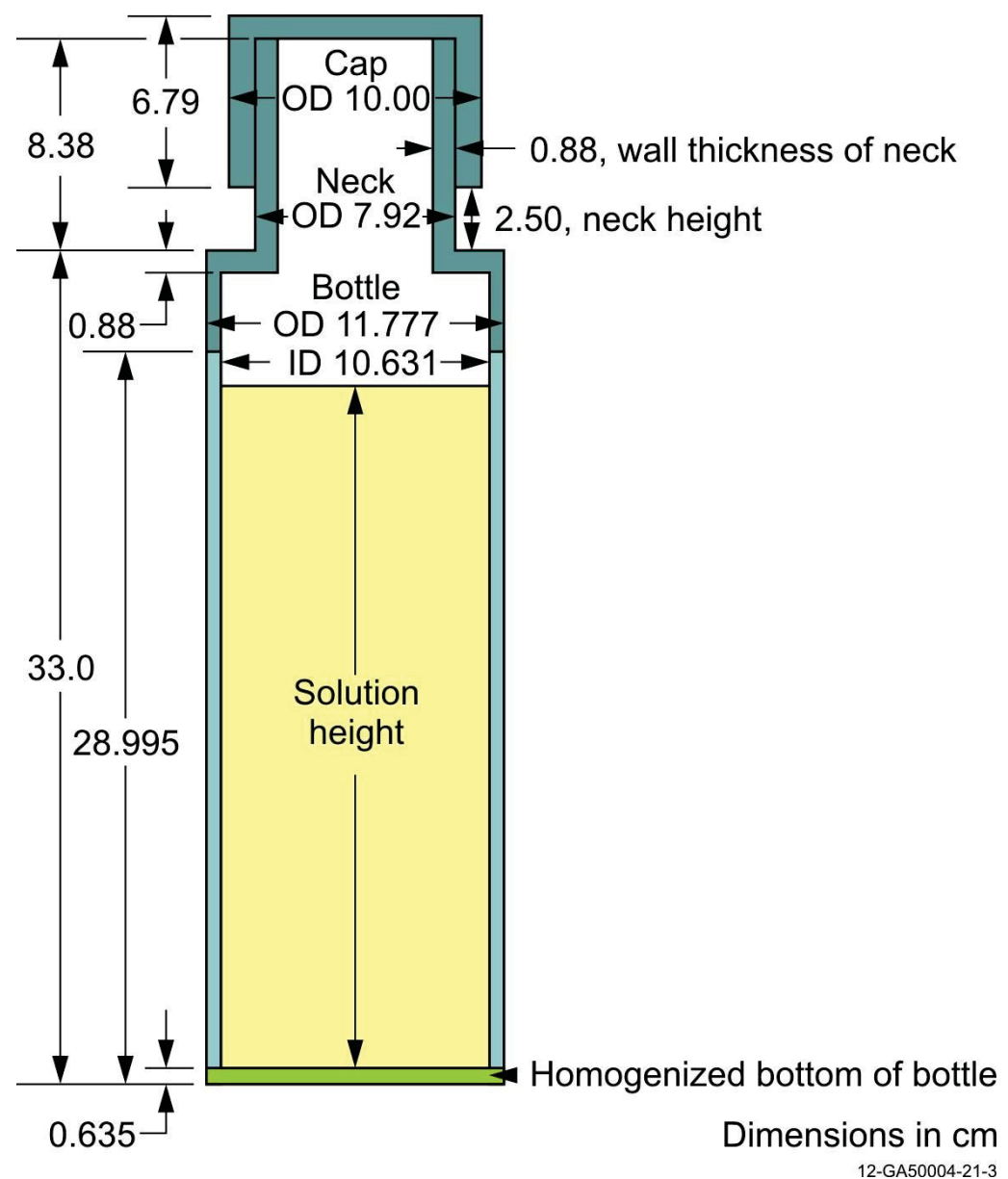

Figure 14. Simple Model of L-3 Bottle.

The geometry of the bottom of the bottle was very uncertain. To estimate the volume of the bottom of the bottle two different geometries were assumed. First, the volume of the bottom of the bottle was found by assuming the outer curve of the bottom of the bottle could be defined as a quarter of a torus with a distance from the center of the bottle to the center of the torus being $5.254 \mathrm{~cm}$ and the radius of the torus being $0.635 \mathrm{~cm}$. Inside of the quarter torus is a cylinder of polyethylene with a dome removed with a height of $0.48 \mathrm{~cm}$ and an arbitrarily assumed distance across the dome of $8.923 \mathrm{~cm}$. This yielded a volume of $50.44 \mathrm{~cm}^{3}$ (see Figure 15a). Second, the volume of the bottom of the bottle was found by assuming a constant $0.635-\mathrm{cm}$-thick curve along the bottom of the bottle; the dimensions of the quarter torus were the same. This yielded a volume of $65.5 \mathrm{~cm}^{3}$ which is believed to be an overestimate (see Figure 15b). In the simple model the geometry shown in Figure 15a was homogenized to a cylinder with a radius of $5.8885 \mathrm{~cm}$ and height of $0.635 \mathrm{~cm}$. The uncertainty in the volume of the bottom of the bottle was arbitrarily chosen as $30 \%$ so that the volume of the bottom of the bottle shown in Figure $15 \mathrm{~b}$ was encompassed in the $1 \sigma$ uncertainty. Mass of the bottle was conserved when performing this analysis by adjusting the homogenized density of the bottle above the solution height. Table 15 contains the results of this analysis. 


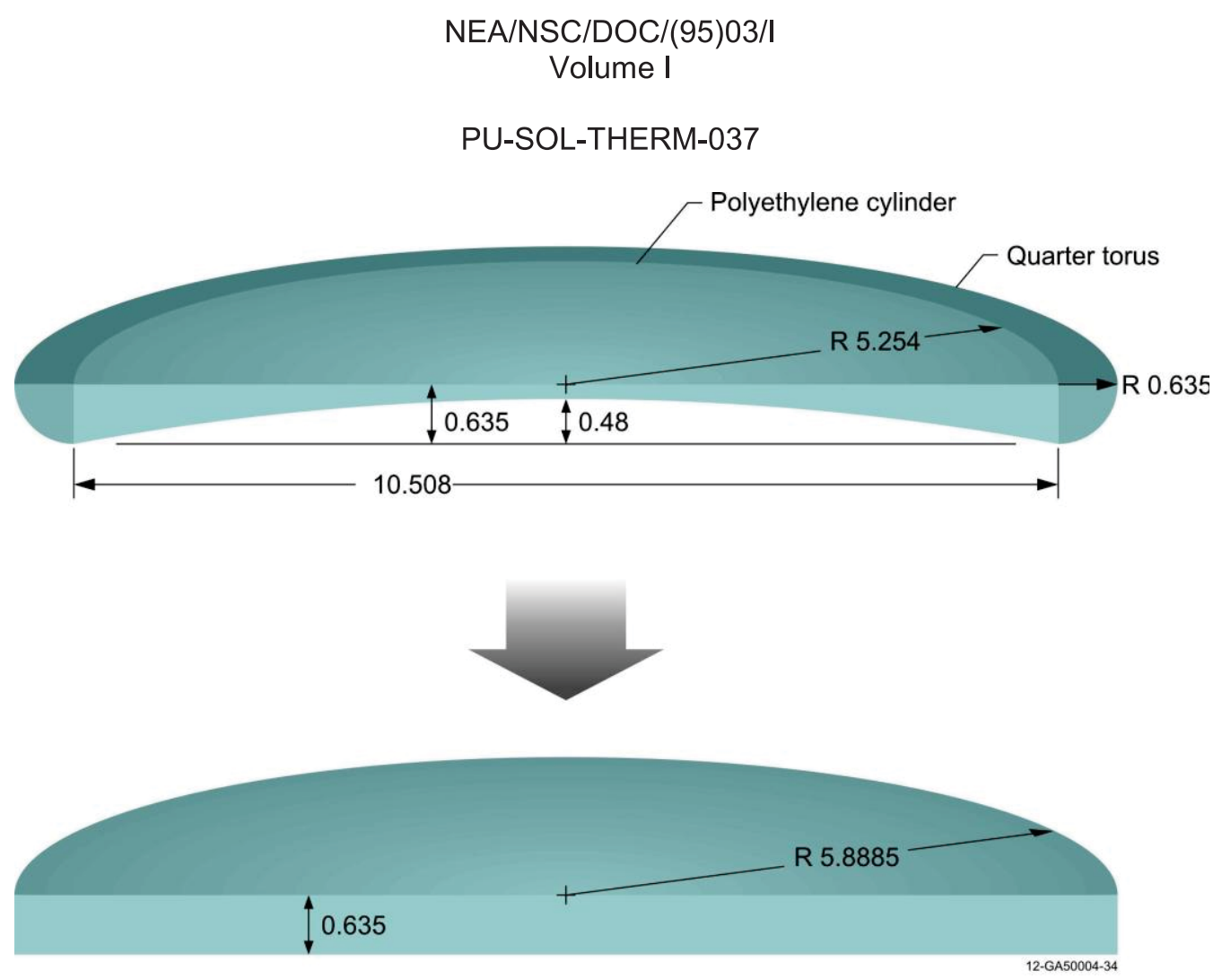

(a)
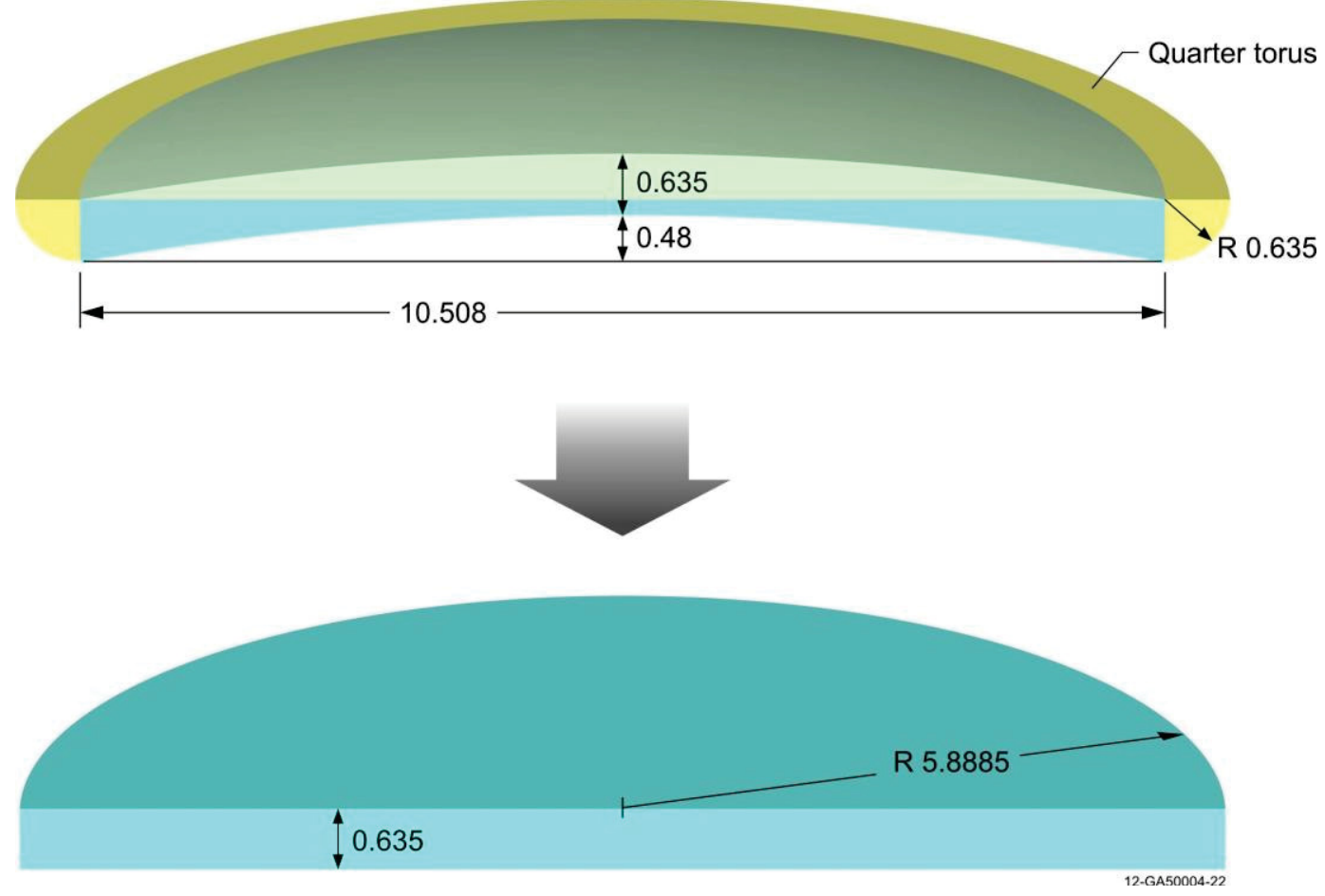

(b)

Figure 15. Homogenization of the Bottom of the Bottle.

Revision: 0

Date: September 30, 2012 


\section{NEA/NSC/DOC/(95)03/l}

Volume I

\section{PU-SOL-THERM-037}

Table 15. $\Delta \mathrm{k}_{\text {eff }}$ for Uncertainty in Bottom of Bottle Volume.

\begin{tabular}{|c|c|c|c|c|c|c|c|c|}
\hline RSTM-L3- & $\Delta \mathrm{Vol}$ & $\Delta \mathrm{k}$ & \pm & $\sigma_{\mathrm{MCNP}}$ & $\begin{array}{l}\text { Scaling } \\
\text { Factor }\end{array}$ & $\Delta \mathrm{k}_{1 \sigma}$ & $\perp$ & $\sigma_{\mathrm{MCNP}, 1 \sigma}$ \\
\hline & $-50 \%$ & -0.00020 & \pm & 0.00006 & $5 / 3$ & -0.00012 & \pm & 0.00004 \\
\hline & $50 \%$ & -0.00048 & \pm & 0.00006 & $5 / 3$ & -0.00029 & \pm & 0.00004 \\
\hline & $-50 \%$ & -0.00012 & \pm & 0.00006 & $5 / 3$ & \multicolumn{3}{|c|}{ NEG } \\
\hline & $50 \%$ & -0.00049 & \pm & 0.00006 & $5 / 3$ & \multicolumn{2}{|c|}{$29 \pm$} & 0.00004 \\
\hline & $-50 \%$ & -0.00010 & \pm & 0.00006 & $5 / 3$ & \multicolumn{3}{|c|}{ NEG } \\
\hline & $50 \%$ & -0.00050 & \pm & 0.00006 & $5 / 3$ & -0.00030 & \pm & 0.00004 \\
\hline & $-50 \%$ & -0.00043 & \pm & 0.00006 & $5 / 3$ & -0.00026 & \pm & 0.00004 \\
\hline & $50 \%$ & -0.00123 & \pm & 0.00006 & $5 / 3$ & -0.00074 & \pm & 0.00003 \\
\hline & $-50 \%$ & -0.00030 & \pm & 0.00006 & $5 / 3$ & -0.00018 & \pm & 0.00004 \\
\hline & $50 \%$ & -0.00125 & \pm & 0.00006 & $5 / 3$ & -0.00075 & \pm & 0.00003 \\
\hline \multirow{2}{*}{12} & $-50 \%$ & -0.00055 & \pm & 0.00006 & $5 / 3$ & -0.00033 & \pm & 0.00003 \\
\hline & $50 \%$ & -0.00187 & \pm & 0.00006 & $5 / 3$ & -0.00112 & \pm & 0.00004 \\
\hline \multirow{2}{*}{13} & $-50 \%$ & -0.00041 & \pm & 0.00006 & $5 / 3$ & -0.00025 & \pm & 0.00003 \\
\hline & $50 \%$ & -0.00106 & \pm & 0.00006 & $5 / 3$ & -0.00064 & \pm & 0.00004 \\
\hline
\end{tabular}

Bottle dimensions, except for the inside and outside diameters, were given as single measurements for all bottles in Figure 1. These measurements were found using calipers with an accuracy of $0.001 \mathrm{in}$. or $0.00254 \mathrm{~cm}$. This value was taken to be the systematic uncertainty in the bottle dimension measurements, $\sigma_{\text {sys. }}$. It is also possible that random errors in the bottle dimension measurements could have been made thus a random component of the uncertainty of $1 / 32 \mathrm{in}$. or $0.0794 \mathrm{~cm}$ was used. The systematic and random uncertainties were combined for a total uncertainty, $\sigma_{\text {tot }}$, using Equation 1 with $N$ as the total number of bottles used in all experiments (16). This yields a total uncertainty of $0.020 \mathrm{~cm}$ which applies to all bottle dimensions made using calipers: bottle neck height, neck diameter, neck wall thickness, cap height, cap diameter, and bottle inside and outside diameters.

Tables 16 through 20 summarize the effect of a $\pm 0.020 \mathrm{~cm}$ uncertainty in the neck height, neck diameter, neck wall thickness, cap height, and cap diameter dimensions. When perturbations were made to bottle dimensions the atom density of the entire portion of the bottle above the solution height was varied to conserve mass.

Revision: 0

Date: September 30, 2012 


\section{NEA/NSC/DOC/(95)03//}

Volume I

\section{PU-SOL-THERM-037}

Table 16. $\Delta \mathrm{k}_{\text {eff }}$ for Uncertainty in the Bottle Neck Height.

\begin{tabular}{|c|c|rcc|c|c|}
\hline \multirow{2}{*}{ RSTM-L3- } & $\begin{array}{c}\Delta \\
(\mathrm{cm})\end{array}$ & \multicolumn{1}{|c|}{$\Delta \mathrm{k}$} & \pm & $\sigma_{\text {MCNP }}$ & $\begin{array}{c}\text { Scaling } \\
\text { Factor }\end{array}$ & $\Delta \mathrm{k}_{1 \sigma}$ \\
\hline \multirow{2}{*}{3} & -2.5 & 0.00013 & \pm & 0.00006 & 125 & NEG \\
\cline { 2 - 7 } & 2.5 & -0.00032 & \pm & 0.00006 & 125 & NEG \\
\hline \multirow{2}{*}{4} & -2.5 & 0.00010 & \pm & 0.00006 & 125 & NEG \\
\cline { 2 - 7 } & 2.5 & -0.00034 & \pm & 0.00006 & 125 & NEG \\
\hline \multirow{2}{*}{5} & -2.5 & 0.00007 & \pm & 0.00007 & 125 & NEG \\
\cline { 2 - 7 } & 2.5 & -0.00027 & \pm & 0.00006 & 125 & NEG \\
\hline \multirow{3}{*}{6} & -2.5 & -0.00037 & \pm & 0.00006 & 125 & NEG \\
\cline { 2 - 7 } & 2.5 & -0.00031 & \pm & 0.00006 & 125 & NEG \\
\hline \multirow{3}{*}{7} & -2.5 & -0.00043 & \pm & 0.00006 & 125 & NEG \\
\cline { 2 - 7 } & 2.5 & -0.00033 & \pm & 0.00006 & 125 & NEG \\
\hline \multirow{2}{*}{12} & -2.5 & -0.00246 & \pm & 0.00006 & 125 & NEG \\
\cline { 2 - 6 } & 2.5 & 0.00151 & \pm & 0.00006 & 125 & NEG \\
\hline \multirow{2}{*}{13} & -2.5 & -0.00027 & \pm & 0.00006 & 125 & NEG \\
\cline { 2 - 6 } & 2.5 & -0.00010 & \pm & 0.00006 & 125 & NEG \\
\hline
\end{tabular}

Table 17. $\Delta \mathrm{k}_{\mathrm{eff}}$ for Uncertainty in the Bottle Neck Wall Thickness.

\begin{tabular}{|c|c|rcc|c|c|}
\hline \multirow{2}{*}{ RSTM-L3- } & $\begin{array}{c}\Delta \\
(\mathrm{cm})\end{array}$ & $\Delta \mathrm{k}$ & \pm & $\sigma_{\mathrm{MCNP}}$ & $\begin{array}{c}\text { Scaling } \\
\text { Factor }\end{array}$ & $\Delta \mathrm{k}_{1 \sigma}$ \\
\hline \multirow{2}{*}{3} & -0.2 & 0.00012 & \pm & 0.00007 & 10 & NEG \\
\cline { 2 - 7 } & 0.2 & 0.00004 & \pm & 0.00006 & 10 & NEG \\
\hline \multirow{3}{*}{4} & -0.2 & 0.00006 & \pm & 0.00006 & 10 & NEG \\
\cline { 2 - 7 } & 0.2 & -0.00013 & \pm & 0.00007 & 10 & NEG \\
\hline \multirow{2}{*}{5} & -0.2 & 0.00012 & \pm & 0.00006 & 10 & NEG \\
\cline { 2 - 7 } & 0.2 & -0.00008 & \pm & 0.00006 & 10 & NEG \\
\hline \multirow{3}{*}{6} & -0.2 & -0.00011 & \pm & 0.00006 & 10 & NEG \\
\cline { 2 - 7 } & 0.2 & -0.00012 & \pm & 0.00006 & 10 & NEG \\
\hline \multirow{3}{*}{7} & -0.2 & 0.00001 & \pm & \pm .00007 & 10 & NEG \\
\cline { 2 - 6 } & 0.2 & -0.00014 & \pm 0.00007 & 10 & NEG \\
\hline \multirow{2}{*}{12} & -0.2 & 0.00003 & \pm 0.00006 & 10 & NEG \\
\cline { 2 - 6 } & 0.2 & -0.00011 & \pm & 0.00006 & 10 & NEG \\
\hline \multirow{2}{*}{13} & -0.2 & 0.00007 & \pm & 0.00006 & 10 & NEG \\
\cline { 2 - 6 } & 0.2 & -0.00005 & \pm & 0.00006 & 10 & NEG \\
\hline
\end{tabular}

Revision: 0

Date: September 30, 2012 
NEA/NSC/DOC/(95)03/l

Volume I

PU-SOL-THERM-037

Table 18. $\Delta \mathrm{k}_{\text {eff }}$ for Uncertainty in the Bottle Neck Diameter.

\begin{tabular}{|c|c|rcc|c|c|}
\hline \multirow{2}{*}{ RSTM-L3- } & $\begin{array}{c}\Delta \\
(\mathrm{cm})\end{array}$ & \multicolumn{1}{|c|}{$\Delta \mathrm{k}$} & \pm & $\sigma_{\mathrm{MCNP}}$ & $\begin{array}{c}\text { Scaling } \\
\text { Factor }\end{array}$ & $\Delta \mathrm{k}_{1 \sigma}$ \\
\hline \multirow{2}{*}{3} & -2 & -0.00006 & \pm & 0.00007 & 100 & NEG \\
\cline { 2 - 7 } & 2 & 0.00056 & \pm & 0.00007 & 100 & NEG \\
\hline \multirow{2}{*}{4} & -2 & -0.00003 & \pm & 0.00006 & 100 & NEG \\
\cline { 2 - 7 } & 2 & 0.00061 & \pm & 0.00007 & 100 & NEG \\
\hline \multirow{2}{*}{5} & -2 & -0.00008 & \pm & 0.00007 & 100 & NEG \\
\cline { 2 - 7 } & 2 & 0.00053 & \pm & 0.00006 & 100 & NEG \\
\hline \multirow{3}{*}{6} & -2 & -0.00028 & \pm & 0.00006 & 100 & NEG \\
\cline { 2 - 7 } & 2 & 0.00055 & \pm & 0.00006 & 100 & NEG \\
\hline \multirow{3}{*}{7} & -2 & -0.00024 & \pm & 0.00006 & 100 & NEG \\
\cline { 2 - 6 } & 2 & 0.00050 & \pm & 0.00007 & 100 & NEG \\
\hline \multirow{2}{*}{12} & -2 & -0.00014 & \pm & 0.00006 & 100 & NEG \\
\cline { 2 - 6 } & 2 & 0.00032 & \pm & 0.00006 & 100 & NEG \\
\hline \multirow{2}{*}{13} & -2 & -0.00011 & \pm & 0.00006 & 100 & NEG \\
\cline { 2 - 6 } & 2 & 0.00069 & \pm & 0.00006 & 100 & NEG \\
\hline
\end{tabular}

Table 19. $\Delta \mathrm{k}_{\text {eff }}$ for Uncertainty in the Cap Height.

\begin{tabular}{|c|c|rcc|c|c|}
\hline \multirow{2}{*}{ RSTM-L3- } & $\begin{array}{c}\Delta \\
(\mathrm{cm})\end{array}$ & \multicolumn{1}{|c}{$\Delta \mathrm{k}$} & \pm & $\sigma_{\text {MCNP }}$ & $\begin{array}{c}\text { Scaling } \\
\text { Factor }\end{array}$ & $\Delta \mathrm{k}_{1 \sigma}$ \\
\hline \multirow{2}{*}{3} & -0.5 & 0.00001 & \pm & 0.00007 & 0.5 & NEG \\
\cline { 2 - 6 } & 0.5 & -0.00002 & \pm & 0.00007 & 0.5 & NEG \\
\hline \multirow{3}{*}{4} & -0.5 & 0.00011 & \pm & 0.00006 & 0.5 & NEG \\
\cline { 2 - 7 } & 0.5 & 0.00006 & \pm & 0.00007 & 0.5 & NEG \\
\hline \multirow{2}{*}{5} & -0.5 & 0.00002 & \pm & 0.00007 & 0.5 & NEG \\
\cline { 2 - 7 } & 0.5 & 0.00003 & \pm & 0.00007 & 0.5 & NEG \\
\hline \multirow{3}{*}{6} & -0.5 & -0.00004 & \pm & 0.00006 & 0.5 & NEG \\
\cline { 2 - 6 } & 0.5 & -0.00010 & \pm & 0.00006 & 0.5 & NEG \\
\hline \multirow{3}{*}{7} & -0.5 & -0.00007 & \pm & 0.00006 & 0.5 & NEG \\
\cline { 2 - 6 } & 0.5 & -0.00007 & \pm & 0.00006 & 0.5 & NEG \\
\hline \multirow{2}{*}{12} & -0.5 & -0.00009 & \pm & 0.00006 & 0.5 & NEG \\
\cline { 2 - 6 } & 0.5 & -0.00011 & \pm & 0.00006 & 0.5 & NEG \\
\hline \multirow{2}{*}{13} & -0.5 & 0.00003 & \pm & 0.00006 & 0.5 & NEG \\
\cline { 2 - 6 } & 0.5 & -0.00007 & \pm & 0.00006 & 0.5 & NEG \\
\hline
\end{tabular}

Revision: 0

Date: September 30, 2012 


\section{NEA/NSC/DOC/(95)03/l}

Volume I

\section{PU-SOL-THERM-037}

Table 20. $\Delta \mathrm{k}_{\mathrm{eff}}$ for Uncertainty in the Cap Diameter.

\begin{tabular}{|c|c|ccc|c|c|}
\hline \multirow{2}{*}{ RSTM-L3- } & $\begin{array}{c}\Delta \\
(\mathrm{cm})\end{array}$ & $\Delta \mathrm{k}$ & \pm & $\sigma_{\text {MCNP }}$ & $\begin{array}{c}\text { Scaling } \\
\text { Factor }\end{array}$ & $\Delta \mathrm{k}_{1 \sigma}$ \\
\hline \multirow{2}{*}{3} & -0.16 & 0.00002 & \pm & 0.00006 & 8 & $\mathrm{NEG}$ \\
\cline { 2 - 7 } & 0.16 & 0.00008 & \pm & 0.00006 & 8 & $\mathrm{NEG}$ \\
\hline \multirow{2}{*}{4} & -0.16 & 0.00007 & \pm & 0.00007 & 8 & $\mathrm{NEG}$ \\
\cline { 2 - 7 } & 0.16 & 0.00006 & \pm & 0.00007 & 8 & $\mathrm{NEG}$ \\
\hline \multirow{2}{*}{5} & -0.16 & -0.00001 & \pm & 0.00006 & 8 & $\mathrm{NEG}$ \\
\cline { 2 - 7 } & 0.16 & -0.00004 & \pm & 0.00006 & 8 & $\mathrm{NEG}$ \\
\hline \multirow{3}{*}{6} & -0.16 & -0.00011 & \pm & 0.00006 & 8 & $\mathrm{NEG}$ \\
\cline { 2 - 7 } & 0.16 & -0.00006 & \pm & 0.00006 & 8 & $\mathrm{NEG}$ \\
\hline \multirow{3}{*}{7} & -0.16 & -0.00005 & \pm & 0.00007 & 8 & $\mathrm{NEG}$ \\
\cline { 2 - 7 } & 0.16 & -0.00004 & \pm & 0.00006 & 8 & $\mathrm{NEG}$ \\
\hline \multirow{2}{*}{12} & -0.16 & -0.00012 & \pm & 0.00006 & 8 & $\mathrm{NEG}$ \\
\cline { 2 - 6 } & 0.16 & -0.00004 & \pm & 0.00006 & 8 & $\mathrm{NEG}$ \\
\hline \multirow{2}{*}{13} & -0.16 & 0.00006 & \pm 0.00006 & 8 & $\mathrm{NEG}$ \\
\cline { 2 - 6 } & 0.16 & 0.00006 & \pm 0.00006 & 8 & $\mathrm{NEG}$ \\
\hline
\end{tabular}

The effect of the uncertainty in the bottle outside and inside diameter was evaluated. The outside diameter was adjusted by $\pm 0.02 \mathrm{~cm}$ while holding the bottle inside diameter constant. Because the bottle-to-bottle separation measurements were independently made the placement of the bottles (overall array dimensions) also had to be adjusted with the bottle outside diameter to maintain the bottle-to-bottle separation. When the outer diameter of the bottle was varied the atom density of the entire portion of the bottle above the solution height was varied to conserve mass. The results of this evaluation can be found in Table 21.

Revision: 0

Date: September 30, 2012 
NEA/NSC/DOC/(95)03/l

Volume I

PU-SOL-THERM-037

Table 21. $\Delta \mathrm{k}_{\text {eff }}$ for Uncertainty in Bottle Outer Diameter.

\begin{tabular}{|c|c|rcc|c|rcc|}
\hline \multirow{2}{*}{ RSTM-L3- } & $\begin{array}{c}\Delta \mathrm{OD} \\
(\mathrm{cm})\end{array}$ & $\Delta \mathrm{k}$ & \pm & $\sigma_{\mathrm{MCNP}}$ & $\begin{array}{c}\text { Scaling } \\
\text { Factor }\end{array}$ & $\Delta \mathrm{k}_{1 \sigma}$ & \pm & $\sigma_{\mathrm{MCNP}, 1 \sigma}$ \\
\hline \multirow{2}{*}{3} & -0.22 & 0.00458 & \pm & 0.00006 & 11 & 0.00042 & \pm & 0.00001 \\
\cline { 2 - 9 } & 0.22 & -0.00774 & \pm & 0.00006 & 11 & -0.00070 & \pm & 0.00001 \\
\hline \multirow{3}{*}{4} & -0.22 & 0.00972 & \pm & 0.00006 & 11 & 0.00088 & \pm & 0.00001 \\
\cline { 2 - 9 } & 0.22 & -0.00777 & \pm & 0.00006 & 11 & -0.00071 & \pm & 0.00001 \\
\hline \multirow{3}{*}{5} & -0.22 & 0.00464 & \pm & 0.00006 & 11 & 0.00042 & \pm & 0.00001 \\
\cline { 2 - 9 } & 0.22 & -0.00773 & \pm & 0.00007 & 11 & -0.00070 & \pm & 0.00001 \\
\hline \multirow{3}{*}{6} & -0.22 & 0.00570 & \pm & 0.00007 & 11 & 0.00052 & \pm & 0.00001 \\
\cline { 2 - 8 } & 0.22 & -0.00908 & \pm & 0.00007 & 11 & -0.00082 & \pm & 0.00001 \\
\hline \multirow{3}{*}{7} & -0.22 & 0.01970 & \pm & 0.00006 & 11 & 0.00179 & \pm & 0.00001 \\
\cline { 2 - 8 } & 0.22 & -0.00897 & \pm & 0.00007 & 11 & -0.00081 & \pm & 0.00001 \\
\hline \multirow{2}{*}{12} & -0.22 & 0.00222 & \pm & 0.00006 & 11 & 0.00020 & \pm & 0.00001 \\
\cline { 2 - 8 } & 0.22 & -0.01252 & \pm & 0.00006 & 11 & -0.00114 & \pm & 0.00001 \\
\hline \multirow{2}{*}{13} & -0.22 & -0.00677 & \pm & 0.00006 & 11 & -0.00061 & \pm & 0.00001 \\
\cline { 2 - 7 } & 0.22 & -0.00907 & \pm & 0.00006 & 11 & -0.00082 & \pm & 0.00001 \\
\hline
\end{tabular}

The inside diameter of the bottle was adjusted by $\pm 0.02 \mathrm{~cm}$ while holding the bottle outside diameter, solution volume and solution mass constant. The solution height was changed to compensate for the change in diameter. In order to conserve mass, the atom density of the bottle above the solution height was varied when the inner diameter of the bottle was changed. Table 22 summarizes the effect of the uncertainty in the bottle inside diameter on $\mathrm{k}_{\text {eff. }}$ It is seen in Table 22 that the uncertainty for RSTM-L312 does not follow the same trend as the other experiments. This is believed, in this case, to be due to the presence of additional interstitial moderation provided by the Plexiglas shells.

Revision: 0

Date: September 30, 2012 


\section{NEA/NSC/DOC/(95)03//}

Volume I

\section{PU-SOL-THERM-037}

Table 22. $\Delta \mathrm{k}_{\text {eff }}$ for Uncertainty in Bottle Inside Diameter.

\begin{tabular}{|c|c|rcc|c|ccc|}
\hline \multirow{2}{*}{ RSTM-L3- } & $\begin{array}{c}\Delta \mathrm{ID} \\
(\mathrm{cm})\end{array}$ & $\Delta \mathrm{k}$ & \pm & $\sigma_{\mathrm{MCNP}}$ & $\begin{array}{c}\text { Scaling } \\
\text { Factor }\end{array}$ & $\Delta \mathrm{k}_{1 \sigma}$ & \pm & $\sigma_{\mathrm{MCNP}, 1 \sigma}$ \\
\hline \multirow{2}{*}{3} & -0.16 & 0.00107 & \pm & 0.00006 & 8 & 0.00013 & \pm & 0.00001 \\
\cline { 2 - 9 } & 0.16 & -0.00260 & \pm & 0.00007 & 8 & -0.00032 & \pm & 0.00001 \\
\hline \multirow{2}{*}{4} & -0.16 & 0.00094 & \pm & 0.00006 & 8 & 0.00012 & \pm & 0.00001 \\
\cline { 2 - 9 } & 0.16 & -0.00264 & \pm & 0.00006 & 8 & -0.00033 & \pm & 0.00001 \\
\hline \multirow{3}{*}{5} & -0.16 & 0.00097 & \pm & 0.00006 & 8 & 0.00012 & \pm & 0.00001 \\
\cline { 2 - 9 } & 0.16 & -0.00265 & \pm & 0.00006 & 8 & -0.00033 & \pm & 0.00001 \\
\hline \multirow{3}{*}{6} & -0.16 & 0.00113 & \pm & 0.00006 & 8 & 0.00014 & \pm & 0.00001 \\
\cline { 2 - 9 } & 0.16 & -0.00301 & \pm & 0.00006 & 8 & -0.00037 & \pm & 0.00001 \\
\hline \multirow{3}{*}{7} & -0.16 & 0.00121 & \pm & 0.00006 & 8 & 0.00015 & \pm & 0.00001 \\
\cline { 2 - 8 } & 0.16 & -0.00301 & \pm & 0.00007 & 8 & -0.00037 & \pm & 0.00001 \\
\hline \multirow{2}{*}{12} & -0.16 & -0.00178 & \pm & 0.00006 & 8 & -0.00022 & \pm & 0.00001 \\
\cline { 2 - 8 } & 0.16 & 0.00013 & \pm & 0.00006 & 8 & \multicolumn{3}{|c}{ NEG } \\
\hline \multirow{2}{*}{13} & -0.16 & 0.00123 & \pm & 0.00006 & 8 & 0.00015 & \pm & 0.00001 \\
\cline { 2 - 8 } & 0.16 & -0.00305 & \pm & 0.00006 & 8 & -0.00038 & \pm & 0.00001 \\
\hline
\end{tabular}

The mass of each bottle was given in the experimenter's logbook (see Table 2); however, for the detailed and simple models the average bottle mass was used. A mass measurement uncertainty was recorded but is unreadable in the experimenter's logbook. This uncertainty is clearly between 0.1 and 1.0 gram. Thus, a $1.0 \mathrm{~g} 1 \sigma$ total uncertainty was used for all mass measurements. The effect of $\mathrm{a} \pm 1.0 \mathrm{~g}$ uncertainty in bottle mass on $\mathrm{k}_{\mathrm{eff}}$ can be seen in Table 23 .

Revision: 0

Date: September 30, 2012 


\section{NEA/NSC/DOC/(95)03/I}

Volume I

PU-SOL-THERM-037

Table 23. $\Delta \mathrm{k}_{\text {eff }}$ for Uncertainty in Bottle Mass.

\begin{tabular}{|c|c|rcc|c|c|}
\hline \multirow{2}{*}{ RSTM-L3- } & $\begin{array}{c}\Delta \\
(\mathrm{g})\end{array}$ & \multicolumn{1}{|c|}{$\Delta \mathrm{k}$} & \pm & $\sigma_{\text {MCNP }}$ & $\begin{array}{c}\text { Scaling } \\
\text { Factor }\end{array}$ & $\Delta \mathrm{k}_{1 \sigma}$ \\
\hline \multirow{2}{*}{3} & -18.4 & -0.00060 & \pm & 0.00006 & 18.4 & NEG \\
\cline { 2 - 7 } & 18.4 & 0.00059 & \pm & 0.00006 & 18.4 & NEG \\
\hline \multirow{2}{*}{4} & -18.4 & -0.00062 & \pm & 0.00006 & 18.4 & NEG \\
\cline { 2 - 7 } & 18.4 & 0.00051 & \pm & 0.00006 & 18.4 & NEG \\
\hline \multirow{2}{*}{5} & -18.4 & -0.00052 & \pm & 0.00007 & 18.4 & NEG \\
\cline { 2 - 7 } & 18.4 & 0.00066 & \pm & 0.00007 & 18.4 & NEG \\
\hline \multirow{2}{*}{6} & -18.4 & -0.00070 & \pm & 0.00006 & 18.4 & NEG \\
\cline { 2 - 7 } & 18.4 & 0.00067 & \pm & 0.00006 & 18.4 & NEG \\
\hline \multirow{2}{*}{7} & -18.4 & -0.00068 & \pm & 0.00006 & 18.4 & NEG \\
\cline { 2 - 7 } & 18.4 & 0.00075 & \pm & 0.00007 & 18.4 & NEG \\
\hline \multirow{2}{*}{12} & -18.4 & -0.00056 & \pm & 0.00006 & 18.4 & NEG \\
\cline { 2 - 6 } & 18.4 & 0.00063 & \pm & 0.00006 & 18.4 & NEG \\
\hline \multirow{2}{*}{13} & -18.4 & -0.00080 & \pm & 0.00006 & 18.4 & NEG \\
\cline { 2 - 6 } & 18.4 & 0.00064 & \pm & 0.00006 & 18.4 & NEG \\
\hline
\end{tabular}

\subsubsection{Solution Measurements}

The volume and mass of the solution were measured and reported at the time of bottle filling (see Table 2). The volume and mass of solution rather than the density reported in Reference 1 were used when modeling the experiment because these numbers were measured and reported for each individual bottle. The effects of the uncertainty in both the volume and mass of the solution were found by varying one while holding the other constant. The solution height and atom densities were both affected by a change in the solution volume and mass.

A $1 \sigma$ total uncertainty of \pm 1.0 g per bottle was used for the solution mass (see Section 1.2.1). The effect of this uncertainty is summarized in Table 24.

Revision: 0

Date: September 30, 2012 


\section{NEA/NSC/DOC/(95)03//}

Volume I

\section{PU-SOL-THERM-037}

Table 24. $\Delta \mathrm{k}_{\text {eff }}$ for Uncertainty in Solution Mass.

\begin{tabular}{|c|c|rcc|c|rcc|}
\hline \multirow{2}{*}{ RSTM-L3- } & $\begin{array}{c}\Delta \\
(\mathrm{g})\end{array}$ & \multicolumn{1}{|c|}{$\Delta \mathrm{k}$} & \pm & $\sigma_{\mathrm{MCNP}}$ & $\begin{array}{c}\text { Scaling } \\
\text { Factor }\end{array}$ & \multicolumn{1}{|c|}{$\Delta \mathrm{k}_{1 \sigma}$} & \pm & $\sigma_{\mathrm{MCNP}, 1 \sigma}$ \\
\hline \multirow{2}{*}{3} & -5 & -0.00074 & \pm & 0.00007 & 5 & -0.00015 & \pm & 0.00001 \\
\cline { 2 - 9 } & 5 & 0.00099 & \pm & 0.00007 & 5 & 0.00020 & \pm & 0.00001 \\
\hline \multirow{3}{*}{4} & -5 & -0.00084 & \pm & 0.00006 & 5 & -0.00017 & \pm & 0.00001 \\
\cline { 2 - 9 } & 5 & 0.00093 & \pm & 0.00006 & 5 & 0.00019 & \pm & 0.00001 \\
\hline \multirow{3}{*}{5} & -5 & -0.00088 & \pm & 0.00006 & 5 & -0.00018 & \pm & 0.00001 \\
\cline { 2 - 9 } & 5 & 0.00095 & \pm & 0.00006 & 5 & 0.00019 & \pm & 0.00001 \\
\hline \multirow{3}{*}{6} & -5 & -0.00090 & \pm & 0.00006 & 5 & -0.00018 & \pm & 0.00001 \\
\cline { 2 - 9 } & 5 & 0.00083 & \pm & 0.00006 & 5 & 0.00017 & \pm & 0.00001 \\
\hline \multirow{3}{*}{7} & -5 & -0.00078 & \pm & 0.00007 & 5 & -0.00016 & \pm & 0.00001 \\
\cline { 2 - 9 } & 5 & 0.00083 & \pm & 0.00007 & 5 & 0.00017 & \pm & 0.00001 \\
\hline \multirow{2}{*}{12} & -5 & -0.00080 & \pm & 0.00006 & 5 & -0.00016 & \pm & 0.00001 \\
\cline { 2 - 8 } & 5 & 0.00084 & \pm & 0.00006 & 5 & 0.00017 & \pm & 0.00001 \\
\hline \multirow{2}{*}{13} & -5 & -0.00093 & \pm & 0.00006 & 5 & -0.00019 & \pm & 0.00001 \\
\cline { 2 - 8 } & 5 & 0.00084 & \pm & 0.00006 & 5 & 0.00017 & \pm & 0.00001 \\
\hline
\end{tabular}

Reference 1 states the bottles had a "filling accuracy on volume of less than $1 / 2 \%$ per bottle." Because the accuracy was less than $1 / 2 \%$, this uncertainty was taken to be a bounding uncertainty with a uniform distribution. To study the effect of the uncertainty of the volume of solution in the bottle the solution height within all bottles was varied and solution mass was maintained. The $\Delta \mathrm{k}_{\mathrm{eff}}$ for the uncertainty in solution volume is summarized in Table 25.

Revision: 0

Date: September 30, 2012 
NEA/NSC/DOC/(95)03/l

Volume I

PU-SOL-THERM-037

Table 25. $\Delta \mathrm{k}_{\text {eff }}$ for Uncertainty in Solution Volume.

\begin{tabular}{|c|c|rcc|c|rcc|}
\hline \multirow{2}{*}{ RSTM-L3- } & $\Delta$ & $\Delta \mathrm{k}$ & \pm & $\sigma_{\mathrm{MCNP}}$ & $\begin{array}{c}\text { Scaling } \\
\text { Factor }\end{array}$ & $\Delta \mathrm{k}_{1 \sigma}$ & \pm & $\sigma_{\mathrm{MCNP}, 1 \sigma}$ \\
\hline \multirow{3}{*}{3} & $-0.5 \%$ & 0.00196 & \pm & 0.00007 & $\sqrt{3}$ & 0.00113 & \pm & 0.00004 \\
\cline { 2 - 8 } & $0.5 \%$ & -0.00173 & \pm & 0.00006 & $\sqrt{3}$ & -0.00100 & \pm & 0.00004 \\
\hline \multirow{3}{*}{4} & $-0.5 \%$ & 0.00187 & \pm & 0.00006 & $\sqrt{3}$ & 0.00108 & \pm & 0.00004 \\
\cline { 2 - 8 } & $0.5 \%$ & -0.00177 & \pm & 0.00006 & $\sqrt{3}$ & -0.00102 & \pm & 0.00004 \\
\hline \multirow{3}{*}{5} & $-0.5 \%$ & 0.00188 & \pm & 0.00006 & $\sqrt{3}$ & 0.00109 & \pm & 0.00003 \\
\cline { 2 - 8 } & $0.5 \%$ & -0.00179 & \pm & 0.00006 & $\sqrt{3}$ & -0.00103 & \pm & 0.00004 \\
\hline \multirow{3}{*}{6} & $-0.5 \%$ & 0.00167 & \pm & 0.00006 & $\sqrt{3}$ & 0.00096 & \pm & 0.00004 \\
\cline { 2 - 8 } & $0.5 \%$ & -0.00174 & \pm & 0.00006 & $\sqrt{3}$ & -0.00100 & \pm & 0.00003 \\
\hline \multirow{2}{*}{7} & $-0.5 \%$ & 0.00167 & \pm & 0.00007 & $\sqrt{3}$ & 0.00096 & \pm & 0.00004 \\
\cline { 2 - 8 } & $0.5 \%$ & -0.00170 & \pm & 0.00006 & $\sqrt{3}$ & -0.00098 & \pm & 0.00004 \\
\hline \multirow{2}{*}{12} & $-0.5 \%$ & 0.00160 & \pm & 0.00006 & $\sqrt{3}$ & 0.00092 & \pm & 0.00004 \\
\cline { 2 - 8 } & $0.5 \%$ & -0.00148 & \pm & 0.00006 & $\sqrt{3}$ & -0.00085 & \pm & 0.00004 \\
\hline \multirow{2}{*}{13} & $-0.5 \%$ & 0.00172 & \pm & 0.00006 & $\sqrt{3}$ & 0.00099 & \pm & 0.00003 \\
\cline { 2 - 8 } & $0.5 \%$ & -0.00166 & \pm & 0.00006 & $\sqrt{3}$ & -0.00096 & \pm & 0.00003 \\
\hline
\end{tabular}

\subsubsection{Reflector Measurements}

The array of bottles was surrounded on five sides by a Plexiglas reflector. The side reflectors were pushed against the bottles on the outside of the array. ${ }^{a}$ Due to random variations in the reflector and/or bottle surface it is possible that a gap of up to $0.254 \mathrm{~cm}$ between the bottles and the reflector could have existed. To determine the effect of any possible gaps between the reflector and the bottle surfaces the reflector was moved out by $0.254 \mathrm{~cm}$ on all sides. Because the gap was no more than one-tenth of an inch, in order to obtain a $1 \sigma$ uncertainty a scaling factor of $2 \sqrt{3}$ was used for this one-sided, bounded uncertainty. Since the variations in the reflector blocks and bottle surfaces that would have caused a possible gap were random, the gap would not have been present between all four reflectors and bottle surfaces thus an additional scaling factor of $\sqrt{4}$ was used to account for the fact that the reflectors on all four sides of the array were moved out simultaneously. A summary of this uncertainty analysis can be found in Table 26 .

${ }^{\text {a }}$ Personal phone communication with B.M. Durst, Aug. 10, 2010.

Revision: 0

Date: September 30, 2012 


\section{NEA/NSC/DOC/(95)03/l}

Volume I

\section{PU-SOL-THERM-037}

Table 26. $\Delta \mathrm{k}_{\text {eff }}$ for Uncertainty in Reflector Position.

\begin{tabular}{|c|c|ccc|c|ccc|}
\hline RSTM-L3- & $\begin{array}{c}\Delta \\
(\mathrm{cm})\end{array}$ & $\Delta \mathrm{k}$ & \pm & $\sigma_{\mathrm{MCNP}}$ & $\begin{array}{c}\text { Scaling } \\
\text { Factor }\end{array}$ & $\Delta \mathrm{k}_{1 \sigma}$ & \pm & $\sigma_{\mathrm{MCNP}, 1 \sigma}$ \\
\hline 3 & 0.254 & -0.00312 & \pm & 0.00006 & $2 \sqrt{3} \sqrt{4}$ & -0.00045 & \pm & 0.00001 \\
\hline 4 & 0.254 & -0.00301 & \pm & 0.00006 & $2 \sqrt{3} \sqrt{4}$ & -0.00043 & \pm & 0.00001 \\
\hline 5 & 0.254 & -0.00301 & \pm & 0.00006 & $2 \sqrt{3} \sqrt{4}$ & -0.00043 & \pm & 0.00001 \\
\hline 6 & 0.254 & -0.00254 & \pm & 0.00006 & $2 \sqrt{3} \sqrt{4}$ & -0.00037 & \pm & 0.00001 \\
\hline 7 & 0.254 & -0.00240 & \pm & 0.00006 & $2 \sqrt{3} \sqrt{4}$ & -0.00035 & \pm & 0.00001 \\
\hline 12 & 0.254 & -0.00220 & \pm & 0.00006 & $2 \sqrt{3} \sqrt{4}$ & -0.00032 & \pm & 0.00001 \\
\hline 13 & 0.254 & -0.00248 & \pm & 0.00006 & $2 \sqrt{3} \sqrt{4}$ & -0.00036 & \pm & 0.00001 \\
\hline
\end{tabular}

The dimensions of the reflectors were given in Reference 1 . These were measured using a ruler with an accuracy of $1 / 32$ in. or $0.0794 \mathrm{~cm}$. ${ }^{\text {a }}$ The systematic and random components of the uncertainty were both assumed to be $0.0794 \mathrm{~cm}$. To find the total uncertainty Equation 1 was used assuming $N$ to be the number of reflectors (5). This yields a total uncertainty of $0.087 \mathrm{~cm}$. The width and height of all reflector blocks were increased and decreased simultaneously. Results of the uncertainty in reflector dimensions can be found in Table 27.

${ }^{a}$ Personal phone communication with B.M. Durst, January 24, 2011.

Revision: 0

Date: September 30, 2012 
NEA/NSC/DOC/(95)03/I

Volume I

PU-SOL-THERM-037

Table 27. $\Delta \mathrm{k}_{\mathrm{eff}}$ for Uncertainty in Reflector Dimensions.

\begin{tabular}{|c|c|rcc|c|ccc|}
\hline \multirow{2}{*}{ RSTM-L3- } & $\begin{array}{c}\Delta \\
(\mathrm{cm})\end{array}$ & $\Delta \mathrm{k}$ & \pm & $\sigma_{\mathrm{MCNP}}$ & $\begin{array}{c}\text { Scaling } \\
\text { Factor }\end{array}$ & $\Delta \mathrm{k}_{1 \sigma}$ & \pm & $\sigma_{\mathrm{MCNP}, 1 \sigma}$ \\
\hline \multirow{2}{*}{3} & -2.54 & -0.00400 & \pm & 0.00006 & 29.2 & -0.00014 & \pm & $<0.00001$ \\
\cline { 2 - 9 } & 2.54 & 0.00299 & \pm & 0.00006 & -29.2 & -0.00010 & \pm & $<0.00001$ \\
\hline \multirow{2}{*}{4} & -2.54 & -0.00417 & \pm & 0.00006 & 29.2 & -0.00014 & \pm & $<0.00001$ \\
\cline { 2 - 9 } & 2.54 & 0.00307 & \pm & 0.00006 & -29.2 & -0.00011 & \pm & $<0.00001$ \\
\hline \multirow{2}{*}{5} & -2.54 & -0.00398 & \pm & 0.00007 & 29.2 & -0.00014 & \pm & $<0.00001$ \\
\cline { 2 - 9 } & 2.54 & 0.00299 & \pm & 0.00006 & -29.2 & -0.00010 & \pm & $<0.00001$ \\
\hline \multirow{2}{*}{6} & -2.54 & -0.00402 & \pm & 0.00007 & 29.2 & -0.00014 & \pm & $<0.00001$ \\
\cline { 2 - 9 } & 2.54 & 0.00306 & \pm & 0.00006 & -29.2 & -0.00010 & \pm & $<0.00001$ \\
\hline \multirow{2}{*}{7} & -2.54 & -0.00402 & \pm & 0.00007 & 29.2 & -0.00014 & \pm & $<0.00001$ \\
\cline { 2 - 9 } & 2.54 & 0.00312 & \pm & 0.00006 & -29.2 & -0.00011 & \pm & $<0.00001$ \\
\hline \multirow{2}{*}{12} & -2.54 & -0.00349 & \pm & 0.00006 & 29.2 & -0.00012 & \pm & $<0.00001$ \\
\cline { 2 - 8 } & 2.54 & 0.00253 & \pm & 0.00006 & -29.2 & & NEG \\
\hline \multirow{2}{*}{13} & -2.54 & -0.00401 & \pm & 0.00006 & 29.2 & -0.00014 & \pm & $<0.00001$ \\
\cline { 2 - 8 } & 2.54 & 0.00300 & \pm & 0.00006 & -29.2 & -0.00010 & \pm & $<0.00001$ \\
\hline
\end{tabular}

The bottom reflector length and width were not recorded in Reference 1 or the logbooks. For the simple model, the bottom reflector was modeled as being the same length and width as the aluminum honeycomb structure below it. In Figures 4 and 5 the bottom reflector appears to overhang the aluminum honeycomb structure. It was found that the uncertainty in the bottom reflector length and width had negligible effect on the simple model.

\subsubsection{Shell Measurements}

Experiment RSTM-L3-12 had Plexiglas shells surrounding each bottle to determine the effect of interstitial moderation on array spacing. The experimenter's logbook contains shell measurements made by the experimenter and an order form to Port Plastics for the Plexiglas tubing used to make these shells (see Tables 3 and 4). The measurements recorded in the experimenter's logbook, Table 3, are believed to be the most accurate values. ${ }^{\text {a }}$ Although all three shell types were used during the experimental series only the $1 / 8$ " nominal shell thickness shell was used in the experiments modeled as part of this evaluation.

The reported $5.010 \pm 0.029 \mathrm{in}$. for shell OD in Table 3 is not the correct average or standard deviation of the 12 diameter measurements shown. The correct value is $5.001 \pm 0.017 \mathrm{in}$. (or $12.702 \pm 0.043 \mathrm{~cm}$ ). This is believed to be a mistake on the part of the experimenter. ${ }^{\mathrm{b}}$ The correct average value and standard deviation was used for the purpose of this evaluation.

The shell used for RSTM-L3-12 had a nominal wall thickness of $1 / 8$ in. $(0.33 \mathrm{~cm}$ per Table 5$)$. The experimenter's measurements of outside diameter and shell thickness are listed in Table 3 . The accuracy

\footnotetext{
${ }^{\mathrm{a}}$ The shell thickness for the $15.25 \mathrm{~cm}$ outer diameter shell is believed to actually be $0.63 \pm 0.03 \mathrm{~cm}$ as reported in Table 3 rather than $1.62 \pm 0.03 \mathrm{~cm}$ as shown in Figure 3 because this thickness values agrees more with the thickness given by the manufacturer (see Table 4). However, this shell was not used in any of the experiments modeled for this evaluation.

${ }^{\mathrm{b}}$ Personal phone communication with B.M. Durst, March 9, 2011.
}

Revision: 0

Date: September 30, 2012 


\section{NEA/NSC/DOC/(95)03/I}

Volume I

\section{PU-SOL-THERM-037}

of the calipers which were used to measure outside diameter and shell thickness, $0.00254 \mathrm{~cm}$, was taken to be the systematic uncertainty. The standard deviation of the twelve measurements, $0.043 \mathrm{~cm}$ for the shell outer diameter and $0.014 \mathrm{~cm}$ for the shell thickness, was taken to be the random component of the uncertainty. Using Equation 1, with $N$ being 12, the total uncertainties for the shell outer diameter and shell thickness are $0.013 \mathrm{~cm}$ and $0.005 \mathrm{~cm}$, respectively. To study the effect of the uncertainty in each parameter separately, the outer radius of the shell was varied while holding the shell thickness constant and then the shell thickness was varied while holding the outer radius constant. The shell height was measured by the experimenter with the same accuracy as the bottle dimension and reflector dimension measurements $( \pm 0.020 \mathrm{~cm}$, see Section 2.2.1). The results of these three uncertainties can be found in Table 28.

Table 28. $\Delta \mathrm{k}_{\mathrm{eff}}$ for Uncertainty in Shell Dimensions.

\begin{tabular}{|c|ccc|c|ccc|}
\hline $\begin{array}{c}\Delta \\
(\mathrm{cm})\end{array}$ & $\Delta \mathrm{k}$ & \pm & $\sigma_{\mathrm{MCNP}}$ & $\begin{array}{c}\text { Scaling } \\
\text { Factor }\end{array}$ & $\Delta \mathrm{k}_{1 \sigma}$ & \pm & $\sigma_{\mathrm{MCNP}, 1 \sigma}$ \\
\hline \multicolumn{7}{|c|}{ Outer Radius of Shell } \\
\hline-0.013 & 0.00081 & \pm & 0.00006 & 1 & 0.00081 & \pm & 0.00006 \\
0.013 & -0.00076 & \pm & 0.00006 & 1 & -0.00076 & \pm & 0.00006 \\
\hline \multicolumn{7}{|c|}{ Thickness of Shell } \\
\hline-0.005 & -0.00032 & \pm & 0.00006 & 1 & -0.00032 & \pm & 0.00006 \\
0.005 & 0.00036 & \pm & 0.00006 & 1 & 0.00036 & \pm & 0.00006 \\
\hline \multicolumn{7}{|c|}{ Height of Shell } \\
\hline-1.00 & -0.00093 & 0.00006 & 50 & NEG \\
1.00 & 0.00102 & 0.00006 & 50 & NEG \\
\hline
\end{tabular}

It is important to note that when varying the outer diameter of the shells the pitch of the array was changed in order to maintain constant shell to shell spacing.

\section{$2.3 \quad$ Materials}

Material data and uncertainties were taken from Reference 1 and the experimenter's logbook if available. For material compositions not specified material data and uncertainties were obtained from other sources as described here and in Appendix C. All elements were broken down into isotopes for use in the detailed and simple models. For all elements, except plutonium, natural isotopic abundances were assumed and obtained from The Chart of the Nuclides $16^{\text {th }}$ edition. $^{\text {a }}$

\subsubsection{Plutonium Nitrate Solution}

Table 8 summarizes all information given in Reference 1 describing the plutonium nitrate solution.

\footnotetext{
${ }^{\text {a }}$ E. M. Baum, H. D. Knox, and T. R. Miller, Nuclides and Isotopes: $16^{\text {th }}$ Edition, Knolls Atomic Power Laboratory (2002).
}

Revision: 0

Date: September 30, 2012 
NEA/NSC/DOC/(95)03/l

Volume I

PU-SOL-THERM-037

\subsubsection{Uranium and Impurity Concentration}

A spectrochemical analysis report was inserted into the experimenter's logbook for what appeared to be the plutonium nitrate solution although the impurities listed did not match those in Reference 1 (see Tables 8 and 10). Discussion with the experimenter did not clarify the reason for the differences between the report in the experimenter's logbook and the table in Reference 1 but led to the fuel composition and impurities given in Reference 1 being used in the models. ${ }^{a}$ Although it is not believed that these additional impurities were present in the solution it was uncertain; thus, an additional analysis was completed to study the effect of impurities given in Table 10 that did not appear in Reference 1. Calcium, cobalt, titanium, and vanadium were added to the solution at the maximum ppm levels given in Table 10. Because the impurities were added at their maximum levels, they are considered to be bounding. Assuming a uniform distribution a scaling factor of $\sqrt{3}$ is used to adjust the uncertainty to a $1 \sigma$ value. The results of the addition of these impurities can be seen in Table 29 .

Table 29. $\Delta \mathrm{k}_{\text {eff }}$ for Uncertain Presence of $\mathrm{Ca}, \mathrm{Co}, \mathrm{Ti}$, and $\mathrm{V}$ in Plutonium Solution.

\begin{tabular}{|c|ccc|c|ccc|}
\hline RSTM-L3- & $\Delta \mathrm{k}$ & \pm & $\sigma_{\mathrm{MCNP}}$ & $\begin{array}{c}\text { Scaling } \\
\text { Factor }\end{array}$ & $\Delta \mathrm{k}_{1 \sigma}$ & \pm & $\sigma_{\mathrm{MCNP}, 1 \sigma}$ \\
\hline 3 & -0.00257 & \pm & 0.00007 & $\sqrt{3}$ & -0.00148 & \pm & 0.00004 \\
\hline 4 & -0.00233 & \pm & 0.00006 & $\sqrt{3}$ & -0.00135 & \pm & 0.00004 \\
\hline 5 & -0.00236 & \pm & 0.00006 & $\sqrt{3}$ & -0.00136 & \pm & 0.00003 \\
\hline 6 & -0.00236 & \pm & 0.00006 & $\sqrt{3}$ & -0.00136 & \pm & 0.00004 \\
\hline 7 & -0.00240 & \pm & 0.00007 & $\sqrt{3}$ & -0.00139 & \pm & 0.00004 \\
\hline 12 & -0.00222 & \pm & 0.00006 & $\sqrt{3}$ & -0.00128 & \pm & 0.00003 \\
\hline 13 & -0.00236 & \pm & 0.00006 & $\sqrt{3}$ & -0.00136 & \pm & 0.00003 \\
\hline
\end{tabular}

No uncertainty was reported for the fuel composition given in Reference 1; however, the experimenter has indicated that the uncertainties in the fuel composition are one half the least significant digits in the reported concentrations. ${ }^{\mathrm{b}}$ This uncertainty was used for the concentrations of uranium and all solution impurities. Tables 30 through 37 summarize the uncertainty associated with the uranium and impurity concentrations.

A natural isotopic distribution for uranium was assumed and used in the simple and detailed model. The effect of using a non-natural isotopic distribution was studied. A distribution was arbitrarily chosen from MIX-SOL-THERM-004 (U-238 wt. \% 99.406, U-236 wt. \% 0.023, U-235 wt. \% 0.564, and U-234 wt. \% 0.007). It was found that the effect of changing from a natural to a non-natural uranium isotopic distribution on $\mathrm{k}_{\text {eff }}$ was negligible thus the uncertainty in the uranium isotopic distribution is negligible.

Table 30. $\Delta \mathrm{k}_{\text {eff }}$ for Uncertainty in Uranium ${ }^{(a)}$ Concentration in Solution.

\footnotetext{
${ }^{\text {a }}$ Personal phone communication with B.M. Durst, September 21, 2010.

${ }^{\mathrm{b}}$ Personal phone communication with B.M. Durst, September 21, 2010.

Revision: 0

Date: September 30, 2012
} 
NEA/NSC/DOC/(95)03/l

Volume I

PU-SOL-THERM-037

\begin{tabular}{|c|c|rcc|c|c|}
\hline \multirow{2}{*}{ RSTM-L3- } & $\begin{array}{c}\Delta \\
\mathrm{g} / \mathrm{L})\end{array}$ & $\Delta \mathrm{k}$ & \pm & $\sigma_{\text {MCNP }}$ & Scaling Factor & $\Delta \mathrm{k}_{1 \sigma}$ \\
\hline \multirow{3}{*}{3} & -0.5 & 0.00042 & \pm 0.00006 & 10 & NEG \\
\cline { 2 - 6 } & 0.5 & -0.00035 & \pm 0.00007 & 10 & NEG \\
\cline { 2 - 6 } & -0.5 & 0.00033 & \pm 0.00007 & 10 & NEG \\
\hline \multirow{2}{*}{5} & 0.5 & -0.00039 & \pm 0.00007 & 10 & NEG \\
\cline { 2 - 6 } & -0.5 & 0.00043 & \pm 0.00006 & 10 & NEG \\
\hline \multirow{2}{*}{6} & 0.5 & -0.00038 & \pm 0.00006 & 10 & NEG \\
\cline { 2 - 6 } & -0.5 & 0.00033 & \pm 0.00006 & 10 & NEG \\
\hline \multirow{3}{*}{7} & 0.5 & -0.00055 & \pm 0.00006 & 10 & NEG \\
\cline { 2 - 6 } & -0.5 & 0.00037 & \pm 0.00006 & 10 & NEG \\
\hline \multirow{2}{*}{12} & 0.5 & -0.00048 & \pm 0.00006 & 10 & NEG \\
\cline { 2 - 6 } & 0.5 & 0.00025 & \pm 0.00006 & 10 & NEG \\
\hline \multirow{2}{*}{13} & -0.5 & 0.00045 & \pm 0.00006 & 10 & NEG \\
\cline { 2 - 6 } & 0.5 & -0.00046 & \pm 0.00006 & 10 & NEG \\
\hline
\end{tabular}

(a) A natural isotopic distribution was assumed for uranium.

Table 31. $\Delta \mathrm{k}_{\mathrm{eff}}$ for Uncertainty in Iron Concentration in Solution.

\begin{tabular}{|c|c|rcc|c|c|}
\hline \multirow{2}{*}{ RSTM-L3- } & $\begin{array}{c}\Delta \\
(\mathrm{g} / \mathrm{L})\end{array}$ & $\Delta \mathrm{k}$ & \pm & $\sigma_{\text {MCNP }}$ & $\begin{array}{c}\text { Scaling } \\
\text { Factor }\end{array}$ & $\Delta \mathrm{k}_{1 \sigma}$ \\
\hline \multirow{3}{*}{3} & -0.5 & 0.00025 & \pm & 0.00006 & 10 & NEG \\
\cline { 2 - 6 } & 0.5 & -0.00025 & \pm & 0.00007 & 10 & NEG \\
\hline \multirow{2}{*}{4} & -0.5 & 0.00029 & \pm & 0.00007 & 10 & NEG \\
\cline { 2 - 6 } & 0.5 & -0.00021 & \pm & 0.00006 & 10 & NEG \\
\hline \multirow{2}{*}{5} & -0.5 & 0.00017 & \pm & 0.00006 & 10 & NEG \\
\cline { 2 - 7 } & 0.5 & -0.00017 & \pm & 0.00007 & 10 & NEG \\
\hline \multirow{2}{*}{6} & -0.5 & 0.00004 & \pm 0.00006 & 10 & NEG \\
\cline { 2 - 7 } & 0.5 & -0.00031 & \pm 0.00006 & 10 & NEG \\
\hline \multirow{2}{*}{7} & -0.5 & 0.00023 & \pm 0.00007 & 10 & NEG \\
\cline { 2 - 7 } & 0.5 & -0.00024 & \pm 0.00006 & 10 & NEG \\
\hline \multirow{2}{*}{12} & -0.5 & 0.00018 & \pm 0.00006 & 10 & NEG \\
\cline { 2 - 7 } & 0.5 & -0.00028 & \pm 0.00006 & 10 & NEG \\
\hline \multirow{2}{*}{13} & -0.5 & 0.00026 & \pm 0.00006 & 10 & NEG \\
\cline { 2 - 6 } & 0.5 & -0.00023 & \pm 0.00006 & 10 & NEG \\
\hline
\end{tabular}

Revision: 0

Date: September 30, 2012 
NEA/NSC/DOC/(95)03/l

Volume I

PU-SOL-THERM-037

Table 32. $\Delta \mathrm{k}_{\text {eff }}$ for Uncertainty in Chromium Concentration in Solution.

\begin{tabular}{|c|c|c|c|c|c|c|}
\hline RSTM-L3- & $\begin{array}{c}\Delta \\
(\mathrm{g} / \mathrm{L})\end{array}$ & $\Delta \mathrm{k}$ & \pm & $\sigma_{\mathrm{MCNP}}$ & $\begin{array}{l}\text { Scaling } \\
\text { Factor }\end{array}$ & $\Delta \mathrm{k}_{1 \sigma}$ \\
\hline \multirow{2}{*}{3} & -0.5 & 0.00029 & \pm & 0.00006 & 10 & NEG \\
\hline & 0.5 & -0.00019 & \pm & 0.00006 & 10 & NEG \\
\hline \multirow{2}{*}{4} & -0.5 & 0.00030 & \pm & 0.00006 & 10 & NEG \\
\hline & 0.5 & -0.00016 & \pm & 0.00007 & 10 & NEG \\
\hline \multirow{2}{*}{5} & -0.5 & 0.00028 & \pm & 0.00007 & 10 & NEG \\
\hline & 0.5 & -0.00026 & \pm & 0.00006 & 10 & NEG \\
\hline \multirow{2}{*}{6} & -0.5 & 0.00024 & \pm & 0.00006 & 10 & NEG \\
\hline & 0.5 & -0.00027 & \pm & 0.00006 & 10 & NEG \\
\hline \multirow{2}{*}{7} & -0.5 & 0.00021 & \pm & 0.00007 & 10 & $\mathrm{NEG}$ \\
\hline & 0.5 & -0.00028 & \pm & 0.00006 & 10 & NEG \\
\hline \multirow{2}{*}{12} & -0.5 & 0.00016 & \pm & 0.00006 & 10 & NEG \\
\hline & 0.5 & -0.00035 & \pm & 0.00006 & 10 & $\mathrm{NEG}$ \\
\hline \multirow{2}{*}{13} & -0.5 & 0.00020 & \pm & 0.00006 & 10 & NEG \\
\hline & 0.5 & -0.00022 & \pm & 0.00006 & 10 & NEG \\
\hline
\end{tabular}

Table 33. $\Delta \mathrm{k}_{\text {eff }}$ for Uncertainty in Nickel Concentration in Solution.

\begin{tabular}{|c|c|rcc|c|c|}
\hline \multirow{2}{*}{ RSTM-L3- } & $\begin{array}{c}\Delta \\
(\mathrm{g} / \mathrm{L})\end{array}$ & $\Delta \mathrm{k}$ & \pm & $\sigma_{\text {MCNP }}$ & $\begin{array}{c}\text { Scaling } \\
\text { Factor }\end{array}$ & $\Delta \mathrm{k}_{1 \sigma}$ \\
\hline \multirow{3}{*}{3} & -0.5 & 0.00027 & \pm & 0.00007 & 10 & NEG \\
\cline { 2 - 7 } & 0.5 & -0.00019 & \pm & 0.00006 & 10 & NEG \\
\hline \multirow{3}{*}{4} & -0.5 & 0.00026 & \pm & 0.00006 & 10 & NEG \\
\cline { 2 - 7 } & 0.5 & -0.00024 & \pm & 0.00006 & 10 & NEG \\
\hline \multirow{2}{*}{5} & -0.5 & 0.00022 & \pm & 0.00007 & 10 & NEG \\
\cline { 2 - 7 } & 0.5 & -0.00022 & \pm & 0.00007 & 10 & NEG \\
\hline \multirow{3}{*}{6} & -0.5 & 0.00022 & \pm & 0.00006 & 10 & NEG \\
\cline { 2 - 7 } & 0.5 & -0.00033 & \pm & 0.00006 & 10 & NEG \\
\hline \multirow{3}{*}{7} & -0.5 & 0.00018 & \pm & 0.00006 & 10 & NEG \\
\cline { 2 - 7 } & 0.5 & -0.00037 & \pm & 0.00007 & 10 & NEG \\
\hline \multirow{2}{*}{12} & -0.5 & 0.00009 & \pm & 0.00006 & 10 & NEG \\
\cline { 2 - 7 } & 0.5 & -0.00024 & \pm & 0.00006 & 10 & NEG \\
\hline \multirow{2}{*}{13} & -0.5 & 0.00023 & \pm & 0.00006 & 10 & NEG \\
\cline { 2 - 6 } & 0.5 & -0.00031 & \pm & 0.00006 & 10 & NEG \\
\hline
\end{tabular}

Revision: 0

Date: September 30, 2012 
NEA/NSC/DOC/(95)03/l

Volume I

PU-SOL-THERM-037

Table 34. $\Delta \mathrm{k}_{\text {eff }}$ for Uncertainty in Aluminum Concentration in Solution.

\begin{tabular}{|c|c|c|c|c|c|c|}
\hline RSTM-L3- & $\begin{array}{c}\Delta \\
(\mathrm{g} / \mathrm{L})\end{array}$ & $\Delta \mathrm{k}$ & \pm & $\sigma_{\mathrm{MCNP}}$ & $\begin{array}{l}\text { Scaling } \\
\text { Factor }\end{array}$ & $\Delta \mathrm{k}_{1 \sigma}$ \\
\hline \multirow{2}{*}{3} & -0.5 & 0.00022 & \pm & 0.00007 & 10 & NEG \\
\hline & 0.5 & -0.00018 & \pm & 0.00006 & 10 & NEG \\
\hline \multirow{2}{*}{4} & -0.5 & 0.00031 & \pm & 0.00007 & 10 & $\mathrm{NEG}$ \\
\hline & 0.5 & -0.00017 & \pm & 0.00007 & 10 & NEG \\
\hline \multirow{2}{*}{5} & -0.5 & 0.00021 & \pm & 0.00006 & 10 & NEG \\
\hline & -0.5 & 0.00021 & \pm & 0.00006 & 10 & NEG \\
\hline \multirow{2}{*}{6} & -0.5 & 0.00025 & \pm & 0.00006 & 10 & NEG \\
\hline & 0.5 & -0.00030 & \pm & 0.00006 & 10 & NEG \\
\hline \multirow{2}{*}{7} & -0.5 & 0.00011 & \pm & 0.00006 & 10 & NEG \\
\hline & 0.5 & -0.00029 & \pm & 0.00006 & 10 & NEG \\
\hline \multirow{2}{*}{12} & -0.5 & 0.00005 & \pm & 0.00006 & 10 & NEG \\
\hline & 0.5 & -0.00020 & \pm & 0.00006 & 10 & NEG \\
\hline \multirow{2}{*}{13} & -0.5 & 0.00011 & \pm & 0.00006 & 10 & NEG \\
\hline & 0.5 & -0.00023 & \pm & 0.00006 & 10 & NEG \\
\hline
\end{tabular}

Table 35. $\Delta \mathrm{k}_{\mathrm{eff}}$ for Uncertainty in Manganese Concentration in Solution.

\begin{tabular}{|c|c|c|c|c|c|c|}
\hline RSTM-L3- & $\begin{array}{c}\Delta \\
(\mathrm{g} / \mathrm{L})\end{array}$ & $\Delta \mathrm{k}$ & \pm & $\sigma_{\mathrm{MCNP}}$ & $\begin{array}{l}\text { Scaling } \\
\text { Factor }\end{array}$ & $\Delta \mathrm{k}_{1 \sigma}$ \\
\hline \multirow{2}{*}{3} & -0.5 & 0.00041 & \pm & 0.00006 & 10 & NEG \\
\hline & 0.5 & -0.00020 & \pm & 0.00006 & 10 & NEG \\
\hline \multirow{2}{*}{4} & -0.5 & 0.00043 & \pm & 0.00007 & 10 & NEG \\
\hline & 0.5 & -0.00035 & \pm & 0.00007 & 10 & NEG \\
\hline \multirow{2}{*}{5} & -0.5 & 0.00039 & \pm & 0.00007 & 10 & NEG \\
\hline & 0.5 & -0.00036 & \pm & 0.00007 & 10 & NEG \\
\hline \multirow{2}{*}{6} & -0.5 & 0.00033 & \pm & 0.00006 & 10 & NEG \\
\hline & 0.5 & -0.00045 & \pm & 0.00006 & 10 & NEG \\
\hline \multirow{2}{*}{7} & -0.5 & 0.00034 & \pm & 0.00006 & 10 & NEG \\
\hline & 0.5 & -0.00047 & \pm & 0.00007 & 10 & NEG \\
\hline \multirow{2}{*}{12} & -0.5 & 0.00037 & \pm & 0.00006 & 10 & NEG \\
\hline & 0.5 & -0.00056 & \pm & 0.00006 & 10 & NEG \\
\hline \multirow{2}{*}{13} & -0.5 & 0.00038 & \pm & 0.00006 & 10 & NEG \\
\hline & 0.5 & -0.00033 & \pm & 0.00006 & 10 & NEG \\
\hline
\end{tabular}

Revision: 0

Date: September 30, 2012 
NEA/NSC/DOC/(95)03/l

Volume I

PU-SOL-THERM-037

Table 36. $\Delta \mathrm{k}_{\text {eff }}$ for Uncertainty in Cadmium Concentration in Solution.

\begin{tabular}{|c|c|rcc|c|c|}
\hline \multirow{2}{*}{ RSTM-L3- } & $\begin{array}{c}\Delta \\
(\mathrm{g} / \mathrm{L})\end{array}$ & $\Delta \mathrm{k}$ & \pm & $\sigma_{\text {MCNP }}$ & $\begin{array}{c}\text { Scaling } \\
\text { Factor }\end{array}$ & $\Delta \mathrm{k}_{1 \sigma}$ \\
\hline \multirow{3}{*}{3} & -0.0005 & 0.00008 & \pm & 0.00006 & 10 & NEG \\
\cline { 2 - 7 } & 0.0005 & -0.00005 & \pm & 0.00007 & 10 & NEG \\
\hline \multirow{3}{*}{4} & -0.0005 & -0.00004 & \pm & 0.00007 & 10 & NEG \\
\cline { 2 - 7 } & 0.0005 & -0.00003 & \pm & 0.00006 & 10 & NEG \\
\hline \multirow{2}{*}{5} & -0.0005 & 0.00014 & \pm & 0.00006 & 10 & NEG \\
\cline { 2 - 7 } & 0.0005 & 0.00005 & \pm & 0.00007 & 10 & NEG \\
\hline \multirow{2}{*}{6} & -0.0005 & -0.00005 & \pm & 0.00006 & 10 & NEG \\
\cline { 2 - 7 } & 0.0005 & -0.00021 & \pm & 0.00006 & 10 & NEG \\
\hline \multirow{3}{*}{7} & -0.0005 & -0.00008 & \pm & 0.00006 & 10 & NEG \\
\cline { 2 - 7 } & 0.0005 & -0.00015 & \pm & 0.00006 & 10 & NEG \\
\hline \multirow{2}{*}{12} & -0.0005 & -0.00005 & \pm & 0.00006 & 10 & NEG \\
\cline { 2 - 7 } & 0.0005 & -0.00013 & \pm & 0.00006 & 10 & NEG \\
\hline \multirow{2}{*}{13} & -0.0005 & 0.00002 & \pm & 0.00006 & 10 & NEG \\
\cline { 2 - 6 } & 0.0005 & -0.00003 & \pm & 0.00006 & 10 & NEG \\
\hline
\end{tabular}

Table 37. $\Delta \mathrm{k}_{\mathrm{eff}}$ for Uncertainty in Boron Concentration in Solution.

\begin{tabular}{|c|c|rcc|c|c|}
\hline \multirow{2}{*}{ RSTM-L3- } & $\begin{array}{c}\Delta \\
(\mathrm{g} / \mathrm{L})\end{array}$ & $\Delta \mathrm{k}$ & \pm & $\sigma_{\mathrm{MCNP}}$ & $\begin{array}{c}\text { Scaling } \\
\text { Factor }\end{array}$ & $\Delta \mathrm{k}_{1 \sigma}$ \\
\hline \multirow{3}{*}{3} & -0.005 & 0.00063 & \pm & 0.00007 & 10 & NEG \\
\cline { 2 - 7 } & 0.005 & -0.00044 & \pm & 0.00007 & 10 & NEG \\
\hline \multirow{2}{*}{4} & -0.005 & 0.00049 & \pm & 0.00006 & 10 & NEG \\
\cline { 2 - 7 } & 0.005 & -0.00038 & \pm & 0.00007 & 10 & NEG \\
\hline \multirow{2}{*}{5} & -0.005 & 0.00054 & \pm & 0.00007 & 10 & NEG \\
\cline { 2 - 7 } & 0.005 & -0.00055 & \pm & 0.00007 & 10 & NEG \\
\hline \multirow{2}{*}{6} & -0.005 & 0.00038 & \pm & 0.00006 & 10 & NEG \\
\cline { 2 - 7 } & 0.005 & -0.00060 & \pm & 0.00006 & 10 & NEG \\
\hline \multirow{2}{*}{7} & -0.005 & 0.00045 & \pm & 0.00006 & 10 & NEG \\
\cline { 2 - 6 } & 0.005 & -0.00061 & \pm & 0.00007 & 10 & NEG \\
\hline \multirow{2}{*}{12} & -0.005 & 0.00045 & \pm & 0.00006 & 10 & NEG \\
\cline { 2 - 6 } & 0.005 & -0.00061 & \pm & 0.00006 & 10 & NEG \\
\hline \multirow{2}{*}{13} & -0.005 & 0.00058 & \pm & 0.00006 & 10 & NEG \\
\cline { 2 - 6 } & 0.005 & -0.00048 & \pm & 0.00006 & 10 & NEG \\
\hline
\end{tabular}

Revision: 0

Date: September 30, 2012 


\section{NEA/NSC/DOC/(95)03//}

Volume I

\section{PU-SOL-THERM-037}

The Am-241 content for the solution was measured at $0.18 \mathrm{~g} / \mathrm{L}$ on April 6, 1983, approximately 17 months after the experiments were completed. The Am-241 content was decreased to account for the build up over the 17 months between the experiment and the time the content was measured. To calculate the Am-241 content at the time of the experiments it was assumed that Am-241 build up was only due to $\mathrm{Pu}-241$ decay and a negligible amount of Am-241 decayed off during the 17 months. The following equation was used to determine how much Am-241 built up from Pu-241 during the 17 months.

$$
X_{A m}(t)=X_{P u}^{o}\left(1-e^{-\lambda t}\right)
$$

Equation 2

Where $X_{P u}^{o}$ is the $\mathrm{Pu}-241$ content at the time of the experiment, $\lambda$ is the decay constant for $\mathrm{Pu}-241$ $\left(\ln 2 / 14.4=0.048 \mathrm{yr}^{-1}\right)^{\mathrm{a}}$, and $t$ is the time in years $(17 / 12 \mathrm{yr})$. It was found that $0.008236 \mathrm{~g} / \mathrm{L}$ of Am-241 had built up during the 17 months and thus only $0.171763 \mathrm{~g} / \mathrm{L}$ of Am-241 was used in the simple model. Because of additional uncertainty arising from this adjustment of the Am-241 concentration the $1 \sigma$ uncertainty in the Am-241 content was increased by a factor of three from $0.005 \mathrm{~g} / \mathrm{L}$ to $0.015 \mathrm{~g} / \mathrm{L}$. The results are given in Table 38 .

Table 38. $\Delta \mathrm{k}_{\mathrm{eff}}$ for Uncertainty in Americium-241 Concentration in Solution.

\begin{tabular}{|c|c|c|c|c|c|c|c|}
\hline RSTM-L3- & $\underset{(\mathrm{g} / \mathrm{L})}{\Delta}$ & $\Delta \mathrm{k}$ & \pm & $\sigma_{\mathrm{MCNP}}$ & $\begin{array}{l}\text { Scaling } \\
\text { Factor }\end{array}$ & $\Delta \mathrm{k}_{1 \sigma}$ & $\sigma_{\mathrm{MCNP}, 1 \sigma}$ \\
\hline \multirow{2}{*}{3} & -0.05 & 0.00041 & \pm & 0.00006 & 3.33 & $0.00012 \pm$ & 0.00002 \\
\hline & 0.05 & -0.00030 & \pm & 0.00007 & 3.33 & $-0.00009 \pm$ & 0.00002 \\
\hline \multirow{2}{*}{4} & -0.05 & 0.00039 & \pm & 0.00007 & 3.33 & $0.00012 \pm$ & 0.00002 \\
\hline & 0.05 & -0.00027 & \pm & 0.00006 & 3.33 & \multicolumn{2}{|c|}{ NEG } \\
\hline \multirow{2}{*}{5} & -0.05 & 0.00029 & \pm & 0.00007 & 3.33 & \multicolumn{2}{|l|}{ NEG } \\
\hline & 0.05 & -0.00032 & \pm & 0.00006 & 3.33 & \multicolumn{2}{|l|}{ NEG } \\
\hline \multirow{2}{*}{6} & -0.05 & 0.00022 & \pm & 0.00006 & 3.33 & \multicolumn{2}{|c|}{ NEG } \\
\hline & 0.05 & -0.00031 & \pm & 0.00006 & 3.33 & \multicolumn{2}{|c|}{ NEG } \\
\hline \multirow{2}{*}{7} & -0.05 & 0.00029 & \pm & 0.00007 & 3.33 & \multicolumn{2}{|c|}{ NEG } \\
\hline & 0.05 & -0.00043 & \pm & 0.00006 & 3.33 & $-0.00013 \pm$ & 0.00002 \\
\hline \multirow{2}{*}{12} & -0.05 & 0.00030 & \pm & 0.00006 & 3.33 & \multicolumn{2}{|c|}{ NEG } \\
\hline & 0.05 & -0.00040 & \pm & 0.00006 & 3.33 & $-0.00012 \pm$ & 0.00002 \\
\hline \multirow{2}{*}{13} & -0.05 & 0.00031 & \pm & 0.00006 & 3.33 & \multicolumn{2}{|c|}{ NEG } \\
\hline & 0.05 & -0.00038 & \pm & 0.00006 & 3.33 & $-0.00011 \pm$ & 0.00002 \\
\hline
\end{tabular}

${ }^{a}$ E. M. Baum, H. D. Knox, and T. R. Miller, Nuclides and Isotopes: 16th Edition, Knolls Atomic Power Laboratory (2002).

Revision: 0

Date: September 30, 2012 
NEA/NSC/DOC/(95)03/l

Volume I

PU-SOL-THERM-037

\subsubsection{Plutonium and Free Acid Concentration}

The density of the solution was measured as being $1.420 \mathrm{~g} / \mathrm{cm}^{3}$. A solution density of $1.321 \mathrm{~g} / \mathrm{cm}^{3}$ is predicted using Sakurai's equation, see Equation 3. ${ }^{\text {a }}$

$$
\begin{aligned}
& \rho_{T}=0.99928+1.7132 \times 10^{-3} C_{P u}+1.4225 \times 10^{-3} C_{U} \\
& +3.9039 \times 10^{-2} C_{H N}-9.744 \times 10^{-8} C_{P u}{ }^{2} \\
& -1.076 \times 10^{-7} C_{U}{ }^{2}-7.361 \times 10^{-4} C_{H N}{ }^{2} \\
& -5.548 \times 10^{-6} T^{2}-7.280 \times 10^{-8} C_{P u} C_{U} \\
& -4.876 \times 10^{-5} C_{P U} C_{H N}-1.427 \times 10^{-6} C_{P u} T \\
& -1.520 \times 10^{-5} C_{U} C_{H N}-8.865 \times 10^{-7} C_{U} T \\
& -8.494 \times 10^{-5} C_{H N} T \text {, }
\end{aligned}
$$

where $C_{P u}, C_{U}$, and $C_{H N}$ are the concentration of plutonium and uranium in gram per liter and the acid molarity in moles per liter.

It is believed that the density of the solution was measured correctly; thus, based on the variables in Sakurai's equation, the difference between the measured and predicted density was due to temperature or the concentration of plutonium, uranium, or free acid. It is believed that the temperature and uranium concentrations were correct. ${ }^{b}$ Thus the plutonium concentration or free acid molarity must have been incorrectly measured or reported. Values for these two parameters required in order for the calculated and measured solution densities to be equal were determined by varying those two parameters independently. A plutonium concentration of $175 \mathrm{~g} / \mathrm{L}$ or an acid molarity of $9.9 \mathrm{~mol} / \mathrm{L}$ would have been required in order for the calculated solution density to match the measured density. The effect on $\mathrm{k}_{\mathrm{eff}}$ of changing the plutonium concentration to $175 \mathrm{~g} / \mathrm{L}$ and the acid molarity to $9.9 \mathrm{~mol} / \mathrm{L}$, independently, is given in Tables 39 and 40 . The plutonium concentration and acid molarity in the solution are correlated and, in Table 41 the uncertainties are summed using Equation $4 .^{\mathrm{c}}$

$$
\Delta k_{\text {total }}=\frac{1}{\sqrt{3}} \sqrt{\left(\Delta k_{P u}^{2}+\Delta k_{H}^{2}+2 \cdot \Delta k_{P u} \cdot \Delta k_{H}\right)}
$$

Equation 4

\footnotetext{
${ }^{a}$ S. Sakurai and S. Tachimori, "Density Equation of Aqueous Solution Containing Plutonium (IV), Uranium (VI), and Nitric Acid," Journal of Nuclear Science and Technology, Vol. 33, No. 2, p. 187-189 (February 1996).

${ }^{b}$ Personal communication with the experimenter, June 29, 2011 and December 14, 2011.

${ }^{\mathrm{c}}$ The derivation of Equation 4 is outlined in Appendix F.

Revision: 0
}

Date: September 30, 2012 


\section{NEA/NSC/DOC/(95)03/l}

Volume I

\section{PU-SOL-THERM-037}

Table 39. $\Delta \mathrm{k}_{\text {eff }}$ for Uncertainty in Plutonium Concentration in Solution.

\begin{tabular}{|c|c|cc|}
\hline RSTM-L3- & $\begin{array}{c}\mathrm{Pu} \\
(\mathrm{g} / \mathrm{L})\end{array}$ & $\Delta \mathrm{k}_{\mathrm{Pu}} \pm$ & $\sigma_{\mathrm{MCNP}}$ \\
\hline 3 & 175 & 0.00212 & \pm 0.00007 \\
\hline 4 & 175 & 0.00241 & \pm 0.00007 \\
\hline 5 & 175 & 0.00236 & \pm 0.00007 \\
\hline 6 & 175 & 0.00366 & \pm 0.00007 \\
\hline 7 & 175 & 0.00369 & \pm 0.00007 \\
\hline 12 & 175 & 0.00980 & \pm 0.00007 \\
\hline 13 & 175 & $0.00362 \pm 0.00007$ \\
\hline
\end{tabular}

Table 40. $\Delta \mathrm{k}_{\text {eff }}$ for Uncertainty in Acid Molarity.

\begin{tabular}{|c|c|ccc|}
\hline RSTM-L3- & $\begin{array}{c}\text { Acid Molarity } \\
(\mathrm{mol} / \mathrm{L})\end{array}$ & $\Delta \mathrm{k}_{\mathrm{H}} \pm$ & $\sigma_{\mathrm{MCNP}}$ \\
\hline 3 & 9.9 & 0.01432 & \pm & 0.00006 \\
\hline 4 & 9.9 & 0.01429 & \pm & 0.00007 \\
\hline 5 & 9.9 & 0.01438 & \pm & 0.00007 \\
\hline 6 & 9.9 & 0.01406 & \pm & 0.00008 \\
\hline 7 & 9.9 & 0.01418 & \pm & 0.00006 \\
\hline 12 & 9.9 & 0.01318 & \pm & 0.00006 \\
\hline 13 & 9.9 & 0.01418 & \pm & 0.00007 \\
\hline
\end{tabular}

Table 41. $\Delta \mathrm{k}_{\mathrm{eff}}$ for Uncertainty in Plutonium Concentration and Acid Molarity.

\begin{tabular}{|c|c|}
\hline RSTM-L3- & $\Delta k_{\text {total }}$ \\
\hline 3 & 0.00949 \\
\hline 4 & 0.00964 \\
\hline 5 & 0.00966 \\
\hline 6 & 0.01023 \\
\hline 7 & 0.01032 \\
\hline 12 & 0.01327 \\
\hline 13 & 0.01028 \\
\hline
\end{tabular}

Revision: 0

Date: September 30, 2012 
NEA/NSC/DOC/(95)03/l

Volume I

PU-SOL-THERM-037

\subsubsection{Nitrate Concentration}

Reference 1 describes the plutonium and nitrate as forming a $\mathrm{Pu}\left(\mathrm{NO}_{3}\right)$ complex. However, plutonium can vary in valence states and different complexes can form with nitrate depending on the properties of the solution; thus it is uncertain if the plutonium and nitrate was actually in a $\mathrm{Pu}\left(\mathrm{NO}_{3}\right)$ complex. ${ }^{\mathrm{a}}$ This does not affect the simple model since, regardless of valence state and complex, the total nitrate content would not have changed; however, it could have affected the accuracy with which the total nitrate concentration could be measured. The nitrate content in the solution was difficult to measure and could have varied by as much as $10 \%( \pm 50.5 \mathrm{~g} / \mathrm{L})$. ${ }^{\mathrm{b}}$. This uncertainty was taken to be a bounding uncertainty with a uniform distribution. The results of the uncertainty in the nitrate content is given in Table 42 .

Table 42. $\Delta \mathrm{k}_{\mathrm{eff}}$ for Uncertainty in Nitrate Concentration in Solution.

\begin{tabular}{|c|c|rcc|c|ccc|}
\hline \multirow{2}{*}{ RSTM-L3- } & $\Delta$ & $\Delta \mathrm{k}$ & \pm & $\sigma_{\mathrm{MCNP}}$ & $\begin{array}{c}\text { Scaling } \\
\text { Factor }\end{array}$ & $\Delta \mathrm{k}_{1 \sigma}$ & \pm & $\sigma_{\mathrm{MCNP}, 1 \sigma}$ \\
\hline \multirow{3}{*}{3} & $-20 \%$ & 0.04148 & \pm & 0.00009 & $2 \sqrt{3}$ & 0.01197 & \pm & 0.00003 \\
\cline { 2 - 8 } & $20 \%$ & -0.04624 & \pm & 0.00051 & $2 \sqrt{3}$ & -0.01335 & \pm & 0.00015 \\
\hline \multirow{3}{*}{4} & $-20 \%$ & 0.04149 & \pm & 0.00007 & $2 \sqrt{3}$ & 0.01198 & \pm & 0.00002 \\
\cline { 2 - 8 } & $20 \%$ & -0.04611 & \pm & 0.00007 & $2 \sqrt{3}$ & -0.01331 & \pm & 0.00002 \\
\hline \multirow{2}{*}{5} & $-20 \%$ & 0.04125 & \pm & 0.00015 & $2 \sqrt{3}$ & 0.01191 & \pm & 0.00004 \\
\cline { 2 - 8 } & $20 \%$ & -0.04590 & \pm & 0.00024 & $2 \sqrt{3}$ & -0.01325 & \pm & 0.00007 \\
\hline \multirow{2}{*}{6} & $-20 \%$ & 0.04048 & \pm & 0.00022 & $2 \sqrt{3}$ & 0.01169 & \pm & 0.00006 \\
\cline { 2 - 8 } & $20 \%$ & -0.04528 & \pm & 0.00006 & $2 \sqrt{3}$ & -0.01307 & \pm & 0.00002 \\
\hline \multirow{2}{*}{7} & $-20 \%$ & 0.04036 & \pm & 0.00006 & $2 \sqrt{3}$ & 0.01165 & \pm & 0.00002 \\
\hline \multirow{2}{*}{12} & $20 \%$ & -0.04537 & \pm & 0.00010 & $2 \sqrt{3}$ & -0.01310 & \pm & 0.00003 \\
\cline { 2 - 8 } & $-20 \%$ & 0.03752 & \pm & 0.00012 & $2 \sqrt{3}$ & 0.01083 & \pm & 0.00003 \\
\hline \multirow{2}{*}{13} & $20 \%$ & -0.04173 & \pm & 0.00012 & $2 \sqrt{3}$ & -0.01205 & \pm & 0.00003 \\
\hline & $-20 \%$ & 0.04012 & \pm & 0.00012 & $2 \sqrt{3}$ & 0.01158 & \pm & 0.00003 \\
\hline & $20 \%$ & -0.04543 & \pm & 0.00018 & $2 \sqrt{3}$ & -0.01311 & \pm & 0.00005 \\
\hline
\end{tabular}

\subsubsection{Isotopic Distribution}

The isotopic distribution of plutonium in the solution was given in Reference 1 . The uncertainty in the distribution was one half the least significant digit. A weight percent total of $100 \%$ was maintained by varying the major isotope, ${ }^{239} \mathrm{Pu}$, thus ${ }^{239} \mathrm{Pu}$ was not varied separately. The results can be found in Tables 43 through 46.

\footnotetext{
${ }^{a}$ J. A. Brothers, R. G. Hart and W. G. Mathers, The nitrate complexes of tetravalent plutonium, Pergamon Press Ltd., London, Journal of Inorganic Nuclear Chemistry, Vol. 7, pp 85 to 95, (1958).

${ }^{b}$ The nitrate concentration was probably measured by ion chromatography which had an uncertainty of $\pm 10 \%$. Personal phone communication with Jeffery Giglio, December 14, 2011.
}

Revision: 0

Date: September 30, 2012 


\section{NEA/NSC/DOC/(95)03/I}

Volume I

\section{PU-SOL-THERM-037}

Table 43. $\Delta \mathrm{k}_{\text {eff }}$ for Uncertainty in ${ }^{238} \mathrm{Pu}$ Weight Percent.

\begin{tabular}{|c|c|rcc|c|c|}
\hline \multirow{2}{*}{ RSTM-L3- } & $\begin{array}{c}\Delta \\
(\text { wt. } \%)\end{array}$ & $\Delta \mathrm{k}$ & \pm & $\sigma_{\text {MCNP }}$ & $\begin{array}{c}\text { Scaling } \\
\text { Factor }\end{array}$ & $\Delta \mathrm{k}_{1 \sigma}$ \\
\hline \multirow{2}{*}{3} & -0.005 & 0.00004 & \pm & 0.00006 & 10 & NEG \\
\cline { 2 - 7 } & 0.005 & 0.00006 & \pm & 0.00006 & 10 & NEG \\
\hline \multirow{2}{*}{4} & -0.005 & 0.00002 & \pm & 0.00006 & 10 & NEG \\
\cline { 2 - 7 } & 0.005 & -0.00002 & \pm & 0.00007 & 10 & NEG \\
\hline \multirow{2}{*}{5} & -0.005 & 0.00009 & \pm & 0.00006 & 10 & NEG \\
\cline { 2 - 7 } & 0.005 & 0.00001 & \pm & 0.00007 & 10 & NEG \\
\hline \multirow{2}{*}{6} & -0.005 & -0.00019 & \pm & 0.00006 & 10 & NEG \\
\cline { 2 - 7 } & 0.005 & -0.00006 & \pm & 0.00006 & 10 & NEG \\
\hline \multirow{2}{*}{7} & -0.005 & -0.00002 & \pm & 0.00007 & 10 & NEG \\
\cline { 2 - 7 } & 0.005 & -0.00017 & \pm & 0.00007 & 10 & NEG \\
\hline \multirow{2}{*}{12} & -0.005 & -0.00008 & \pm & 0.00006 & 10 & NEG \\
\cline { 2 - 7 } & 0.005 & -0.00009 & \pm & 0.00006 & 10 & NEG \\
\hline \multirow{2}{*}{13} & -0.005 & 0.00005 & \pm & 0.00006 & 10 & NEG \\
\cline { 2 - 6 } & 0.005 & 0.00001 & \pm & 0.00006 & 10 & NEG \\
\hline
\end{tabular}

Table 44. $\Delta \mathrm{k}_{\mathrm{eff}}$ for Uncertainty in ${ }^{240} \mathrm{Pu}$ Weight Percent.

\begin{tabular}{|c|c|rcc|c|c|}
\hline \multirow{2}{*}{ RSTM-L3- } & $\begin{array}{c}\Delta \\
(\text { wt. } \%)\end{array}$ & $\Delta \mathrm{k}$ & \pm & $\sigma_{\text {MCNP }}$ & $\begin{array}{c}\text { Scaling } \\
\text { Factor }\end{array}$ & $\Delta \mathrm{k}_{1 \sigma}$ \\
\hline \multirow{3}{*}{3} & -0.005 & 0.00000 & \pm & 0.00007 & 10 & NEG \\
\cline { 2 - 7 } & 0.005 & -0.00005 & \pm & 0.00007 & 10 & NEG \\
\hline \multirow{2}{*}{4} & -0.005 & 0.00017 & \pm & 0.00007 & 10 & NEG \\
\cline { 2 - 7 } & 0.005 & 0.00008 & \pm & 0.00007 & 10 & NEG \\
\hline \multirow{2}{*}{5} & -0.005 & -0.00003 & \pm & 0.00006 & 10 & NEG \\
\cline { 2 - 7 } & 0.005 & -0.00008 & \pm & 0.00007 & 10 & NEG \\
\hline \multirow{2}{*}{6} & -0.005 & -0.00009 & \pm & 0.00006 & 10 & NEG \\
\cline { 2 - 7 } & 0.005 & -0.00015 & \pm & 0.00006 & 10 & NEG \\
\hline \multirow{2}{*}{7} & -0.005 & -0.00002 & \pm & 0.00006 & 10 & NEG \\
\cline { 2 - 7 } & 0.005 & -0.00017 & \pm & 0.00007 & 10 & NEG \\
\hline \multirow{2}{*}{12} & -0.005 & -0.00004 & \pm & 0.00006 & 10 & NEG \\
\cline { 2 - 7 } & 0.005 & -0.00010 & \pm & 0.00006 & 10 & NEG \\
\hline \multirow{2}{*}{13} & -0.005 & 0.00013 & \pm & 0.00006 & 10 & NEG \\
\cline { 2 - 6 } & 0.005 & -0.00001 & \pm & 0.00006 & 10 & NEG \\
\hline
\end{tabular}

Revision: 0 


\section{NEA/NSC/DOC/(95)03/I}

Volume I

\section{PU-SOL-THERM-037}

Table 45. $\Delta \mathrm{k}_{\text {eff }}$ for Uncertainty in ${ }^{241} \mathrm{Pu}$ Weight Percent.

\begin{tabular}{|c|c|ccc|c|c|}
\hline \multirow{2}{*}{ RSTM-L3- } & $\begin{array}{c}\Delta \\
(\text { wt. } \%)\end{array}$ & $\Delta \mathrm{k}$ & \pm & $\sigma_{\text {MCNP }}$ & $\begin{array}{c}\text { Scaling } \\
\text { Factor }\end{array}$ & $\Delta \mathrm{k}_{1 \sigma}$ \\
\hline \multirow{2}{*}{3} & -0.005 & 0.00010 & \pm & 0.00006 & 10 & NEG \\
\cline { 2 - 7 } & 0.005 & 0.00004 & \pm & 0.00007 & 10 & NEG \\
\hline \multirow{2}{*}{4} & -0.005 & 0.00006 & \pm & 0.00007 & 10 & NEG \\
\cline { 2 - 7 } & 0.005 & 0.00003 & \pm & 0.00006 & 10 & NEG \\
\hline \multirow{2}{*}{5} & -0.005 & -0.00005 & \pm & 0.00007 & 10 & NEG \\
\cline { 2 - 7 } & 0.005 & -0.00001 & \pm & 0.00006 & 10 & NEG \\
\hline \multirow{2}{*}{6} & -0.005 & -0.00010 & \pm & 0.00006 & 10 & NEG \\
\cline { 2 - 7 } & 0.005 & 0.00000 & \pm & 0.00006 & 10 & NEG \\
\hline \multirow{2}{*}{7} & -0.005 & -0.00019 & \pm & 0.00006 & 10 & NEG \\
\cline { 2 - 7 } & 0.005 & -0.00002 & \pm & 0.00007 & 10 & NEG \\
\hline \multirow{2}{*}{12} & -0.005 & -0.00011 & \pm & 0.00006 & 10 & NEG \\
\cline { 2 - 7 } & 0.005 & -0.00011 & \pm & 0.00006 & 10 & NEG \\
\hline \multirow{2}{*}{13} & -0.005 & -0.00002 & \pm & 0.00006 & 10 & NEG \\
\cline { 2 - 6 } & 0.005 & -0.00005 & \pm & 0.00006 & 10 & NEG \\
\hline
\end{tabular}

Table 46. $\Delta \mathrm{k}_{\mathrm{eff}}$ for Uncertainty in ${ }^{242} \mathrm{Pu}$ Weight Percent.

\begin{tabular}{|c|c|ccc|c|c|}
\hline \multirow{2}{*}{ RSTM-L3- } & $\begin{array}{c}\Delta \\
(\text { wt. } \%)\end{array}$ & $\Delta \mathrm{k}$ & \pm & $\sigma_{\mathrm{MCNP}}$ & $\begin{array}{c}\text { Scaling } \\
\text { Factor }\end{array}$ & $\Delta \mathrm{k}_{1 \sigma}$ \\
\hline \multirow{3}{*}{3} & -0.005 & 0.00007 & \pm & 0.00007 & 10 & NEG \\
\cline { 2 - 7 } & 0.005 & 0.00013 & \pm & 0.00006 & 10 & NEG \\
\hline \multirow{3}{*}{4} & -0.005 & 0.00008 & \pm & 0.00006 & 10 & NEG \\
\cline { 2 - 7 } & 0.005 & 0.00005 & \pm & 0.00007 & 10 & NEG \\
\hline \multirow{2}{*}{5} & -0.005 & -0.00003 & \pm & 0.00007 & 10 & NEG \\
\cline { 2 - 7 } & 0.005 & 0.00003 & \pm & 0.00007 & 10 & NEG \\
\hline \multirow{3}{*}{6} & -0.005 & -0.00006 & \pm & 0.00006 & 10 & NEG \\
\cline { 2 - 7 } & 0.005 & -0.00020 & \pm & 0.00006 & 10 & NEG \\
\hline \multirow{3}{*}{7} & -0.005 & -0.00003 & \pm & 0.00006 & 10 & NEG \\
\cline { 2 - 7 } & 0.005 & -0.00014 & \pm & 0.00006 & 10 & NEG \\
\hline \multirow{2}{*}{12} & -0.005 & -0.00013 & \pm & 0.00006 & 10 & NEG \\
\cline { 2 - 7 } & 0.005 & -0.00012 & \pm & 0.00006 & 10 & NEG \\
\hline \multirow{2}{*}{13} & -0.005 & 0.00000 & \pm & 0.00006 & 10 & NEG \\
\cline { 2 - 6 } & 0.005 & 0.00001 & \pm & 0.00006 & 10 & NEG \\
\hline
\end{tabular}

Revision: 0 
NEA/NSC/DOC/(95)03/l

Volume I

PU-SOL-THERM-037

\subsubsection{Solution Temperature}

The temperature of the experiment was not reported in Reference 1 or recorded in the logbooks, but according to the experimenter, the experiment was performed at room temperature with $20-24^{\circ} \mathrm{C}$ being a typical range and $22^{\circ} \mathrm{C}$ being a good average. This differed from the temperature at which the bottles were filled with solution $\left(28.5^{\circ} \mathrm{C}\right)$. The difference in these temperatures was consistent with the temperature differences observed in the mixing room and the experiment room. ${ }^{\mathrm{a}}$ The solution volumes in Table 2 had to be adjusted for this temperature change by calculating the change in density of the plutonium nitrate solution for a temperature change from $28^{\circ} \mathrm{C}$ to $22^{\circ} \mathrm{C}$. This adjustment of volume was found using Equation 5.

$$
V_{22}=\frac{m}{\Delta \rho+\frac{m}{V_{28.5}}}
$$

Equation 5

Where $V_{i}$ is the solution volume at temperature $i, m$ is the mass of the solution, and $\Delta \rho$ is the temperature correction factor. Equation 5 was found by using the fact that mass is independent of temperatures (i.e., $m_{28.5}=m_{22}$ ) and mass is the product of density and volume (i.e., $m=\rho_{i} V_{i}$ ), solving for $V_{22}$ after substituting in the temperature correction factor and mass over volume for density.

The temperature correction factor is the change in density of a pure plutonium nitrate solution between 28.5 and $22^{\circ} \mathrm{C}, \Delta \rho=\rho_{28.5}-\rho_{22}$, which is $0.00563 \mathrm{~g} / \mathrm{cm}^{3}$. The densities of an impurity free plutonium, uranium and nitric acid solution at 28.5 and $22^{\circ} \mathrm{C}, \rho_{28.5}$ and $\rho_{22}$, were calculated using the following equation $^{\text {b }}$ :

$$
\begin{aligned}
\rho_{T}=0.99928 & +1.7132 \times 10^{-3} C_{P u}+1.4225 \times 10^{-3} C_{U} \\
& +3.9039 \times 10^{-2} C_{H N}-9.744 \times 10^{-8} C_{P u}{ }^{2} \\
& -1.076 \times 10^{-7} C_{U}{ }^{2}-7.361 \times 10^{-4} C_{H N}{ }^{2} \\
& -5.548 \times 10^{-6} T^{2}-7.280 \times 10^{-8} C_{P u} C_{U} \\
& -4.876 \times 10^{-5} C_{P u} C_{H N}-1.427 \times 10^{-6} C_{P u} T \\
& -1.520 \times 10^{-5} C_{U} C_{H N}-8.865 \times 10^{-7} C_{U} T \\
& -8.494 \times 10^{-5} C_{H N} T
\end{aligned}
$$

Equation 6

where $C_{P u}, C_{U}$, and $C_{H N}$ are the concentration of plutonium and uranium in gram per liter, the acid molarity in moles per liter, and the temperature is in ${ }^{\circ} \mathrm{C}$. "The estimated standard error in the regression analysis for the density equation is $0.00294 \mathrm{~g} / \mathrm{cm}^{3}$." calculated solution densities and because the temperature correction depended on a change in density the total uncertainty in the temperature correction was taken to be $\pm \sqrt{0.00294^{2}+0.00294^{2}}$ or \pm 0.00416 $\mathrm{g} / \mathrm{cm}^{3}$. The effect of this uncertainty can be seen in Table 47 .

\footnotetext{
${ }^{a}$ Personal email communication with B.M. Durst, November 30, 2010 and December 16, 2010.

${ }^{\mathrm{b}}$ S. Sakurai and S. Tachimori, "Density Equation of Aqueous Solution Containing Plutonium (IV), Uranium (VI), and Nitric Acid," Journal of Nuclear Science and Technology, Vol. 33, No. 2, p. 187-189 (February 1996).

Revision: 0
}

Date: September 30, 2012

Page 61 of 142 
NEA/NSC/DOC/(95)03//

Volume I

PU-SOL-THERM-037

Table 47. $\Delta \mathrm{k}_{\mathrm{eff}}$ for Uncertainty in Temperature Correction.

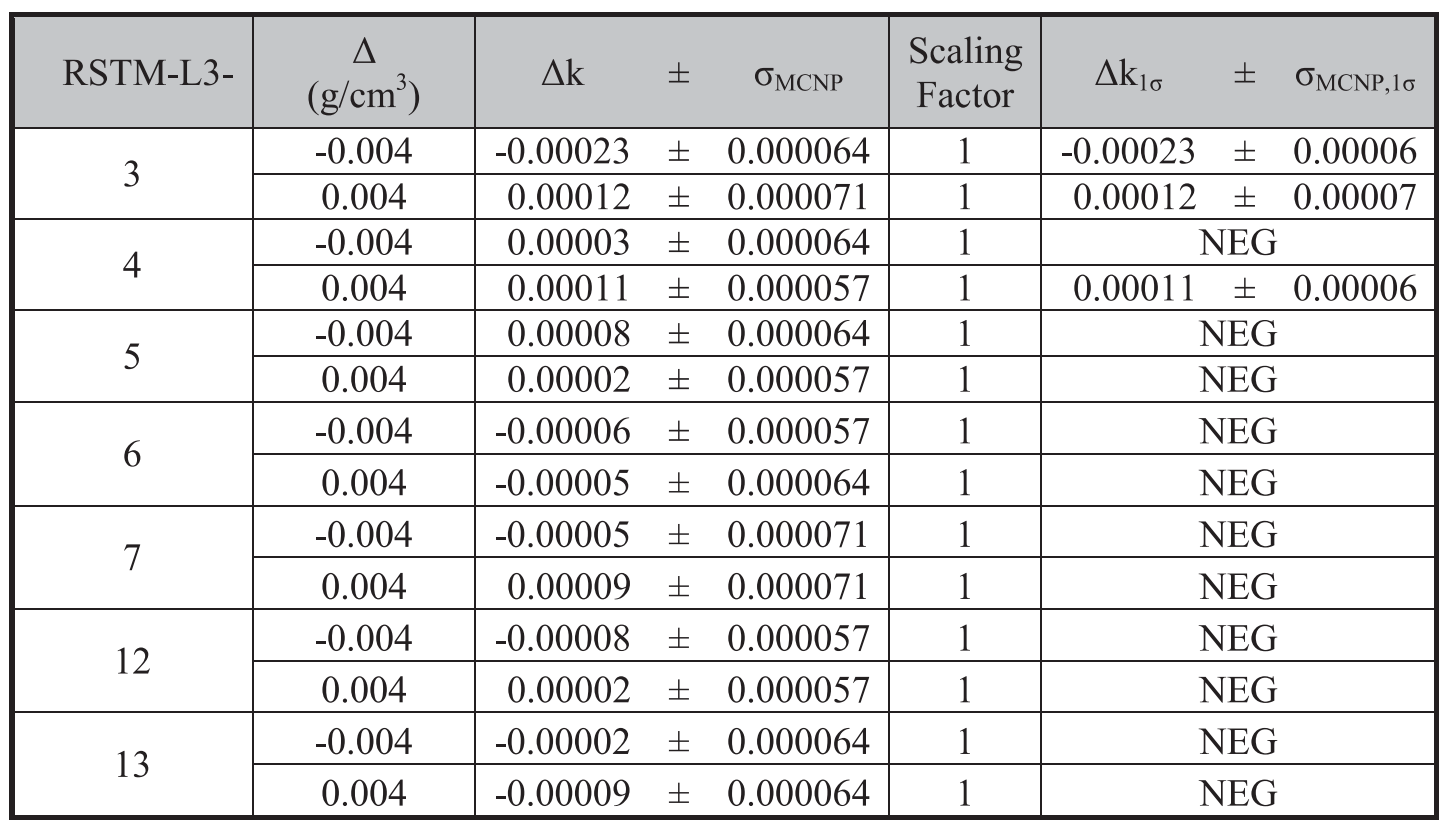

The solution temperature was assumed to be $22^{\circ} \mathrm{C}$ during the experiment although it could have ranged between 20 and $24^{\circ} \mathrm{C}$. This temperature variation would have led to a change in the solution density of approximately 0.0017 and $-0.0016 \mathrm{~g} / \mathrm{cm}^{3}$. The effect of this uncertainty can be seen in Table 48 .

Table 48. $\Delta \mathrm{k}_{\text {eff }}$ for Uncertainty in Solution Temperature.

\begin{tabular}{|c|c|c|ccc|c|c|}
\hline \multirow{2}{*}{ RSTM-L3- } & $\begin{array}{c}\Delta \\
\left({ }^{\circ} \mathrm{C}\right)\end{array}$ & $\begin{array}{c}\Delta \text { Temp. } \\
\text { Correction } \\
\left(\mathrm{g} / \mathrm{cm}^{3}\right)\end{array}$ & $\Delta \mathrm{k}$ & \pm & $\sigma_{\text {MCNP }}$ & $\begin{array}{c}\text { Scaling } \\
\text { Factor }\end{array}$ & $\Delta \mathrm{k}_{1 \sigma}$ \\
\hline \multirow{3}{*}{3} & -4 & $-3.28 \times 10^{-3}$ & -0.00017 & \pm & 0.00007 & 2 & NEG \\
\cline { 2 - 7 } & 4 & $3.36 \times 10^{-3}$ & 0.00017 & \pm & 0.00005 & 2 & NEG \\
\hline \multirow{2}{*}{4} & -4 & $-3.28 \times 10^{-3}$ & -0.00001 & \pm & 0.00006 & 2 & NEG \\
\cline { 2 - 7 } & 4 & $3.36 \times 10^{-3}$ & 0.00007 & \pm & 0.00006 & 2 & NEG \\
\hline \multirow{2}{*}{5} & -4 & $-3.28 \times 10^{-3}$ & 0.00000 & \pm & 0.00006 & 2 & NEG \\
\cline { 2 - 7 } & 4 & $3.36 \times 10^{-3}$ & 0.00004 & \pm & 0.00006 & 2 & NEG \\
\hline \multirow{2}{*}{6} & -4 & $-3.28 \times 10^{-3}$ & -0.00006 & \pm & 0.00006 & 2 & NEG \\
\cline { 2 - 7 } & 4 & $3.36 \times 10^{-3}$ & -0.00003 & \pm & 0.00006 & 2 & NEG \\
\hline \multirow{2}{*}{7} & -4 & $-3.28 \times 10^{-3}$ & 0.00007 & \pm & 0.00006 & 2 & NEG \\
\cline { 2 - 7 } & 4 & $3.36 \times 10^{-3}$ & 0.00006 & \pm & 0.00007 & 2 & NEG \\
\hline \multirow{2}{*}{12} & -4 & $-3.28 \times 10^{-3}$ & -0.00003 & \pm & 0.00006 & 2 & NEG \\
\cline { 2 - 7 } & 4 & $3.36 \times 10^{-3}$ & 0.00011 & \pm & 0.00006 & 2 & NEG \\
\hline \multirow{2}{*}{13} & -4 & $-3.28 \times 10^{-3}$ & -0.00004 & \pm & 0.00006 & 2 & NEG \\
\cline { 2 - 7 } & 4 & $3.36 \times 10^{-3}$ & -0.00004 & \pm & 0.00006 & 2 & NEG \\
\hline
\end{tabular}

Revision: 0

Date: September 30, 2012 
NEA/NSC/DOC/(95)03/l

Volume I

PU-SOL-THERM-037

\subsubsection{Polyethylene}

Polyethylene was used for the bottles. An impurity uncertainty analysis was performed for the bottle polyethylene incorporating impurity data in Table 11. For the simple model all impurities except samarium, europium, and gadolinium were removed (see Appendix C.1.5). For samarium and gadolinium, the uncertainty was tested by evaluation of the effect on $\mathrm{k}_{\mathrm{eff}}$ with the impurities at the minimum level, 0 ppm, and the maximum level given in Table 11. The uncertainty in the samarium and gadolinium was taken to be a bounding uncertainty with a uniform distribution. The $1 \sigma$ uncertainty for the europium content was found by propagating the uncertainties in Table 11. The effects of uncertainty in the impurities are summarized in Tables 49, 50, and 51.

Table 49. $\Delta \mathrm{k}_{\mathrm{eff}}$ for Uncertainty in Samarium Content.

\begin{tabular}{|c|c|rcc|c|ccc|}
\hline \multirow{2}{*}{ RSTM-L3- } & $\begin{array}{c}\Delta \\
(\mathrm{ppm})\end{array}$ & $\Delta \mathrm{k}$ & \pm & $\sigma_{\mathrm{MCNP}}$ & $\begin{array}{c}\text { Scaling } \\
\text { Factor }\end{array}$ & $\Delta \mathrm{k}_{1 \sigma}$ & \pm & $\sigma_{\mathrm{MCNP}, 1 \sigma}$ \\
\hline \multirow{3}{*}{3} & -12.5 & 0.00044 & \pm & 0.00007 & $\sqrt{3}$ & 0.00025 & \pm & 0.00004 \\
\cline { 2 - 9 } & 12.5 & -0.00053 & \pm & 0.00007 & $\sqrt{3}$ & -0.00031 & \pm & 0.00004 \\
\hline \multirow{3}{*}{4} & -12.5 & 0.00055 & \pm & 0.00007 & $\sqrt{3}$ & 0.00032 & \pm & 0.00004 \\
\cline { 2 - 9 } & 12.5 & -0.00058 & \pm & 0.00006 & $\sqrt{3}$ & -0.00033 & \pm & 0.00004 \\
\hline \multirow{3}{*}{5} & -12.5 & 0.00058 & \pm & 0.00006 & $\sqrt{3}$ & 0.00033 & \pm & 0.00004 \\
\cline { 2 - 9 } & 12.5 & -0.00065 & \pm & 0.00006 & $\sqrt{3}$ & -0.00038 & \pm & 0.00004 \\
\hline \multirow{3}{*}{6} & -12.5 & 0.00054 & \pm & 0.00006 & $\sqrt{3}$ & 0.00031 & \pm & 0.00004 \\
\cline { 2 - 9 } & 12.5 & -0.00052 & \pm & 0.00007 & $\sqrt{3}$ & -0.00030 & \pm & 0.00004 \\
\hline \multirow{3}{*}{7} & -12.5 & 0.00050 & \pm & 0.00006 & $\sqrt{3}$ & 0.00029 & \pm & 0.00003 \\
\cline { 2 - 8 } & 12.5 & -0.00046 & \pm & 0.00006 & $\sqrt{3}$ & -0.00027 & \pm & 0.00003 \\
\hline \multirow{2}{*}{12} & -12.5 & 0.00039 & \pm & 0.00006 & $\sqrt{3}$ & 0.00023 & \pm & 0.00004 \\
\cline { 2 - 8 } & 12.5 & -0.00060 & \pm & 0.00007 & $\sqrt{3}$ & -0.00035 & \pm & 0.00004 \\
\hline \multirow{2}{*}{13} & -12.5 & 0.00050 & \pm & 0.00006 & $\sqrt{3}$ & 0.00029 & \pm & 0.00004 \\
\cline { 2 - 8 } & 12.5 & -0.00053 & \pm & 0.00006 & $\sqrt{3}$ & -0.00031 & \pm & 0.00004 \\
\hline
\end{tabular}

Revision: 0

Date: September 30, 2012 
NEA/NSC/DOC/(95)03//

Volume I

PU-SOL-THERM-037

Table 50. $\Delta \mathrm{k}_{\text {eff }}$ for Uncertainty in Gadolinium Content.

\begin{tabular}{|c|c|c|c|c|c|c|c|c|}
\hline RSTM-L3- & $\begin{array}{c}\Delta \\
(\mathrm{ppm})\end{array}$ & $\Delta \mathrm{k}$ & \pm & $\sigma_{\mathrm{MCNP}}$ & $\begin{array}{l}\text { Scaling } \\
\text { Factor }\end{array}$ & $\Delta \mathrm{k}_{1 \sigma}$ & \pm & $\sigma_{\mathrm{MCNP}, 1 \sigma}$ \\
\hline \multirow{2}{*}{3} & -21.5 & 0.00324 & \pm & 0.00007 & $\sqrt{3}$ & 0.00187 & \pm & 0.00004 \\
\hline & 21.5 & -0.00332 & \pm & 0.00007 & $\sqrt{3}$ & -0.00192 & & 0.00004 \\
\hline \multirow{2}{*}{4} & -21.5 & 0.00323 & \pm & 0.00006 & $\sqrt{3}$ & 0.00186 & & 0.00004 \\
\hline & 21.5 & -0.00323 & \pm & 0.00006 & $\sqrt{3}$ & -0.00186 & & 0.00004 \\
\hline \multirow{2}{*}{5} & -21.5 & 0.00326 & \pm & 0.00006 & $\sqrt{3}$ & 0.00188 & & 0.00004 \\
\hline & 21.5 & -0.00318 & \pm & 0.00006 & $\sqrt{3}$ & -0.00184 & & 0.00004 \\
\hline \multirow{2}{*}{6} & -21.5 & 0.00329 & \pm & 0.00007 & $\sqrt{3}$ & 0.00190 & & 0.00004 \\
\hline & 21.5 & -0.00311 & \pm & 0.00006 & $\sqrt{3}$ & -0.00180 & & 0.00004 \\
\hline \multirow{2}{*}{7} & -21.5 & 0.00329 & \pm & 0.00006 & $\sqrt{3}$ & 0.00190 & & 0.00003 \\
\hline & 21.5 & -0.00325 & \pm & 0.00006 & $\sqrt{3}$ & -0.00188 & & 0.00003 \\
\hline \multirow{2}{*}{12} & -21.5 & 0.00343 & \pm & 0.00006 & $\sqrt{3}$ & 0.00198 & & 0.00004 \\
\hline & 21.5 & -0.00348 & \pm & 0.00006 & $\sqrt{3}$ & -0.00201 & & 0.00004 \\
\hline \multirow{2}{*}{13} & -21.5 & 0.00325 & \pm & 0.00006 & $\sqrt{3}$ & 0.00188 & & 0.00004 \\
\hline & 21.5 & -0.00324 & \pm & 0.00006 & $\sqrt{3}$ & -0.00187 & & 0.00004 \\
\hline
\end{tabular}

Table 51. $\Delta \mathrm{k}_{\text {eff }}$ for Uncertainty in Europium Content.

\begin{tabular}{|c|c|c|c|c|c|c|c|}
\hline RSTM-L3- & $\begin{array}{c}\Delta \\
(\mathrm{ppm})\end{array}$ & $\Delta \mathrm{k}$ & \pm & $\sigma_{\mathrm{MCNP}}$ & $\begin{array}{l}\text { Scaling } \\
\text { Factor }\end{array}$ & $\Delta \mathrm{k}_{1 \sigma}$ & $\sigma_{\mathrm{MCNP}, 1 \sigma}$ \\
\hline \multirow{2}{*}{3} & -8.46 & 0.00008 & \pm & 0.00007 & $\sqrt{3}$ & \multicolumn{2}{|c|}{ NEG } \\
\hline & 8.46 & -0.00030 & \pm & 0.00007 & $\sqrt{3}$ & $-0.00017 \pm$ & 0.00004 \\
\hline \multirow{2}{*}{4} & -8.46 & 0.00003 & \pm & 0.00007 & $\sqrt{3}$ & \multicolumn{2}{|c|}{ NEG } \\
\hline & 8.46 & -0.00019 & \pm & 0.00007 & $\sqrt{3}$ & $-0.00011 \pm$ & 0.00004 \\
\hline \multirow{2}{*}{5} & -8.46 & 0.00007 & \pm & 0.00006 & $\sqrt{3}$ & \multicolumn{2}{|c|}{ NEG } \\
\hline & 8.46 & -0.00016 & \pm & 0.00006 & $\sqrt{3}$ & \multicolumn{2}{|c|}{ NEG } \\
\hline \multirow{2}{*}{6} & -8.46 & 0.00016 & \pm & 0.00006 & $\sqrt{3}$ & \multicolumn{2}{|c|}{ NEG } \\
\hline & 8.46 & -0.00007 & \pm & 0.00007 & $\sqrt{3}$ & \multicolumn{2}{|c|}{ NEG } \\
\hline \multirow{2}{*}{7} & -8.46 & 0.00011 & \pm & 0.00006 & $\sqrt{3}$ & \multicolumn{2}{|c|}{ NEG } \\
\hline & 8.46 & -0.00022 & \pm & 0.00006 & $\sqrt{3}$ & $-0.00013 \pm$ & 0.00003 \\
\hline \multirow{2}{*}{12} & -8.46 & 0.00013 & \pm & 0.00006 & $\sqrt{3}$ & \multicolumn{2}{|c|}{ NEG } \\
\hline & 8.46 & -0.00029 & \pm & 0.00006 & $\sqrt{3}$ & $-0.00017 \pm$ & 0.00004 \\
\hline \multirow{2}{*}{13} & -8.46 & 0.00015 & \pm & 0.00006 & $\sqrt{3}$ & \multicolumn{2}{|c|}{ NEG } \\
\hline & 8.46 & -0.00017 & \pm & 0.00007 & $\sqrt{3}$ & \multicolumn{2}{|c|}{ NEG } \\
\hline
\end{tabular}

Revision: 0

Date: September 30, 2012 


\section{NEA/NSC/DOC/(95)03//}

Volume I

\section{PU-SOL-THERM-037}

The density of the polyethylene was measured by the technicians performing the chemical analysis on the bottle and was given as $0.98 \pm 0.04 \mathrm{~g} / \mathrm{cc}$ in Reference 1 . The $0.04 \mathrm{~g} / \mathrm{cc}$ was taken to be the $1 \sigma$ uncertainty in the polyethylene density. The effect of this uncertainty can be found in Table 52.

Table 52. $\Delta \mathrm{k}_{\mathrm{eff}}$ for Uncertainty in Polyethylene Density.

\begin{tabular}{|c|c|rcc|c|rcc|}
\hline \multirow{2}{*}{ RSTM-L3- } & $\begin{array}{c}\Delta \\
\left(\mathrm{g} / \mathrm{cm}^{3}\right)\end{array}$ & $\Delta \mathrm{k}$ & \pm & $\sigma_{\mathrm{MCNP}}$ & $\begin{array}{c}\text { Scaling } \\
\text { Factor }\end{array}$ & $\Delta \mathrm{k}_{1 \sigma}$ & \pm & $\sigma_{\mathrm{MCNP}, 1 \sigma}$ \\
\hline \multirow{3}{*}{3} & -0.04 & -0.00286 & \pm & 0.00006 & 1 & -0.00286 & \pm & 0.00006 \\
\cline { 2 - 9 } & 0.04 & 0.00267 & \pm & 0.00006 & 1 & 0.00267 & \pm & 0.00006 \\
\hline \multirow{2}{*}{4} & -0.04 & -0.00275 & \pm & 0.00006 & 1 & -0.00275 & \pm & 0.00006 \\
\cline { 2 - 9 } & 0.04 & 0.00265 & \pm & 0.00006 & 1 & 0.00265 & \pm & 0.00006 \\
\hline \multirow{2}{*}{5} & -0.04 & -0.00281 & \pm & 0.00007 & 1 & -0.00281 & \pm & 0.00007 \\
\cline { 2 - 9 } & 0.04 & 0.00272 & \pm & 0.00006 & 1 & 0.00272 & \pm & 0.00006 \\
\hline \multirow{3}{*}{6} & -0.04 & -0.00255 & \pm & 0.00006 & 1 & -0.00255 & \pm & 0.00006 \\
\cline { 2 - 8 } & 0.04 & 0.00266 & \pm & 0.00007 & 1 & 0.00266 & \pm & 0.00007 \\
\hline \multirow{2}{*}{7} & -0.04 & -0.00272 & \pm & 0.00007 & 1 & -0.00272 & \pm & 0.00007 \\
\cline { 2 - 8 } & 0.04 & 0.00269 & \pm & 0.00006 & 1 & 0.00269 & \pm & 0.00006 \\
\hline \multirow{2}{*}{12} & -0.04 & -0.00162 & \pm & 0.00006 & 1 & -0.00162 & \pm & 0.00006 \\
\cline { 2 - 8 } & 0.04 & 0.00149 & \pm & 0.00006 & 1 & 0.00149 & \pm & 0.00006 \\
\hline \multirow{2}{*}{13} & -0.04 & -0.00284 & \pm & 0.00006 & 1 & -0.00284 & \pm & 0.00006 \\
\cline { 2 - 8 } & 0.04 & 0.00260 & \pm & 0.00006 & 1 & 0.00260 & \pm & 0.00006 \\
\hline
\end{tabular}

\subsubsection{Plexiglas}

The density of the Plexiglas for the reflector and the shells was given as $1.185 \mathrm{~g} / \mathrm{cc}$. Plexiglas densities can typically range from 1.17 to $1.20 \mathrm{~g} / \mathrm{cc}^{\mathrm{a}}{ }^{\mathrm{a}}$ The uncertainty in the Plexiglas density is bounding with a uniform probability and was evaluated by varying the density across this range, results are in Table 53.

\footnotetext{
${ }^{a}$ HEU-SOL-THERM-034

Revision: 0

Date: September 30, 2012
} 
NEA/NSC/DOC/(95)03/I

Volume I

PU-SOL-THERM-037

Table 53. $\Delta \mathrm{k}_{\text {eff }}$ for Uncertainty in Plexiglas Density.

\begin{tabular}{|c|r|rcc|c|rcc|}
\hline \multirow{2}{*}{ RSTM-L3- } & $\begin{array}{c}\Delta \\
\left(\mathrm{g} / \mathrm{cm}^{3}\right)\end{array}$ & $\Delta \mathrm{k}$ & \pm & $\sigma_{\mathrm{MCNP}}$ & $\begin{array}{c}\text { Scaling } \\
\text { Factor }\end{array}$ & $\Delta \mathrm{k}_{1 \sigma}$ & \pm & $\sigma_{\mathrm{MCNP}, 1 \sigma}$ \\
\hline \multirow{3}{*}{3} & -0.015 & -0.00027 & \pm & 0.00006 & $\sqrt{3}$ & -0.00016 & \pm & 0.00004 \\
\cline { 2 - 8 } & 0.015 & 0.00029 & \pm & 0.00006 & $\sqrt{3}$ & 0.00017 & \pm & 0.00004 \\
\hline \multirow{3}{*}{4} & -0.015 & -0.00039 & \pm & 0.00006 & $\sqrt{3}$ & -0.00023 & \pm & 0.00003 \\
\cline { 2 - 9 } & 0.015 & 0.00040 & \pm & 0.00006 & $\sqrt{3}$ & 0.00023 & \pm & 0.00003 \\
\hline \multirow{2}{*}{5} & -0.015 & -0.00022 & \pm & 0.00006 & $\sqrt{3}$ & -0.00013 & \pm & 0.00004 \\
\cline { 2 - 9 } & 0.015 & 0.00045 & \pm & 0.00006 & $\sqrt{3}$ & 0.00026 & \pm & 0.00004 \\
\hline \multirow{3}{*}{6} & -0.015 & -0.00030 & \pm & 0.00007 & $\sqrt{3}$ & -0.00017 & \pm & 0.00004 \\
\cline { 2 - 9 } & 0.015 & 0.00027 & \pm & 0.00006 & $\sqrt{3}$ & 0.00016 & \pm & 0.00004 \\
\hline \multirow{3}{*}{7} & -0.015 & -0.00028 & \pm & 0.00007 & $\sqrt{3}$ & -0.00016 & \pm & 0.00004 \\
\cline { 2 - 8 } & 0.015 & 0.00036 & \pm & 0.00006 & $\sqrt{3}$ & 0.00021 & \pm & 0.00004 \\
\hline \multirow{2}{*}{12} & -0.015 & -0.00051 & \pm & 0.00007 & $\sqrt{3}$ & -0.00029 & \pm & 0.00004 \\
\cline { 2 - 8 } & 0.015 & 0.00064 & \pm & 0.00006 & $\sqrt{3}$ & 0.00037 & \pm & 0.00004 \\
\hline \multirow{2}{*}{13} & -0.015 & -0.00032 & \pm & 0.00006 & $\sqrt{3}$ & -0.00018 & \pm & 0.00004 \\
\cline { 2 - 7 } & 0.015 & 0.00021 & \pm & 0.00006 & $\sqrt{3}$ & 0.00012 & \pm & 0.00004 \\
\hline
\end{tabular}

The Plexiglas composition given in Reference 1 ( 8 wt.\% H, 60 wt.\% C, and 32 wt.\% O) was used in the models. No impurity analysis for the Plexiglas was given in any of the logbooks or any other relevant benchmark evaluations. To investigate the effect of possible impurities $1 \mathrm{ppm}$ of boron was added to all Plexiglas. The results are given in Table 54.

Table 54. $\Delta \mathrm{k}_{\text {eff }}$ for Uncertainty in Plexiglas Purity.

\begin{tabular}{|c|c|c|c|c|c|c|c|}
\hline RSTM-L3- & $\begin{array}{c}\Delta \\
(\mathrm{ppm})\end{array}$ & $\Delta \mathrm{k}$ & \pm & $\sigma_{\mathrm{MCNP}}$ & $\begin{array}{l}\text { Scaling } \\
\text { Factor }\end{array}$ & $\Delta \mathrm{k}_{1 \sigma}$ & $\sigma_{\mathrm{MCNP}, 1 \sigma}$ \\
\hline 3 & 1 & -0.00020 & \pm & 0.00006 & 1 & $-0.00020 \pm$ & 0.00006 \\
\hline 4 & 1 & -0.00009 & \pm & 0.00006 & 1 & \multicolumn{2}{|l|}{ NEG } \\
\hline 5 & 1 & 0.00001 & \pm & 0.00006 & 1 & \multicolumn{2}{|l|}{ NEG } \\
\hline 6 & 1 & -0.00017 & \pm & 0.00006 & 1 & $-0.00017 \pm$ & 0.00006 \\
\hline 7 & 1 & -0.00017 & \pm & 0.00006 & 1 & $-0.00017 \quad \pm$ & 0.00006 \\
\hline 12 & 1 & -0.00019 & \pm & 0.00006 & 1 & $-0.00019 \pm$ & 0.00006 \\
\hline 13 & 1 & -0.00007 & \pm & 0.00007 & 1 & \multicolumn{2}{|l|}{ NEG } \\
\hline
\end{tabular}

Revision: 0

Date: September 30, 2012 


\subsubsection{Supporting Structure}

The material used for the bottle support structure was specified as aluminum 6061 on an engineering drawing in the experimenter's logbook. The aluminum 6061 composition in Table 54 was used for the support structure. Elements with a range of weight percents were assumed to be at the middle of the range, elements with maximum values were assumed to be at one half the maximum weight percent, 'other' elements were assumed to be at zero weight percent and the aluminum weight percent was adjusted to maintain total weight percent of 100 .

To find the effect of the uncertainty in the aluminum composition two analyses were completed. The first varied the elements shown in Table 55. Elements with a range of impurities were varied between the minimum and maximum of the range. Elements with a maximum impurity were varied between zero and the maximum content. This uncertainty was taken to be a bounding uncertainty with a uniform distribution and thus a scaling factor of $\sqrt{3}$ was included. Aluminum content was adjusted to maintain total mass. 'Other' impurities were not considered in this analysis. The results can be found in Table 56.

Table 55. Al 6061 Composition. ${ }^{(a)}$

\begin{tabular}{|c|c|}
\hline Element & wt. $^{\left({ }^{(b)}\right.}$ \\
\hline Silicon & $0.40-0.80$ \\
\hline Iron & $<0.7$ \\
\hline Copper & $0.15-0.40$ \\
\hline Manganese & $<0.15$ \\
\hline Magnesium & $0.8-1.2$ \\
\hline Chromium & $0.04-0.35$ \\
\hline Zinc & $<0.25$ \\
\hline Titanium & $<0.15$ \\
\hline Other Elements Each & $<0.05$ \\
\hline & $<0.15$ \\
\hline Tluminum & Remainder \\
\hline Density $(\mathrm{g} / \mathrm{cc})$ & 2.70 \\
\hline
\end{tabular}

(a) Where single units are shown, these indicate the maximum amounts permitted.

(b) ASTM Standard B308M, 2010, "Standard Specification for Aluminum-Alloy 6061-T6 Standard Structural Profiles," ASTM International, West Conshohocken, PA, 2010.

Revision: 0

Date: September 30, 2012 
NEA/NSC/DOC/(95)03/l

Volume I

PU-SOL-THERM-037

Table 56. $\Delta \mathrm{k}_{\mathrm{eff}}$ for Uncertainty in $\mathrm{Al} 6061$ Composition.

\begin{tabular}{|c|c|rcc|c|ccc|}
\hline \multirow{2}{*}{ RSTM-L3- } & & $\Delta \mathrm{k}$ & \pm & $\sigma_{\mathrm{MCNP}}$ & $\begin{array}{c}\text { Scaling } \\
\text { Factor }\end{array}$ & $\Delta \mathrm{k}_{1 \sigma}$ & \pm & $\sigma_{\mathrm{MCNP}, 1 \sigma}$ \\
\hline \multirow{3}{*}{3} & Lower & 0.00010 & \pm & 0.00006 & $\sqrt{3}$ & \multicolumn{2}{|c|}{ NEG } \\
\cline { 2 - 8 } & Upper & -0.00020 & \pm & 0.00006 & $\sqrt{3}$ & -0.00012 & \pm & 0.00004 \\
\hline \multirow{3}{*}{4} & Lower & 0.00019 & \pm & 0.00006 & $\sqrt{3}$ & 0.00011 & \pm & 0.00003 \\
\cline { 2 - 8 } & Upper & -0.00023 & \pm & 0.00006 & $\sqrt{3}$ & -0.00013 & \pm & 0.00003 \\
\hline \multirow{2}{*}{5} & Lower & 0.00023 & \pm & 0.00006 & $\sqrt{3}$ & 0.00013 & \pm & 0.00004 \\
\cline { 2 - 8 } & Upper & -0.00014 & \pm & 0.00006 & $\sqrt{3}$ & \multicolumn{2}{|c|}{ NEG } \\
\hline \multirow{2}{*}{6} & Lower & 0.00025 & \pm & 0.00006 & $\sqrt{3}$ & 0.00014 & \pm & 0.00003 \\
\cline { 2 - 8 } & Upper & -0.00029 & \pm & 0.00006 & $\sqrt{3}$ & -0.00017 & \pm & 0.00003 \\
\hline \multirow{2}{*}{7} & Lower & 0.00028 & \pm & 0.00006 & $\sqrt{3}$ & 0.00016 & \pm & 0.00004 \\
\cline { 2 - 8 } & Upper & -0.00014 & \pm & 0.00007 & $\sqrt{3}$ & \multicolumn{2}{|c|}{ NEG } \\
\hline \multirow{2}{*}{12} & Lower & 0.00020 & \pm & 0.00006 & $\sqrt{3}$ & 0.00012 & \pm & 0.00003 \\
\cline { 2 - 8 } & Upper & -0.00015 & \pm & 0.00006 & $\sqrt{3}$ & \multicolumn{2}{|c|}{ NEG } \\
\hline \multirow{2}{*}{13} & Lower & 0.00010 & \pm & 0.00006 & $\sqrt{3}$ & \multicolumn{2}{|c|}{ NEG } \\
\cline { 2 - 8 } & Upper & -0.00023 & \pm & 0.00006 & $\sqrt{3}$ & -0.00013 & \pm & 0.00004 \\
\hline
\end{tabular}

The second analysis looked at the effect of 'other' impurities. Three impurities, cobalt, nickel, and tin, were included in the Al 6061 composition at $0.05 \mathrm{wt} \% \%$ each while adjusting the aluminum content accordingly. Because all of these impurities were added at their maximum concentration this was taken to be a one-sided bounding uncertainty. The effect of adding these impurities are shown in Table 57 to be negligible.

Table 57. $\Delta \mathrm{k}_{\text {eff }}$ for Uncertainty in $\mathrm{Al} 6061$ 'Other' Impurities. ${ }^{\mathrm{a}}$

\begin{tabular}{|c|ccc|c|c|}
\hline RSTM-L3- & $\Delta \mathrm{k}$ & \pm & $\sigma_{\mathrm{MCNP}}$ & $\begin{array}{c}\text { Scaling } \\
\text { Factor }\end{array}$ & $\Delta \mathrm{k}_{1 \sigma}$ \\
\hline 3 & -0.00021 & \pm 0.00006 & $2 \sqrt{3}$ & $\mathrm{NEG}$ \\
\hline 4 & -0.00021 & \pm 0.00006 & $2 \sqrt{3}$ & NEG \\
\hline 5 & -0.00022 & \pm 0.00006 & $2 \sqrt{3}$ & NEG \\
\hline 6 & -0.00009 & \pm 0.00006 & $2 \sqrt{3}$ & NEG \\
\hline 7 & -0.00023 & \pm 0.00007 & $2 \sqrt{3}$ & NEG \\
\hline 12 & -0.00018 & \pm 0.00006 & $2 \sqrt{3}$ & NEG \\
\hline 13 & -0.00014 & \pm 0.00006 & $2 \sqrt{3}$ & NEG \\
\hline
\end{tabular}

(a) 'Other' impurities are cobalt, nickel, and tin.

Revision: 0

Date: September 30, 2012 


\section{NEA/NSC/DOC/(95)03/I}

Volume I

\section{PU-SOL-THERM-037}

The density of the $\mathrm{Al} 6061$ was $2.70 \mathrm{~g} / \mathrm{cm}^{3}$. The uncertainty in the aluminum density was assumed to be $0.05 \mathrm{~g} / \mathrm{cm}^{3}$. The aluminum density was varied by $0.5 \mathrm{~g} / \mathrm{cm}^{3}$ in the simple model. This uncertainty was found to be negligible as can be seen in Table 58 .

Table 58. $\Delta \mathrm{k}_{\text {eff }}$ for Uncertainty in Al 6061 Density.

\begin{tabular}{|c|c|rcc|c|c|}
\hline \multirow{2}{*}{ RSTM-L3- } & $\begin{array}{c}\Delta \\
\left(\mathrm{g} / \mathrm{cm}^{3}\right)\end{array}$ & $\Delta \mathrm{k}$ & \pm & $\sigma_{\mathrm{MCNP}}$ & $\begin{array}{c}\text { Scaling } \\
\text { Factor }\end{array}$ & $\Delta \mathrm{k}_{1 \sigma}$ \\
\hline \multirow{3}{*}{3} & -0.5 & -0.00036 & \pm & 0.00006 & 10 & NEG \\
\cline { 2 - 7 } & 0.5 & 0.00040 & \pm & 0.00006 & 10 & NEG \\
\hline \multirow{2}{*}{4} & -0.5 & -0.00043 & \pm & 0.00006 & 10 & NEG \\
\cline { 2 - 7 } & 0.5 & 0.00037 & \pm & 0.00006 & 10 & NEG \\
\hline \multirow{2}{*}{5} & -0.5 & -0.00026 & \pm & 0.00007 & 10 & NEG \\
\cline { 2 - 7 } & 0.5 & 0.00053 & \pm & 0.00007 & 10 & NEG \\
\hline \multirow{3}{*}{6} & -0.5 & -0.00031 & \pm & 0.00007 & 10 & NEG \\
\cline { 2 - 7 } & 0.5 & 0.00039 & \pm & 0.00006 & 10 & NEG \\
\hline \multirow{3}{*}{7} & -0.5 & -0.00035 & \pm & 0.00006 & 10 & NEG \\
\cline { 2 - 7 } & 0.5 & 0.00038 & \pm & 0.00007 & 10 & NEG \\
\hline \multirow{3}{*}{12} & -0.5 & -0.00027 & \pm & 0.00006 & 10 & NEG \\
\cline { 2 - 7 } & 0.5 & 0.00032 & \pm & 0.00006 & 10 & NEG \\
\hline \multirow{2}{*}{13} & -0.5 & -0.00042 & \pm & 0.00006 & 10 & NEG \\
\cline { 2 - 6 } & 0.5 & 0.00032 & \pm & 0.00006 & 10 & NEG \\
\hline
\end{tabular}

\subsection{Total Experimental Uncertainty}

A summary of all uncertainties can be found in Table 59. In Table 59 only the maximum of the magnitude of the upper and lower uncertainties for each parameter was reported. The total experimental uncertainty was found by taking the square root of the sum of the squares of all uncertainties in Table 59 for each experiment. The total uncertainty in $\mathrm{k}_{\text {eff }}$ ranged from $0.0169-0.0189$. Uncertainties larger than 0.00080 are highlighted. There is a large correlation between the cases.

It was determined that due to the large experimental uncertainty these experiments are unacceptable as benchmark experiments. The largest contribution to the total experimental uncertainty was due to uncertainty in the solution composition. Because of the discrepancy between the measured solution density and the density predicted with Sakurai's equation it is believed that there is a large systematic error in the reported plutonium concentration or acid molarity (see Section 2.3.1.2).

Revision: 0

Date: September 30, 2012 
NEA/NSC/DOC/(95)03/I

Volume I

PU-SOL-THERM-037

Table 59. Total Experimental Uncertainty, $\Delta \mathrm{k}_{\mathrm{eff}}(1 \sigma)$.

\begin{tabular}{|c|c|c|c|c|c|c|c|}
\hline RSTM-L3- & 3 & 4 & 5 & 6 & 7 & 12 & 13 \\
\hline \multicolumn{8}{|c|}{ Critical Array Spacing Uncertainties } \\
\hline X Array Spacing & 0.00016 & 0.00014 & 0.00066 & 0.00025 & 0.00018 & 0.00031 & 0.00015 \\
\hline Y Array Spacing & 0.00220 & 0.00456 & NEG & 0.00129 & 0.00771 & 0.00050 & 0.00057 \\
\hline Total & 0.00221 & 0.00456 & 0.00066 & 0.00131 & 0.00771 & 0.00059 & 0.00059 \\
\hline \multicolumn{8}{|c|}{ Bottle Dimension Uncertainties } \\
\hline $\begin{array}{l}\text { Bottom of Bottle } \\
\text { Volume }\end{array}$ & 0.00029 & 0.00029 & 0.00030 & 0.00074 & 0.00075 & 0.00112 & 0.00064 \\
\hline Neck Height & NEG & NEG & NEG & NEG & NEG & NEG & NEG \\
\hline $\begin{array}{ll}\text { Neck } & \text { Wall } \\
\text { Thickness } & \\
\end{array}$ & NEG & NEG & NEG & NEG & NEG & NEG & NEG \\
\hline Neck Diameter & NEG & NEG & NEG & NEG & NEG & NEG & NEG \\
\hline Cap Height & NEG & NEG & NEG & NEG & NEG & NEG & NEG \\
\hline Cap diameter & NEG & NEG & NEG & NEG & NEG & NEG & NEG \\
\hline $\begin{array}{ll}\text { Bottle } & \text { Outer } \\
\text { Diameter } & \\
\end{array}$ & 0.00070 & 0.00088 & 0.00070 & 0.00082 & 0.00179 & 0.00114 & 0.00082 \\
\hline $\begin{array}{ll}\text { Bottle } & \text { Inner } \\
\text { Diamteter } & \\
\end{array}$ & 0.00032 & 0.00033 & 0.00033 & 0.00037 & 0.00037 & 0.00022 & 0.00038 \\
\hline Bottle Mass & NEG & NEG & NEG & NEG & NEG & NEG & NEG \\
\hline Total & 0.00077 & 0.00094 & 0.00077 & 0.00094 & 0.00184 & 0.00122 & 0.00093 \\
\hline \multicolumn{8}{|c|}{ Solution Measurements Uncertainties } \\
\hline Solution Mass & 0.00020 & 0.00019 & 0.00019 & 0.00018 & 0.00017 & 0.00017 & 0.00019 \\
\hline Solution Volume & 0.00113 & 0.00108 & 0.00109 & 0.00100 & 0.00098 & 0.00092 & 0.00099 \\
\hline Total & 0.00115 & 0.00110 & 0.00110 & 0.00102 & 0.00100 & 0.00094 & 0.00101 \\
\hline \multicolumn{8}{|c|}{ Reflector Measurements Uncertainties } \\
\hline Reflector Position & 0.00045 & 0.00043 & 0.00043 & 0.00037 & 0.00035 & 0.00032 & 0.00036 \\
\hline $\begin{array}{l}\text { Reflector } \\
\text { Dimensions } \\
\end{array}$ & 0.00014 & 0.00014 & 0.00014 & 0.00014 & 0.00014 & 0.00012 & 0.00014 \\
\hline Total & 0.00047 & 0.00046 & 0.00046 & 0.00039 & 0.00037 & 0.00034 & $\mathbf{0 . 0 0 0 3 8}$ \\
\hline \multicolumn{8}{|c|}{ Shell Measurements Uncertainties } \\
\hline Outer Radius Shell & - & - & - & - & - & 0.00081 & - \\
\hline Thickness of Shell & - & - & - & - & - & 0.00036 & - \\
\hline Height of Shell & - & - & - & - & - & NEG & - \\
\hline Total & 0.00000 & 0.00000 & 0.00000 & 0.00000 & 0.00000 & 0.00089 & $\overline{0.00000}$ \\
\hline \multicolumn{8}{|c|}{ Solution Composition Uncertainties } \\
\hline $\begin{array}{l}\text { Ca, Co, } \quad \mathrm{Ti}, \quad \mathrm{V} \\
\text { Solution Impurities }\end{array}$ & 0.00148 & 0.00135 & 0.00136 & 0.00136 & 0.00139 & 0.00128 & 0.00136 \\
\hline U Concentration & NEG & NEG & NEG & NEG & NEG & NEG & NEG \\
\hline Fe Concentration & NEG & NEG & NEG & NEG & NEG & NEG & NEG \\
\hline
\end{tabular}

Revision: 0

Date: September 30, 2012 
NEA/NSC/DOC/(95)03/I

Volume I

PU-SOL-THERM-037

\begin{tabular}{|c|c|c|c|c|c|c|c|}
\hline Cr Concentration & NEG & NEG & NEG & NEG & NEG & NEG & NEG \\
\hline Ni Concentration & NEG & NEG & NEG & NEG & NEG & NEG & NEG \\
\hline Al Concentration & NEG & NEG & NEG & NEG & NEG & NEG & NEG \\
\hline Mn Concentration & NEG & NEG & NEG & NEG & NEG & NEG & NEG \\
\hline Cd Concentration & NEG & NEG & NEG & NEG & NEG & NEG & NEG \\
\hline B Concentration & NEG & NEG & NEG & NEG & NEG & NEG & NEG \\
\hline $\begin{array}{l}\text { Am-241 } \\
\text { Concentration }\end{array}$ & 0.00012 & 0.00012 & NEG & NEG & 0.00013 & 0.00012 & 0.00011 \\
\hline Total & 0.00149 & 0.00135 & 0.00136 & 0.00136 & 0.00139 & 0.00129 & 0.00137 \\
\hline \multicolumn{8}{|c|}{ Plutonium and Free Acid Concentration } \\
\hline Pu Content ${ }^{(\mathrm{a})}$ & 0.00212 & 0.00241 & 0.00236 & 0.00366 & 0.00369 & 0.00980 & 0.00362 \\
\hline Acid Molarity $^{(\mathrm{a})}$ & 0.01432 & 0.01429 & 0.01438 & 0.01406 & 0.01418 & 0.01318 & 0.01418 \\
\hline Total & 0.00949 & 0.00964 & 0.00966 & 0.01023 & 0.01032 & 0.01327 & 0.01028 \\
\hline \multicolumn{8}{|c|}{ Nitrate Density } \\
\hline $\begin{array}{l}\text { Nitrate } \\
\text { Concentration }\end{array}$ & 0.01335 & 0.01331 & 0.01325 & 0.01307 & 0.01310 & 0.01205 & 0.01311 \\
\hline Total & 0.01335 & 0.01331 & 0.01325 & 0.01307 & 0.01310 & 0.01205 & 0.01311 \\
\hline \multicolumn{8}{|c|}{ Plutonium Isotopic Distribution } \\
\hline Pu-238 wt \% & NEG & NEG & NEG & NEG & NEG & NEG & NEG \\
\hline Pu-240 wt \% & NEG & NEG & NEG & NEG & NEG & NEG & NEG \\
\hline Pu-241 wt\% & NEG & NEG & NEG & NEG & NEG & NEG & NEG \\
\hline Pu-242 wt\% & NEG & NEG & NEG & NEG & NEG & NEG & NEG \\
\hline Total & NEG & NEG & NEG & NEG & NEG & NEG & NEG \\
\hline \multicolumn{8}{|c|}{ Solution Temperature Uncertainties } \\
\hline $\begin{array}{l}\text { Temperature } \\
\text { Correction }\end{array}$ & 0.00023 & 0.00011 & NEG & NEG & NEG & NEG & NEG \\
\hline $\begin{array}{l}\text { Solution } \\
\text { Temperature }\end{array}$ & NEG & NEG & NEG & NEG & NEG & NEG & NEG \\
\hline Total & 0.00023 & 0.00011 & 0.00000 & 0.00000 & 0.00000 & 0.00000 & 0.00000 \\
\hline \multicolumn{8}{|c|}{ Polyethylene Uncertainties } \\
\hline Sm Content & 0.00031 & 0.00033 & 0.00038 & 0.00031 & 0.00029 & 0.00035 & 0.00031 \\
\hline Gd Content & 0.00192 & 0.00186 & 0.00188 & 0.00190 & 0.00190 & 0.00201 & 0.00188 \\
\hline Eu Content & 0.00017 & 0.00011 & NEG & NEG & 0.00013 & 0.00017 & NEG \\
\hline $\begin{array}{l}\text { Polyethylene } \\
\text { Density } \\
\end{array}$ & 0.00286 & 0.00275 & 0.00281 & 0.00266 & 0.00272 & 0.00162 & 0.00284 \\
\hline Total & 0.00346 & 0.00334 & 0.00340 & 0.00328 & 0.00333 & 0.00261 & 0.00342 \\
\hline \multicolumn{8}{|c|}{ Plexiglas Uncertainties } \\
\hline Plexiglas Density & 0.00017 & 0.00023 & 0.00026 & 0.00017 & 0.00021 & 0.00037 & 0.00018 \\
\hline Plexiglas Purity & 0.00020 & NEG & NEG & 0.00017 & 0.00017 & 0.00019 & NEG \\
\hline Total & 0.00026 & 0.00023 & 0.00026 & 0.00024 & 0.00027 & 0.00042 & 0.00018 \\
\hline
\end{tabular}

Revision: 0

Date: September 30, 2012

Page 71 of 142 


\section{NEA/NSC/DOC/(95)03/I \\ Volume I}

PU-SOL-THERM-037

\begin{tabular}{|l|l|l|l|l|l|l|l|}
\hline \multicolumn{7}{|c|}{ Support Structure Uncertainties } \\
\hline Al Composition & 0.00012 & 0.00013 & 0.00013 & 0.00017 & 0.00016 & 0.00012 & 0.00013 \\
\hline Other' Al Impurities & NEG & NEG & NEG & NEG & NEG & NEG & NEG \\
\hline Aluminum Density & NEG & NEG & NEG & NEG & NEG & NEG & NEG \\
\hline Total & $\mathbf{0 . 0 0 0 1 2}$ & $\mathbf{0 . 0 0 0 1 3}$ & $\mathbf{0 . 0 0 0 1 3}$ & $\mathbf{0 . 0 0 0 1 7}$ & $\mathbf{0 . 0 0 0 1 6}$ & $\mathbf{0 . 0 0 0 1 2}$ & $\mathbf{0 . 0 0 0 1 3}$ \\
\hline \multicolumn{7}{|c|}{ Total Experimental Uncertainty } \\
\hline Total & $\mathbf{0 . 0 1 7 0 2}$ & $\mathbf{0 . 0 1 7 5 0}$ & $\mathbf{0 . 0 1 6 8 8}$ & $\mathbf{0 . 0 1 7 1 0}$ & $\mathbf{0 . 0 1 8 8 6}$ & $\mathbf{0 . 0 1 8 2 9}$ & $\mathbf{0 . 0 1 7 1 5}$ \\
\hline
\end{tabular}

(a) These uncertainties are correlated. See Section 2.3.1.2. 
NEA/NSC/DOC/(95)03/l

Volume I

PU-SOL-THERM-037

\subsection{BENCHMARK SPECIFICATIONS}

These experiments were judged to be unacceptable for use as criticality safety benchmarks, therefore no benchmark specifications are given. However, models were created for these experiments and the description of the models can be found in Appendix C.

\subsection{RESULTS OF SAMPLE CALCULATIONS}

These experiments were judged to be unacceptable for use as criticality safety benchmarks, therefore no calculation results are given. However, models were created for these experiments and the sample calculation results of the models can be found in Appendix D.

\subsection{REFERENCES}

1. B. M. Durst, E. D. Clayton, and J. H. Smith, "Criticality Experiments with Planar Arrays of ThreeLiter Bottles Containing Plutonium Nitrate Solution," PNL-5387, Pacific Northwest National Laboratory (January 1985).

Revision: 0

Date: September 30, 2012 
NEA/NSC/DOC/(95)03/l

Volume I

PU-SOL-THERM-037

\section{APPENDIX A: TYPICAL INPUT LISTINGS}

These experiments were judged to be unacceptable for use as criticality safety benchmarks, therefore no sample input decks are given. However, models was created for these experiments and the sample input decks for these models can be found in Appendix G.

Revision: 0

Date: September 30, 2012 


\section{NEA/NSC/DOC/(95)03/l}

Volume I

PU-SOL-THERM-037

\section{APPENDIX B: EXAMPLE OF EXTRAPOLATIONS}

It is important to note that the following extrapolation examples are the work of the evaluator to reproduce the experimenter's results. The logbooks provided computer print outs of results and a summary table of all results; but equations used in the extrapolations were not provided by the experimenter.

\section{Extrapolation to Critical Array Spacing Example- RSTM-L3-3}

Experimental data were collected from three detectors for each array spacing tested. Multiple count rates, with units of counts per 90 seconds, were collected and then averaged. Only the last two array spacings were used in the extrapolation to critical thus results for only the last two array spacings are included in Table 60.

Table 60. Detector Count Rates. ${ }^{(a)}$

\begin{tabular}{|c|c|c|c|}
\hline \multicolumn{4}{|c|}{ RSTM-L3-3 } \\
\hline $\begin{array}{c}\text { Y-Dir. Array } \\
\text { Spacing }\end{array}$ & Detector 1 & Detector 2 & Detector 3 \\
\hline & 3485 & 20696 & 7048 \\
& 3513 & 20836 & 7088 \\
0.507 in. & 3500 & 20925 & 7143 \\
& 3551 & 20866 & 7117 \\
& 3547 & 21073 & 7011 \\
\hline Average & 3519.2 & 20879.2 & 7081.4 \\
\hline \multicolumn{4}{|c|}{} \\
\hline \\
0.253 in. & 11967 & 80673 & 24794 \\
& 11997 & 80931 & 25660 \\
& 11832 & 81779 & 25353 \\
& & 81188 & 25477 \\
\hline Average & 11997.25 & 81085.6 & 25378.2 \\
\hline
\end{tabular}

(a) These count rates still include background.

The first method extrapolated spacing divided by count rate versus spacing. The count rate used in the extrapolation had background subtracted from the average count rates. The background $\left(C R_{B}\right)$ was 745 , 1161, and 1105 for Detectors 1, 2, and 3 respectively. The second method extrapolated one divided by the average count rate less the back ground count rate versus spacing. Results of both methods can be found in Table 61.

Revision: 0

Date: September 30, 2012 
NEA/NSC/DOC/(95)03/l

Volume I

PU-SOL-THERM-037

Table 61. Extrapolation Values.

\begin{tabular}{|c|c|c|c|c|c|}
\hline \multicolumn{2}{|c|}{ Method 1 } & \multicolumn{4}{c|}{ Spacing } \\
\hline \multicolumn{2}{|c|}{ Spacing } & Detector 1 & Detector 2 & Detector 3 & \\
\hline 0.507 in. & $\left(x_{1}\right)$ & $1.829 \mathrm{E}-04$ & $2.574 \mathrm{E}-05$ & $8.492 \mathrm{E}-05$ & $\left(y_{1}\right)$ \\
\hline 0.253 in. & $\left(x_{2}\right)$ & $2.248 \mathrm{E}-05$ & $3.165 \mathrm{E}-06$ & $1.042 \mathrm{E}-05$ & $\left(y_{2}\right)$ \\
\hline \multicolumn{5}{|c|}{ Method 2 } & \multicolumn{5}{c|}{ CR -CR } \\
\hline \multicolumn{2}{|c|}{ Spacing } & Detector 1 & Detector 2 & Detector 3 & \\
\hline 0.507 in. & $\left(x_{1}\right)$ & $3.605 \mathrm{E}-04$ & $5.072 \mathrm{E}-05$ & $1.673 \mathrm{E}-04$ & $\left(y_{1}\right)$ \\
\hline 0.253 in. & $\left(x_{2}\right)$ & $8.887 \mathrm{E}-05$ & $1.251 \mathrm{E}-05$ & $4.120 \mathrm{E}-05$ & $\left(y_{2}\right)$ \\
\hline
\end{tabular}

Next it was assumed that the extrapolation from the last two points to critical was linear, thus the following equation could be used to find the spacing at which the system is critical. Table 62 summarizes the results. (It should be noted that the defining of values with $x$ and $y$ variables has no connection with whether the spacing was in the $\mathrm{X}$ - or Y-direction of the arrays.)

$$
x_{\text {crit }}=x_{1}-y_{1} \frac{x_{2}-x_{1}}{y_{2}-y_{1}}
$$

Equation

B.1

Table 62. Critical Spacing Values.

\begin{tabular}{|c|c|c|c|c|c|}
\hline \multicolumn{2}{|c|}{ Method 1 } & Detector 1 & Detector 2 & Detector 3 & Average \\
\hline $\begin{array}{c}\text { Critical } \\
\text { Spacing }\end{array}$ & $\begin{array}{c}\left(x_{\text {crit }},\right. \\
\text { in. })\end{array}$ & 0.21734 & 0.21731 & 0.21739 & 0.21735 \\
\hline \multicolumn{2}{|c|}{ Method 2 } & Detector 1 & Detector 2 & Detector 3 & Average \\
\hline $\begin{array}{l}\text { Critical } \\
\text { Spacing }\end{array}$ & $\begin{array}{c}\left(x_{\text {crit }},\right. \\
\text { in.) }\end{array}$ & 0.16973 & 0.16965 & 0.16988 & 0.16975 \\
\hline
\end{tabular}

To obtain the final results the $x_{\text {crit }}$ for the two methods were averaged. This yielded a result of 0.19355 in. spacing in the Y-direction of the array. This result agrees reasonably well with the results listed in Table 6.

Table 63 summarizes the extrapolation to critical results for all experiments evaluated in this evaluation. It is important to note that the results in Table 63 are the results of the extrapolation-to-critical as done by the evaluator. They are reasonable although not in exact agreement with results reported by the experimenter as given in Table 6. For the models, extrapolation-to-critical results reported by the experimenter were used.

Revision: 0

Date: September 30, 2012 


\section{NEA/NSC/DOC/(95)03//}

Volume I

PU-SOL-THERM-037

Table 63. Critical Spacing Values.

\begin{tabular}{|c|c|c|}
\hline Case & $\begin{array}{c}\text { RSTM- } \\
\text { L3- }\end{array}$ & $\begin{array}{c}\text { Critical } \\
\text { Spacing } \\
\text { (in.) }\end{array}$ \\
\hline 1 & 3 & 0.19355 \\
\hline 2 & 4 & 0.14206 \\
\hline 3 & 5 & 0.23023 \\
\hline 4 & 6 & 0.75695 \\
\hline 5 & 7 & 0.27907 \\
\hline 6 & 12 & 0.48835 \\
\hline 7 & 13 & 0.47396 \\
\hline
\end{tabular}

\section{Extrapolation to Critical Number of Bottles Example- RSTM-L3-2}

The approach for extrapolation to critical number of bottles was similar to the one described above for critical array spacing. The only difference is number of bottles rather than spacing was used. Tables 64-66 summarize the extrapolation to critical number of bottles.

Table 64. Detector Count Rates. ${ }^{(a)}$

\begin{tabular}{|c|c|c|c|}
\hline \multicolumn{4}{|c|}{ RSTM-L3-3 } \\
\hline $\begin{array}{c}\text { Number of } \\
\text { Bottles }\end{array}$ & Detector 1 & Detector 2 & Detector 3 \\
\hline \multirow{5}{*}{9} & 2693 & 14102 & 5320 \\
\hline & 2662 & 13873 & 5207 \\
\hline & 2749 & 14069 & 5354 \\
\hline & 2614 & 13802 & 5326 \\
\hline & 2762 & 13934 & 5318 \\
\hline Average & 2696.0 & 13956.0 & 5305.0 \\
\hline \multirow{5}{*}{10} & 5089 & 29369 & 10606 \\
\hline & 5154 & 29171 & 10712 \\
\hline & 5098 & 29073 & 10736 \\
\hline & 5108 & 29395 & 10876 \\
\hline & 5227 & 29499 & 10574 \\
\hline Average & 5135.2 & 29301.4 & 10700.8 \\
\hline
\end{tabular}

(a) These count rates include background.

Revision: 0

Date: September 30, 2012 


\section{NEA/NSC/DOC/(95)03/I}

Volume I

PU-SOL-THERM-037

Table 65. Extrapolation Values.

\begin{tabular}{|c|c|c|c|c|c|}
\hline \multicolumn{2}{|c|}{ Method 1 } & \multicolumn{4}{|c|}{ Bottles } \\
\hline \multicolumn{2}{|c|}{ Bottles } & Detector 1 & Detector 2 & Detector 3 & \\
\hline 9 & $\left(x_{1}\right)$ & $4.613 \mathrm{E}-03$ & $7.034 \mathrm{E}-04$ & $2.143 \mathrm{E}-03$ & $\left(y_{1}\right)$ \\
\hline 10 & $\left(x_{2}\right)$ & $2.278 \mathrm{E}-03$ & $3.554 \mathrm{E}-04$ & $1.042 \mathrm{E}-03$ & $\left(y_{2}\right)$ \\
\hline \multicolumn{5}{|c|}{ Method 2 } & \multicolumn{5}{c|}{ CR -CR } \\
\hline \multicolumn{2}{|c|}{ Bottles } & Detector 1 & Detector 2 & Detector 3 & \\
\hline 9 & $\left(x_{1}\right)$ & $5.126 \mathrm{E}-04$ & $7.816 \mathrm{E}-05$ & $2.381 \mathrm{E}-04$ & $\left(y_{1}\right)$ \\
\hline 10 & $\left(x_{2}\right)$ & $2.278 \mathrm{E}-04$ & $3.554 \mathrm{E}-05$ & $1.042 \mathrm{E}-04$ & $\left(y_{2}\right)$ \\
\hline
\end{tabular}

Table 66. Critical Bottles Values.

\begin{tabular}{|c|c|c|c|c|c|}
\hline \multicolumn{2}{|c|}{ Method 1 } & Detector 1 & Detector 2 & Detector 3 & $\begin{array}{c}\text { Average } \\
\text { (Bottles) }\end{array}$ \\
\hline $\begin{array}{l}\text { Critical } \\
\text { Spacing }\end{array}$ & $\left(x_{\text {crit }}\right)$ & 10.976 & 11.021 & 10.947 & 10.981 \\
\hline \multicolumn{2}{|c|}{ Method 2 } & Detector 1 & Detector 2 & Detector 3 & $\begin{array}{c}\text { Average } \\
\text { (Bottles) }\end{array}$ \\
\hline $\begin{array}{c}\text { Critical } \\
\text { Spacing }\end{array}$ & $\left(x_{\text {crit }}\right)$ & 10.800 & 10.834 & 10.778 & 10.804 \\
\hline
\end{tabular}

The average of the two methods yields a critical number of bottles of 10.893, which agrees with the value given in Table 6. 
NEA/NSC/DOC/(95)03/l

Volume I

PU-SOL-THERM-037

APPENDIX C: DESCRIPTION OF SIMPLE MODEL

\section{C.0 SIMPLE MODEL SPECIFICATIONS}

A detailed model was created with MCNP5 using the ENDF/B-VII.0 neutron cross-section libraries. The model was then simplified and the effect on $\mathrm{k}_{\text {eff }}$ was calculated for each simplifications. All models were run in MCNP5 such that the statistical uncertainty of $\mathrm{k}_{\text {eff }}$ was no more than 0.00005 leading to a $\Delta \mathrm{k}_{\text {eff }}$ statistical uncertainty of no more than 0.00007 . Section C.1 summarizes all simplifications made and biases applied to the expected $\mathrm{k}_{\mathrm{eff}}$.

Biases were evaluated in a stepwise fashion where a part of the model was removed or simplified, $\mathrm{k}_{\text {eff }}$ and $\Delta \mathrm{k}_{\mathrm{eff}}$ were calculated, and then the next simplification was made. Figure 16 is a flow diagram of this process. Biases were considered negligible (NEG) if the $\Delta \mathrm{k}_{\mathrm{eff}}$ was less than 0.00010 .

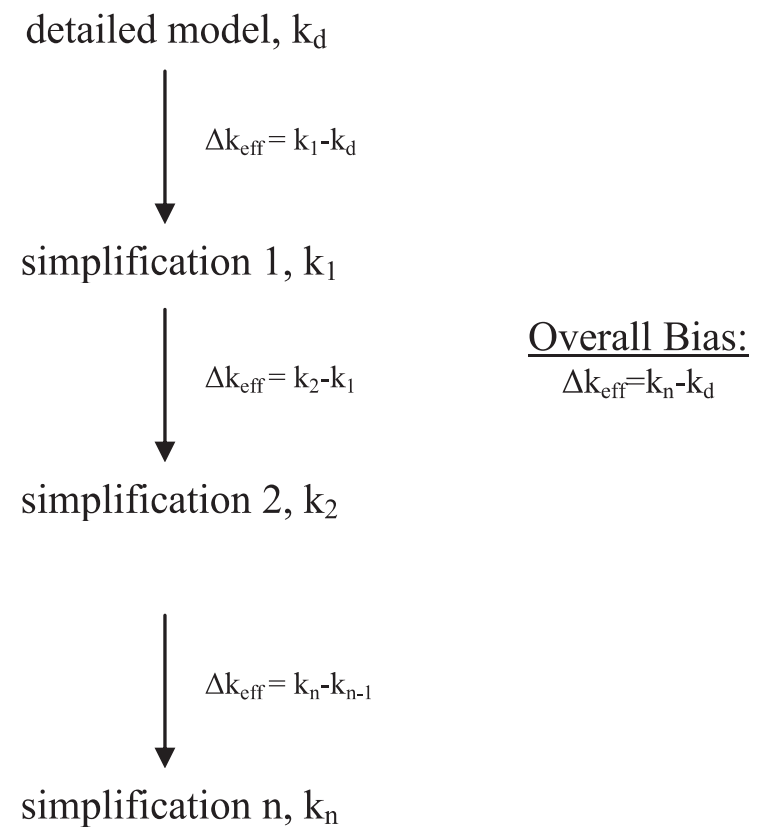

Figure 16. Bias Analysis Flow Diagram.

\section{C.1 Description of Model}

A detailed model of the experimental setup was first created to model the experiments as closely as possible. Simplifications were then made to create the simple model and the change in the neutron multiplication factor, $\Delta \mathrm{k}_{\text {eff }}$, was found for each simplification. The following simplifications were made and are described in Sections C.1.1 through C.1.6: structures surrounding the experimental set up were removed if not specifically part of the experiment, the bottle dimensions were simplified, the bottle support structure was simplified, and material impurities were removed.

Revision: 0

Date: September 30, 2012 


\section{NEA/NSC/DOC/(95)03/l}

Volume I

PU-SOL-THERM-037

\section{C.1.1 Removal of Surroundings}

The effects of removing the reactor room walls, the hoods, the split table machine, and the honeycomb aluminum structure below the bottom Plexiglas reflector were investigated as well as the effect of replacing air with void. Because of the small bias associated with the removal of the reactor room walls the solution storage tank and Amercoat coating were both assumed to have a negligible effect of $\mathrm{k}_{\text {eff. }}$.

The reactor room was modeled with inner dimensions of $35-\mathrm{ft} . \times 35-\mathrm{ft}$. and 20 -ft. tall with 5 -ft. thick walls on three sides, a 3 -ft. thick wall opposite the hoods, and a 2 -ft. thick ceiling and floor. The solution storage tank, which would have been empty, and the room access ports were not modeled. This is simpler than the actual dimensions but is believed to be sufficient to adequately determine the effects of room return.

The two hoods in the reactor room were 8-ft. square and 15-ft. tall and were made of a SS 304L framework with Plexiglas windows. ${ }^{\text {a }}$ Because of the lack of given dimensions both hoods were modeled as a box of 0.95 -cm-thick Plexiglas surrounded by a box of $1 / 4$-in.-thick SS 304L.

The split table machine was built out of Stainless Steel $304 \mathrm{~L}^{\mathrm{c}}$, but the dimensions were not given. The table was modeled as a framework of $0.635-\mathrm{cm}$-square SS 304L $\left(\rho=7.92 \mathrm{~g} / \mathrm{cm}^{3}\right)$ beams above the bottom of the aluminum honeycomb up to approximately six foot from the floor level. All of the gears and equipment to remotely move the split table were located below the aluminum honeycomb. This was assumed to be all SS 304L and was modeled as a solid volume of SS 304L at half density extending from the floor to the bottom of the honeycomb.

The honeycomb structure was 30-in. wide, 42 -in. long when the table was closed (stationary half 24 in. and moveable half $18 \mathrm{in}$.), and 12-in. thick with the top $32 \mathrm{in}$. above the floor ${ }^{\mathrm{d}}$ and made of low-density aluminum $\left(\rho=0.037 \mathrm{~g} / \mathrm{cm}^{3}\right)$. ${ }^{\mathrm{e}}$ The aluminum composition or alloy for the honeycomb was not given but was modeled as aluminum 6061 to match the bottle support structure material.

The SS304L and aluminum 6061 data used to derive the compositions used in the experiment models are shown in Tables 67 and 68, respectively.

\footnotetext{
${ }^{\text {a }}$ Personal phone communication with B.M. Durst, Sept. 21, 2010.

${ }^{\mathrm{b}}$ PU-COMP-MIXED-001

${ }^{\mathrm{c}}$ Personal phone communication with B.M. Durst, Sept. 21, 2010.

${ }^{\mathrm{d}}$ C.R. Richey, E.D. Clayton, R.H. Odegaarden, J.D. White, and W.A. Reardon, "Hazards Summary Report For The Hanford Plutonium Critical Mass Laboratory, Supplement No. 1, The Remote Split-Table Machine,” HW-6266 SUP1 REV, October 1963.

${ }^{\text {e }}$ C.R. Richey, J.D. White, E.D. Clayton, and R.C. Lloyd, "Criticality of Homogeneous Plutonium Oxide-Plastic Compacts at $\mathrm{H}: \mathrm{Pu}=15, ”$ Nuclear Science and Engineering, 23, 150-158, 1965.
}

Revision: 0

Date: September 30, 2012 


\section{NEA/NSC/DOC/(95)03/l}

Volume I

\section{PU-SOL-THERM-037}

Table 67. SS 304L Composition. ${ }^{(a)}$

\begin{tabular}{|c|c|}
\hline Element & wt. ${ }^{(\mathrm{b})}$ \\
\hline Carbon & 0.08 \\
\hline Chromium & $18.0-20.0$ \\
\hline Manganese & 2.00 \\
\hline Nickel & $8.0-11.0$ \\
\hline Phosphorus & 0.045 \\
\hline Silicon & 1.00 \\
\hline Sulfur & 0.030 \\
\hline Iron & Remainder \\
\hline Density $(\mathrm{g} / \mathrm{cc})$ & 8.00 \\
\hline
\end{tabular}

(a) ASTM Standard A312M, 2009, "Standard Specification for Seamless, Welded, and Heavily Cold Worked Austentic Stainless Steel Pipes," ASTM International, West Conshohocken, PA, 2009.

(b) Maximum, unless otherwise indicated.

Table 68. Al 6061 Composition. ${ }^{(a)}$

\begin{tabular}{|c|c|}
\hline Element & wt. $^{\left({ }^{(b)}\right.}$ \\
\hline Silicon & $0.40-0.80$ \\
\hline Iron & 0.7 \\
\hline Copper & $0.15-0.40$ \\
\hline Manganese & 0.15 \\
\hline Magnesium & $0.8-1.2$ \\
\hline Chromium & $0.04-0.35$ \\
\hline Zinc & 0.25 \\
\hline Titanium & 0.15 \\
\hline Other Elements Each & 0.05 \\
\hline & 0.15 \\
\hline Tluminum & Remainder \\
\hline Density $(\mathrm{g} / \mathrm{cc})$ & 2.70 \\
\hline
\end{tabular}

(a) Where single units are shown, these indicate the maximum amounts permitted.

(b) ASTM Standard B308M, 2010, "Standard Specification for Aluminum-Alloy 6061-T6 Standard Structural Profiles," ASTM International, West Conshohocken, PA, 2010.

Revision: 0

Date: September 30, 2012 


\section{NEA/NSC/DOC/(95)03/l}

Volume I

\section{PU-SOL-THERM-037}

Elements with a range of weight percents were assumed to be at the middle of the range, elements with maximum values were assumed to be at one half the maximum weight percent, 'other' elements were assumed to be at zero weight percent and the aluminum and iron weight percents were adjusted to maintain a total weight percent of 100 . Table 69 summarizes the $\Delta \mathrm{k}_{\text {eff }}$ results for the removal of the surroundings.

Table 69. $\Delta \mathrm{k}_{\mathrm{eff}}$ for Removing Surroundings.

\begin{tabular}{|c|c|c|c|c|c|c|c|}
\hline Case & 1 & 2 & 3 & 4 & 5 & 6 & 7 \\
\hline Replace Air with Void & NEG & NEG & NEG & 0.00014 & NEG & NEG & NEG \\
\hline Room & NEG & NEG & NEG & -0.00023 & -0.00018 & NEG & -0.00012 \\
\hline Hood & NEG & -0.00020 & -0.00025 & -0.00027 & -0.00012 & -0.00022 & -0.00030 \\
\hline Split Table Machine & -0.00015 & NEG & NEG & NEG & -0.00016 & NEG & NEG \\
\hline Honeycomb & NEG & NEG & NEG & NEG & NEG & NEG & NEG \\
\hline
\end{tabular}

\section{C.1.2 Bottle Dimension Simplifications}

A detailed model of the bottle was created to match Figure 1 as closely as possible. Because of the lack of information about the curve at the top of the bottle the model did not include this curve but rather a constant height up to $33 \mathrm{~cm}$ and then a decrease in diameter to the size of the neck. This simplification is discussed in Section 2.2.1 and is believed to be negligible. Simplifications made to the detailed model of the bottle were: the homogenization of the curve and dome at the bottom of the bottle, averaging of all bottle diameters, and the averaging of solution volume and mass within each experiment. The effects of these simplifications are summarized in Table 70.

The homogenization of the bottom of the bottle is discussed in Section 2.2.1. The inner diameters of the bottles were modeled exactly as they appear in Table 1 and then modeled with an averaged radius of $5.3156 \mathrm{~cm}$ for the simple model. An average outer diameter was used for both the detailed and simple models since only three outer diameter measurements were reported by the experimenter for an unknown reason.

In the detailed model the solution volume and masses were modeled individually in each bottle using data in Table 2. Because the data in Table 2 were measured at $28.5^{\circ} \mathrm{C}$ and the experiment was carried out at an average temperature of $22^{\circ} \mathrm{C}$, the solution volumes were adjusted to account for the volume change. This temperature correction is discussed in Section 2.3.2. The solution volumes and masses were averaged for use in the simple model. In order to conserve mass, averages were taken for bottles $1,2,3,4,6,8,10,11$, $12,15,16$, and 17 for Cases 1-3 and all 16 bottles for Cases $4-7$. This yielded slightly different mass and volume averages but still identical solution densities for the 12- and 16-bottle configurations. Averages used in the simple model are shown in Table 71.

Revision: 0

Date: September 30, 2012

Page 82 of 142 
NEA/NSC/DOC/(95)03/I

Volume I

PU-SOL-THERM-037

Table 70. $\Delta \mathrm{k}_{\text {eff }}$ for Bottle Simplifications.

\begin{tabular}{|c|c|c|c|c|c|c|c|}
\hline Case & 1 & 2 & 3 & 4 & 5 & 6 & 7 \\
\hline $\begin{array}{c}\text { Homogenize Bottom } \\
\text { of Bottle }\end{array}$ & -0.00015 & $\mathrm{NEG}$ & -0.00010 & -0.00017 & -0.00022 & $\mathrm{NEG}$ & $\mathrm{NEG}$ \\
\hline $\begin{array}{c}\text { Average Bottle } \\
\text { Inner Diameter }\end{array}$ & $\mathrm{NEG}$ & $\mathrm{NEG}$ & $\mathrm{NEG}$ & $\mathrm{NEG}$ & $\mathrm{NEG}$ & $\mathrm{NEG}$ & 0.00013 \\
\hline $\begin{array}{c}\text { Average Solution } \\
\text { Volume }\end{array}$ & 0.00013 & 0.00014 & -0.00013 & 0.00011 & $\mathrm{NEG}$ & $\mathrm{NEG}$ & $\mathrm{NEG}$ \\
\hline $\begin{array}{c}\text { Average Solution } \\
\text { Mass }\end{array}$ & -0.00023 & -0.00011 & $\mathrm{NEG}$ & -0.00014 & $\mathrm{NEG}$ & $\mathrm{NEG}$ & $\mathrm{NEG}$ \\
\hline
\end{tabular}

Table 71. Solution Mass, Volume, and Density.

\begin{tabular}{|c|c|c|c|c|}
\hline Case & Mass $(\mathrm{g})$ & $\begin{array}{c}\text { Volume, } \\
\mathrm{T}=28^{\circ} \mathrm{C} \\
\left(\mathrm{cm}^{3}\right)\end{array}$ & $\begin{array}{c}\text { Volume, } \\
\mathrm{T}=22^{\circ} \mathrm{C} \\
\left(\mathrm{cm}^{3}\right)\end{array}$ & $\begin{array}{c}\text { Calculated Solution Density } \\
\text { in Simple Model } \\
\left(\mathrm{g} / \mathrm{cm}^{3}\right)\end{array}$ \\
\hline $1,2,3^{(\mathrm{a})}$ & 3421.5 & 2407.7750 & 2407.7655 & $1.42102^{(\mathrm{b})}$ \\
\hline $4,5,6,7$ & 3420.4 & 2406.9813 & 2406.9717 & $1.42102^{(\mathrm{b})}$ \\
\hline
\end{tabular}

(a) Uses bottles 1, 2, 3, 4, 6, 8, 10, 11, 12, 15, 16, and 17 .

(b) No rounding was done in the computation of the solution density.

\section{C.1.3 Bottle Support Structure Simplifications}

An aluminum 6061 support structure was used to hold the bottle positions constant within the array. Individual bottles were positioned on bottle slider plates which moved on dove-tailed slider rails positioned on side slider plates. The side slider plates could then be moved on dove-tailed slider rails on top of the Plexiglas bottom reflector to change the position of an entire row of bottles. For the detailed model the $11.75-\mathrm{cm} \times 11.75-\mathrm{cm} \times 0.635-\mathrm{cm}$-thick bottle slider plates were modeled as a solid block of aluminum 6061 centered below each bottle. The slider rail was assumed to fit snugly within the dove-tail with minimal gaps. The side slider plates were modeled as being $11.75-\mathrm{cm}$ wide, $0.635-\mathrm{cm}$ thick and extending from one reflector to the reflector opposite. Again the slider rail was assumed to fit snugly within the dove-tail with negligible air gaps. The length of slider rails exposed between the slider plates and the mass of the aluminum spacers between the bottles was assumed to be small and have negligible effect and was not included in the model. Four support rods were attached to each bottle slider plate to hold the bottle securely. These support rods were $0.635-\mathrm{cm}$ in diameter, $10.16-\mathrm{cm}$ tall and made of aluminum 6061. For the simple model the slider plates were homogenized over the entire $1.27-\mathrm{cm}$ thick space below the bottles, within the reflector walls. The support rods were removed and for experiment RSTM-L3-12 the Plexiglas shell was homogenized to fill the grooves in the shells when the support rods were removed. Table 72 summarizes the $\Delta \mathrm{k}_{\text {eff }}$ results of these simplifications.

Revision: 0

Date: September 30, 2012

Page 83 of 142 
NEA/NSC/DOC/(95)03/l

Volume I

PU-SOL-THERM-037

Table 72. $\Delta \mathrm{k}_{\mathrm{eff}}$ for Bottle Support Structure Simplifications.

\begin{tabular}{|c|c|c|c|c|c|c|c|}
\hline Case & 1 & 2 & 3 & 4 & 5 & 6 & 7 \\
\hline Al Support Rods & -0.00031 & -0.00034 & -0.00025 & -0.00011 & -0.00030 & $-0.00045^{(\mathrm{a})}$ & -0.00020 \\
\hline $\begin{array}{c}\text { Homogenized } \\
\text { Slider Plates }\end{array}$ & 0.00013 & NEG & NEG & 0.00026 & NEG & 0.00025 & 0.00015 \\
\hline
\end{tabular}

(a) Case 6 also includes the homogenization of the Plexiglas shell to fill the void space when the support rods were removed.

\section{C.1.4 Removal of Polyethylene Impurities}

An impurity analysis of the polyethylene used in the L-3 bottles was provided in the logbook data of the experimenter (see Table 11). An analysis was performed on three samples from a bottle, one each from the top, the middle and the bottom of the bottle to obtain the impurity analysis. For the detailed model, when an impurity was reported as a detection limit a concentration of one half the reported value was used in the detailed model. Concentrations from the three sections of bottles were averaged for use in the simple model. To determine the effect of removing the impurities the equivalent boron content (EBC) was found for each of the impurities by standard methods as set forth by ASTM International. ${ }^{\text {a }}$ The impurities were then put into 14 different groups. Impurities were grouped together in such a way that the total EBC for any one group was not too large. Table 73 lists the EBCs and the groupings for the impurities.

a ASTM Standard C1233, 2009, "Standard Practice for Determining Equivalent Boron Contents of Nuclear Materials," ASTM International, West Conshohocken, PA, 2003.

Revision: 0

Date: September 30, 2012 
NEA/NSC/DOC/(95)03/l

Volume I

PU-SOL-THERM-037

Table 73. Equivalent Boron Content (EBC) for Polyethylene Impurities.

\begin{tabular}{|c|c|c|}
\hline Impurity & $\mathrm{EBC}(\mathrm{ppm})$ & Group \\
\hline $\mathrm{Pb}$ & $5.59 \mathrm{E}-06$ & \multirow{7}{*}{1} \\
\hline $\mathrm{Rb}$ & $1.20 \mathrm{E}-05$ & \\
\hline $\mathrm{Zr}$ & $1.23 \mathrm{E}-05$ & \\
\hline $\mathrm{Sr}$ & $6.92 \mathrm{E}-05$ & \\
\hline Y & 7.80E-05 & \\
\hline $\mathrm{Nb}$ & $8.36 \mathrm{E}-05$ & \\
\hline $\mathrm{Ga}$ & $8.44 \mathrm{E}-05$ & \\
\hline As & $1.22 \mathrm{E}-04$ & \multirow{9}{*}{2} \\
\hline $\mathrm{Zn}$ & $1.25 \mathrm{E}-04$ & \\
\hline $\mathrm{Br}$ & $1.75 \mathrm{E}-04$ & \\
\hline Mo & $1.80 \mathrm{E}-04$ & \\
\hline $\mathrm{Ni}$ & $2.06 \mathrm{E}-04$ & \\
\hline $\mathrm{Sn}$ & $2.14 \mathrm{E}-04$ & \\
\hline $\mathrm{Ce}$ & $2.43 \mathrm{E}-04$ & \\
\hline V & $2.69 \mathrm{E}-04$ & \\
\hline $\mathrm{Se}$ & $3.01 \mathrm{E}-04$ & \\
\hline $\mathrm{Te}$ & $1.24 \mathrm{E}-03$ & \multirow{7}{*}{3} \\
\hline $\mathrm{Ba}$ & $1.30 \mathrm{E}-03$ & \\
\hline $\mathrm{Mn}$ & $1.64 \mathrm{E}-03$ & \\
\hline I & $1.65 \mathrm{E}-03$ & \\
\hline $\mathrm{Cr}$ & $1.84 \mathrm{E}-03$ & \\
\hline $\mathrm{Cu}$ & $1.85 \mathrm{E}-03$ & \\
\hline $\mathrm{Sb}$ & $1.98 \mathrm{E}-03$ & \\
\hline
\end{tabular}

\begin{tabular}{|c|c|c|}
\hline Impurity & $\mathrm{EBC}(\mathrm{ppm})$ & Group \\
\hline Co & $2.13 \mathrm{E}-03$ & \multirow{5}{*}{4} \\
\hline $\mathrm{Fe}$ & $2.29 \mathrm{E}-03$ & \\
\hline $\mathrm{La}$ & $3.06 \mathrm{E}-03$ & \\
\hline Po & $6.04 \mathrm{E}-03$ & \\
\hline Cs & $8.86 \mathrm{E}-03$ & \\
\hline $\mathrm{Hg}$ & $1.01 \mathrm{E}-02$ & \multirow{5}{*}{5} \\
\hline $\mathrm{Ag}$ & $1.59 \mathrm{E}-02$ & \\
\hline K & $1.82 \mathrm{E}-02$ & \\
\hline $\mathrm{Ca}$ & $3.44 \mathrm{E}-02$ & \\
\hline In & $4.57 \mathrm{E}-02$ & \\
\hline $\mathrm{S}$ & $6.78 \mathrm{E}-02$ & \multirow{3}{*}{6} \\
\hline $\mathrm{Ti}$ & $7.00 \mathrm{E}-02$ & \\
\hline $\mathrm{P}$ & $7.51 \mathrm{E}-02$ & \\
\hline $\mathrm{Nd}$ & $1.09 \mathrm{E}-01$ & \multirow{2}{*}{7} \\
\hline $\mathrm{Si}$ & $1.65 \mathrm{E}-01$ & \\
\hline $\mathrm{Cd}$ & $4.54 \mathrm{E}-01$ & 8 \\
\hline $\mathrm{Al}$ & $7.52 \mathrm{E}-01$ & 9 \\
\hline $\mathrm{Cl}$ & $1.73 E+00$ & 10 \\
\hline $\mathrm{Sm}$ & $6.38 \mathrm{E}+00$ & 11 \\
\hline $\mathrm{Eu}$ & $2.26 \mathrm{E}+01$ & 12 \\
\hline $\mathrm{Gd}$ & $9.04 \mathrm{E}+01$ & 13 \\
\hline $\mathrm{U}$ & - & 14 \\
\hline
\end{tabular}

Revision: 0

Date: September 30, 2012 
NEA/NSC/DOC/(95)03/l

Volume I

PU-SOL-THERM-037

The bias for the removal of each group of impurities can be found in Table 74 .

Table 74. $\Delta \mathrm{k}_{\mathrm{eff}}$ for Removal of Polyethylene Impurities.

\begin{tabular}{|c|c|c|c|c|c|c|c|}
\hline Case & 1 & 2 & 3 & 4 & 5 & 6 & 7 \\
\hline $\begin{array}{c}\text { Group 1- Pb, Rb, Zr, Sr, } \\
\text { Y, Nb, Ga }\end{array}$ & 0.00011 & 0.00011 & NEG & NEG & NEG & NEG & NEG \\
\hline $\begin{array}{c}\text { Group 2- As, Zn, Br, Mo, } \\
\text { Ni, Sn, Ce, V, Se }\end{array}$ & NEG & NEG & 0.00013 & NEG & NEG & NEG & NEG \\
\hline $\begin{array}{c}\text { Group 3- Te, Ba, Mn, I, } \\
\text { Cr, Cu, Sb }\end{array}$ & 0.00011 & NEG & NEG & NEG & NEG & NEG & NEG \\
\hline $\begin{array}{c}\text { Group 4-Co, Fe, La, Po, } \\
\text { Cs }\end{array}$ & NEG & NEG & NEG & NEG & -0.00011 & NEG & NEG \\
\hline $\begin{array}{c}\text { Group 5- Hg, Ag, K, Ca, } \\
\text { In }\end{array}$ & NEG & NEG & NEG & NEG & -0.00011 & NEG & NEG \\
\hline Group 6- S, Ti, P & NEG & 0.00011 & NEG & NEG & NEG & -0.00013 & NEG \\
\hline Group 7- Nd, Si & 0.00015 & NEG & NEG & NEG & NEG & -0.00013 & NEG \\
\hline Group 8- Cd & NEG & 0.00018 & 0.00012 & NEG & NEG & NEG & NEG \\
\hline Group 9- Al & NEG & NEG & NEG & -0.00012 & NEG & NEG & NEG \\
\hline Group 10- Cl & 0.0002 & NEG & NEG & NEG & NEG & NEG & NEG \\
\hline Group 11- Sm & 0.00059 & 0.00066 & 0.00051 & 0.00045 & 0.00041 & 0.00054 & 0.00064 \\
\hline Group 12- Eu & 0.00119 & 0.00112 & 0.00109 & 0.00097 & 0.00093 & 0.00113 & 0.00113 \\
\hline Group 13- Gd & 0.00337 & 0.00331 & 0.00339 & 0.00313 & 0.00317 & 0.00345 & 0.00323 \\
\hline Group 14- U & NEG & NEG & NEG & NEG & NEG & NEG & NEG \\
\hline
\end{tabular}

From these results it was decided to remove all polyethylene impurities except for samarium, europium, and gadolinium. The total bias for the removal of all but these three polyethylene impurities can be found in Table 76.

\section{C.1.5 Removal of Solution Impurities}

For the simple model the solution composition was calculated using concentrations in Table 8 and an adjusted Am-241 content (see Section 2.3.1). The water content was found using the difference in total density of the solution and the concentration of all other elements in the solution. The effect of removing each non-plutonium, uranium, nitrate and water component, henceforth called impurities, from the plutonium nitrate solution was found by replacing each element individually with void. All other atom densities were held constant when an impurity was removed which changed the total atom density of the solution. Results of this analysis can be seen in Table 75. Additional impurities, calcium, cobalt, titanium, and vanadium, not given in Reference 1 were possibly present in the solution as is evident in Table 10. These additional impurities were not included in the detailed model or the simple model because it is not believed that they were actually present in the solution thus no bias analysis was completed for them but an uncertainty analysis was performed and can be found in Section 2.3.1. The uncertainty associated with these additional impurities is summarized in Table 29.

Revision: 0

Date: September 30, 2012

Page 86 of 142 


\section{NEA/NSC/DOC/(95)03/l}

Volume I

PU-SOL-THERM-037

Table 75. $\Delta \mathrm{k}_{\mathrm{eff}}$ for Removal of Solution Impurities.

\begin{tabular}{|l|c|c|c|c|c|c|c|}
\hline \multicolumn{1}{|c|}{ Case } & 1 & 2 & 3 & 4 & 5 & 6 & 7 \\
\hline Iron & 0.00020 & 0.00015 & NEG & 0.00012 & 0.00030 & NEG & NEG \\
\hline Chromium & 0.00016 & NEG & -0.00016 & NEG & NEG & NEG & NEG \\
\hline Nickel & NEG & NEG & NEG & NEG & 0.00011 & NEG & NEG \\
\hline Aluminum & -0.00026 & -0.00018 & -0.00024 & -0.00021 & NEG & -0.00026 & -0.00015 \\
\hline Manganese & 0.00023 & NEG & 0.00024 & 0.00024 & 0.00028 & 0.00018 & 0.00018 \\
\hline Cadmium & NEG & NEG & NEG & NEG & NEG & NEG & NEG \\
\hline Boron & 0.00257 & 0.00253 & 0.00262 & 0.00254 & 0.00265 & 0.00249 & 0.00253 \\
\hline Am-241 & 0.00117 & 0.00108 & 0.00095 & 0.00103 & 0.00122 & 0.00108 & 0.00115 \\
\hline
\end{tabular}

From these results it was decided to remove all solution impurities except for boron and Americium-241. The total simplification bias for removing the solution impurities can be found in Table 76 .

\section{C.1.6 Total Bias Results}

A summary of all biases is included as Table 76. As can be seen in Figure 16 the overall, or total, bias was found by comparing the detailed model to the simple model. Biases were considered negligible (NEG) if the $\Delta \mathrm{k}_{\text {eff }}$ was less than 0.00010 .

Revision: 0

Date: September 30, 2012 
NEA/NSC/DOC/(95)03/l

Volume I

PU-SOL-THERM-037

Table 76. Summary of Simplification Biases.

\begin{tabular}{|c|c|c|c|c|c|c|c|}
\hline Case & 1 & 2 & 3 & 4 & 5 & 6 & 7 \\
\hline Honeycomb & -0.00012 & NEG & NEG & NEG & NEG & NEG & NEG \\
\hline Split Table & NEG & NEG & -0.00012 & NEG & NEG & NEG & NEG \\
\hline Hood & NEG & -0.00015 & -0.0002 & -0.00018 & -0.00017 & -0.00019 & -0.00031 \\
\hline Room & NEG & NEG & NEG & -0.00014 & -0.00022 & NEG & NEG \\
\hline $\begin{array}{c}\text { Replace Air } \\
\text { with Void }\end{array}$ & NEG & NEG & -0.00017 & NEG & NEG & NEG & -0.00013 \\
\hline $\begin{array}{c}\text { Homogenize } \\
\text { Bottom of } \\
\text { Bottle }\end{array}$ & -0.00015 & NEG & -0.00010 & -0.00017 & -0.00022 & NEG & NEG \\
\hline $\begin{array}{c}\text { Average } \\
\text { Bottle } \\
\text { Diameter }\end{array}$ & NEG & NEG & NEG & NEG & NEG & NEG & 0.00013 \\
\hline $\begin{array}{c}\text { Average } \\
\text { Solution } \\
\text { Volume }\end{array}$ & 0.00013 & 0.00014 & -0.00013 & 0.00011 & NEG & NEG & NEG \\
\hline $\begin{array}{c}\text { Average } \\
\text { Solution } \\
\text { Mass }\end{array}$ & -0.00023 & -0.00011 & NEG & -0.00014 & NEG & NEG & NEG \\
\hline $\begin{array}{c}\text { Al Support } \\
\text { Rods }\end{array}$ & -0.00031 & -0.00034 & -0.00025 & -0.00011 & -0.00030 & $-0.00045^{(\mathrm{a})}$ & -0.00020 \\
\hline $\begin{array}{c}\text { Homogenize } \\
\text { Slider Plates }\end{array}$ & 0.00013 & NEG & NEG & 0.00026 & NEG & 0.00025 & 0.00015 \\
\hline $\begin{array}{c}\text { Polyethylene } \\
\text { Impurities }\end{array}$
\end{tabular}

(a) Case 6 also includes the homogenization of the Plexiglas shell to fill the void space when the spacers were removed.

(b) All impurities except samarium, europium, and gadolinium were removed and replaced with void for this bias.

(c) All impurities except boron and americium-241 were replaced with void for this bias.

(d) The total bias was found by comparing the $\mathrm{k}_{\mathrm{eff}}$ of the detailed model to the $\mathrm{k}_{\mathrm{eff}}$ of the simple model.

Revision: 0

Date: September 30, 2012 
NEA/NSC/DOC/(95)03/l

Volume I

PU-SOL-THERM-037

\section{C.2 Dimensions}

Simple models were created for seven of the experiments (RSTM-L3-3, 4, 5, 6, 7, 12, and 13). These models consisted of 12 or 16 bottles filled with plutonium nitrate solution, a homogenized volume of aluminum below each bottle array, and five Plexiglas reflectors. RSTM-L3-12, Case 6, also included Plexiglas shells around each bottle to simulate interstitial moderation. Each part of the simple model is described in Section C.2.1-C.2.3 with material data found in Section C.3.

\section{C.2.1 Bottle Dimensions}

Every bottle in the simple model was identical. The effect of making all the bottles identical can be found in Section C.1.2. Figure 17 shows dimensions used for the simple model of the L-3 bottles. All dimensions in Figure 17 were derived from Figure 1 except for the bottle diameters which were from Table 1 and the average solution height which was calculated from values in Table 2 . The vent cap shown in Figure 1 was not modeled in either the detailed or simple model and the outer diameter of the cap rather than the wall thickness of the cap was used. It is believed that the wall thickness shown differs from the wall thickness calculated using the cap and neck diameters due to threading on the neck and other intricacies of the cap not depicted in Figure 1. The homogenizations of the bottom and top of the bottle are discussed in Section 2.2.1.

Revision: 0

Date: September 30, 2012 
NEA/NSC/DOC/(95)03/l

Volume I

PU-SOL-THERM-037

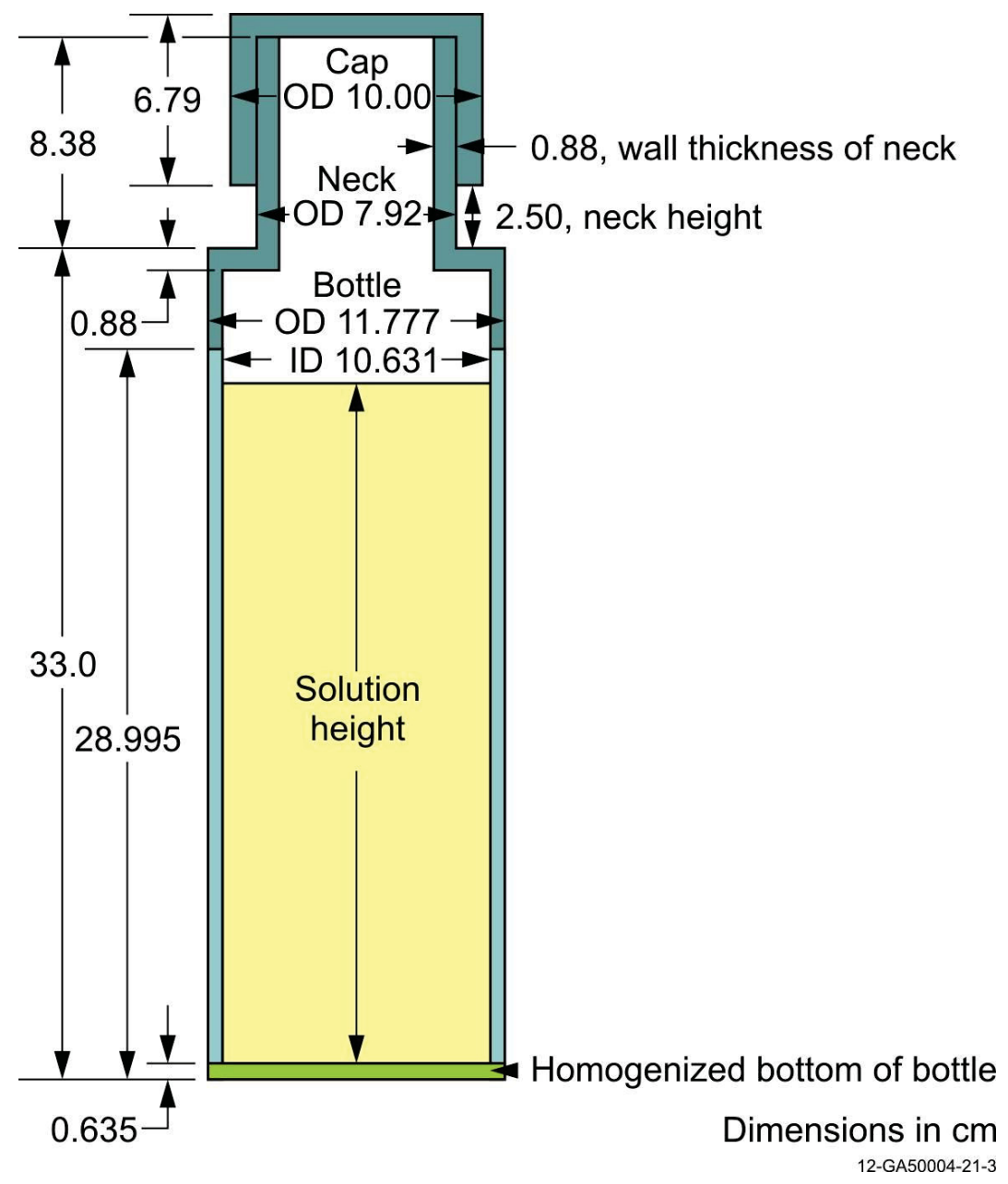

Figure 17. Simple Model Bottle Dimensions

Because Case 1, 2, and 3 used only 12 of the 16 bottles the average solution volume, mass, and thus solution height for these three experiments were slightly different than for the other four experiments. Table 77 shows the solution heights for the 12- and 16-bottle configurations.

Revision: 0

Date: September 30, 2012 
NEA/NSC/DOC/(95)03/l

Volume I

PU-SOL-THERM-037

Table 77. Solution Height.

\begin{tabular}{|c|c|}
\hline Case & Solution Height \\
\hline $1,2,3^{(\mathrm{a})}$ & 27.12539 \\
\hline $4,5,6,7$ & 27.11645 \\
\hline
\end{tabular}

(a) Uses bottles 1, 2, 3, 4, 6, 8, 10, 11, $12,15,16$, and 17 .

These solution heights were calculated using the inside diameter of the bottles and the solution volumes at $22^{\circ} \mathrm{C}$.

\section{C.2.2 Array Spacing}

The extrapolated array spacings for the bottles were taken from the experimenter's logbook, see Table 6. All other array spacings, whether touching or held at constant spacings, were taken from the approach-tocritical logbook, see Table 7. Table 78 shows the bottle-to-bottle surface array spacing, except for Case 6 which is shell to shell surface array spacing, and the distance between the reflector walls used in the simple models. Figures 18, 19, 20 and 21 show the array setup of the simple models.

Table 78. Array Spacing. ${ }^{(a)}$

\begin{tabular}{|c|c|c|c|c|}
\hline Case & $\begin{array}{c}x \text { Spacing } \\
(\mathrm{cm})\end{array}$ & $\begin{array}{c}y \text { Spacing } \\
(\mathrm{cm})\end{array}$ & $\begin{array}{c}\mathbf{X} \\
(\mathrm{cm})\end{array}$ & $\begin{array}{c}\mathbf{Y} \\
(\mathrm{cm})\end{array}$ \\
\hline 1 & 0 & 0.49187 & 35.33100 & 48.58361 \\
\hline 2 & 0.33020 & 0.36132 & 35.99140 & 48.19196 \\
\hline 3 & 0.58486 & 0 & 36.50072 & 47.10800 \\
\hline 4 & 0 & 1.92265 & 47.10799 & 52.87595 \\
\hline 5 & 1.25730 & 0.70884 & 50.81016 & 49.23452 \\
\hline 6 & 0 & 1.24043 & 50.81016 & 54.53145 \\
\hline 7 & 0.68580 & 1.20386 & 49.16540 & 50.71958 \\
\hline
\end{tabular}

(a) Spacings are bottle-to-bottle surface except Case 6 which is shell to shell surface. Extrapolated spacings are highlighted.

Revision: 0

Date: September 30, 2012 
NEA/NSC/DOC/(95)03/l

Volume I

PU-SOL-THERM-037

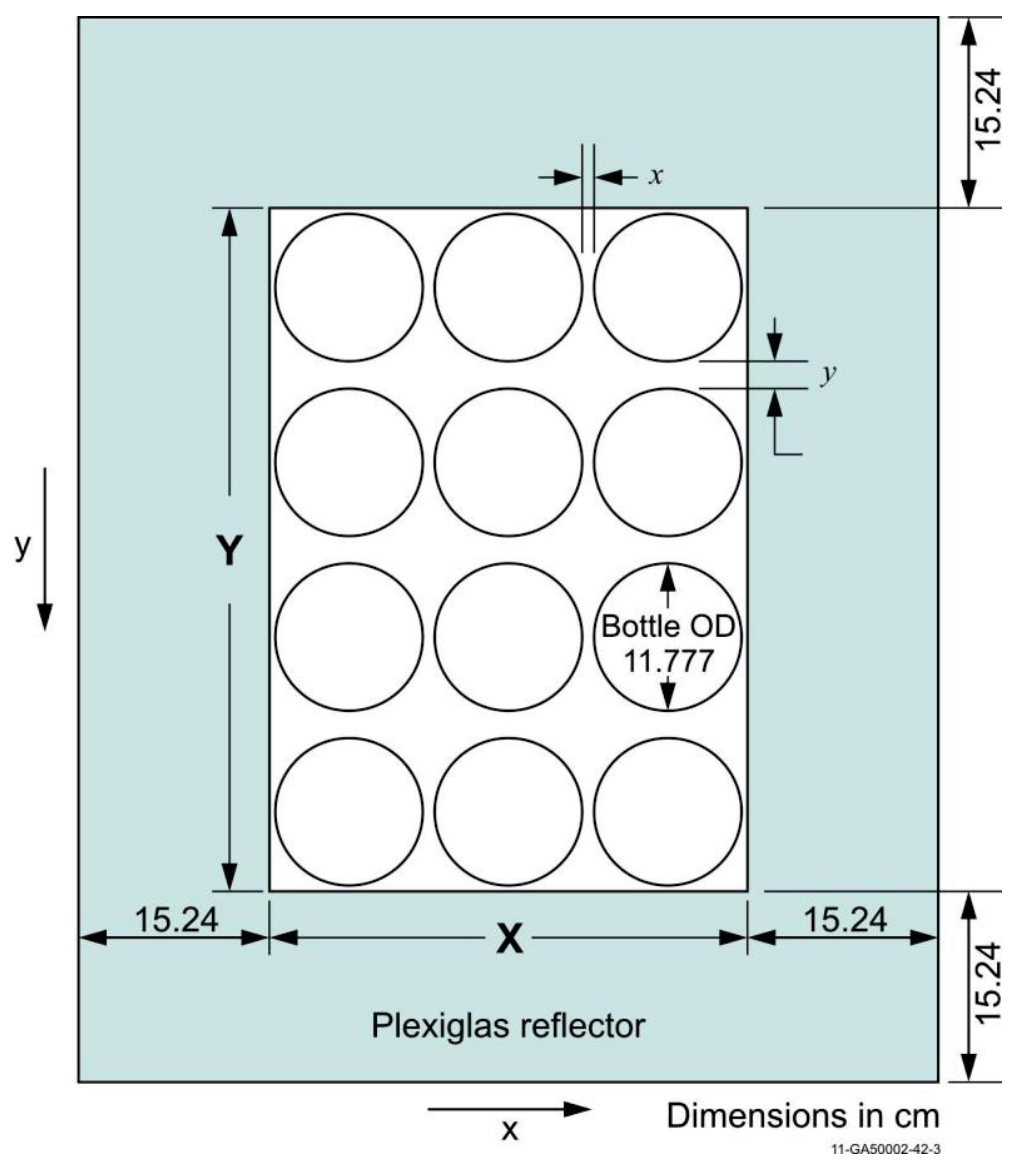

Figure 18. Array Setup for Cases 1, 2, and 3. 


\section{NEA/NSC/DOC/(95)03/l \\ Volume I}

PU-SOL-THERM-037

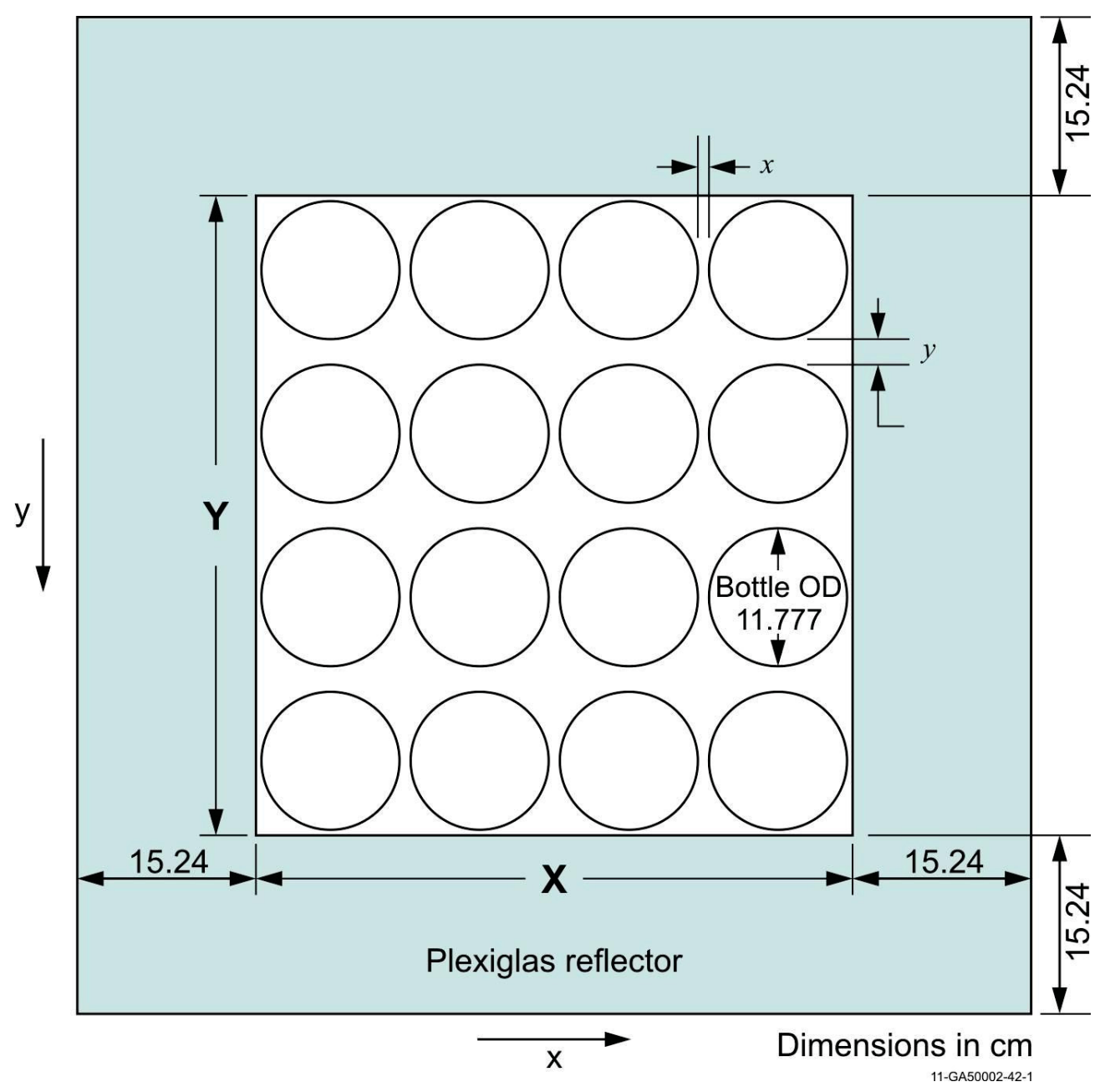

Figure 19. Array Setup for Cases 4, 5, and 7. 


\section{NEA/NSC/DOC/(95)03/I \\ Volume I}

PU-SOL-THERM-037

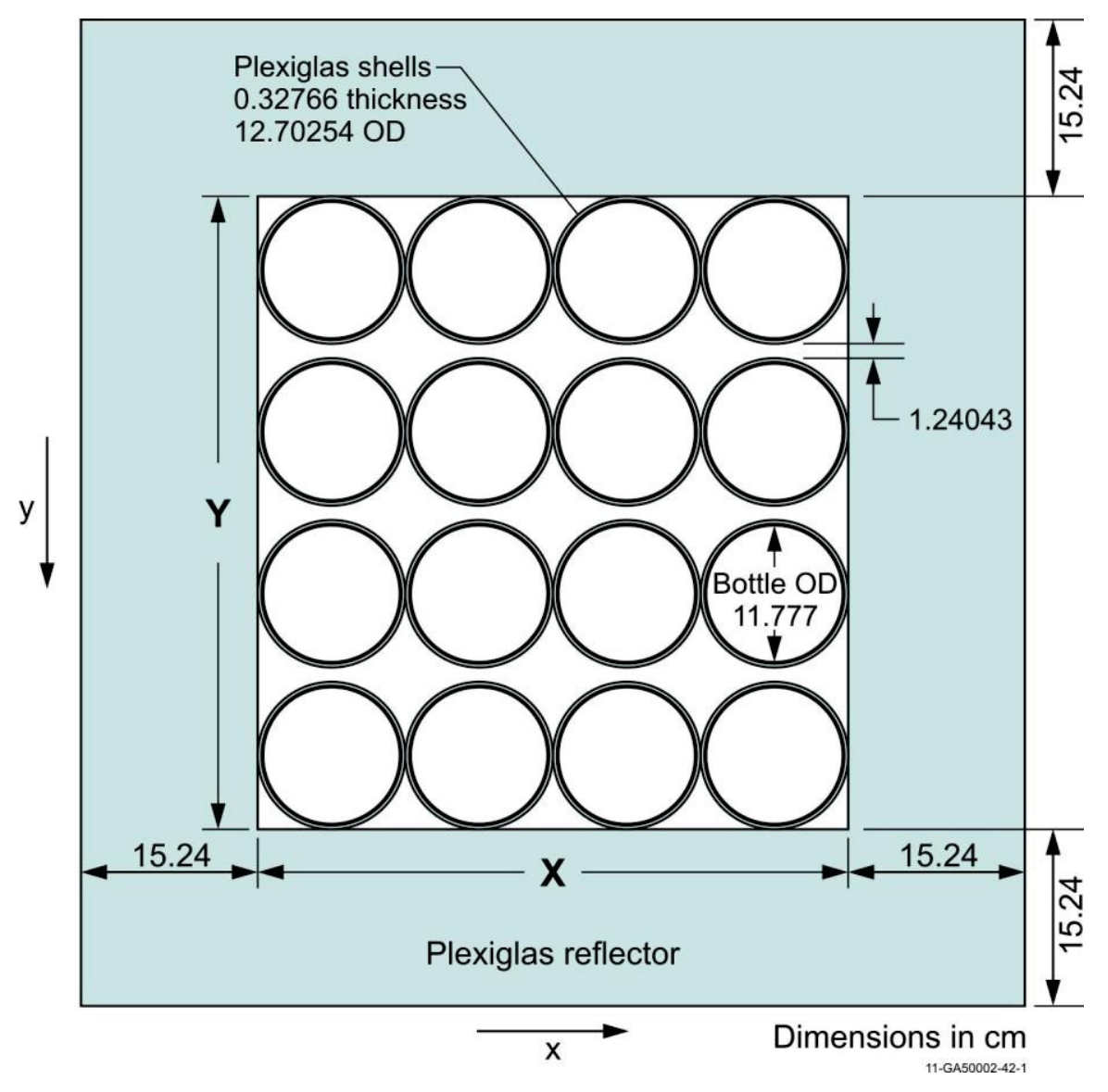

Figure 20. Array Setup for Case 6. 


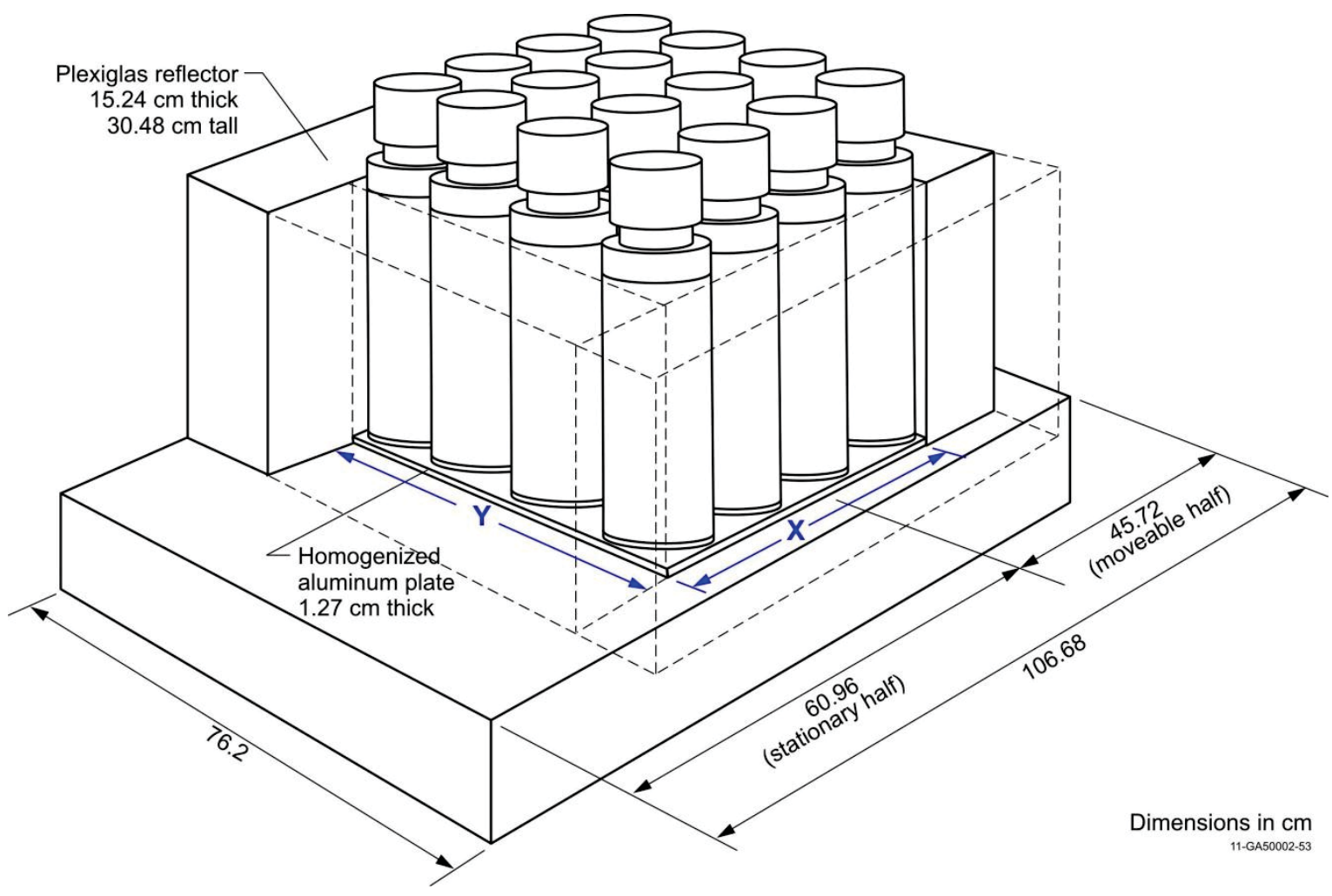

Figure 21. Isometric Drawing of Simple Model Array Setup.

\section{C.2.3 Shells, Support Structure, and Reflectors}

RSTM-L3-12 (Case 6) had Plexiglas shells surrounding each bottle. These shells were modeled with an outer diameter of $12.70254 \mathrm{~cm}$, a thickness of $0.32766 \mathrm{~cm}$, and a height of $30.48 \mathrm{~cm}$. These values were taken from Table 3 (diameter and thickness) and Figure 3 (height).

The aluminum support structure for the bottles was simplified to a solid mass of homogenized aluminum below the bottles. The mass was $1.27-\mathrm{cm}$ thick and went from reflector inside wall to reflector inside wall.

The side-Plexiglas reflectors sat on the bottom-Plexiglas reflector and were pushed flush against the outside of the bottle array and were each $15.24-\mathrm{cm}$ thick and $30.48-\mathrm{cm}$. tall. The bottom reflector was $14.92-\mathrm{cm}$ thick and was modeled as being as wide and as long as the aluminum honeycomb structure of the RSTM. Thus the model has the bottom reflector as being $76.2-\mathrm{cm}$ wide and $106.68-\mathrm{cm}$ long when the table is closed, $60.96 \mathrm{~cm}$ on the stationary side and $45.72 \mathrm{~cm}$ on the moveable side. Bottles were arranged on the table such that a $2 \times 4$ array of bottles was on the stationary side and the rest were on the moveable side.

Revision: 0

Date: September 30, 2012 


\section{NEA/NSC/DOC/(95)03/l}

Volume I

PU-SOL-THERM-037

\section{C.3 Material Data}

\section{C.3.1 Solution}

To find the atom densities of the plutonium solution the Am-241 content was adjusted (see Section 2.3.1), the solution volume was corrected for temperature (see Section 2.3.2), the solution volume and mass were averaged (see Section C.1.2), and impurities were replaced with void (see Section C.1.5). The isotopic distribution for plutonium in Table 9 and natural isotopic distributions for uranium and boron were used in the simple model. Table 79 gives the atom densities for the solution.

Table 79. Solution Atom Densities. ${ }^{(a)}$

\begin{tabular}{|c|c|}
\hline Isotope $^{(\mathrm{a})}$ & $\begin{array}{l}\text { Atom Density } \\
\text { (atom/barn-cm) }\end{array}$ \\
\hline $\mathrm{Pu}-238$ & $2.9219 \mathrm{E}-08$ \\
\hline $\mathrm{Pu}-239$ & $2.5642 \mathrm{E}-04$ \\
\hline $\mathrm{Pu}-240$ & 7.5914E-06 \\
\hline $\mathrm{Pu}-241$ & $3.1215 \mathrm{E}-07$ \\
\hline $\mathrm{Pu}-242$ & $1.2016 \mathrm{E}-07$ \\
\hline U-234 $4^{(\mathrm{b})}$ & $4.3136 \mathrm{E}-10$ \\
\hline $\mathrm{U}-235^{(\mathrm{b})}$ & $5.6469 \mathrm{E}-08$ \\
\hline U-238 $8^{(\mathrm{b})}$ & $7.7861 \mathrm{E}-06$ \\
\hline $\mathrm{O}$ & 4.1099E-02 \\
\hline $\mathrm{N}$ & 4.9047E-03 \\
\hline $\mathrm{H}$ & $5.5841 \mathrm{E}-02$ \\
\hline B-10 $0^{(\mathrm{b})}$ & $5.5425 \mathrm{E}-08$ \\
\hline $\mathrm{B}-11^{(\mathrm{b})}$ & $2.2309 \mathrm{E}-07$ \\
\hline Am-241 & $4.2910 \mathrm{E}-07$ \\
\hline Total & $1.0212 \mathrm{E}-01$ \\
\hline
\end{tabular}

(a) All solution impurities except B and Am-241 were replaced with void.

(b) Assuming a natural isotopic distribution.

Revision: 0

Date: September 30, 2012 


\section{NEA/NSC/DOC/(95)03/l}

Volume I

PU-SOL-THERM-037

\section{C.3.2 Polyethylene}

The bottles were composed of polyethylene. The bottoms and tops of the bottles were homogenized in the simple model (see Section 2.2.1). Table 80 summarizes the polyethylene atom densities.

Table C.3-2. Polyethylene Atom Densities.

\begin{tabular}{|c|c|c|c|}
\hline \multirow{2}{*}{ Isotope } & & \multicolumn{2}{|c|}{$\begin{array}{c}\text { Homogenized Atom Density } \\
\text { (atom/barn-cm) }\end{array}$} \\
\cline { 3 - 4 } & $\begin{array}{c}\text { Atom Density } \\
\text { (atom/barn-cm) }\end{array}$ & $\begin{array}{c}\text { Bottom of the } \\
\text { Bottle }\end{array}$ & $\begin{array}{c}\text { Upper Part of the } \\
\text { Bottle }\end{array}$ \\
\hline $\mathrm{H}$ & $8.7852 \mathrm{E}-02$ & $6.4068 \mathrm{E}-02$ & $6.2673 \mathrm{E}-02$ \\
\hline $\mathrm{C}$ & $4.1274 \mathrm{E}-02$ & $3.0100 \mathrm{E}-02$ & $2.9445 \mathrm{E}-02$ \\
\hline Sm & $4.6886 \mathrm{E}-08$ & $3.4193 \mathrm{E}-08$ & $3.3448 \mathrm{E}-08$ \\
\hline Eu & $2.0660 \mathrm{E}-07$ & $1.5067 \mathrm{E}-07$ & $1.4739 \mathrm{E}-07$ \\
\hline Gd & $7.7111 \mathrm{E}-08$ & $5.6235 \mathrm{E}-08$ & $5.5010 \mathrm{E}-08$ \\
\hline Total & $1.2913 \mathrm{E}-01$ & $9.4168 \mathrm{E}-02$ & $9.2118 \mathrm{E}-02$ \\
\hline Homogenization & 1.000 & 0.729 & 0.713 \\
\hline Factor & & & \\
\hline
\end{tabular}

(a) All impurities except $\mathrm{Sm}, \mathrm{Eu}$, and Gd were replaced with void.

\section{C.3.3 Plexiglas}

The composition of Plexiglas is given in Table 12. The calculated atom densities for Plexiglas are given in Table 81.

Table 80. Plexiglas Composition.

\begin{tabular}{|c|c|c|}
\hline Element & $\begin{array}{c}\text { Atom Density } \\
\text { (atom/barn-cm) }\end{array}$ & $\begin{array}{c}\text { Homogenized Plexiglas } \\
\text { Shell Atom Density for Case 6 } \\
\text { (atom/barn-cm) }\end{array}$ \\
\hline $\mathrm{C}$ & $3.5648 \mathrm{E}-02$ & $3.4467 \mathrm{E}-02$ \\
\hline $\mathrm{H}$ & $5.6642 \mathrm{E}-02$ & $5.4764 \mathrm{E}-02$ \\
\hline $\mathrm{O}$ & $1.4273 \mathrm{E}-02$ & $1.3800 \mathrm{E}-02$ \\
\hline Total & $1.0656 \mathrm{E}-01$ & $1.0303 \mathrm{E}-01$ \\
\hline $\begin{array}{c}\text { Homogenization } \\
\text { Factor }\end{array}$ & 1.000 & 0.9667 \\
\hline
\end{tabular}

Revision: 0

Date: September 30, 2012 


\section{NEA/NSC/DOC/(95)03//}

Volume I

PU-SOL-THERM-037

\section{C.3.4 Aluminum}

The aluminum 6061 composition used in the simple model was based on the aluminum 6061 data shown in Table 68. The aluminum 6061 density had to be adjusted for each case because of the homogenization of the slider plates over the entire volume below the bottles and inside the Plexiglas reflectors. The calculated aluminum 6061 atom densities for each case are shown in Table 82.

Table 81. Al 6061 Composition.

\begin{tabular}{|c|c|c|c|c|}
\hline \multirow[t]{2}{*}{ Element } & \multirow{2}{*}{$\begin{array}{l}\text { Atom Density } \\
\text { (atom/barn-cm) }\end{array}$} & \multicolumn{3}{|c|}{$\begin{array}{l}\text { Homogenized Slider Plate Atom Density } \\
\text { (atom/barn-cm) }\end{array}$} \\
\hline & & Case 1 & Case 2 & Case 3 \\
\hline $\mathrm{Al}$ & $5.8638 \mathrm{E}-02$ & $5.7596 \mathrm{E}-02$ & $5.6765 \mathrm{E}-02$ & $5.6608 \mathrm{E}-02$ \\
\hline $\mathrm{Cr}$ & $6.0978 \mathrm{E}-05$ & $5.9895 \mathrm{E}-05$ & $5.9030 \mathrm{E}-05$ & $5.8867 \mathrm{E}-05$ \\
\hline $\mathrm{Cu}$ & $7.0365 \mathrm{E}-05$ & $6.9114 \mathrm{E}-05$ & $6.8117 \mathrm{E}-05$ & $6.7929 \mathrm{E}-05$ \\
\hline $\mathrm{Fe}$ & $1.0190 \mathrm{E}-04$ & $1.0009 \mathrm{E}-04$ & $9.8646 \mathrm{E}-05$ & $9.8374 \mathrm{E}-05$ \\
\hline $\mathrm{Mg}$ & $6.6898 \mathrm{E}-04$ & $6.5709 \mathrm{E}-04$ & $6.4761 \mathrm{E}-04$ & $6.4582 \mathrm{E}-04$ \\
\hline $\mathrm{Mn}$ & $2.2197 \mathrm{E}-05$ & $2.1803 \mathrm{E}-05$ & $2.1488 \mathrm{E}-05$ & $2.1429 \mathrm{E}-05$ \\
\hline $\mathrm{Si}$ & $3.4736 \mathrm{E}-04$ & $3.4119 \mathrm{E}-04$ & $3.3626 \mathrm{E}-04$ & $3.3534 \mathrm{E}-04$ \\
\hline $\mathrm{Ti}$ & $2.5469 \mathrm{E}-05$ & $2.5017 \mathrm{E}-05$ & $2.4656 \mathrm{E}-05$ & $2.4588 \mathrm{E}-05$ \\
\hline $\mathrm{Zn}$ & 3.1082E-05 & $3.0530 \mathrm{E}-05$ & $3.0089 \mathrm{E}-05$ & $3.0006 \mathrm{E}-05$ \\
\hline Total & 5.9967E-02 & $5.8901 \mathrm{E}-02$ & $5.8051 \mathrm{E}-02$ & $5.7891 \mathrm{E}-02$ \\
\hline $\begin{array}{l}\text { Homogenization } \\
\text { Factor }\end{array}$ & 1.000 & 0.9822 & 0.9681 & 0.9654 \\
\hline \multirow[t]{2}{*}{ Element } & \multicolumn{4}{|c|}{$\begin{array}{l}\text { Homogenized Slider Plate Atom Density } \\
\text { (atom/barn-cm) }\end{array}$} \\
\hline & Case 4 & Case 5 & Case 6 & Case 7 \\
\hline $\mathrm{Al}$ & $5.5299 \mathrm{E}-02$ & $5.2980 \mathrm{E}-02$ & $5.0408 \mathrm{E}-02$ & $5.4044 \mathrm{E}-02$ \\
\hline $\mathrm{Cr}$ & $5.7506 \mathrm{E}-05$ & $5.5094 \mathrm{E}-05$ & $5.2420 \mathrm{E}-05$ & $5.6201 \mathrm{E}-05$ \\
\hline $\mathrm{Cu}$ & $6.6358 \mathrm{E}-05$ & $6.3575 \mathrm{E}-05$ & $6.0489 \mathrm{E}-05$ & $6.4852 \mathrm{E}-05$ \\
\hline $\mathrm{Fe}$ & $9.6098 \mathrm{E}-05$ & $9.2068 \mathrm{E}-05$ & $8.7599 \mathrm{E}-05$ & $9.3917 \mathrm{E}-05$ \\
\hline $\mathrm{Mg}$ & $6.3089 \mathrm{E}-04$ & $6.0443 \mathrm{E}-04$ & $5.7509 \mathrm{E}-04$ & $6.1657 \mathrm{E}-04$ \\
\hline $\mathrm{Mn}$ & $2.0933 \mathrm{E}-05$ & $2.0055 \mathrm{E}-05$ & $1.9082 \mathrm{E}-05$ & $2.0458 \mathrm{E}-05$ \\
\hline $\mathrm{Si}$ & $3.2758 \mathrm{E}-04$ & $3.1384 \mathrm{E}-04$ & $2.9861 \mathrm{E}-04$ & $3.2015 \mathrm{E}-04$ \\
\hline $\mathrm{Ti}$ & $2.4019 \mathrm{E}-05$ & $2.3012 \mathrm{E}-05$ & $2.1895 \mathrm{E}-05$ & $2.3474 \mathrm{E}-05$ \\
\hline $\mathrm{Zn}$ & $2.9312 \mathrm{E}-05$ & $2.8083 \mathrm{E}-05$ & $2.6720 \mathrm{E}-05$ & $2.8647 \mathrm{E}-05$ \\
\hline Total & $5.6552 \mathrm{E}-02$ & $5.4180 \mathrm{E}-02$ & $5.1550 \mathrm{E}-02$ & $5.5268 \mathrm{E}-02$ \\
\hline $\begin{array}{c}\text { Homogenization } \\
\text { Factor }\end{array}$ & 0.9431 & 0.9035 & 0.8596 & 0.9217 \\
\hline
\end{tabular}

Revision: 0

Date: September 30, 2012 


\section{NEA/NSC/DOC/(95)03//}

Volume I

PU-SOL-THERM-037

\section{C.4 Temperature Data}

The simple model temperature is $22^{\circ} \mathrm{C}$.

\section{C.5 Simple Model $\mathbf{k}_{\text {eff }}$ and Uncertainties}

The experimental configurations were extrapolated to critical; therefore, the experimental $\mathrm{k}_{\mathrm{eff}}$ is 1.0000 . The expected $\mathrm{k}_{\mathrm{eff}} \mathrm{s}$ are shown in Table 83, accounting for the simplification biases from Table 76 . The total experimental uncertainties, from Table 59 in Section 2, are summarized in Table 83.

Table 82. Expected Experimental Eigenvalues.

\begin{tabular}{|c|ccc|}
\hline Case & \multicolumn{3}{|c|}{ Expected $\mathrm{k}_{\text {eff }}$} \\
\hline 1 & 0.9978 & \pm & 0.0170 \\
\hline 2 & 0.9979 & \pm & 0.0175 \\
\hline 3 & 0.9980 & \pm & 0.0169 \\
\hline 4 & 0.9978 & \pm & 0.0171 \\
\hline 5 & 0.9975 & \pm & 0.0189 \\
\hline 6 & 0.9979 & \pm & 0.0183 \\
\hline 7 & 0.9977 & \pm & 0.0172 \\
\hline
\end{tabular}

Revision: 0

Date: September 30, 2012 


\section{NEA/NSC/DOC/(95)03//}

Volume I

\section{PU-SOL-THERM-037}

\section{APPENDIX D: SAMPLE CALCULATION RESULTS}

Simple models were created for MCNP5 and KENO-VI. ENDF/B-VII.0 continuous energy neutron cross section libraries were used for both codes. Within the MCNP5 model a water $\mathrm{S}(\alpha, \beta)$ thermal scatter treatment was used for the solution, a polyethylene $S(\alpha, \beta)$ thermal scatter treatment was used for the polyethylene and Plexiglas, and an aluminum $S(\alpha, \beta)$ thermal scatter treatment was used for aluminum. Example input files can be found in Appendix G. Results of sample calculation for these models can be found in Table 84. The MCNP5 results range from $1.2 \sigma$ to $2.1 \sigma$ above the expected results. It is unclear why the calculated $\mathrm{k}_{\text {eff }}$ values are so much greater than the expected eigenvalues.

Table 83. Sample Calculation Results for Simple Model.

\begin{tabular}{|c|c|c|c|c|c|c|c|c|c|}
\hline \multirow[t]{2}{*}{ Case } & \multirow[t]{2}{*}{ RSTM-L3- } & \multicolumn{4}{|c|}{$\begin{array}{c}\text { MCNP5 } \\
(\text { ENDF/B-VII.0) }\end{array}$} & \multicolumn{4}{|c|}{$\begin{array}{c}\text { KENO-VI }^{(\mathrm{b})} \\
\text { (continuous energy }^{(\mathrm{c})} \\
\text { ENDF/B-VII.0) }\end{array}$} \\
\hline & & $\mathrm{k}_{\mathrm{eff}}$ & \pm & $\sigma_{\mathrm{MCNP}}$ & $\frac{C-E}{E}(\mathrm{~d})$ & $\mathrm{k}_{\mathrm{eff}}$ & \pm & $\sigma_{\mathrm{MCNP}}$ & $\frac{C-E}{E}$ (d) \\
\hline 1 & 3 & 1.03410 & \pm & 0.00005 & $3.64 \%$ & 1.02758 & \pm & 0.00026 & $2.98 \%$ \\
\hline 2 & 4 & 1.02848 & \pm & 0.00005 & $3.06 \%$ & 1.02185 & \pm & 0.00023 & $2.40 \%$ \\
\hline 3 & 5 & 1.03377 & \pm & 0.00005 & $3.58 \%$ & 1.02746 & \pm & 0.00022 & $2.95 \%$ \\
\hline 4 & 6 & 1.03293 & \pm & 0.00005 & $3.52 \%$ & 1.02636 & \pm & 0.00026 & $2.86 \%$ \\
\hline 5 & 7 & 1.02929 & \pm & 0.00005 & $3.19 \%$ & 1.02269 & \pm & 0.00020 & $2.53 \%$ \\
\hline 6 & 12 & 1.01983 & \pm & 0.00004 & $2.20 \%$ & 1.01120 & \pm & 0.00024 & $1.33 \%$ \\
\hline 7 & 13 & 1.03184 & \pm & 0.00005 & $3.42 \%$ & 1.02513 & \pm & 0.00029 & $2.75 \%$ \\
\hline
\end{tabular}

(a) Run using 4000 cycles, skipping the first 100 cycles, with 100,000 histories or particles per cycle.

(b) Results provided by John D. Bess of Idaho National Laboratory.

(c) Run using 155 cycles, skipping the first 5 cycles, with 100,000 histories or particles per cycle.

(d) $C$ is the calculated $\mathrm{k}_{\text {eff }}$ and $E$ is the benchmark (or expected) $\mathrm{k}_{\text {eff. }}$

Revision: 0

Date: September 30, 2012 
NEA/NSC/DOC/(95)03/l

Volume I

PU-SOL-THERM-037

\section{APPENDIX E: SOLUTION ATOM DENSITY CALCULATION}

The following equations were used in the calculation of the solution atom densities.

$$
\begin{aligned}
& \rho_{\text {solution }}=\frac{m_{\text {sol }}}{V_{\text {ol }}} \\
& \rho_{\text {water }}=\rho_{\text {solution }}-\sum_{k} \rho_{k} \\
& N_{P u-i}\left[\frac{\text { atom }}{\text { barn } \cdot \mathrm{cm}}\right] \\
& =\frac{\rho_{P u}\left[\frac{g}{L}\right] \cdot w t_{P u-i}^{\%}}{A W_{P u-i}\left[\frac{g}{m o l}\right]} \cdot 0.001\left[\frac{L}{\mathrm{~cm}^{3}}\right] \cdot \frac{6.02 \times 10^{23}\left[\frac{\text { atom }}{\mathrm{mol}}\right]}{1 \times 10^{-24}\left[\frac{\mathrm{cm}^{2}}{b a r n}\right]} \\
& N_{k-i}\left[\frac{\text { atom }}{\mathrm{barn} \cdot \mathrm{cm}}\right] \\
& =\frac{\rho_{k}\left[\frac{g}{L}\right] \cdot w t_{P u-i}^{\%}}{A W_{k}\left[\frac{g}{\mathrm{~mol}}\right]} \cdot 0.001\left[\frac{L}{\mathrm{~cm}^{3}}\right] \cdot \frac{6.02 \times 10^{23}\left[\frac{\text { atom }}{\mathrm{mol}}\right]}{1 \times 10^{-24}\left[\frac{\mathrm{cm}^{2}}{\mathrm{barn}}\right]} \\
& N_{O}=N_{\mathrm{H}_{2} \mathrm{O}}+3 \mathrm{~N}_{\mathrm{NO}_{3}} \\
& N_{H}=2 N_{H_{2} O}+N_{H^{+}} \\
& N_{N}=N_{N O_{3}}
\end{aligned}
$$

where:

\begin{tabular}{|c|l|}
\hline$m_{\text {sol }}$ & Solution mass \\
\hline Vol $_{\text {sol }}$ & Solution volume \\
\hline$\rho_{\text {solution }}$ & Solution density \\
\hline$\rho_{\text {water }}$ & Water density \\
\hline & Density of kth constituent of solution: \\
& $\cdot$ Plutonium \\
& $\cdot$ Uranium \\
& $\cdot$ Nitrate \\
& $\cdot$ Iron \\
& $\cdot$ Chromium \\
$\rho_{k}$ & $\cdot$ Nickel \\
& $\cdot$ Aluminum \\
& . Manganese \\
\hline
\end{tabular}

Revision: 0

Date: September 30, 2012

Page 101 of 142 
NEA/NSC/DOC/(95)03/l

Volume I

PU-SOL-THERM-037

\begin{tabular}{|c|c|}
\hline & $\begin{array}{ll}\text { · } & \text { Cadmium } \\
\text {. } & \text { Boron } \\
\text {. } & \text { Am-241 } \\
\text {. } & \text { Free H+ Ion } \\
\text {. Water- the density of water is NOT } & \\
\text { included in the summation in } \\
\text { Equation E.2 }\end{array}$ \\
\hline$N_{P u-i}$ & Atom density of $i^{\text {th }}$ Plutonium isotope. \\
\hline$A W_{P u-i}$ & Atomic weight of $i^{\text {th }}$ Plutonium isotope. \\
\hline$w t_{P u-i}^{\%}$ & Weight percent of $i^{\text {th }}$ Plutonium isotope \\
\hline$N_{k-i}$ & $\begin{array}{l}\text { Atom density of } i^{\text {th }} \text { isotope of } k^{\text {th }} \text { constituent } \\
\text { of solution. }\end{array}$ \\
\hline$A W_{k}$ & $\begin{array}{l}\text { Atomic weight of } i^{t h} \text { isotope of } k^{\text {th }} \text { constituent } \\
\text { of solution. }\end{array}$ \\
\hline$N_{O}, \quad N_{H}, \quad N_{N}$ & $\begin{array}{l}\text { Atom density of oxygen, hydrogen, and } \\
\text { nitrogen }\end{array}$ \\
\hline$N_{H_{2} \mathrm{O}}, N_{\mathrm{NO}_{3}}, N_{\mathrm{H}^{+}}$ & $\begin{array}{l}\text { Atom density of water, nitrogen, and free } \mathrm{H}^{+} \\
\text {ion as found with Equation E. } 4 .\end{array}$ \\
\hline
\end{tabular}

Revision: 0

Date: September 30, 2012 
NEA/NSC/DOC/(95)03/l

Volume I

PU-SOL-THERM-037

\section{APPENDIX F: CORRELATED UNCERTAINTY EFFECT OF PLUTONIUM AND HYDROGEN CONTENT}

In order to find the combines variance, $\sigma_{c}^{2}(y)$, of the plutonium and hydrogen content the following general equation was used:

$$
\sigma_{c}^{2}(y)=\sum_{i=1}^{N}\left(\frac{\partial f}{\partial x_{i}}\right)^{2} \sigma_{x_{i}}^{2}+2 \sum_{i=1}^{N-1} \sum_{j=i+1}^{N} \frac{\partial f}{\partial x_{i}} \frac{\partial f}{\partial x_{j}} \sigma_{x_{i}, x_{j}}{ }^{\mathrm{a}} \quad \begin{array}{cc}
\text { Equation } \\
\text { F.1 }
\end{array}
$$

Where $\sigma_{c}^{2}(y)$ is the variance of a parameter $y$ that depends on both $x_{i}$ and $x_{j}$ which are correlated variables, $f$ is the dependence of $y$ on $x_{i}$ and $x_{j}$, and $\sigma_{x_{i}, x_{j}}$ is the estimated covariance of $x_{i}$ and $x_{j}$. In order to find the correlated uncertainty in $\mathrm{k}_{\mathrm{eff}}$ with respect to plutonium concentration $\left(\mathrm{x}_{\mathrm{Pu}}\right)$ and acid molarity $\left(\mathrm{x}_{\mathrm{H}}\right)$ the following equation for the variance is derived from Equation F.1.

$$
\sigma_{\mathrm{k}}^{2}=\left(\frac{\partial \mathrm{k}}{\partial \mathrm{x}_{\mathrm{Pu}}}\right)^{2} \sigma_{\mathrm{x}_{\mathrm{Pu}}}^{2}+\left(\frac{\partial \mathrm{k}}{\partial \mathrm{x}_{\mathrm{H}}}\right)^{2} \sigma_{\mathrm{x}_{\mathrm{H}}}^{2}+2 \frac{\partial \mathrm{k}}{\partial \mathrm{x}_{\mathrm{Pu}}} \frac{\partial \mathrm{k}}{\partial \mathrm{x}_{\mathrm{H}}} \sigma_{\mathrm{x}_{\mathrm{Pu}}, \mathrm{x}_{\mathrm{H}}} \quad \begin{gathered}
\text { Equation } \\
\mathrm{F} .2
\end{gathered}
$$

Because there is not a continuous function for $k$ the partial derivatives are approximated by finding the change in $k$ caused by a change in each parameter independently.

$$
\begin{aligned}
\frac{\partial \mathrm{k}}{\partial \mathrm{x}_{\mathrm{Pu}}} & \approx \frac{\Delta \mathrm{k}_{\mathrm{x}_{\mathrm{Pu}}}}{\Delta \mathrm{x}_{\mathrm{Pu}}} \\
\frac{\partial \mathrm{k}}{\partial \mathrm{x}_{\mathrm{H}}} & \approx \frac{\Delta \mathrm{k}_{\mathrm{x}_{\mathrm{H}}}}{\Delta \mathrm{x}_{\mathrm{H}}}
\end{aligned}
$$

Equation

Where $\Delta \mathrm{k}_{\mathrm{x}_{\mathrm{Pu}}}$ is the change in $k$ corresponding to a $\Delta \mathrm{x}_{\mathrm{Pu}}$ change in plutonium concentration and $\Delta \mathrm{k}_{\mathrm{x}_{\mathrm{H}}}$ is the change in $k$ corresponding to a $\Delta \mathrm{x}_{\mathrm{H}}$ change in the acid molarity.

The estimated covariance of the plutonium concentration and acid molarity is found using the correlation coefficient, $\mathrm{r}_{\mathrm{x}_{\mathrm{Pu}}, \mathrm{x}_{\mathrm{H}}}$.

$$
\sigma_{\mathrm{x}_{\mathrm{Pu}}, \mathrm{x}_{\mathrm{H}}}=\mathrm{r}_{\mathrm{x}_{\mathrm{Pu}}, \mathrm{x}_{\mathrm{H}}} \cdot \sigma_{\mathrm{x}_{\mathrm{Pu}}} \sigma_{\mathrm{x}_{\mathrm{H}}}^{\mathrm{b}}
$$

Equation

Because the sakurai equation is an empirical formula we cannot derive a true correlation coefficient. The maximum uncertainty would occur when the correlation coefficient is equal to 1, which is assumed here. Thus the covariance of the plutonium concentration and acid molarity is:

\footnotetext{
a "American Nation Standard for Expressing Uncertainty-U.S. Guide to the Expression of Uncertainty in Measurement" ANSI/NCSL Z540-2-1997, Section 5.2, Equation 13.

b "American National Standard for Expressing Uncertainty-U.S. Guide to the Expression of Uncertainty in Measurement" ANSI/NCSL Z540-2-1997, Section 5.2, Equation 14.
}

Revision: 0

Date: September 30, 2012

Page 103 of 142 


$\begin{aligned} & \text { NEA/NSC/DOC/(95)03/l } \\ & \text { Volume I }\end{aligned}$
PU-SOL-THERM-037
$\sigma_{\mathrm{x}_{\mathrm{Pu}}, \mathrm{x}_{\mathrm{H}}}=\sigma_{\mathrm{x}_{\mathrm{Pu}}} \sigma_{\mathrm{x}_{\mathrm{H}}}$

Now Equation F.3 and F.5 can be combined with Equation F.2 to find the following equation.

$$
\sigma_{\mathrm{k}}^{2}=\left(\frac{\Delta \mathrm{k}}{\Delta \mathrm{x}_{\mathrm{Pu}}}\right)^{2} \sigma_{\mathrm{x}_{\mathrm{Pu}}}^{2}+\left(\frac{\Delta \mathrm{k}}{\Delta \mathrm{x}_{\mathrm{H}}}\right)^{2} \sigma_{\mathrm{x}_{\mathrm{H}}}^{2}+2 \frac{\Delta \mathrm{k}}{\Delta \mathrm{x}_{\mathrm{Pu}}} \frac{\Delta \mathrm{k}}{\Delta \mathrm{x}_{\mathrm{H}}} \sigma_{\mathrm{x}_{\mathrm{Pu}}} \sigma_{\mathrm{x}_{\mathrm{H}}} \quad \begin{gathered}
\text { Equation } \\
\text { F.6 }
\end{gathered}
$$

The plutonium concentration and acid molarity were varied by the bounding uncertainty $\sigma_{\mathrm{x}_{\mathrm{Pu}}}$ and $\sigma_{\mathrm{x}_{\mathrm{H}}}$. Equation F.6 simplifies to:

$$
\sigma_{\mathrm{k}}=\frac{1}{\sqrt{3}} \sqrt{\left(\Delta k_{P u}{ }^{2}+\Delta k_{H}{ }^{2}+2 \cdot \Delta k_{P u} \cdot \Delta k_{H}\right)=\Delta k_{\text {total }}} \quad \begin{gathered}
\text { Equation } \\
\text { F.7 }
\end{gathered}
$$

The $\sqrt{3}$ term arises from the fact that $\sigma_{\mathrm{x}_{\mathrm{Pu}}}$ and $\sigma_{\mathrm{x}_{\mathrm{H}}}$ are bounding uncertainties. 
NEA/NSC/DOC/(95)03/l

Volume I

PU-SOL-THERM-037

\section{APPENDIX G: EXAMPLE INPUT FILES FOR MODELS}

Input examples have material compositions to more decimal places than shown in Appendix C.0. All elements were broken down into isotopes using natural abundances, except for plutonium, for use with ENDF/B-VII.0 cross section libraries.

MCNP5.1.51 models were run using 100,000 particles or histories per cycle for 4000 cycles, skipping the first 100 cycles. Point sources were placed such that one point source was present in each bottle of fissile solution.

KENO-VI models were run using 155 cycles, skipping the first 5 cycles, with 100,000 histories or particles per cycle.

\section{MCNP Input Decks}

\section{Case 1, RSTM-L3-3, Simple Model}

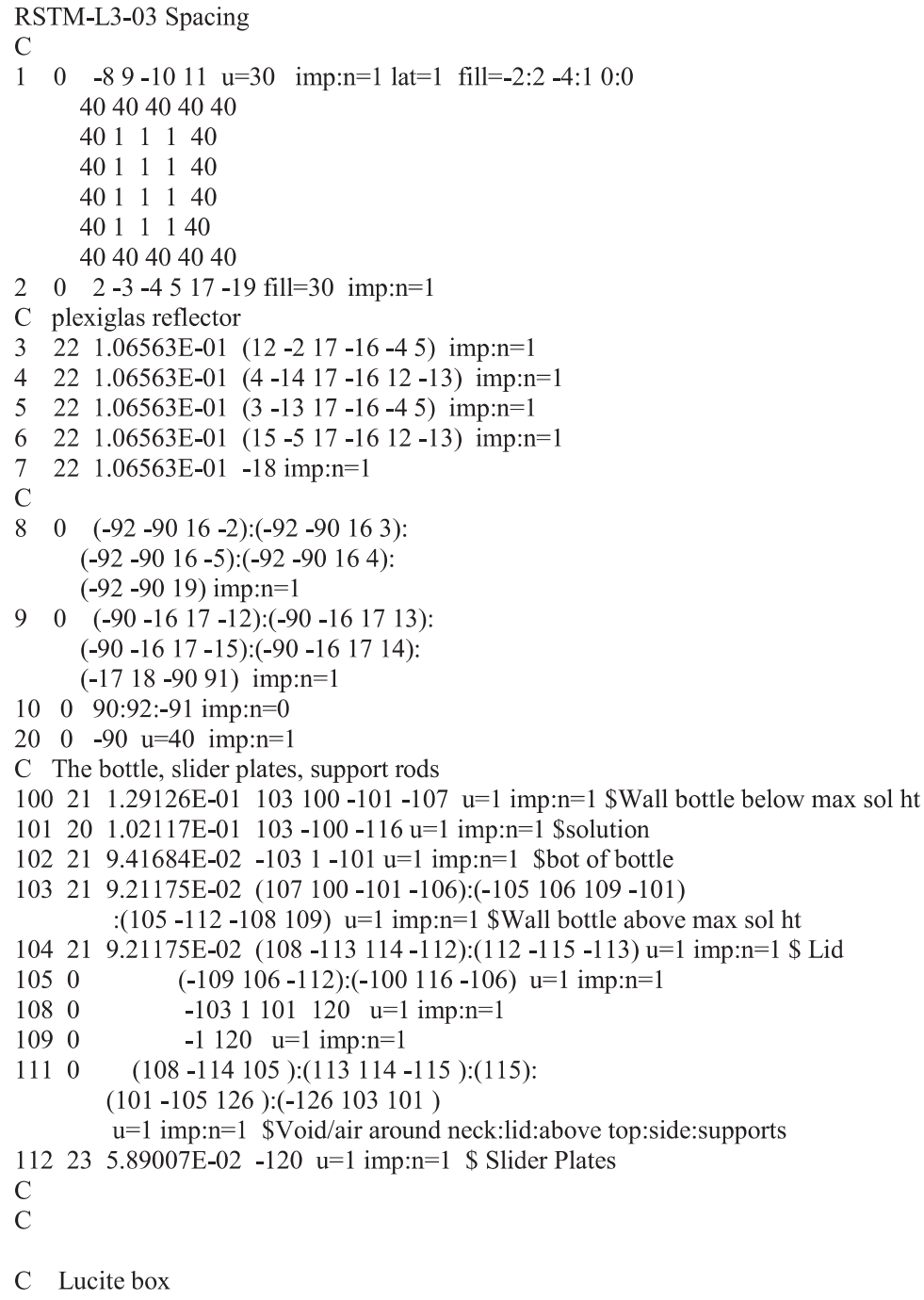

Revision: 0

Date: September 30, 2012 
NEA/NSC/DOC/(95)03/I

Volume I

PU-SOL-THERM-037

1 pz 0

C lattice cutting window

2 px -17.6655 \$assumed

3 px 17.6655

4 py 5.8885

5 py -42.69511

19 pz 50

C lattice propogation window

8 px 5.8885

9 px -5.8885

10 py 6.13444

11 py -6.13444

C Reflector

12 px -32.9055

13 px 32.9055

14 py 21.1285

15 py -57.93511

16 pz 29.21

$17 \mathrm{pz}-1.27$

18 rpp -55.0715 $51.6085-55.071421 .1286-16.19-1.27$

C Bottle/Slider plates

$100 \mathrm{cz} 5.3156$ \$ IR Bottle

$101 \mathrm{cz} 5.8885$ \$OR Bottle

$103 \mathrm{pz} 0.635$ \$bot of solution

$105 \mathrm{pz} 33.000$ \$ to neck of bottle

$106 \mathrm{pz} 32.120$ \$ to neck of bottle

$107 \mathrm{pz} 28.995$ \$ Maximum Solution Height

$108 \mathrm{cz} 3.960$ \$ OR bottle neck

$109 \mathrm{cz} 3.080$ \$ IR bottle neck

$112 \mathrm{pz} 41.380$ \$ Top of neck

$113 \mathrm{cz} 5.000$ \$ outside of lid

$114 \mathrm{pz} 35.500$ \$ Bot of lid

$115 \mathrm{pz} 42.290$ \$ Top of Lid w/o vent cap

$116 \mathrm{pz} 27.76039$ \$Solution height

120 rpp -20 $20-2020-1.270$

$126 \mathrm{pz} 13.8625$ \$ top of rods

$90 \mathrm{cz} 300$

$91 \mathrm{pz}-300$

$92 \mathrm{pz} 300$

c m2: solution

m20 94238.70c 2.92188E-08

94239.70c $2.56423 \mathrm{E}-04$

94240.70c 7.59141E-06

94241.70c $3.12151 \mathrm{E}-07$

94242.70c $1.20164 \mathrm{E}-07$

92234.70c 4.31363E-10

92235.70c 5.64693E-08

92238.70c 7.78606E-06

$8016.70 \mathrm{c} \quad 4.09990 \mathrm{E}-02$

8017.70 c $9.98702 \mathrm{E}-05$

$7014.70 \mathrm{c} \quad 4.88666 \mathrm{E}-03$

$7015.70 \mathrm{c} \quad 1.80493 \mathrm{E}-05$

$5010.70 \mathrm{c} \quad 5.54249 \mathrm{E}-08$

5011.70c $2.23092 \mathrm{E}-07$

$1001.70 \mathrm{c} \quad 5.58407 \mathrm{E}-02$

$95241.70 \mathrm{c} 4.29100 \mathrm{E}-07$ tot $1.02117 \mathrm{E}-01$

mt20 lwtr.10t

c $\mathrm{m} 2$ polyethylene actual

$\mathrm{m} 21 \quad 1001.70 \mathrm{c} \quad 8.78416 \mathrm{E}-02$

$1002.70 \mathrm{c} \quad 1.01029 \mathrm{E}-05$

$6000.70 \mathrm{c} \quad 4.12741 \mathrm{E}-02$

$62144.70 \mathrm{c} \quad 1.43941 \mathrm{E}-09$

$62147.70 \mathrm{c} \quad 7.02825 \mathrm{E}-09$

$62148.70 \mathrm{c} \quad 5.27001 \mathrm{E}-09$

$62149.70 \mathrm{c} \quad 6.47968 \mathrm{E}-09$

$62150.70 \mathrm{c} \quad 3.46021 \mathrm{E}-09$

Revision: 0

Date: September 30, 2012 
NEA/NSC/DOC/(95)03/I

Volume I

PU-SOL-THERM-037

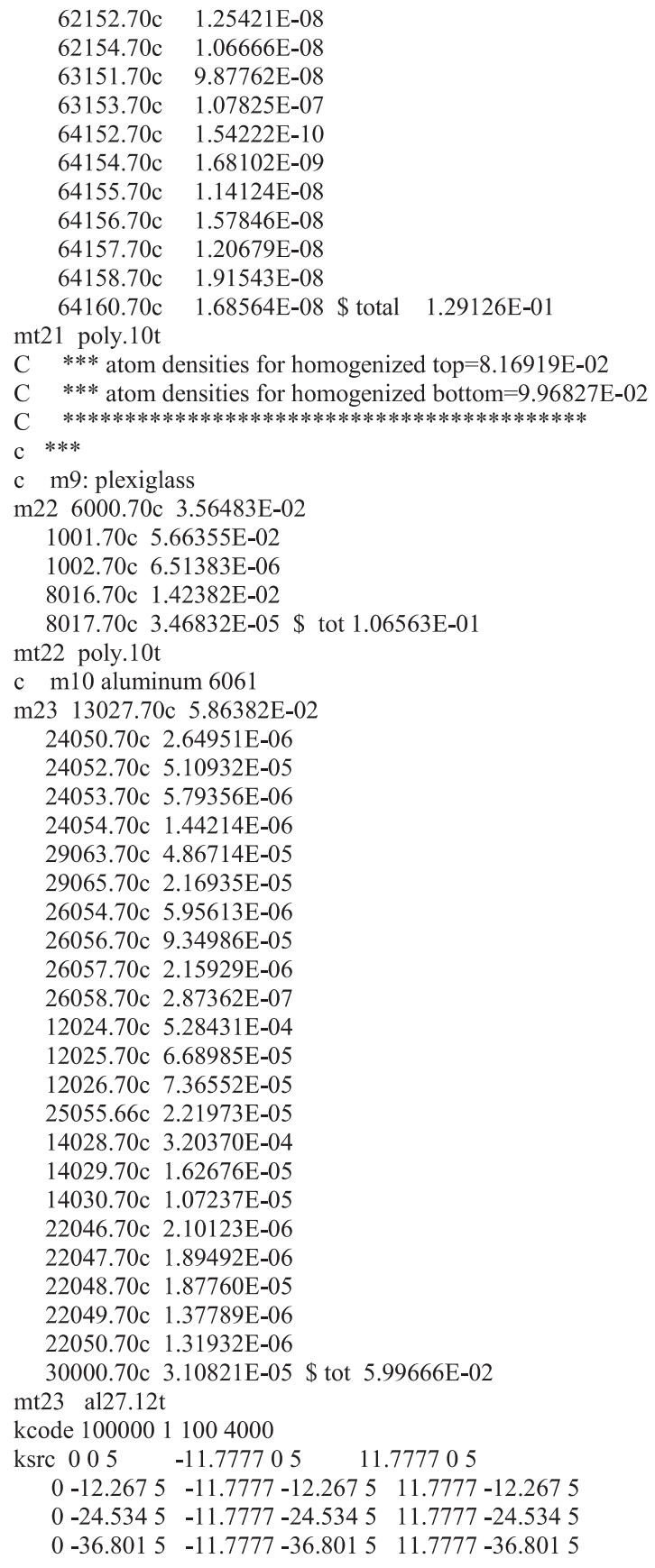

\section{Case 2, RSTM-L3-4, Simple Model}

\section{RSTM-L3-04}

C

$\mathrm{C}$

$10-89-1011 \quad u=30 \quad$ imp:n=1 lat=1 fill=-2:2 $-4: 1 \quad 0: 0$ 4040404040

4011140

$\begin{array}{lllll}40 & 1 & 1 & 1 & 40\end{array}$

4011140

Revision: 0

Date: September 30, 2012 
NEA/NSC/DOC/(95)03/I

Volume I

PU-SOL-THERM-037

4011140

4040404040

$20 \quad 2-3-4517-19$ fill=30 imp:n=1

$\mathrm{C}$ plexiglas reflector

322 1.06563E-01 (12 -2 $17-16-4$ 5) imp:n=1

422 1.06563E-01 (4 -14 $17-16 \quad 12-13)$ imp:n=1

522 1.06563E-01 (3 -13 $17-16-45)$ imp:n=1

$6 \quad 22 \quad 1.06563 \mathrm{E}-01(15-517-16 \quad 12-13)$ imp:n=1

$722 \quad 1.06563 \mathrm{E}-01-18 \mathrm{imp}: \mathrm{n}=1$

C

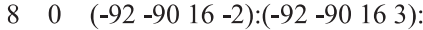

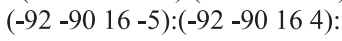

$(-92-90$ 19) imp:n=1

$90 \quad(-90-1617-12):(-90-161713)$ :

$(-90-16 \quad 17-15):(-90-1617$ 14):

(-17 18 -90 91) imp:n=1

100 90:92:-91 imp:n=0

$20 \quad 0 \quad-90 u=40 \quad$ imp:n=1

C The bottle, slider plates, support rods

10021 1.29126E-01 $103100-101-107 \mathrm{u}=1 \mathrm{imp}: \mathrm{n}=1$ \$Wall bottle below max sol ht

$101201.02117 \mathrm{E}-01 \quad 103-100-116 \mathrm{u}=1 \mathrm{imp}: \mathrm{n}=1$ Ssolution

10221 9.41684E-02 (-103 -101 1) u=1 imp:n=1 \$bot of bottle

10321 9.21175E-02 (107 100 -101 -106):(-105 106 109 -101)

:(105 -112 -108 109) u=1 imp:n=1 \$Wall bottle above max sol ht

$104219.21175 \mathrm{E}-02(108-113114-112):(112-115-113) \mathrm{u}=1 \mathrm{imp}: \mathrm{n}=1$ \$ Lid

$1050 \quad(-109106-112):(-100116-106) \mathrm{u}=1 \mathrm{imp}: \mathrm{n}=1$

$1080 \quad-1031101120 \mathrm{u}=1 \mathrm{imp}: \mathrm{n}=1$

$1090 \quad-1120 \quad \mathrm{u}=1 \mathrm{imp}: \mathrm{n}=1$

$1110 \quad(108-114105):(113114-115):(115)$ :

$(101-105126):(-126103101)$

$\mathrm{u}=1 \mathrm{imp}: \mathrm{n}=1$ \$Void/air around neck:lid:above top:side:supports

11223 5.80508E-02 -120 u=1 imp:n=1 \$ Bottle Slider Plate

$\mathrm{C}$

C Lucite box

1 pz 0

C lattice cutting window

2 px -17.9957 \$assumed

3 px 17.9957

4 py 5.8885

5 py -42.30345

19 pz 50

C lattice propogation window

8 px 6.0536

9 px -6.0536

10 py 6.06916

11 py -6.06916

C Reflector

12 px -33.2357

13 px 33.2357

14 py 21.1285

15 py -57.54345

16 pz 29.21

$17 \mathrm{pz}-1.27$

18 rpp -55.0715 51.6085 -55.0714 21.1286 -16.19 -1.27

C Bottle/Slider plates

$100 \mathrm{cz} 5.3156$ \$ IR Bottle

$101 \mathrm{cz} 5.8885$ \$OR Bottle

$103 \mathrm{pz} 0.635$ \$bot of solution

$105 \mathrm{pz} 33.000$ \$ to neck of bottle

$106 \mathrm{pz} 32.120$ \$ to neck of bottle

107 pz 28.995 \$ Maximum Solution Height

$108 \mathrm{cz} 3.960$ \$ OR bottle neck

109 cz 3.080 \$ IR bottle neck

$112 \mathrm{pz} 41.380$ \$ Top of neck

$113 \mathrm{cz} 5.000$ \$ outside of lid

$114 \mathrm{pz} 35.500$ \$ Bot of lid

Revision: 0

Date: September 30, 2012 
NEA/NSC/DOC/(95)03/I

Volume I

PU-SOL-THERM-037

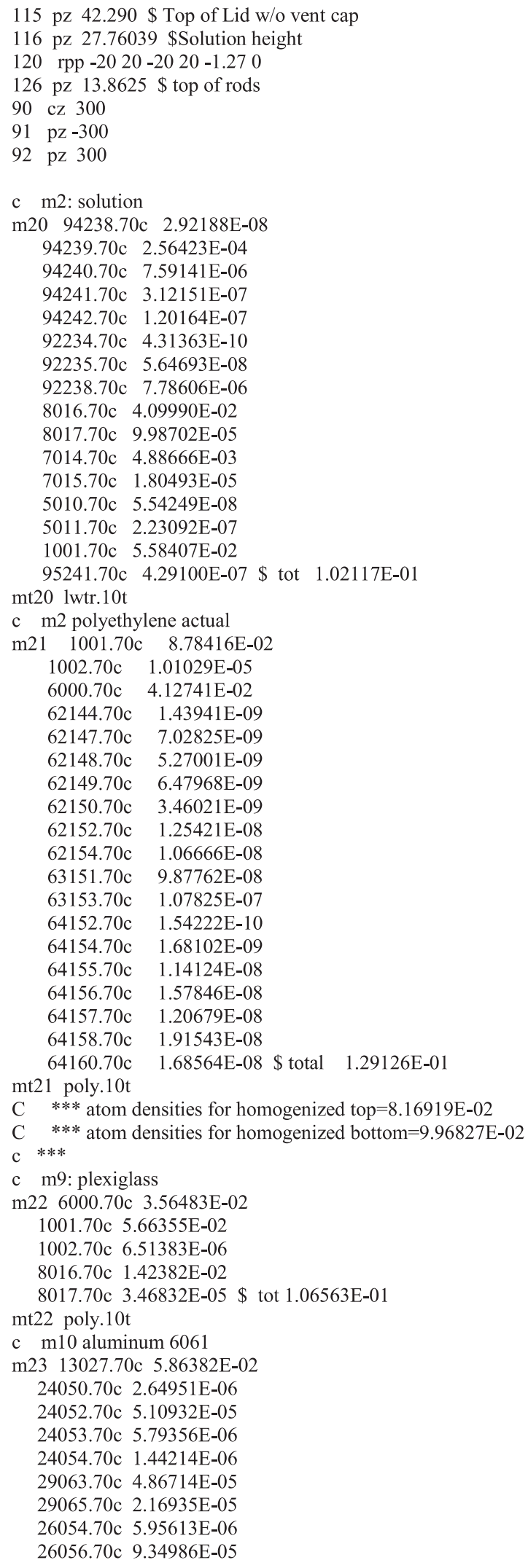

Revision: 0

Date: September 30, 2012 
NEA/NSC/DOC/(95)03/l

Volume I

PU-SOL-THERM-037

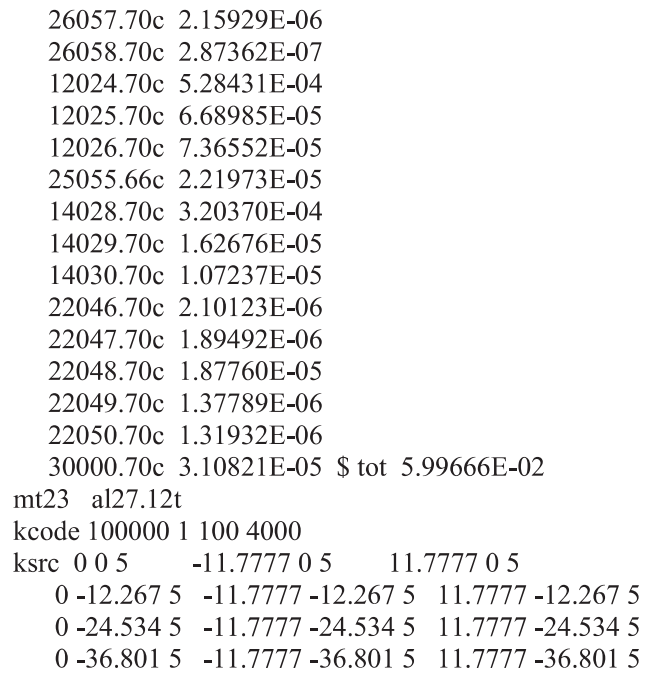

\section{Case 3, RSTM-L3-5, Simple Model}

RSTM-L3-05

C

$\mathrm{C}$

$10 \quad-89-1011 \quad u=30$ imp:n=1 lat=1 fill=-2:2 $-4: 1 \quad 0: 0$

4040404040

4011140

$\begin{array}{lllll}40 & 1 & 1 & 1 & 40\end{array}$

40111140

4011140

4040404040

$20 \quad 2-3-4517-19$ fill=30 imp:n=1

$\mathrm{C}$ plexiglas reflector

322 1.06563E-01 (12 -2 $17-16-4$ 5) imp:n=1

$422 \quad 1.06563 \mathrm{E}-01$ (4 -14 $17-16 \quad 12-13)$ imp:n=1

$5221.06563 \mathrm{E}-01(3-13 \quad 17-16-45)$ imp:n=1

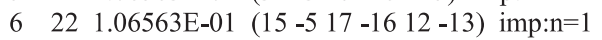

$722 \quad 1.06563 \mathrm{E}-01-18 \mathrm{imp}: \mathrm{n}=1$

C

$80 \quad\left(\begin{array}{lllllll}-92 & -90 & 16 & -2):(-92 & -90 & 16 & 3\end{array}\right)$ :

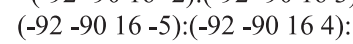
(-92 -90 19) imp:n=1

$90 \quad(-90-1617-12):(-90-161713)$ : $(-90-1617-15):(-90-161714)$ : (-17 $18-90$ 91) imp:n=1

100 90:92:-91 imp:n=0

$20 \quad 0 \quad-90 \quad \mathrm{u}=40$ imp:n=1

C The bottle, slider plates, support rods

10021 1.29126E-01 $103100-101-107 \mathrm{u}=1 \mathrm{imp}: \mathrm{n}=1$ \$Wall bottle below max sol ht

10120 1.02117E-01 $103-100-116 \mathrm{u}=1 \mathrm{imp}: \mathrm{n}=1$ Ssolution

10221 9.41684E-02 (-103 -101 1) u=1 imp:n=1 \$bot of bottle

$103219.21175 \mathrm{E}-02$ (107 $100-101-106):(-105106109-101)$ :(105 -112 -108 109) u=1 imp:n=1 \$Wall bottle above max sol ht $104219.21175 \mathrm{E}-02(108-113114-112):(112-115-113) \mathrm{u}=1$ imp:n=1 \$ Lid $1050 \quad(-109106-112):(-100116-106) \mathrm{u}=1 \mathrm{imp}: \mathrm{n}=1$

$1080 \quad-1031101120 \mathrm{u}=1 \mathrm{imp}: \mathrm{n}=1$

$1090 \quad-1120 \mathrm{u}=1 \mathrm{imp}: \mathrm{n}=1$

$1110 \quad(108-114105):(113114-115):(115):$ (101 -105 126$):(-126103101)$

$\mathrm{u}=1 \mathrm{imp}: \mathrm{n}=1$ \$Void/air around neck:lid:above top:side:supports 11223 5.78905E-02 -120 u=1 imp:n=1 \$ Bottle Slider Plate C

Revision: 0

Date: September 30, 2012 
NEA/NSC/DOC/(95)03/I

Volume I

PU-SOL-THERM-037

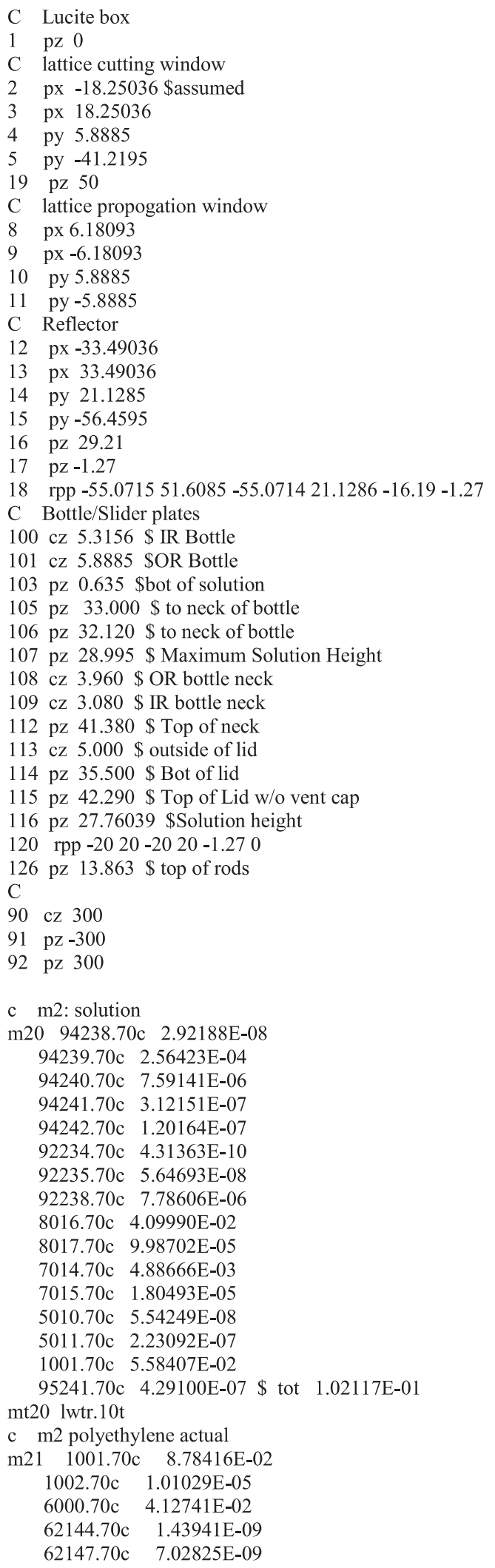

Revision: 0

Date: September 30, 2012 
NEA/NSC/DOC/(95)03/I

Volume I

PU-SOL-THERM-037

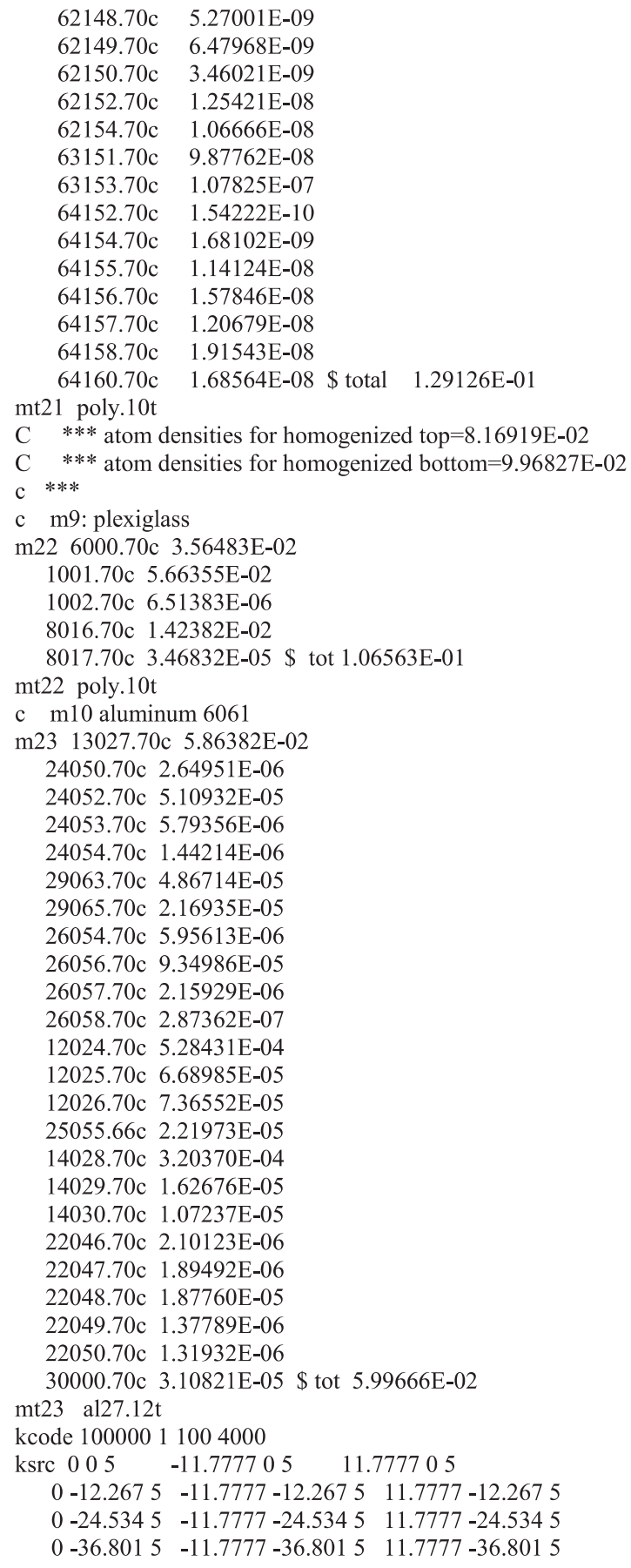

\section{Case 4, RSTM-L3-6, Simple Model}

RSTM-L3-06 Spacing,

$\mathrm{C}$

$\mathrm{C}$

$10 \quad-89-1011 \mathrm{u}=30$ imp:n=1 lat=1 fill=-2:3 $-4: 1$ 0:0 404040404040

$\begin{array}{llllll}40 & 1 & 1 & 1 & 40\end{array}$

Revision: 0

Date: September 30, 2012 
NEA/NSC/DOC/(95)03/I

Volume I

PU-SOL-THERM-037

$\begin{array}{llllll}40 & 1 & 1 & 1 & 1 & 40\end{array}$

4011111140

$\begin{array}{llllll}40 & 1 & 1 & 1 & 1 & 40\end{array}$

404040404040

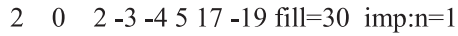

$\mathrm{C}$ plexiglas reflector

322 1.06563E-01 (12 - $217-16-45)$ imp:n=1

422 1.06563E-01 (4 -14 $17-16 \quad 12-13)$ imp:n=1

$522 \quad 1.06563 \mathrm{E}-01(3-1317-16-45)$ imp:n=1

622 1.06563E-01 (15 -5 $17-16 \quad 12-13)$ imp:n=1

$722 \quad 1.06563 \mathrm{E}-01 \quad-18 \mathrm{imp}: \mathrm{n}=1$

C

$8 \quad 0 \quad\left(\begin{array}{lllllll}-92 & -90 & 16 & -2):(-92 & -90 & 16 & 3):\end{array}\right.$

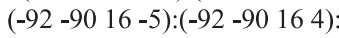

$(-92-90$ 19) imp:n=1

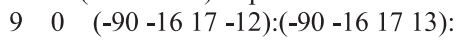

$(-90-16 \quad 17-15):(-90-1617$ 14):

(-17 18 -90 91) imp:n=1

100 90:92:-91 imp:n=0

$20 \quad 0 \quad-90 u=40$ imp:n=1

C The bottle, slider plates, support rods

10021 1.29126E-01 $103100-101-107 \mathrm{u}=1 \mathrm{imp}: \mathrm{n}=1$ \$Wall bottle below max sol ht

10120 1.02117E-01 $103-100-116 \mathrm{u}=1 \mathrm{imp}: \mathrm{n}=1$ \$solution

10221 9.41684E-02 (-103 -101 1) u=1 imp:n=1 \$bot of bottle

10321 9.21175E-02 (107 100 -101 -106):(-105 106 109-101)

$:(105-112-108$ 109) u=1 imp:n=1 \$Wall bottle above max sol ht

$104219.21175 \mathrm{E}-02(108-113114-112):(112-115-113) \mathrm{u}=1 \mathrm{imp}: \mathrm{n}=1$ \$ Lid

$1050 \quad(-109106-112):(-100116-106) \mathrm{u}=1 \mathrm{imp}: \mathrm{n}=1$

$1080 \quad-1031101120 \mathrm{u}=1 \mathrm{imp}: \mathrm{n}=1$

$1090 \quad-1120 \quad \mathrm{u}=1 \mathrm{imp}: \mathrm{n}=1$

$1110 \quad(108-114105):(113114-115):(115):$

$(101-105126):(-126103101)$

$\mathrm{u}=1 \mathrm{imp}: \mathrm{n}=1$ \$Void/air around neck:lid:above top:side:supports

11223 5.65515E-02 -120 u=1 imp:n=1 \$ Bottle Slider Plate

C

C Lucite box

1 pz 0

C lattice cutting window

2 px -17.6655 \$assumed

3 px 29.4425

4 py 5.8885

5 py -46.98746

19 pz 50

C lattice propogation window

8 px 5.8885

9 px -5.8885

10 py 6.84983

11 py -6.84983

C Reflector

12 px -32.9055

13 px 44.6825

14 py 21.1285

15 py -62.22746

16 pz 29.21

$17 \mathrm{pz}-1.27$

18 rpp -55.0715 $51.6085-55.071421 .1286-16.19-1.27$

C Bottle/Slider plates

$100 \mathrm{cz} 5.3156$ \$ IR Bottle

$101 \mathrm{cz} 5.8885$ \$OR Bottle

$103 \mathrm{pz} 0.635$ \$bot of solution

$105 \mathrm{pz} 33.000$ \$ to neck of bottle

$106 \mathrm{pz} 32.120$ \$ to neck of bottle

107 pz 28.995 \$ Maximum Solution Height

$108 \mathrm{cz} 3.960$ \$ OR bottle neck

$109 \mathrm{cz} 3.080$ \$ IR bottle neck

$112 \mathrm{pz} 41.380$ \$ Top of neck

Revision: 0

Date: September 30, 2012 
NEA/NSC/DOC/(95)03/I

Volume I

PU-SOL-THERM-037

$113 \mathrm{cz} 5.000$ \$ outside of lid

$114 \mathrm{pz} 35.500$ \$ Bot of lid

$115 \mathrm{pz} 42.290$ \$ Top of Lid w/o vent cap

$116 \mathrm{pz} 27.75145$ \$Solution height

120 rpp -20 $20-2020-1.270$

$126 \mathrm{pz} 13.8625 \$$ top of rods

C

C

90 cz 300

$91 \mathrm{pz}-300$

$92 \mathrm{pz} 300$

c m2: solution

m20 94238.70c $2.92188 \mathrm{E}-08$

$94239.70 \mathrm{c} \quad 2.56423 \mathrm{E}-04$

$94240.70 \mathrm{c} \quad 7.59141 \mathrm{E}-06$

94241.70c $3.12151 \mathrm{E}-07$

94242.70c $1.20164 \mathrm{E}-07$

92234.70c $4.31363 \mathrm{E}-10$

92235.70c 5.64693E-08

$92238.70 \mathrm{c} \quad 7.78606 \mathrm{E}-06$

$8016.70 \mathrm{c} \quad 4.09990 \mathrm{E}-02$

$8017.70 \mathrm{c} \quad 9.98702 \mathrm{E}-05$

$7014.70 \mathrm{c} \quad 4.88666 \mathrm{E}-03$

$7015.70 \mathrm{c} \quad 1.80493 \mathrm{E}-05$

$5010.70 \mathrm{c} \quad 5.54249 \mathrm{E}-08$

$5011.70 \mathrm{c} \quad 2.23092 \mathrm{E}-07$

$1001.70 \mathrm{c} \quad 5.58407 \mathrm{E}-02$

$95241.70 \mathrm{c} 4.29100 \mathrm{E}-07 \$$ tot $1.02117 \mathrm{E}-01$

mt20 lwtr.10t

c $\mathrm{m} 2$ polyethylene actual

m21 1001.70c 8.78416E-02

$1002.70 \mathrm{c} \quad 1.01029 \mathrm{E}-05$

$6000.70 \mathrm{c} \quad 4.12741 \mathrm{E}-02$

$62144.70 \mathrm{c} \quad 1.43941 \mathrm{E}-09$

$62147.70 \mathrm{c} \quad 7.02825 \mathrm{E}-09$

$62148.70 \mathrm{c} \quad 5.27001 \mathrm{E}-09$

$62149.70 \mathrm{c} \quad 6.47968 \mathrm{E}-09$

$62150.70 \mathrm{c} \quad 3.46021 \mathrm{E}-09$

$62152.70 \mathrm{c} \quad 1.25421 \mathrm{E}-08$

$62154.70 \mathrm{c} \quad 1.06666 \mathrm{E}-08$

$63151.70 \mathrm{c} \quad 9.87762 \mathrm{E}-08$

$63153.70 \mathrm{c} \quad 1.07825 \mathrm{E}-07$

$64152.70 \mathrm{c} \quad 1.54222 \mathrm{E}-10$

$64154.70 \mathrm{c} \quad 1.68102 \mathrm{E}-09$

$64155.70 \mathrm{c} \quad 1.14124 \mathrm{E}-08$

$64156.70 \mathrm{c} \quad 1.57846 \mathrm{E}-08$

$64157.70 \mathrm{c} \quad 1.20679 \mathrm{E}-08$

$64158.70 \mathrm{c} \quad 1.91543 \mathrm{E}-08$

$64160.70 \mathrm{c} \quad 1.68564 \mathrm{E}-08$ \$ total $1.29126 \mathrm{E}-01$

$\mathrm{mt} 21$ poly. $10 \mathrm{t}$

C $* * *$ atom densities for homogenized top $=8.16919 \mathrm{E}-02$

C $* * *$ atom densities for homogenized bottom $=9.96827 \mathrm{E}-02$

C $* * * * * * * * * * * * * * * * * * * * * * * * * * * * * * * * * * * * * * * * * *$

c m9: plexiglass

$\mathrm{m} 226000.70 \mathrm{c} 3.56483 \mathrm{E}-02$

1001.70 c $5.66355 \mathrm{E}-02$

$1002.70 \mathrm{c} 6.51383 \mathrm{E}-06$

$8016.70 \mathrm{c} \quad 1.42382 \mathrm{E}-02$

$8017.70 \mathrm{c} 3.46832 \mathrm{E}-05$ \$ tot $1.06563 \mathrm{E}-01$

$\mathrm{mt} 22$ poly. $10 \mathrm{t}$

c m10 aluminum 6061

m23 13027.70c 5.86382E-02

$24050.70 \mathrm{c} 2.64951 \mathrm{E}-06$

24052.70c 5.10932E-05

24053.70c 5.79356E-06

24054.70c $1.44214 \mathrm{E}-06$

Revision: 0

Date: September 30, 2012 
NEA/NSC/DOC/(95)03/I

Volume I

PU-SOL-THERM-037

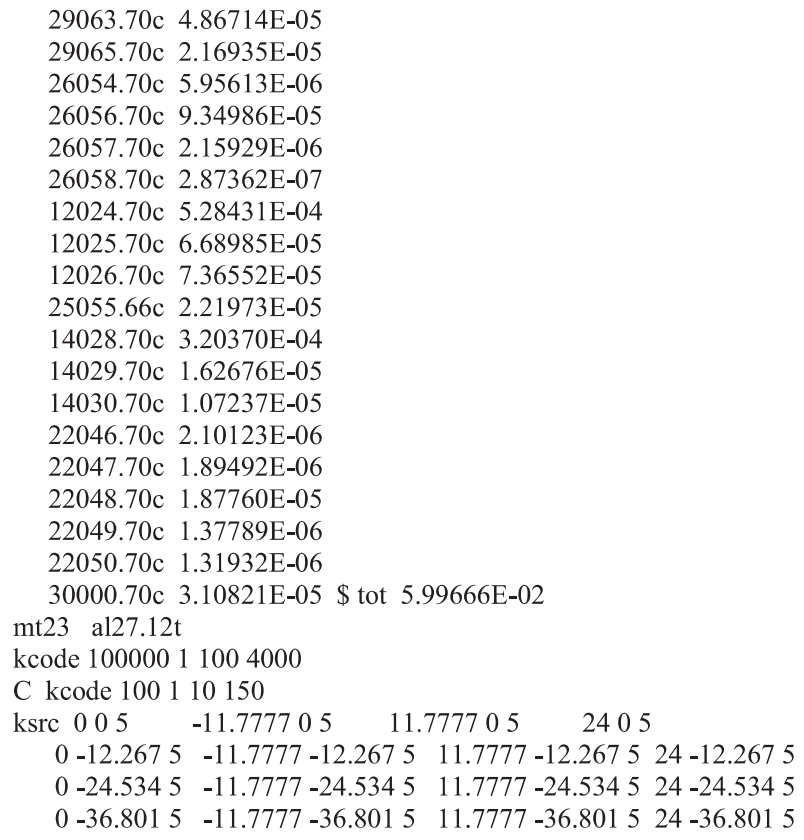

\section{Case 5, RSTM-L3-7, Simple Model}

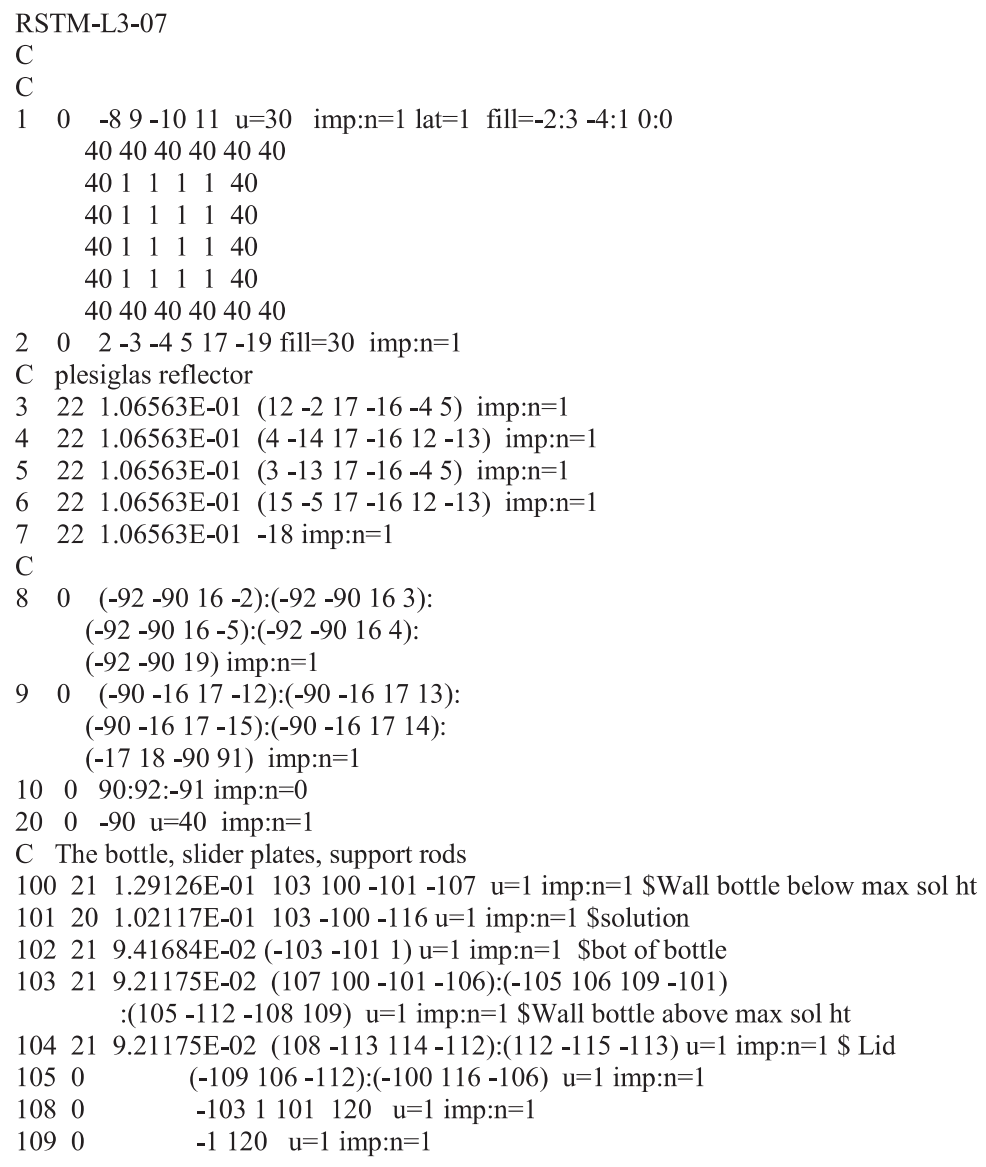

Revision: 0

Date: September 30, 2012 
NEA/NSC/DOC/(95)03/I

Volume I

PU-SOL-THERM-037

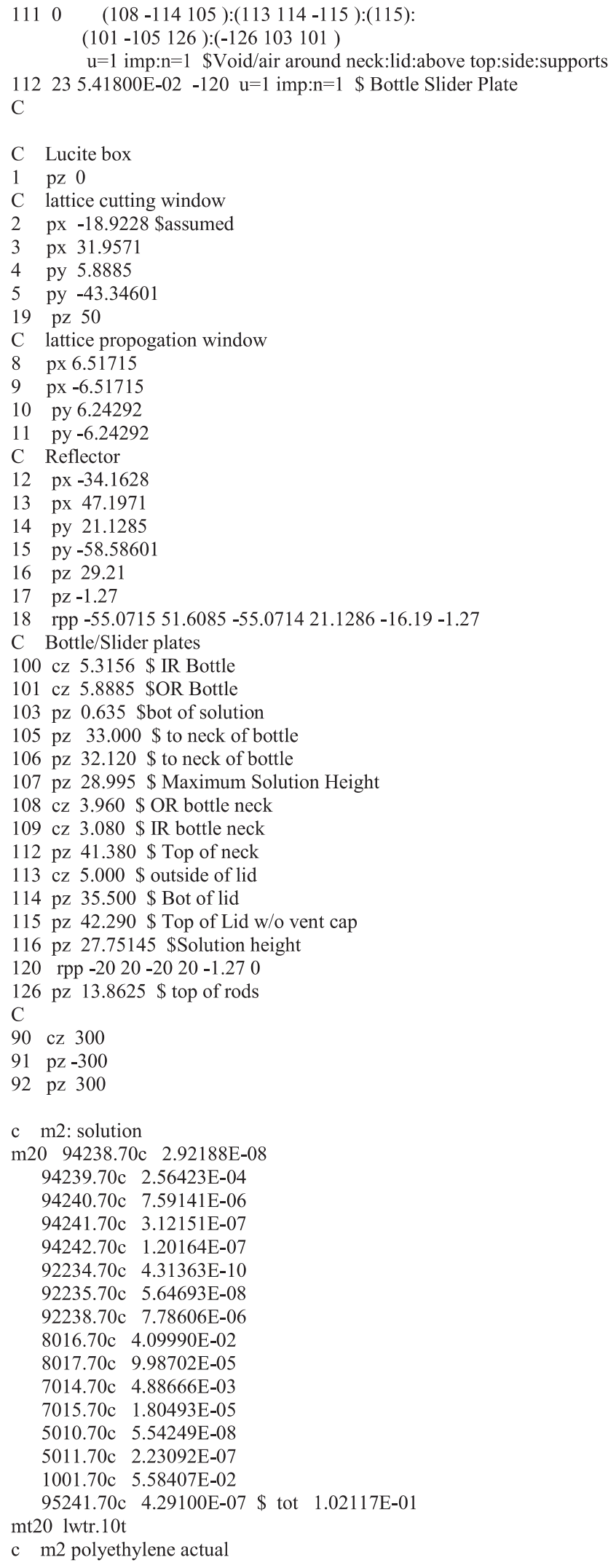

Revision: 0

Date: September 30, 2012 
NEA/NSC/DOC/(95)03/I

Volume I

PU-SOL-THERM-037

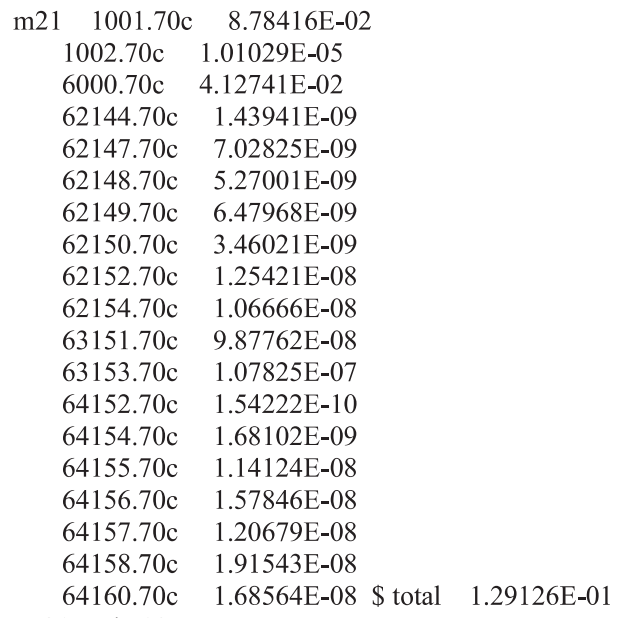

$\mathrm{mt} 21$ poly. $10 \mathrm{t}$

C $* * *$ atom densities for homogenized top $=8.16919 \mathrm{E}-02$

$\mathrm{C} * * *$ atom densities for homogenized bottom $=9.96827 \mathrm{E}-02$

$\mathrm{C} * * * * * * * * * * * * * * * * * * * * * * * * * * * * * * * * * * * * * * * * * *$

c m9: plexiglass

$\mathrm{m} 226000.70 \mathrm{c} \quad 3.56483 \mathrm{E}-02$

1001.70 c $5.66355 \mathrm{E}-02$

$1002.70 \mathrm{c} 6.51383 \mathrm{E}-06$

$8016.70 \mathrm{c} 1.42382 \mathrm{E}-02$

$8017.70 \mathrm{c} 3.46832 \mathrm{E}-05$ \$ tot $1.06563 \mathrm{E}-01$

$\mathrm{mt} 22$ poly. $10 \mathrm{t}$

c m10 aluminum 6061

m23 13027.70c 5.86382E-02

24050.70c 2.64951E-06

24052.70c 5.10932E-05

24053.70c 5.79356E-06

24054.70c 1.44214E-06

29063.70c 4.86714E-05

29065.70c 2.16935E-05

26054.70c 5.95613E-06

26056.70c $9.34986 \mathrm{E}-05$

26057.70 c 2.15929E-06

26058.70c 2.87362E-07

$12024.70 \mathrm{c} 5.28431 \mathrm{E}-04$

$12025.70 \mathrm{c} 6.68985 \mathrm{E}-05$

$12026.70 \mathrm{c} 7.36552 \mathrm{E}-05$

$25055.66 \mathrm{c} 2.21973 \mathrm{E}-05$

$14028.70 \mathrm{c} 3.20370 \mathrm{E}-04$

$14029.70 \mathrm{c} 1.62676 \mathrm{E}-05$

$14030.70 \mathrm{c} 1.07237 \mathrm{E}-05$

22046.70c 2.10123E-06

22047.70 c $1.89492 \mathrm{E}-06$

22048.70c $1.87760 \mathrm{E}-05$

$22049.70 \mathrm{c} 1.37789 \mathrm{E}-06$

$22050.70 \mathrm{c} 1.31932 \mathrm{E}-06$

$30000.70 \mathrm{c} 3.10821 \mathrm{E}-05$ \$ tot $5.99666 \mathrm{E}-02$

$\mathrm{mt} 23$ al27.12t

kcode 10000011004000

C kcode 100110150

$\begin{array}{lllr}\text { ksrc } 005 & -11.777705 & 11.777705 & 23.55405\end{array}$

$0-12.2675-11.7777-12.2675 \quad 11.7777-12.2675 \quad 23.554-12.2675$

$\begin{array}{llllllll}0 & -24.5345 & -11.7777 & -24.5345 & 11.7777 & -24.5345 & 23.554 & -24.5345\end{array}$

$0-36.8015-11.7777-36.801511 .7777-36.801523 .554-36.8015$

\section{Case 6, RSTM-L3-12, Simple Model}

Revision: 0

Date: September 30, 2012 
NEA/NSC/DOC/(95)03/l

Volume I

PU-SOL-THERM-037

RSTM-L3-12

C

$1 \quad 0 \quad-89-1011 \quad u=30$ imp:n=1 lat=1 fill=-2:3 $-4: 1$ 0:0

404040404040

401111140

$\begin{array}{lllllllll}40 & 1 & 1 & 1 & 1 & 40\end{array}$

$\begin{array}{llllll}40 & 1 & 1 & 1 & 1 & 40\end{array}$

401111140

404040404040

2 0 2 - -3 -4 5 17 -19 fill=30 imp:n=1

$\mathrm{C}$ plexiglas reflector

322 1.06563E-01 (12 -2 $17-16-4$ 5) imp:n=1

422 1.06563E-01 (4 -14 $17-16 \quad 12-13)$ imp:n=1

522 1.06563E-01 (3 -13 $17-16-4$ 5) imp:n=1

622 1.06563E-01 (15 -5 $17-16 \quad 12-13)$ imp:n=1

722 1.06563E-01 -18 imp:n=1

$\mathrm{C}$

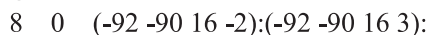

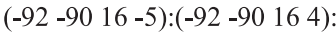

$(-92-90$ 19) imp:n=1

$9 \quad 0 \quad(-90-1617-12):(-90-161713):$

$(-90-1617-15):(-90-1617$ 14):

$(-17$ 18 -90 91) imp:n=1

10 0 90:92:-91 imp:n=0

$20 \quad 0 \quad-90 u=40$ imp:n=1

C The bottle, slider plates, support rods

10021 1.29126E-01 $103100-101-107 \mathrm{u}=1 \mathrm{imp}: \mathrm{n}=1$ \$Wall bottle below max sol ht

$101201.02117 \mathrm{E}-01 \quad 103-100-116 \mathrm{u}=1 \mathrm{imp}: \mathrm{n}=1$ Ssolution

$102219.41684 \mathrm{E}-02(-103-1011) \mathrm{u}=1 \mathrm{imp}: \mathrm{n}=1$ Sbot of bottle

$103219.21175 \mathrm{E}-02$ (107 100 -101 -106):(-105 106109 -101)

:(105 -112 -108 109) u=1 imp:n=1 \$Wall bottle above max sol ht

10421 9.21175E-02 (108 -113 $114-112):(112-115-113) \mathrm{u}=1 \mathrm{imp}: \mathrm{n}=1$ \$ Lid

$1050 \quad(-109106-112):(-100116-106) \mathrm{u}=1 \mathrm{imp}: \mathrm{n}=1$

$1080 \quad-103150120$ u=1 imp:n=1

$1090 \quad-1120 \quad \mathrm{u}=1 \mathrm{imp}: \mathrm{n}=1$

$1110 \quad(108-114105-51):(113114-115-51):(115):$

$(101-105126-51):(-12610350):$

$(-1261-51101):$

(126 -115 50):(52 -115 -50 51)

$\mathrm{u}=1 \mathrm{imp}: \mathrm{n}=1$ \$Void/air around neck:lid:above top:side:supports

11223 5.15499E-02 -120 u=1 imp:n=1 \$ Bottle Slider Plate

$\mathrm{C}$

12022 1.03031E-01 (-50 51 -126 120 1):

$(-5051126-52) u=1$ imp:n=1 \$ shell

C

C

C Lucite box

1 pz 0

C lattice cutting window

2 px -19.05381 \$assumed

3 px 31.75635

4 py 6.35127

5 py -48.18019

19 pz 50

C lattice propogation window

8 px 6.35127

9 px -6.35127

10 py 6.97149

11 py -6.97149

C Reflector

12 px -34.29381

13 px 46.99635

14 py 21.59127

15 py -63.42019

16 pz 29.21

Revision: 0

Date: September 30, 2012 
NEA/NSC/DOC/(95)03/I

Volume I

PU-SOL-THERM-037

$17 \mathrm{pz}-1.27$

$18 \quad$ rpp $-54.596552 .0835 \quad-54.599921 .6001 \quad-16.19-1.27$

$50 \mathrm{cz} 6.35127$

$51 \mathrm{cz} 6.02361$

$52 \mathrm{pz} 30.48$

C Bottle/Slider plates

$100 \mathrm{cz} 5.3156$ \$ IR Bottle

$101 \mathrm{cz} 5.8885$ \$OR Bottle

$103 \mathrm{pz} 0.635$ \$bot of solution

$105 \mathrm{pz} 33.000$ \$ to neck of bottle

$106 \mathrm{pz} 32.120$ \$ to neck of bottle

107 pz 28.995 \$ Maximum Solution Height

$108 \mathrm{cz} 3.960$ \$ OR bottle neck

$109 \mathrm{cz} 3.080$ \$ IR bottle neck

$112 \mathrm{pz} 41.380$ \$ Top of neck

$113 \mathrm{cz} 5.000$ \$ outside of lid

$114 \mathrm{pz} 35.500$ \$ Bot of lid

$115 \mathrm{pz} 42.290$ \$ Top of Lid w/o vent cap

$116 \mathrm{pz} 27.75145$ \$Solution height

120 rpp -20 $20-2020-1.270$

$126 \mathrm{pz} 13.8625 \$$ top of rods

C

C

$90 \mathrm{cz} 300$

$91 \mathrm{pz}-300$

$92 \mathrm{pz} 300$

c m2: solution

m20 94238.70c 2.92188E-08

$94239.70 \mathrm{c} \quad 2.56423 \mathrm{E}-04$

94240.70c $7.59141 \mathrm{E}-06$

94241.70c $3.12151 \mathrm{E}-07$

94242.70c $1.20164 \mathrm{E}-07$

92234.70c $4.31363 \mathrm{E}-10$

92235.70c 5.64693E-08

92238.70c $7.78606 \mathrm{E}-06$

$8016.70 \mathrm{c} \quad 4.09990 \mathrm{E}-02$

8017.70c 9.98702E-05

$7014.70 \mathrm{c} \quad 4.88666 \mathrm{E}-03$

$7015.70 \mathrm{c} \quad 1.80493 \mathrm{E}-05$

$5010.70 \mathrm{c} \quad 5.54249 \mathrm{E}-08$

$5011.70 \mathrm{c} \quad 2.23092 \mathrm{E}-07$

$1001.70 \mathrm{c} \quad 5.58407 \mathrm{E}-02$

$95241.70 \mathrm{c} 4.29100 \mathrm{E}-07$ tot $1.02117 \mathrm{E}-01$

mt20 lwtr.10t

c $\mathrm{m} 2$ polyethylene actual

$\mathrm{m} 21 \quad 1001.70 \mathrm{c} \quad 8.78416 \mathrm{E}-02$

$1002.70 \mathrm{c} \quad 1.01029 \mathrm{E}-05$

$6000.70 \mathrm{c} \quad 4.12741 \mathrm{E}-02$

$62144.70 \mathrm{c} \quad 1.43941 \mathrm{E}-09$

$62147.70 \mathrm{c} \quad 7.02825 \mathrm{E}-09$

$62148.70 \mathrm{c} \quad 5.27001 \mathrm{E}-09$

$62149.70 \mathrm{c} \quad 6.47968 \mathrm{E}-09$

$62150.70 \mathrm{c} \quad 3.46021 \mathrm{E}-09$

$62152.70 \mathrm{c} \quad 1.25421 \mathrm{E}-08$

$62154.70 \mathrm{c} \quad 1.06666 \mathrm{E}-08$

$63151.70 \mathrm{c} \quad 9.87762 \mathrm{E}-08$

$63153.70 \mathrm{c} \quad 1.07825 \mathrm{E}-07$

$64152.70 \mathrm{c} \quad 1.54222 \mathrm{E}-10$

$64154.70 \mathrm{c} \quad 1.68102 \mathrm{E}-09$

$64155.70 \mathrm{c} \quad 1.14124 \mathrm{E}-08$

$64156.70 \mathrm{c} \quad 1.57846 \mathrm{E}-08$

$64157.70 \mathrm{c} \quad 1.20679 \mathrm{E}-08$

$64158.70 \mathrm{c} \quad 1.91543 \mathrm{E}-08$

$64160.70 \mathrm{c} \quad 1.68564 \mathrm{E}-08$ \$ total $1.29126 \mathrm{E}-01$

$\mathrm{mt} 21$ poly. $10 \mathrm{t}$

C $* * *$ atom densities for homogenized top $=8.16919 \mathrm{E}-02$

Revision: 0

Date: September 30, 2012 
NEA/NSC/DOC/(95)03/I

Volume I

PU-SOL-THERM-037

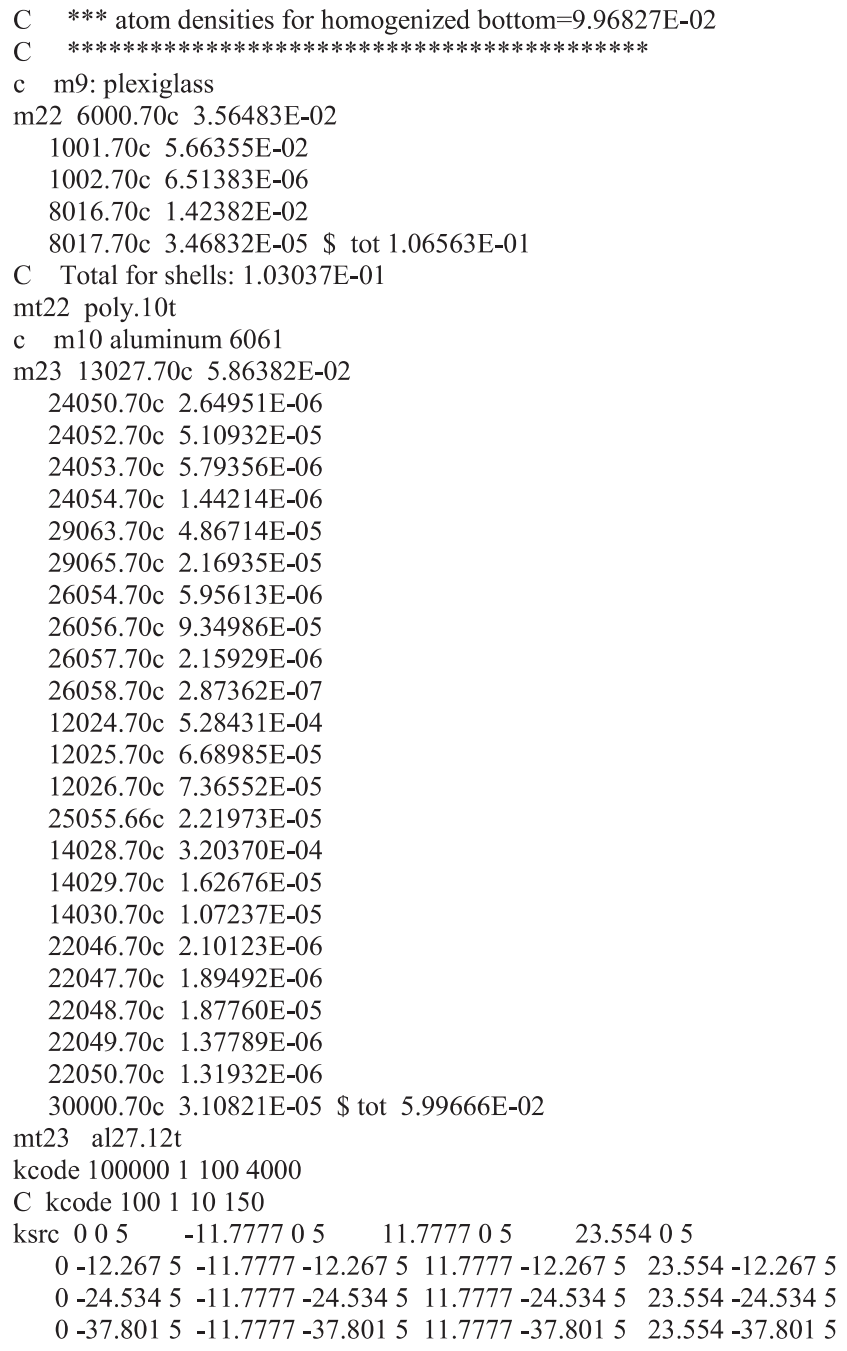

\section{Case 7, RSTM-L3-13, Simple Model}

RSTM-L3-13

$\mathrm{C}$

$\mathrm{C}$

$10 \quad-8 \quad 9-1011 \quad u=30 \quad i m p: n=1$ lat=1 fill=-2:3 $-4: 10: 0$

404040404040

$\begin{array}{llllll}40 & 1 & 1 & 1 & 1 & 40\end{array}$

$\begin{array}{llllll}40 & 1 & 1 & 1 & 1 & 40\end{array}$

$\begin{array}{llllll}40 & 1 & 1 & 1 & 1 & 40\end{array}$

$\begin{array}{llllll}40 & 1 & 1 & 1 & 1 & 40\end{array}$

404040404040

$20 \quad 2-3-4517-19$ fill=30 imp:n=1

$\mathrm{C}$ plexiglas reflector

$322 \quad 1.06563 \mathrm{E}-01(12-217-16-45)$ imp:n=1

$422 \quad 1.06563 \mathrm{E}-01$ (4 -14 $17-16 \quad 12-13)$ imp:n=1

$522 \quad 1.06563 \mathrm{E}-01(3-13 \quad 17-16-45)$ imp:n=1

$622 \quad 1.06563 \mathrm{E}-01(15-517-16 \quad 12-13)$ imp:n=1

722 1.06563E-01 -18 imp:n=1

C

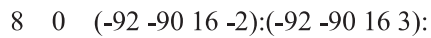

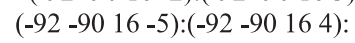

Revision: 0

Date: September 30, 2012 
$(-92-90$ 19) imp:n=1

$9 \quad 0 \quad(-90-16 \quad 17-12):(-90-161713):$

$(-90-1617-15):(-90-161714):$

$(-17$ 18 -90 91) imp:n=1

10 0 90:92:-91 imp:n=0

$20 \quad 0 \quad-90 \mathrm{u}=40$ imp:n=1

C The bottle, slider plates, support rods

$10021 \quad 1.29126 \mathrm{E}-01103100-101-107 \mathrm{u}=1 \mathrm{imp}: \mathrm{n}=1$ \$Wall bottle below max sol ht

$101201.02117 \mathrm{E}-01 \quad 103-100-116 \mathrm{u}=1 \mathrm{imp}: \mathrm{n}=1$ \$solution

$102219.41684 \mathrm{E}-02(-103-1011) \mathrm{u}=1 \mathrm{imp}: \mathrm{n}=1$ \$bot of bottle

10321 9.21175E-02 (107 100 -101 -106):(-105 106 109-101)

:(105 -112 -108 109) u=1 imp:n=1 \$Wall bottle above max sol ht

10421 9.21175E-02 (108 -113 $114-112):(112-115-113) \mathrm{u}=1 \mathrm{imp}: \mathrm{n}=1$ \$ Lid

$1050 \quad(-109106-112):(-100116-106) u=1$ imp:n=1

$1080 \quad-1031101120 \mathrm{u}=1 \mathrm{imp}: \mathrm{n}=1$

$1090 \quad-1120 \quad \mathrm{u}=1 \mathrm{imp}: \mathrm{n}=1$

$1110 \quad(108-114105):(113114-115):(115):$ $\left(\begin{array}{lll}101 & -105 & 126\end{array}\right):(-126103101)$

$\mathrm{u}=1 \mathrm{imp}: \mathrm{n}=1$ \$Void/air around neck:lid:above top:side:supports

11223 5.52682E-02 -120 u=1 imp:n=1 \$ Bottle Slider Plate

C

C Lucite box

1 pz 0

C lattice cutting window

2 px -18.3513 \$assumed

3 px 30.8141

4 py 5.8885

5 py -44.83108

$19 \mathrm{pz} 50$

C lattice propogation window

8 px 6.2314

9 px -6.2314

10 py 6.49043

11 py -6.49043

C Reflector

12 px -33.5913

13 px 46.0541

14 py 21.1285

15 py -60.07108

16 pz 29.21

$17 \mathrm{pz}-1.27$

18 rpp -55.0715 $51.6085-55.071421 .1286-16.19-1.27$

C Bottle/Slider plates

$100 \mathrm{cz} 5.3156$ \$ IR Bottle

$101 \mathrm{cz} 5.8885$ \$OR Bottle

$103 \mathrm{pz} 0.635$ \$bot of solution

$105 \mathrm{pz} 33.000$ \$ to neck of bottle

$106 \mathrm{pz} 32.120$ \$ to neck of bottle

107 pz 28.995 \$ Maximum Solution Height

$108 \mathrm{cz} 3.960$ \$ OR bottle neck

$109 \mathrm{cz} 3.080$ \$ IR bottle neck

$112 \mathrm{pz} 41.380$ \$ Top of neck

$113 \mathrm{cz} 5.000$ \$ outside of lid

$114 \mathrm{pz} 35.500$ \$ Bot of lid

$115 \mathrm{pz} 42.290$ \$ Top of Lid w/o vent cap

$116 \mathrm{pz} 27.75145$ \$Solution height

120 rpp -20 $20-2020-1.270$

$126 \mathrm{pz} 13.8625 \$$ top of rods

C

$\mathrm{C}$

90 cz 300

$91 \mathrm{pz}-300$

$92 \mathrm{pz} 300$

c m2: solution

m20 94238.70c $2.92188 \mathrm{E}-08$

Revision: 0

Date: September 30, 2012 
NEA/NSC/DOC/(95)03/I

Volume I

PU-SOL-THERM-037

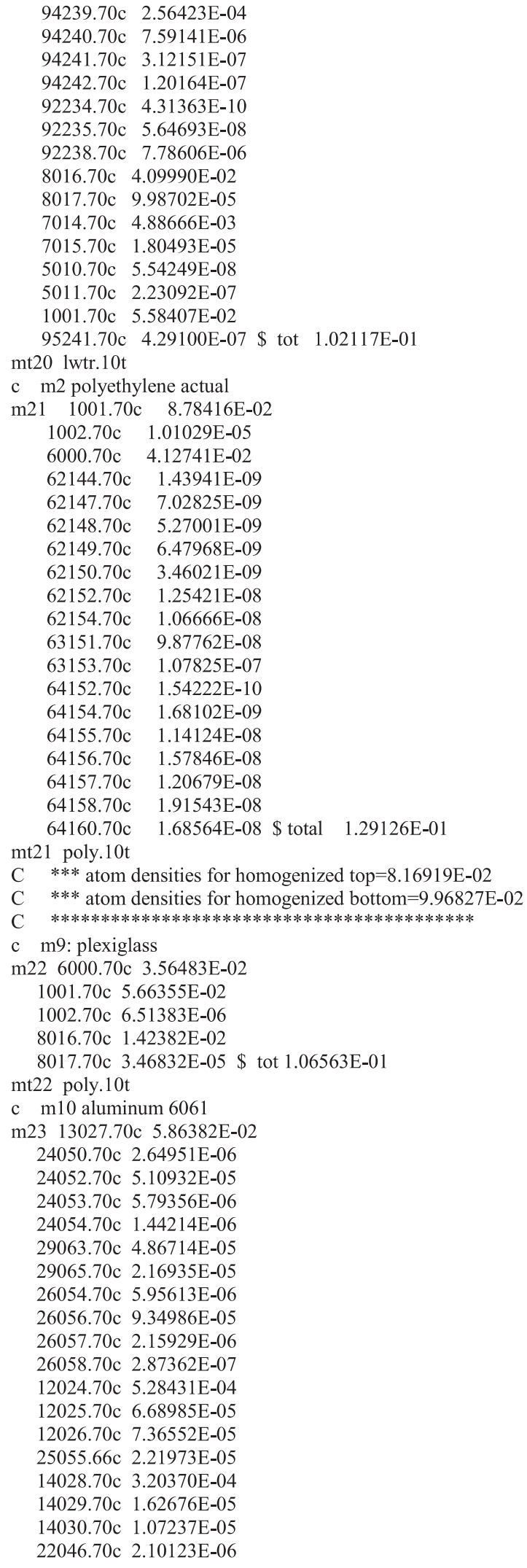

Revision: 0

Date: September 30, 2012 
NEA/NSC/DOC/(95)03/I

Volume I

PU-SOL-THERM-037

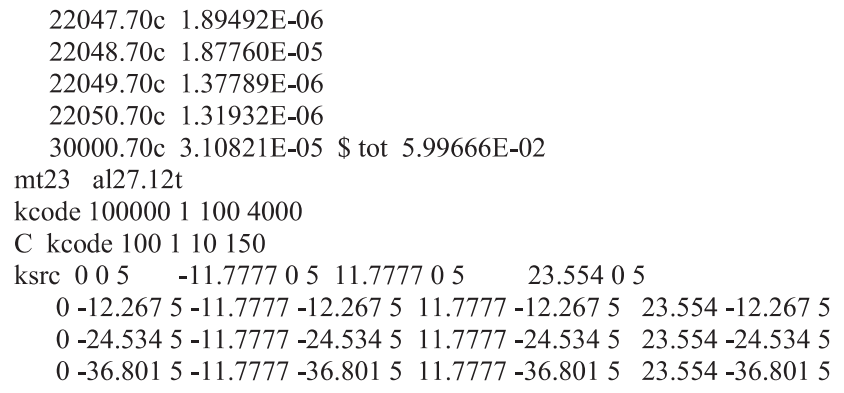

\section{KENO Input Decks}

\section{Case 1, RSTM-L3-3, Simple Model}

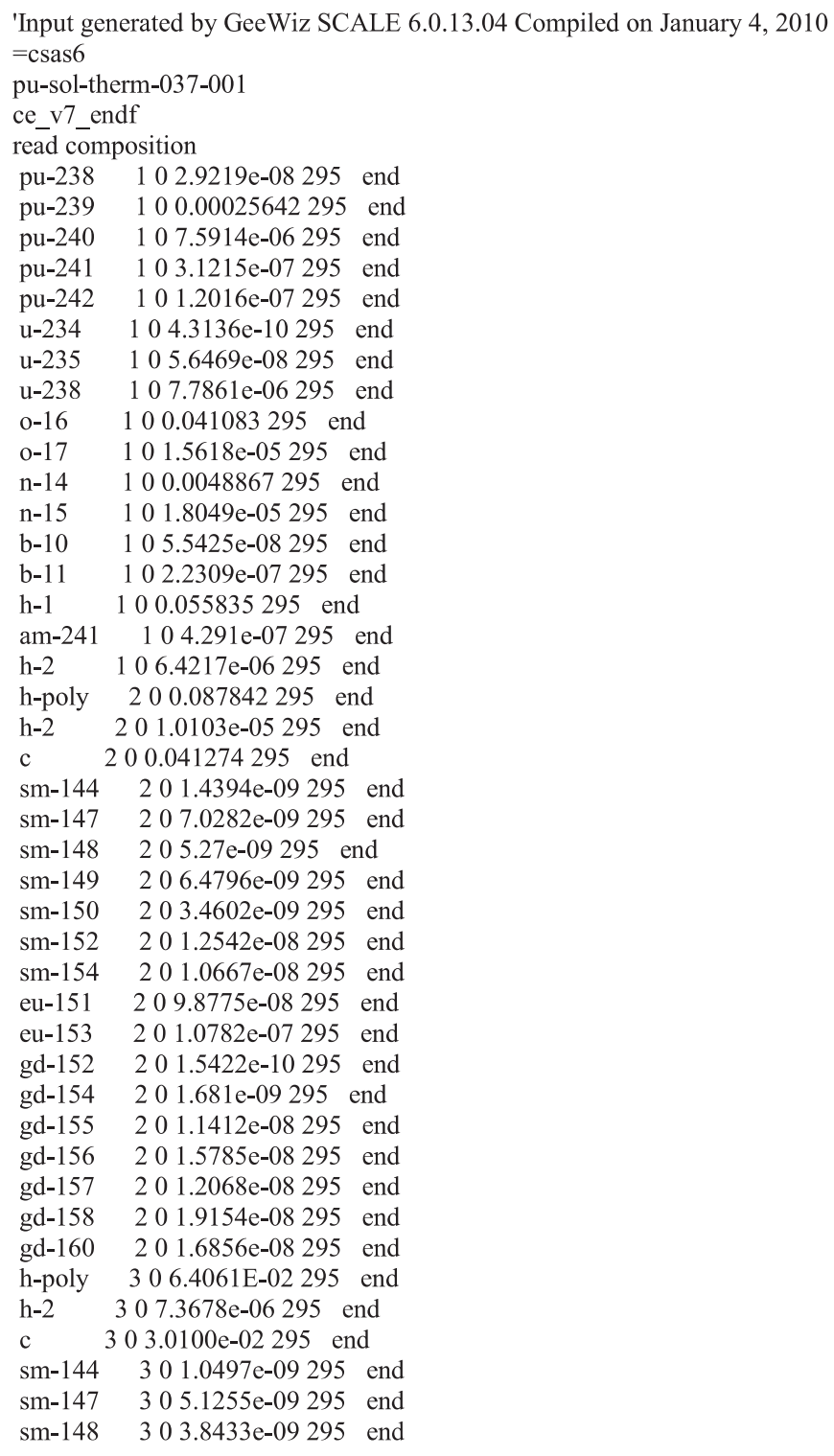

Revision: 0

Date: September 30, 2012 
NEA/NSC/DOC/(95)03/I

Volume I

PU-SOL-THERM-037

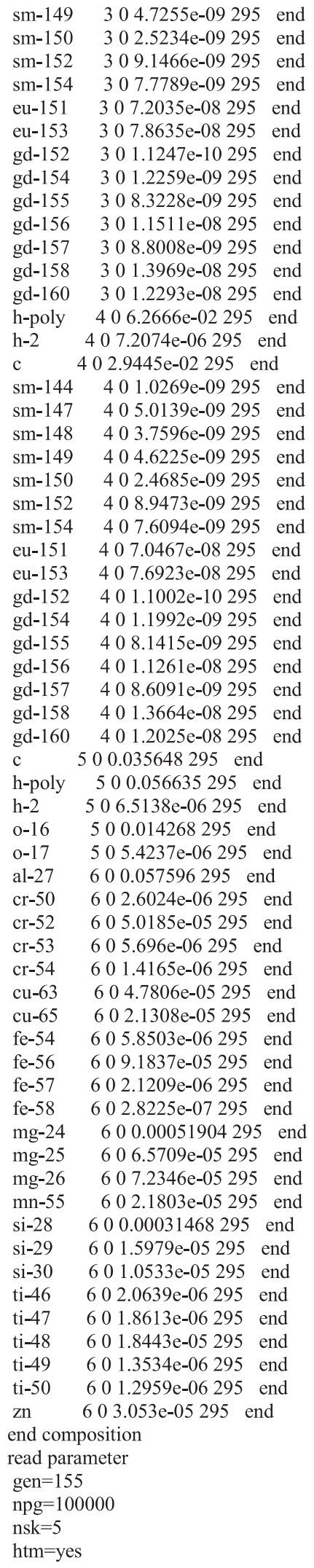

Revision: 0

Date: September 30, 2012 
NEA/NSC/DOC/(95)03/I

Volume I

PU-SOL-THERM-037

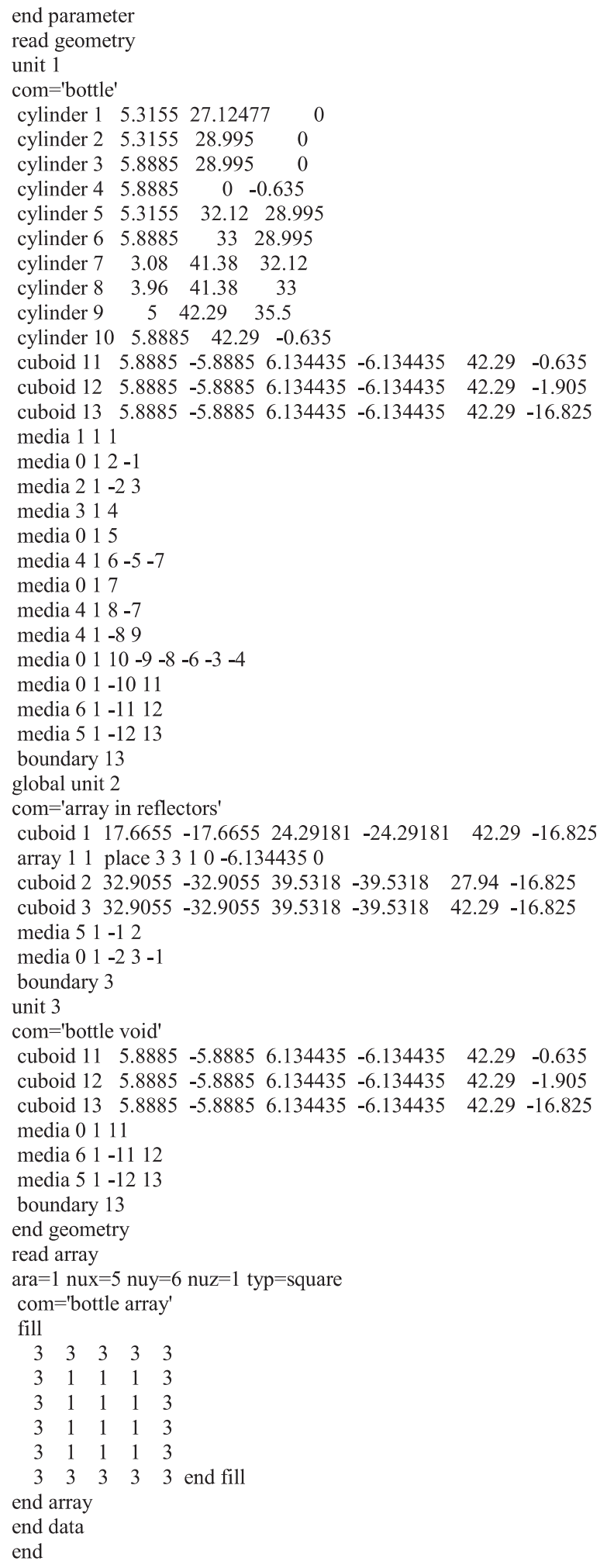

Case 2, RSTM-L3-4, Simple Model

Revision: 0

Date: September 30, 2012 
NEA/NSC/DOC/(95)03/l

Volume I

PU-SOL-THERM-037

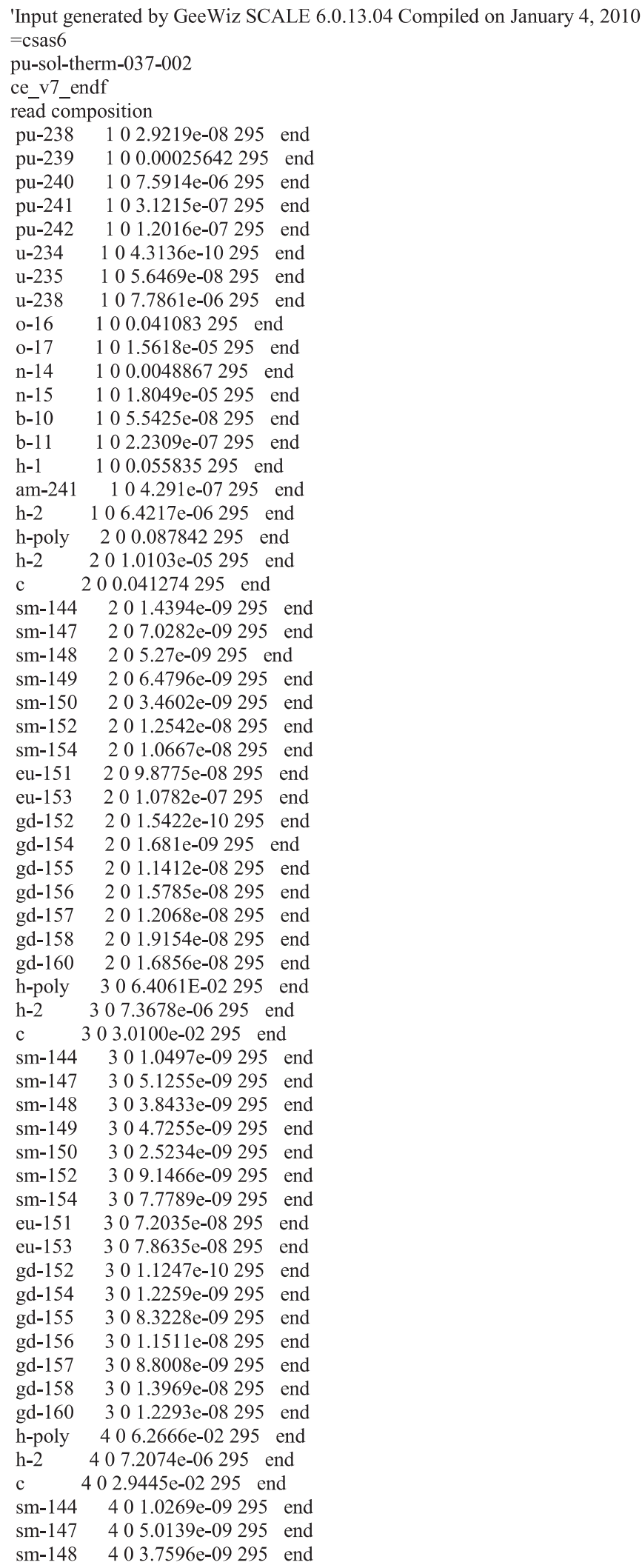

Revision: 0

Date: September 30, 2012 
NEA/NSC/DOC/(95)03/I

Volume I

PU-SOL-THERM-037

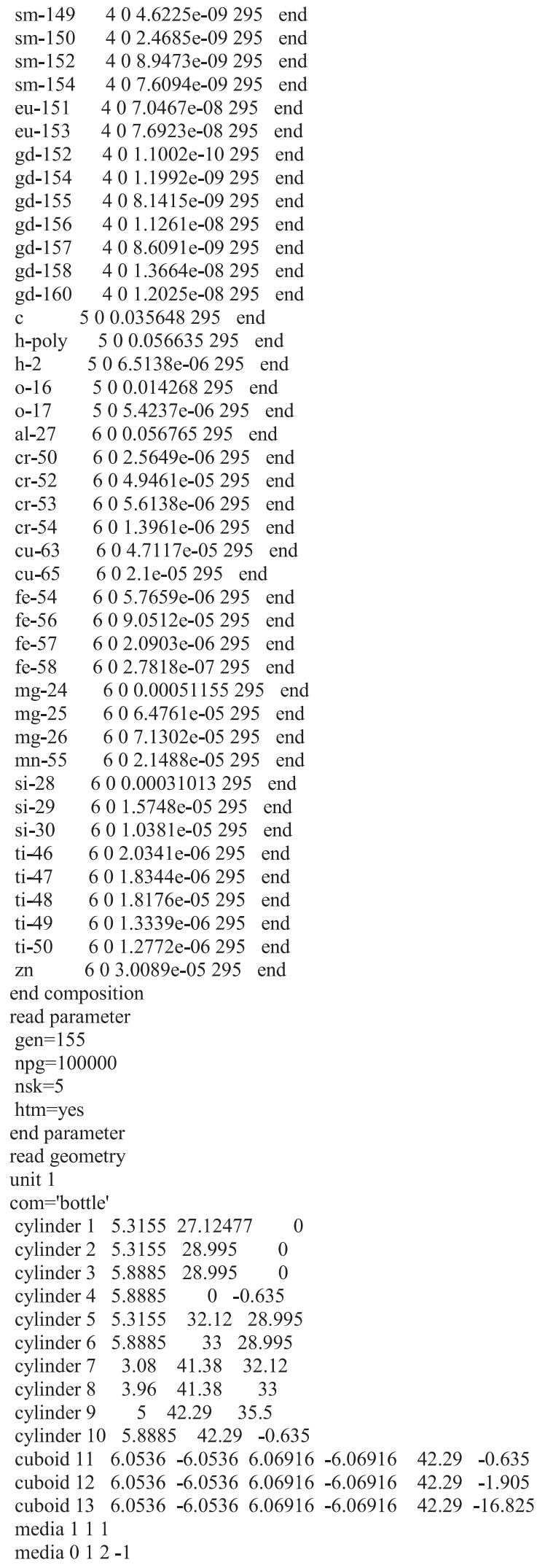

Revision: 0

Date: September 30, 2012 
NEA/NSC/DOC/(95)03/I

Volume I

PU-SOL-THERM-037

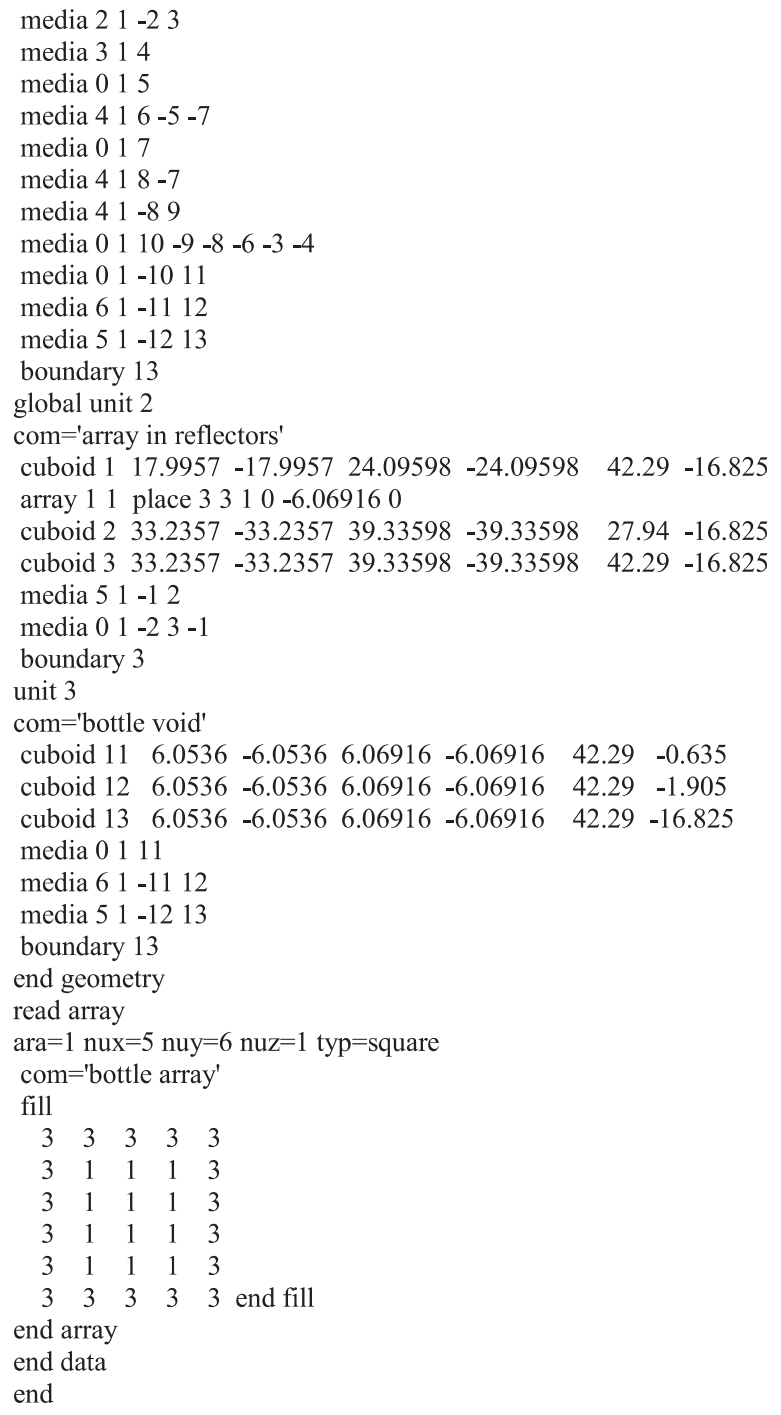

Case 3, RSTM-L3-5, Simple Model

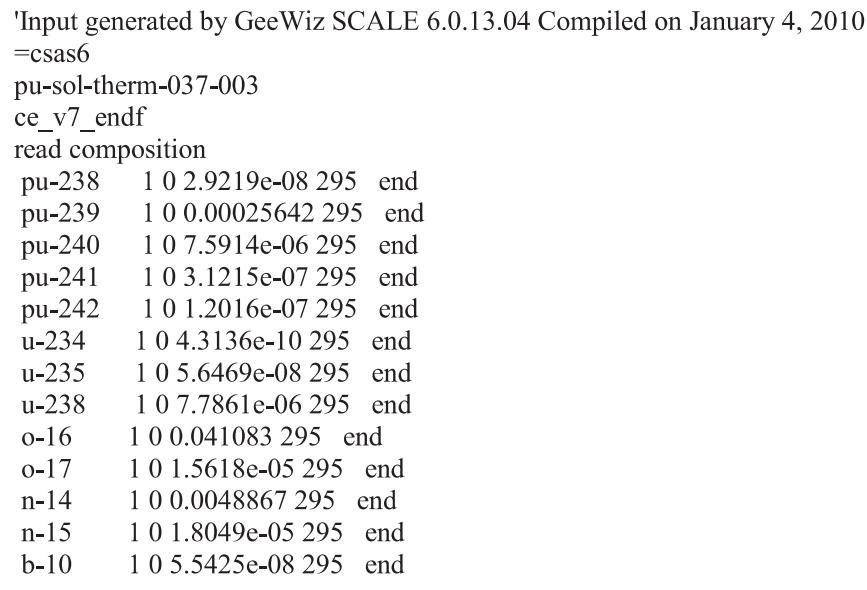

Revision: 0

Date: September 30, 2012 
NEA/NSC/DOC/(95)03/l

Volume I

PU-SOL-THERM-037

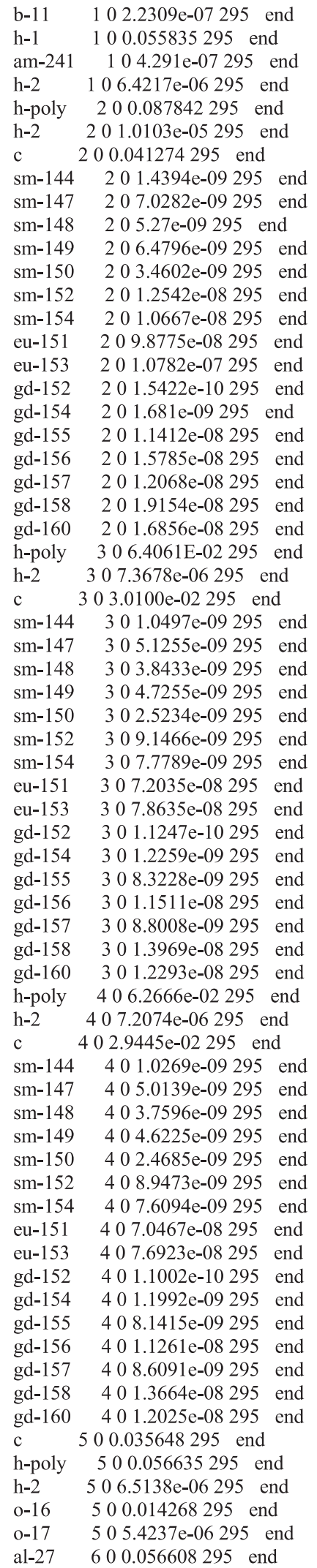

Revision: 0

Date: September 30, 2012 
NEA/NSC/DOC/(95)03/I

Volume I

PU-SOL-THERM-037

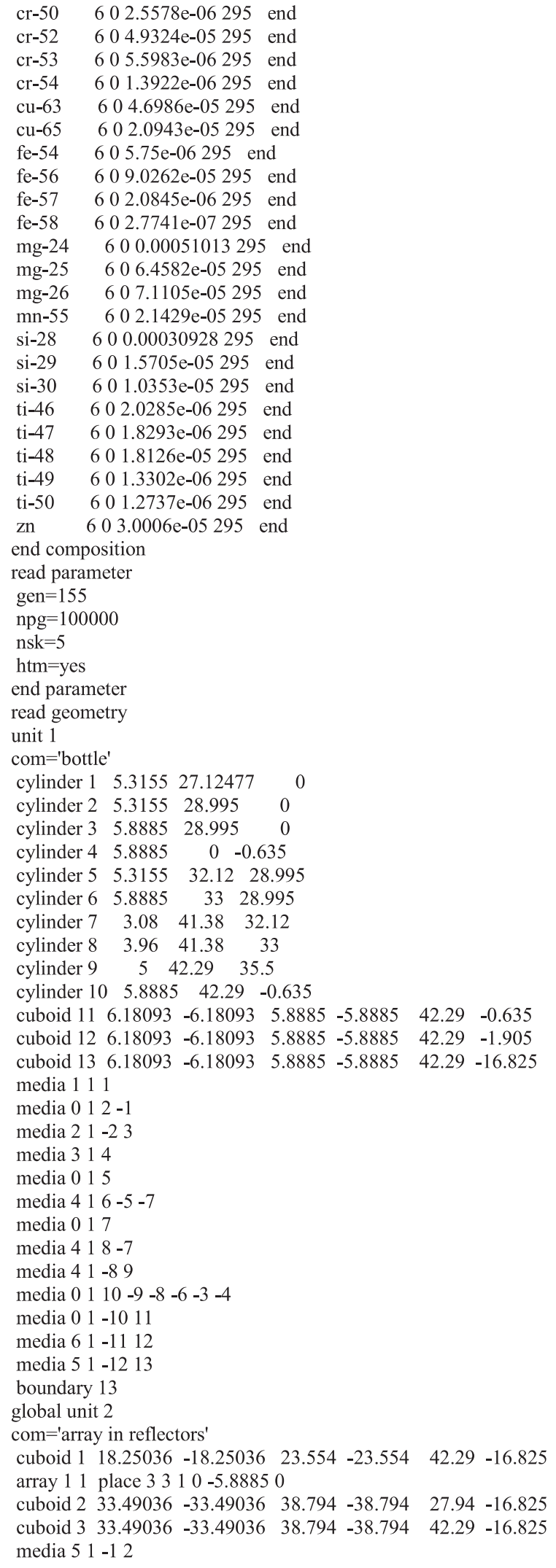

Revision: 0

Date: September 30, 2012 
NEA/NSC/DOC/(95)03/l

Volume I

PU-SOL-THERM-037

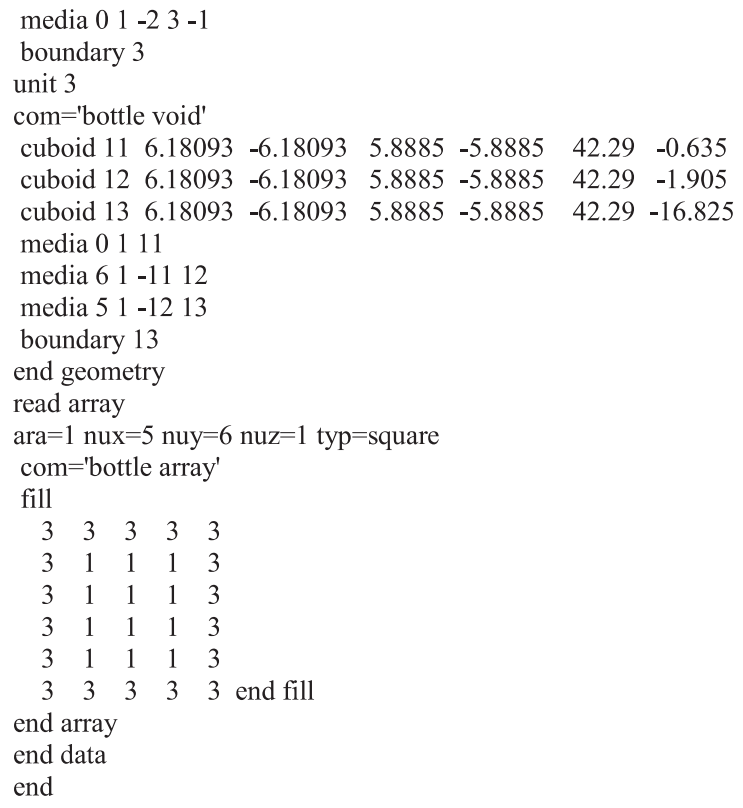

Case 4, RSTM-L3-6, Simple Model

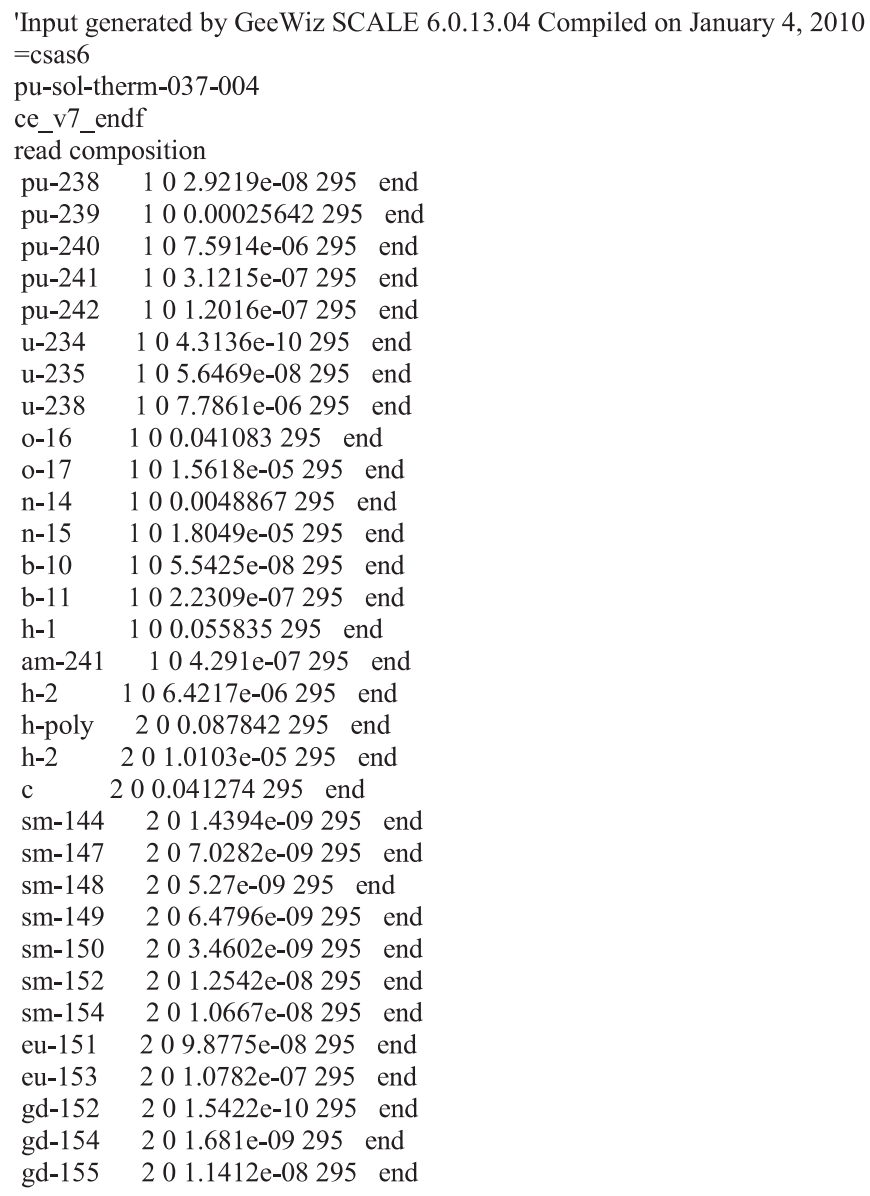

Revision: 0

Date: September 30, 2012 
NEA/NSC/DOC/(95)03/I

Volume I

PU-SOL-THERM-037

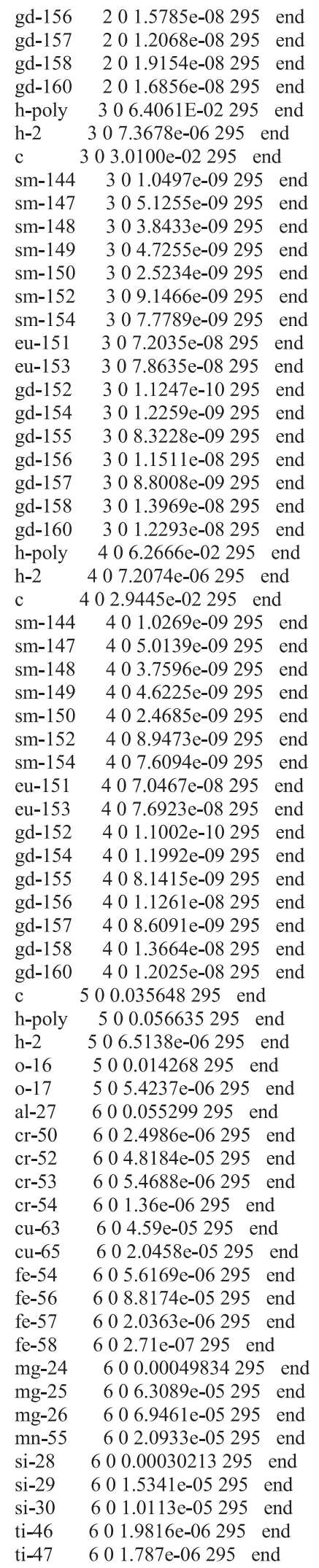

Revision: 0

Date: September 30, 2012 
NEA/NSC/DOC/(95)03/I

Volume I

PU-SOL-THERM-037

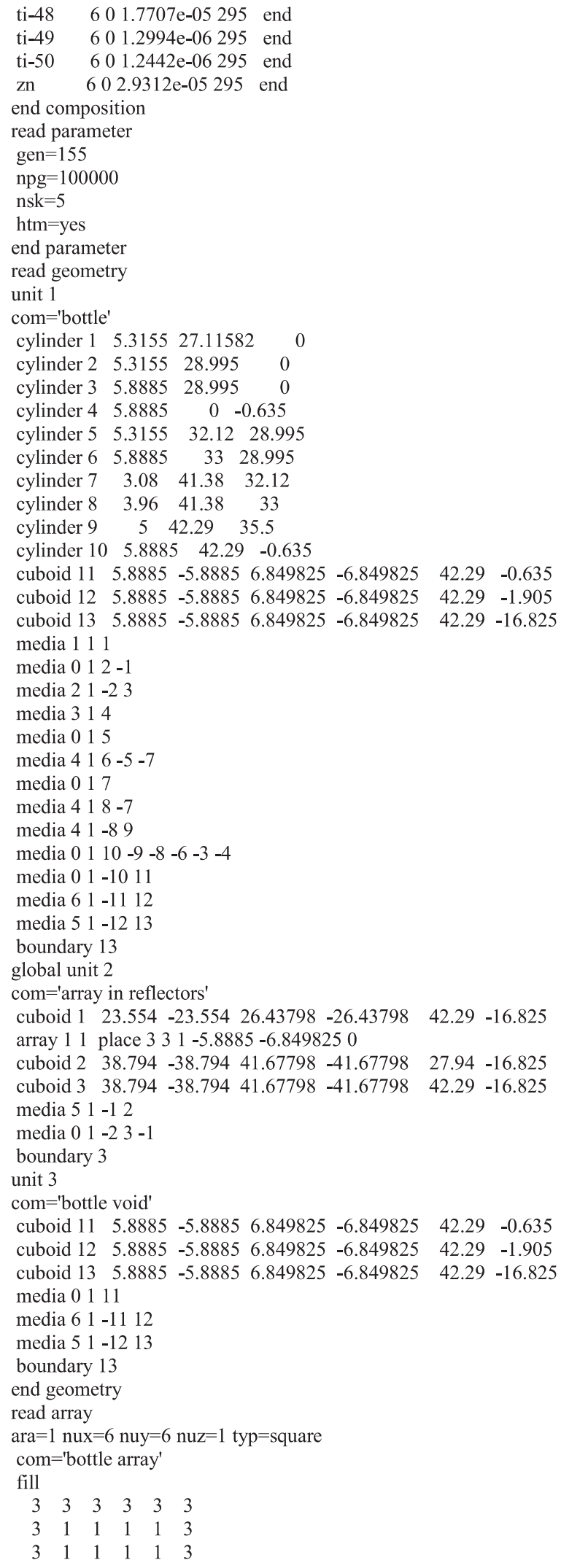

Revision: 0

Date: September 30, 2012 
NEA/NSC/DOC/(95)03/I

Volume I

PU-SOL-THERM-037

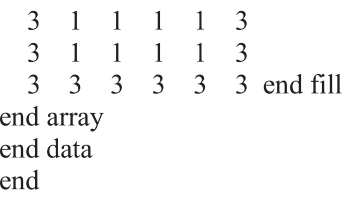

\section{Case 5, RSTM-L3-7, Simple Model}

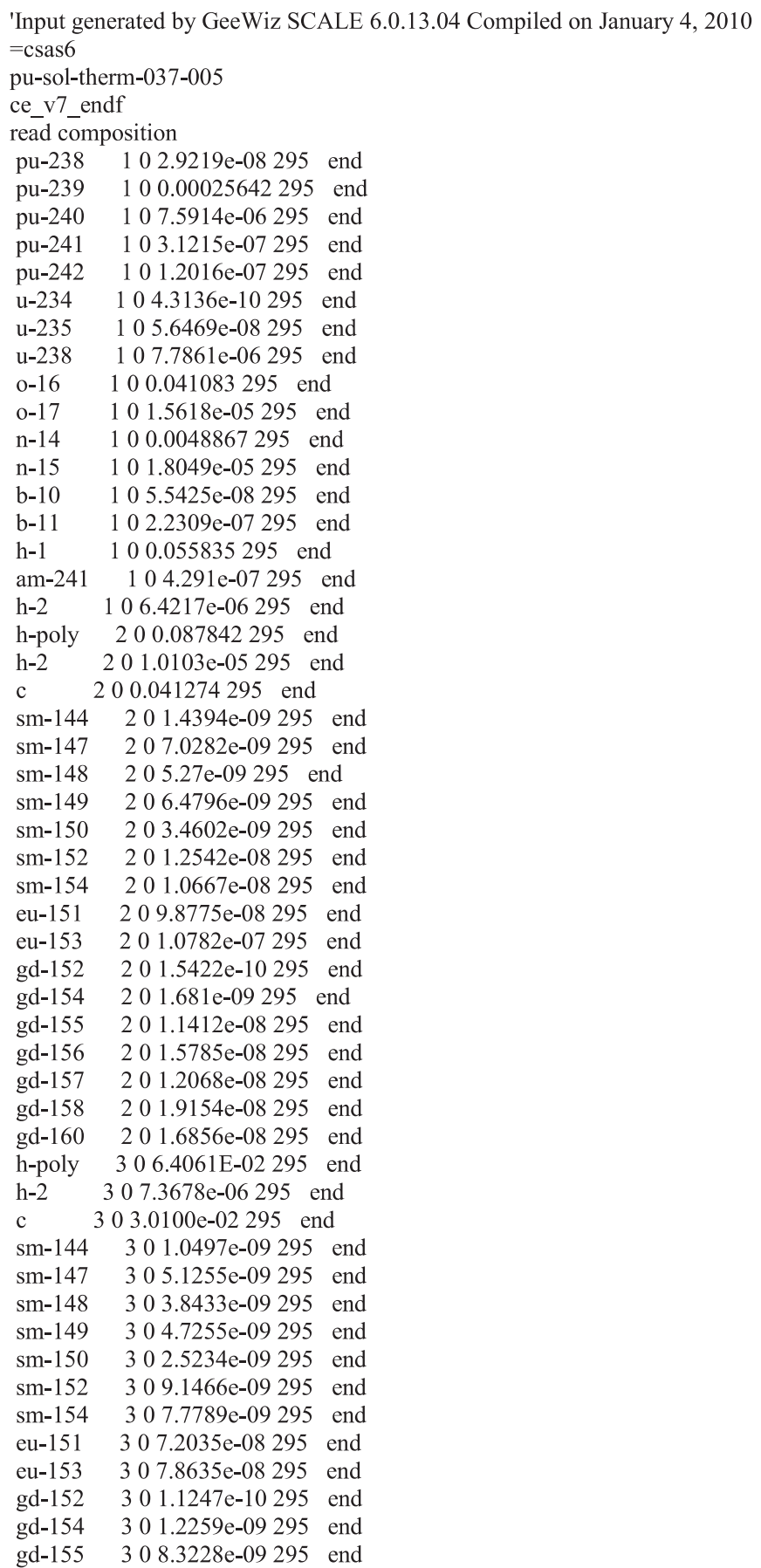

Revision: 0

Date: September 30, 2012 
NEA/NSC/DOC/(95)03/I

Volume I

PU-SOL-THERM-037

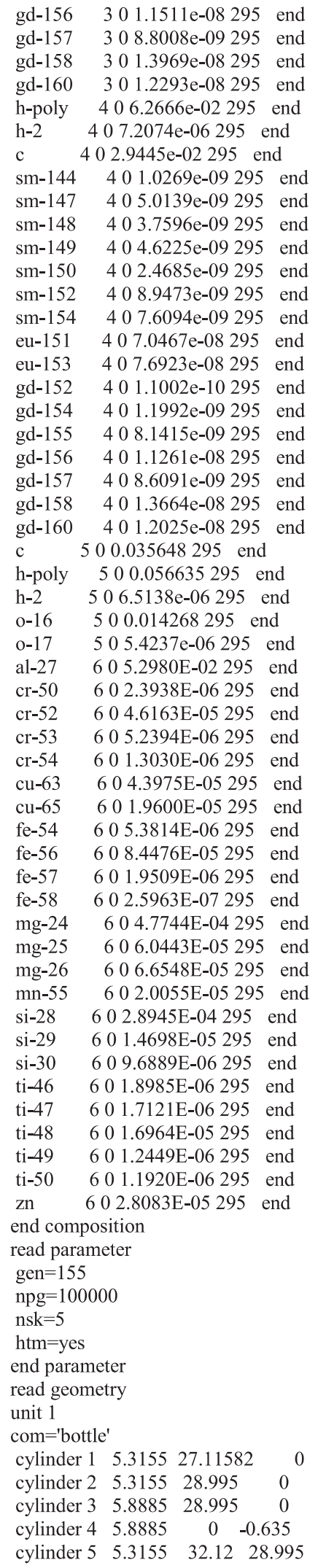

Revision: 0

Date: September 30, 2012 
NEA/NSC/DOC/(95)03/I

Volume I

PU-SOL-THERM-037

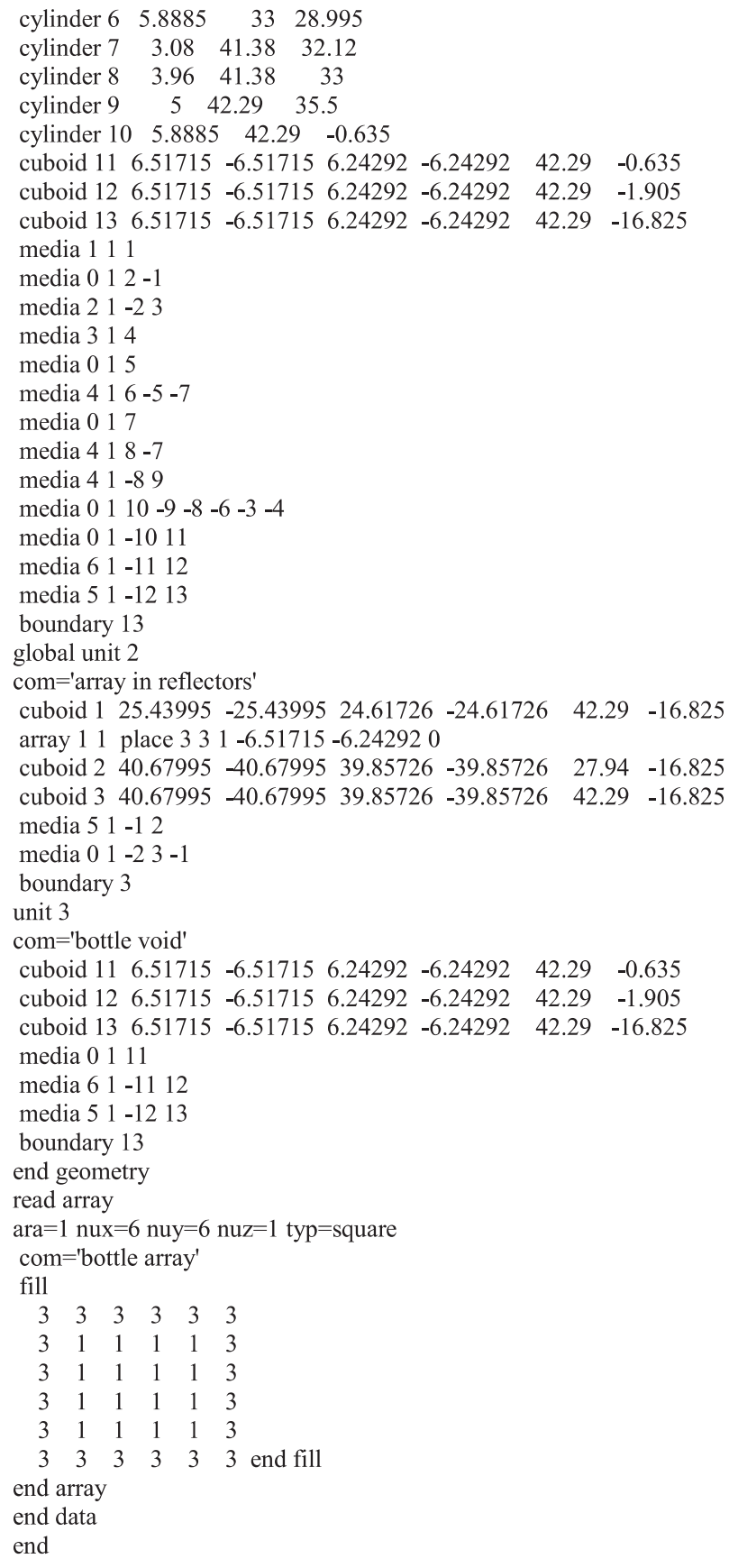

\section{Case 6, RSTM-L3-12, Simple Model}

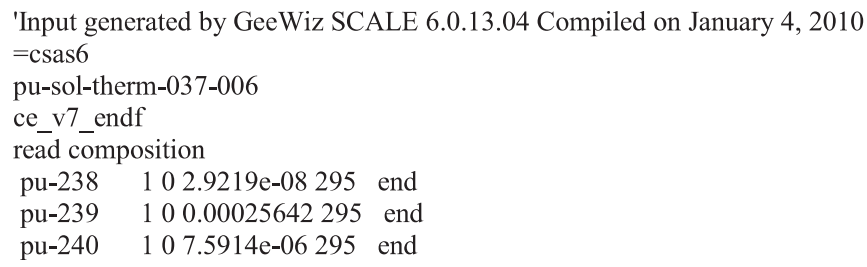

Revision: 0

Date: September 30, 2012 
NEA/NSC/DOC/(95)03/l

Volume I

PU-SOL-THERM-037

\begin{tabular}{|c|c|}
\hline & 8 \\
\hline & 07295 \\
\hline 234 & $104.3136 \mathrm{e}-10295$ \\
\hline & $05.6469 \mathrm{e}$ \\
\hline & 95 \\
\hline-16 & 100.041083295 end \\
\hline & $101.5618 \mathrm{e}-05295$ \\
\hline & 100.0048867 \\
\hline & 1018 \\
\hline & 105.5 \\
\hline & 5 en \\
\hline-1 & 100.055835295 end \\
\hline & \\
\hline-2 & 106.42 \\
\hline & 5 end \\
\hline$h-2$ & 95 end \\
\hline & 200.04 \\
\hline 4 & 20 \\
\hline n- & 207 \\
\hline & 95 end \\
\hline 9 & 20 \\
\hline & \\
\hline 52 & 20 \\
\hline & \\
\hline 51 & 20 \\
\hline & \\
\hline 2 & 201 \\
\hline & 201 \\
\hline & 201 \\
\hline & 20 \\
\hline & 20 \\
\hline & 20 \\
\hline & 95 \\
\hline -poly & 295 en \\
\hline-2 & 5 end \\
\hline & 303.01 \\
\hline & $295 \mathrm{er}$ \\
\hline & \\
\hline & \\
\hline 9 & \\
\hline & 5 \\
\hline & \\
\hline 4 & 95 \\
\hline & 0 \\
\hline & 30 \\
\hline & \\
\hline & \\
\hline & 95 \\
\hline & \\
\hline & \\
\hline gd- & 301 \\
\hline & 301 \\
\hline h-poly & 406. \\
\hline$h-2$ & 295 end \\
\hline c & $402.9445 \mathrm{e}$ \\
\hline 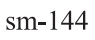 & \\
\hline sm- & \\
\hline sm-148 & 95 \\
\hline sm-1 & \\
\hline sm-150 & \\
\hline sm- & 40 \\
\hline & \\
\hline eu- & 407 \\
\hline & \\
\hline gd-152 & 401 \\
\hline & \\
\hline gd-155 & $408.1415 \mathrm{e}-09295$ \\
\hline
\end{tabular}

Revision: 0

Date: September 30, 2012 
NEA/NSC/DOC/(95)03/I

Volume I

PU-SOL-THERM-037

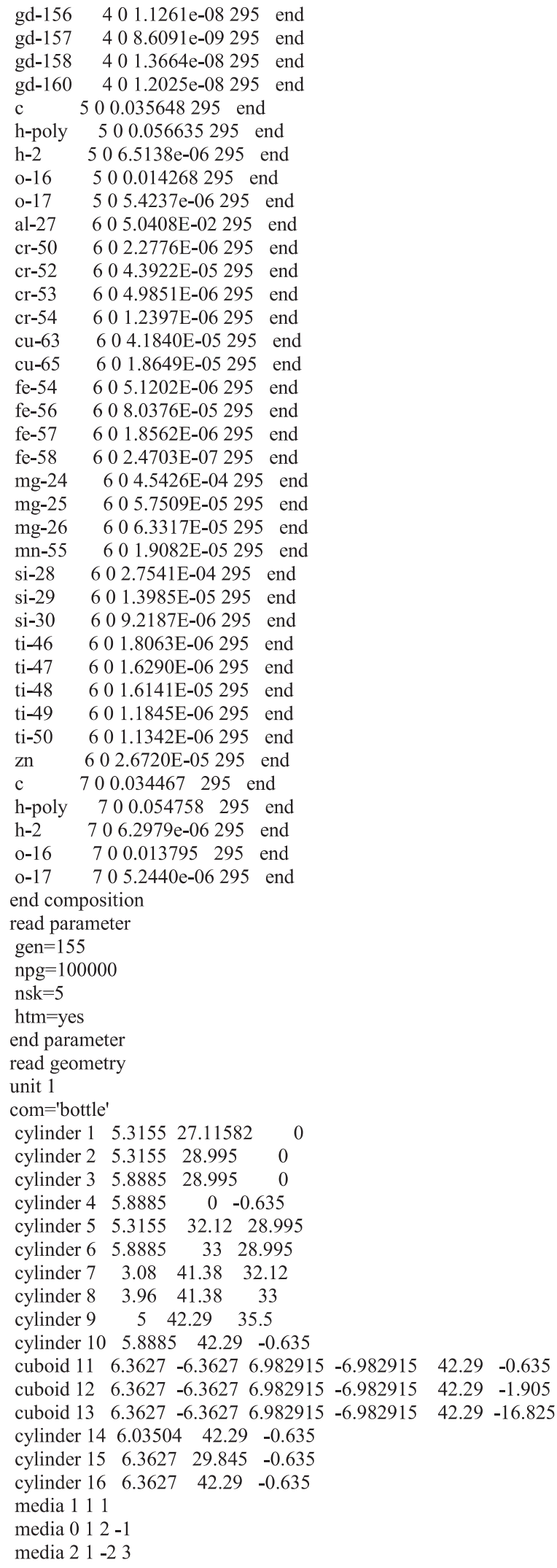

Revision: 0

Date: September 30, 2012 
NEA/NSC/DOC/(95)03/I

Volume I

PU-SOL-THERM-037

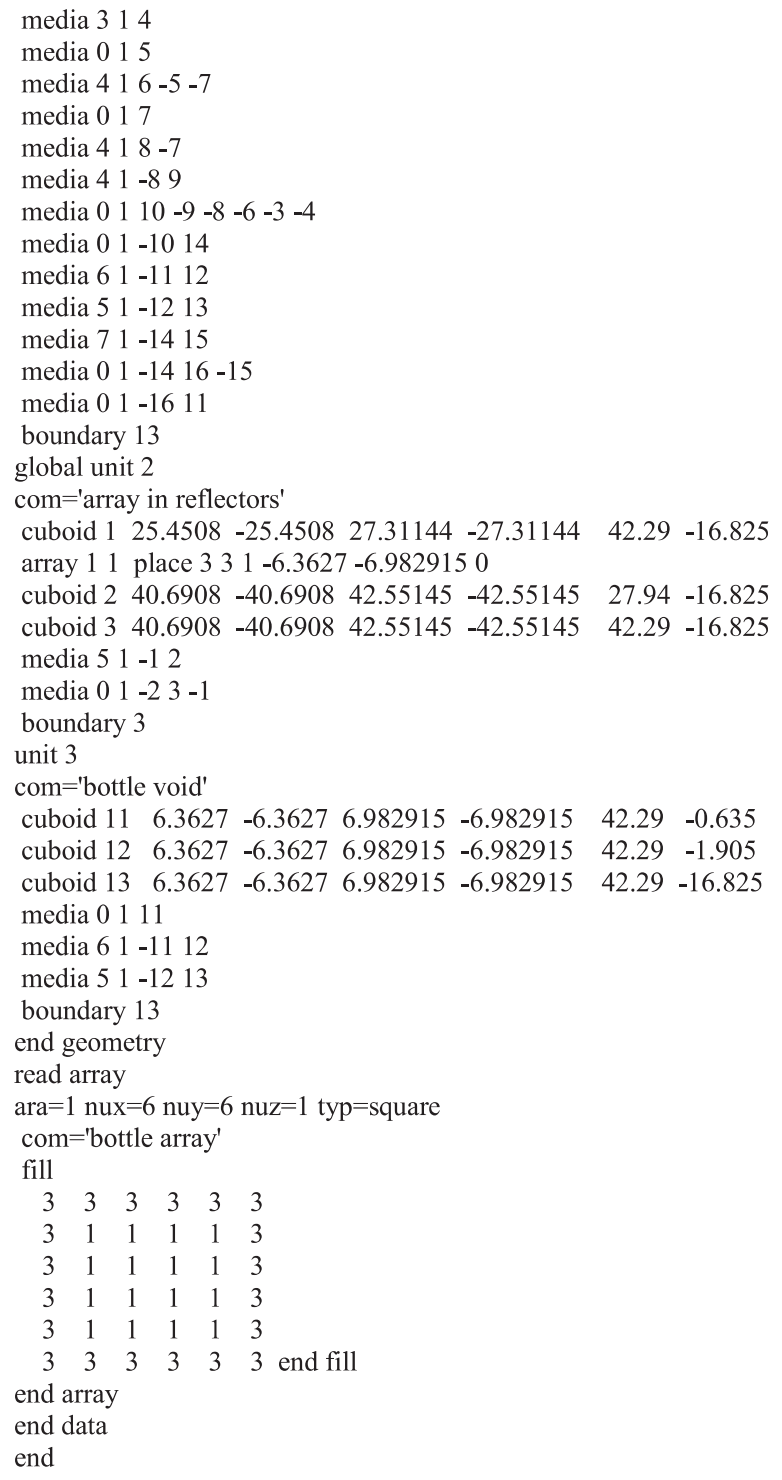

Case 7, RSTM-L3-13, Simple Model

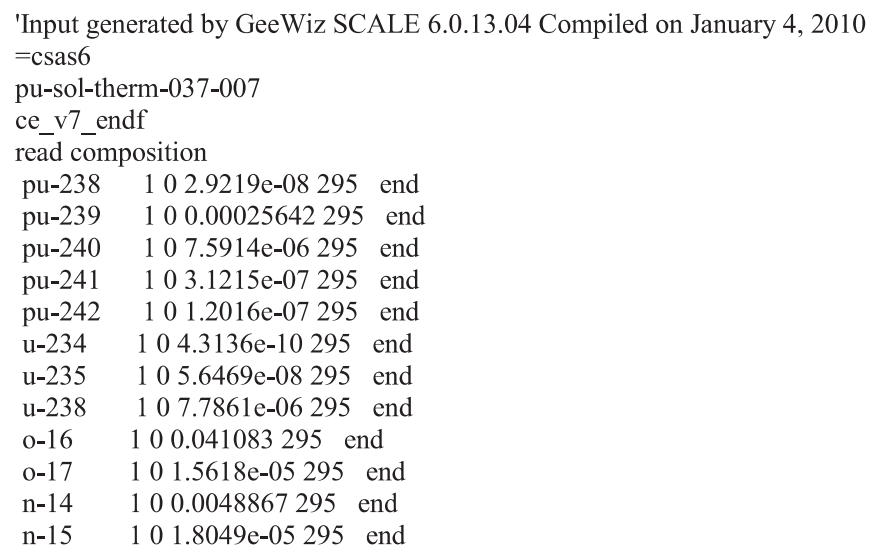

Revision: 0

Date: September 30, 2012 
NEA/NSC/DOC/(95)03/l

Volume I

PU-SOL-THERM-037

\begin{abstract}
b-10 $\quad 105.5425 \mathrm{e}-08295$ end
b-11 $102.2309 \mathrm{e}-07295$ end

h-1 100.055835295 end

am-241 $104.291 \mathrm{e}-07295$ end

h-2 $106.4217 \mathrm{e}-06295$ end

h-poly 200.087842295 end

h-2 $201.0103 \mathrm{e}-05295$ end

c $\quad 200.041274295$ end

sm-144 $201.4394 \mathrm{e}-09295$ end

sm-147 $207.0282 \mathrm{e}-09295$ end

sm-148 $205.27 \mathrm{e}-09295$ end

sm-149 $206.4796 \mathrm{e}-09295$ end

sm-150 $203.4602 \mathrm{e}-09295$ end

sm-152 $201.2542 \mathrm{e}-08295$ end

sm-154 $201.0667 \mathrm{e}-08295$ end

eu-151 $209.8775 \mathrm{e}-08295$ end

eu-153 $201.0782 \mathrm{e}-07295$ end

gd-152 $201.5422 \mathrm{e}-10295$ end

gd-154 $201.681 \mathrm{e}-09295$ end

gd-155 $201.1412 \mathrm{e}-08295$ end

gd-156 $201.5785 \mathrm{e}-08295$ end

gd-157 $201.2068 \mathrm{e}-08295$ end

gd-158 $201.9154 \mathrm{e}-08295$ end

gd-160 $201.6856 \mathrm{e}-08295$ end

h-poly $306.4061 \mathrm{E}-02295$ end

h-2 $307.3678 \mathrm{e}-06295$ end

c $303.0100 \mathrm{e}-02295$ end

sm-144 $301.0497 \mathrm{e}-09295$ end

sm-147 $305.1255 \mathrm{e}-09295$ end

sm-148 $303.8433 \mathrm{e}-09295$ end

sm-149 $304.7255 \mathrm{e}-09295$ end

sm-150 $302.5234 \mathrm{e}-09295$ end

sm-152 $309.1466 \mathrm{e}-09295$ end

sm-154 $307.7789 \mathrm{e}-09295$ end

eu-151 $307.2035 \mathrm{e}-08295$ end

eu-153 $307.8635 \mathrm{e}-08295$ end

gd-152 $301.1247 \mathrm{e}-10295$ end

gd-154 $301.2259 \mathrm{e}-09295$ end

gd-155 $308.3228 \mathrm{e}-09295$ end

gd-156 $301.1511 \mathrm{e}-08295$ end

gd-157 $308.8008 \mathrm{e}-09295$ end

gd-158 $301.3969 \mathrm{e}-08295$ end

gd-160 $301.2293 \mathrm{e}-08295$ end

h-poly $406.2666 \mathrm{e}-02295$ end

h-2 $407.2074 \mathrm{e}-06295$ end

c $\quad 402.9445 \mathrm{e}-02295$ end

sm-144 $401.0269 \mathrm{e}-09295$ end

sm-147 $405.0139 \mathrm{e}-09295$ end

sm-148 $403.7596 \mathrm{e}-09295$ end

sm-149 $404.6225 \mathrm{e}-09295$ end

sm-150 $402.4685 \mathrm{e}-09295$ end

sm-152 $408.9473 \mathrm{e}-09295$ end

sm-154 $407.6094 \mathrm{e}-09295$ end

eu-151 $407.0467 \mathrm{e}-08295$ end

eu-153 $407.6923 \mathrm{e}-08295$ end

gd-152 $401.1002 \mathrm{e}-10295$ end

gd-154 $401.1992 \mathrm{e}-09295$ end

gd-155 $408.1415 \mathrm{e}-09295$ end

gd-156 $401.1261 \mathrm{e}-08295$ end

gd-157 $408.6091 \mathrm{e}-09295$ end

gd-158 $401.3664 \mathrm{e}-08295$ end

gd-160 $401.2025 \mathrm{e}-08295$ end

c $\quad 500.035648295$ end

h-poly 500.056635295 end

h-2 $506.5138 \mathrm{e}-06295$ end

o-16 500.014268295 end

o-17 $505.4237 \mathrm{e}-06295$ end
\end{abstract}

Revision: 0

Date: September 30, 2012 
NEA/NSC/DOC/(95)03/I

Volume I

PU-SOL-THERM-037

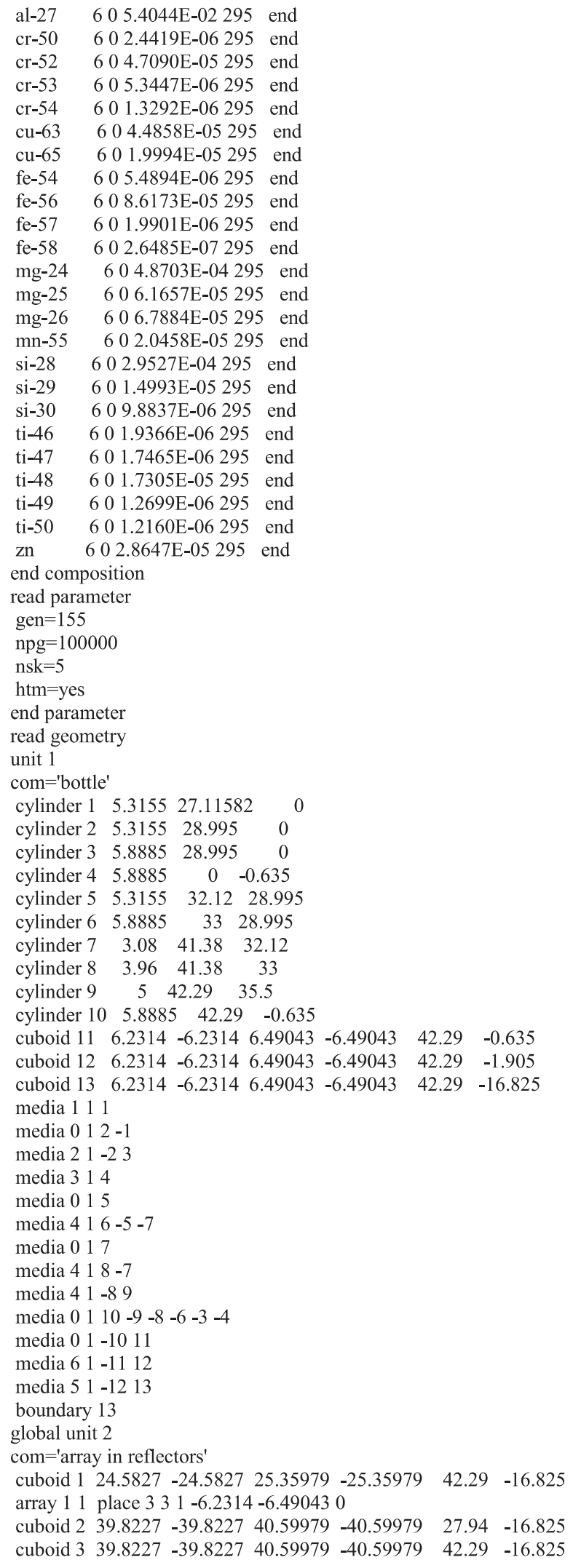

Revision: 0

Date: September 30, 2012 
NEA/NSC/DOC/(95)03/l

Volume I

PU-SOL-THERM-037

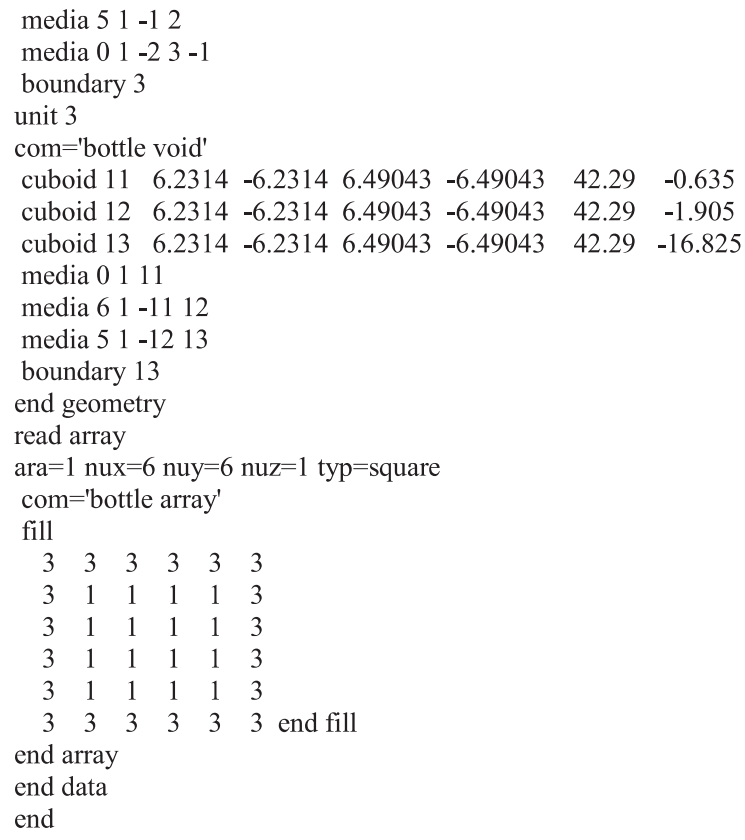

Revision: 0

Date: September 30, 2012 